Göttingen Series in Social and Cultural Anthropology

Julia Vorhölter

\title{
Youth at the Crossroads
}

Discourses on Socio-Cultural Change in Post-War Northern Uganda

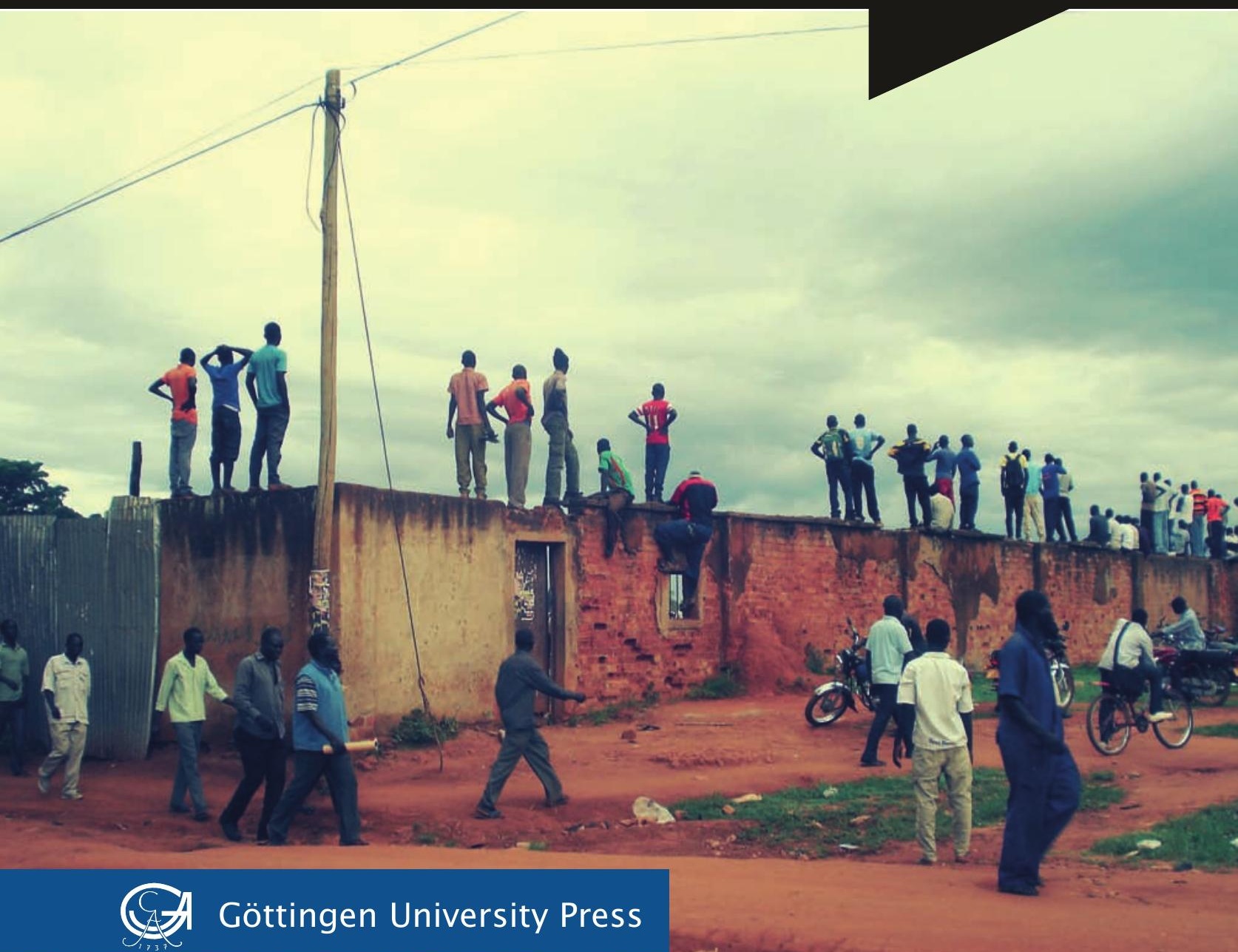





$$
\begin{aligned}
& \text { Julia Vorhölter } \\
& \text { Youth at the Crossroads }
\end{aligned}
$$

This work is licensed under a Creative Commons Attribution-ShareAlike 4.0 International License.

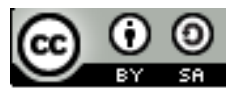


Published in 2014 by Göttingen University Press

as volume 7 in "Göttingen Series in Social and Cultural Anthropology"

This series is a continuation of "Göttinger Beiträge zur Ethnologie". 
Julia Vorhölter

Youth at the Crossroads

Discourses on Socio-Cultural Change in Post-War Northern Uganda

Volume 7

Göttingen Series in Social and Cultural Anthropology

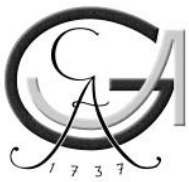

Göttingen University Press 2014 


\section{Bibliographische Information der Deutschen Nationalbibliothek}

Die Deutsche Nationalbibliothek verzeichnet diese Publikation in der Deutschen Nationalbibliographie; detaillierte bibliographische Daten sind im Internet über $<$ http://dnb.ddb.de $>$ abrufbar.

"Göttingen Series in Social and Cultural Anthropology" Editors

Prof. Dr. Elfriede Hermann

Prof. Dr. Andrea Lauser

Prof. Dr. Roman Loimeier

Prof. Dr. Nikolaus Schareika

Institute of Social and Cultural Anthropology

Georg-August-Universität Göttingen

Theaterplatz 15

D-37073 Göttingen

This work is protected by German Intellectual Property Right Law.

It is also available as an Open Access version through the publisher's homepage and the Göttingen University Catalogue (GUK) (http:/ /www.sub.uni-goettingen.de).

The conditions of the license terms of the online version apply.

Set and layout: Steffen Herrmann

Cover: Friedlind Riedel

Cover picture: Lioba Lenhart

(C) 2014 Göttingen University Press

http:/ / univerlag.uni-goettingen.de

ISBN: 978-3-86395-169-6

ISSN: 2199-5346 
For Lisa 



\section{Contents}

Acknowledgements.............................................................................................. 13

1. Introduction ...............................................................................................17

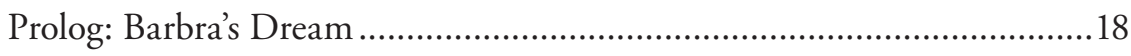

1.1. The War in Northern Uganda: Insecurity, Displacement \& 'Cultural

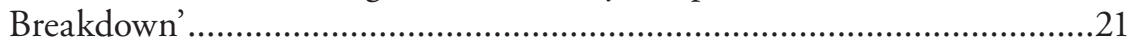

1.2. Growing up in Times of War: Acholi Youth ............................................. 23

1.3. Key Research Questions, Objectives \& Hypotheses................................. 25

1.4. State of the Art: Past \& Contemporary Debates in the Anthropology of Youth ............................................................................. 28

1.4.1. History of Youth Research in Anthropology................................. 28

1.4.2. Defining Youth: Conceptual Challenges \& Debates....................... 30 


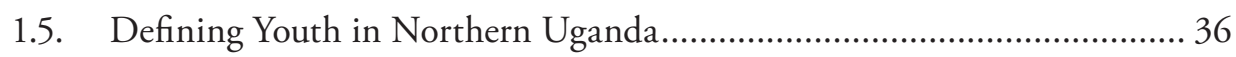

1.6. State of the Art: Contemporary Debates on Youth \& Socio-Cultural

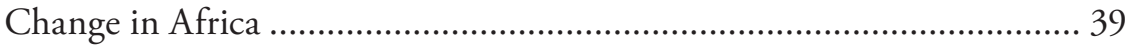

1.6.1. Victims or Agents? Makers or Breakers? ..........................................41

1.6.2. Tradition \& Modernity, Africa \& the West ................................... 44

1.7. Specific Contribution of my Research........................................................ 46

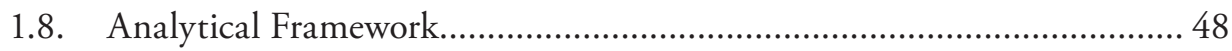

1.8.1. Foucauldian Discourse Analysis .................................................... 48

1.8.2. Power-Knowledge ....................................................................... 50

1.8.3. Discourse \& Power as Analytical Concepts ....................................52

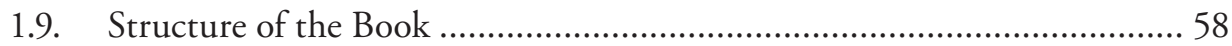

2. 'My Field' - Changing Perceptions of Research in a

Post-War Setting......................................................................................661

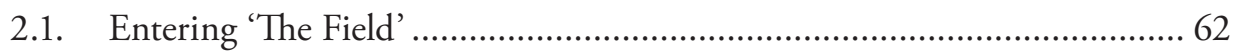

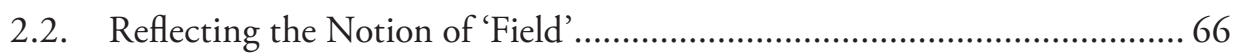

2.3. Fieldwork in Gulu: Basic Overview of Research Methods..........................67

2.4. Progress of Fieldwork ......................................................................... 70

2.5. Biases Inherent in my Research Approach................................................74

3. The War in Northern Uganda - Conflicting Interpretations ............... 77

3.1. Different Accounts of Ugandan History from the Perspective of the Sociology of Knowledge..................................................................... 78

3.2. Colonial Times: Dominant Interpretative Schemes ................................. 83

3.3. Critical Debates on Colonial History........................................................ 85

3.4. Postcolonial Developments: Dominant Interpretative Schemes \&

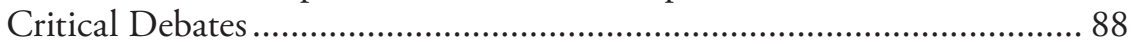

3.5. Critical Debates on the Lead-up to the War............................................... 92

3.6. The War in Northern Uganda.................................................................. 94 
3.7. Critical Debates on the War: Official Discourse versus

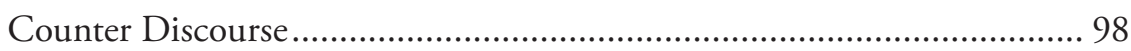

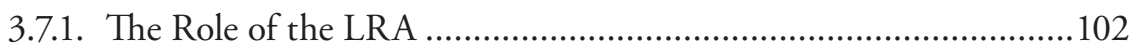

3.7.2. The Role of Museveni, the NRM Government \& the UPDF .......108

3.8. Concluding Remarks - Changing Hegemonies of Interpretation.............109

4. “Our Culture is getting lost!” - Pre- \& Post-War

Representations of Acholi Culture ...........................................................113

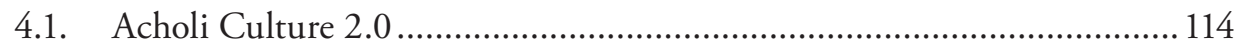

4.2. The Miss Acholi Contest - Extracts from my Field Notes .......................... 118

4.3. Pre-war Ethnographies: Representations of the Ideal Acholi Society ...... 122

4.3.1. The Origin(s) of the Acholi .............................................................. 122

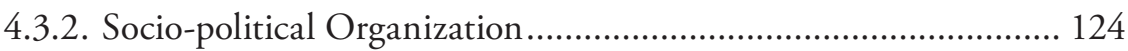

4.3.3. Social Organization \& Family Life................................................ 130

4.3.4. Economic System ..................................................................... 136

4.3.5. Religious \& Spiritual Beliefs.......................................................... 140

4.3.6. External Influences \& Socio-Cultural Changes before the War....144

4.4. The Situation in the Camps \& the Perceived Effects on Acholi

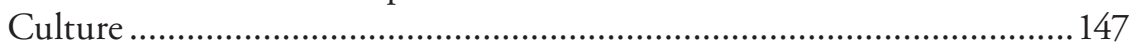

4.4.1. Economic Sphere: Impoverishment \& Loss of Former

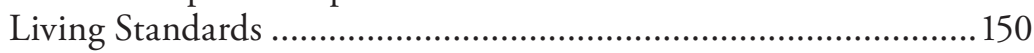

4.4.2. Social Sphere: Increase in Gender \& Generational Conflicts ........ 152

4.4.3. Political Sphere: Foreign Occupation \& Loss of

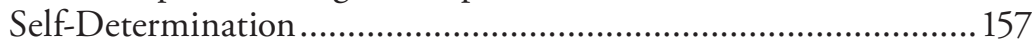

4.4.4. Ethical Sphere: Loss of Morals, Respect \& Values ........................ 159

4.5. Contemporary Attempts to Reconstruct "Traditional Acholi

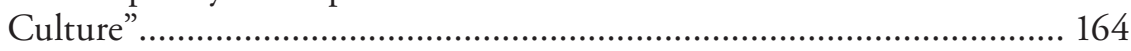

4.5.1. The Revival of Traditional Authorities: Rwodi Moo \& Ker Kwaro Acholi

4.5.2. The Revival of Traditional Justice \& the Reconciliation Ritual Mato Oput 168

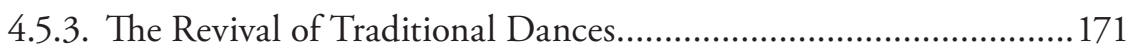

4.6. Concluding Remarks: Contemporary Discourses on Acholi Culture .......179 


\section{Between "Tradition" \& "Modernity"}

Cultural Styles \& Discourses on Socio-Cultural Change Among the

War Generation in Urban Gulu

5.1. Youth Perspectives on Socio-Cultural Change .........................................184

5.2. Hip Hop Contest at Herm's Club - Extracts from my Field Notes ..........188

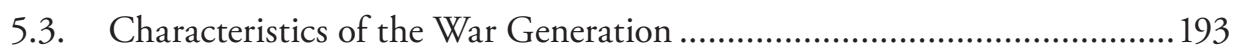

5.3.1. Similarities of the War Generation .................................................194

5.3.2. Differences within the War Generation ....................................... 200

5.4. Youth Practices \& Cultural Styles......................................................... 205

5.5. Discourses on Socio-Cultural Change among the War Generation -

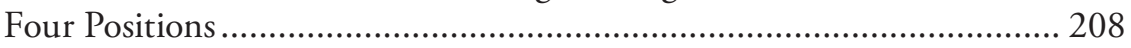

5.5.1. The Retraditionalization Discourse: Idealization of Tradition

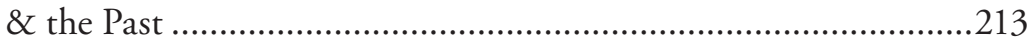

5.5.2. The Modernization Discourse: Idealization of Life in the West ....216

5.5.3. The Ambivalent Discourse: Uncertainty in the Face of

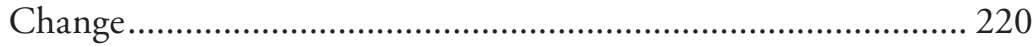

5.5.4. The Creative Discourse: “Translating” Acholi Culture.................. 222

5.6. Concluding Remarks: The Positioning of Youth in Post-War Acholi Society

\section{Westernization versus Neocolonialism}

Representations of "Africa" \& "The West" in Debates on Aid, Capitalism \& Sexuality

6.1. Dissecting Acholi \& Ugandan Notions of "The West"........................... 230

6.2. Simon's Story - Extracts from my Field Notes ........................................ 233

6.3. Discourses on Westernization in the Context of Aid, Modernization \& Generational Change.

6.4. Discourses on Westernization in Relation to Gender, Kinship \& Sexual Relations.

6.4.1. 'Western Models' as Threats? 246

6.4.2. Discourses on Westernization as Forms of Internal Social Critique 254

6.5. Neocolonialism Discourses \& the Debate about the "Anti-Homosexuality Bill" 
6.6. Discourses on Sexuality as Instruments of Power 260

6.7. Concluding Remarks: Sexuality, "Africa” and "The West" as Strategic Fields \& Figures in Discourses on Socio-Cultural Change...... 263

\section{Conclusion: Negotiating Socio-Cultural Change $\&$ the Future of} Acholi Society .............................................................................. 265

7.1. Two Conversations - Extracts from my Field Notes............................ 267

7.2. Discourses on Socio-Cultural Change in the Context of Generational, Gendered \& Globalized Power Dynamics ..................... 271

7.2.1. Generational Conflicts \& Power Relations ............................... 272

7.2.2. Gendered \& Sexualized Power Relations.................................. 277

7.2.3. Local-Global Power Relations ................................................. 280

7.3. Youth at the Crossroads - In Post-War Acholiland \& Beyond................ 283

8. References............................................................................... 289

9. Appendix ..............................................................................321

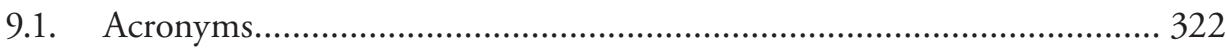

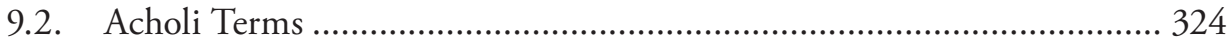

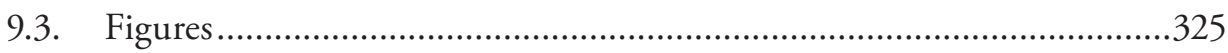

9.3.1. Figure 1: Map of Uganda, including Acholi Sub-Region ..............325

9.3.2. Figure 2: Map of Uganda, including major towns \& neighboring countries ....................................................... 326

9.3.3. Figure 3:

Socio-Demographic Characteristics, Acholi Districts, 2010 Survey.

9.3.4. Figure 4: Urban Population Development in Uganda Selected Towns ................................................................. 328

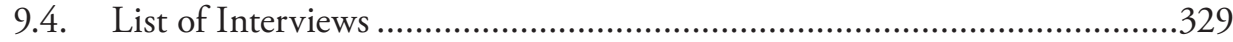

9.4.1. Interview with Acholi Elder................................................329

9.4.2. Interviews with Acholi Youth ...............................................329

9.4.3. Interviews with NGO-Representatives ...................................331

9.4.4. Group Interviews in Rural Areas ...........................................332

9.5. Short Biography of Most Important Interlocutors ...............................333 



\section{Acknowledgements}

The realization of this dissertation project would not have been possible without the support of several 'companions'. Some accompanied me all along, others walked with me only part of the road, but in their different ways they all helped me to navigate through the maze of crossroads which are part of every dissertation project. My special thanks go to the following people.

First of all, I would like to thank my supervisors and academic mentors who guided me through the process of imagining and realizing this work. Particularly, I would like to thank Roman Loimeier for his guidance, his trust and for the freedom he gave me to experiment with theories and styles of 'doing anthropology' throughout what one may call a period of 'academic adolescence'. I am also very grateful to Roman for the excellent working conditions in terms of contract, colleagueship and institutional embeddedness he provided me with throughout my time as a $\mathrm{PhD}$ student and, in fact, beyond. Roman, it was during my defense that I realized the full scale of your loyalty and support - thank you so much for everything! 
I would like to thank Elfriede Hermann for encouraging me and supporting me with her advice in various, critical stages of my work and especially for openly criticizing and persuading me to revise once again what I thought at the time was my final version of the dissertation. Furthermore, I would like to thank Gabriele Rosenthal for 'adopting' me as a doctoral student in the early stages of my work, for introducing me to the scientific community and the 'real life' of academia in her colloquium and by inviting me to present at what was to be my first international conference, and for always being a trusted advisor. I would also like to thank Ulrich Braukämper for enabling me to begin this dissertation project in the first place and for his friendliness and support whenever I was in need of help or advice.

Second, I would like to thank the many different people who read and revised (parts of) my text. Specifically, I would like to thank Cristian Alvarado Leyton, Bianca Volk and Jovan Maud. Cristian, thank you so much for all your valuable and radical comments to the final draft, and for all our battles and raps about anthropology, positivism and the proto-type! Bianca, thanks for your uncountable amounts of advice not only on dissertation-related problems and for the many memorable moments we shared in our daily struggles with life as lecturers and doctoral students. Jovan, cheers mate for always having an open ear for my "English questions" and for all our inspiring conversations, challenging discussions and theoretical debates. Furthermore, I would like to thank all members of the legendary "Dok-AG", specifically Sascha Kesseler, Paul Christensen, Meike Rieger, Jelka Günther, Jannik Schritt, Viola Thimm, Antonie Walther and Judith Moneke-Schmidt, who critically commented on and passionately debated most of my chapters and who were close companions all along. Many thanks go to all of my colleagues at the Institute of Social and Cultural Anthropology in Göttingen. In particular, I want to mention Hans Reithofer who through his sympathetic, supportive and humorous manner makes working life at the Institute so enjoyable.

In Uganda, I would like to thank all the people who supported me during my research - as friends, colleagues and interlocutors. Specifically, I would like to thank Lioba Lenhart for her friendship and companionship, for discussing and helping to facilitate several of my research activities, and for sharing her long-term experiences as anthropologist, researcher and 'Gulu local' with me. Apwoyo matek to Akello and her family - for your kindness and hospitality, for welcoming me into the family and for sharing with me so many experiences and aspects of Acholi life in Gulu. Fred, apwoyo for our good and challenging discussions. Ruth, apwoyo for introducing me to so many people and events in Gulu and beyond. Simon, apwoyo for being such an authentic, open-hearted and funny hip hopper, traditional dancer and interlocutor. Opio, Williams and the guys, apwoyo for the many enjoyable and victorious quiz-nights at BJz. Florence, apwoyo pwonyo ki loko leb Acholi! Joseph, yoga for sharing your inspiring and poetic ideas. I would also like to give special thanks to all the people at Gulu Youth Centre, to the members of the Gulu Theatre Artists and the Gulu Talking Straight Project and to my colleagues and students at the Institute of Peace and Strategic Studies. 
Finally, I would like to thank my family and two very close and special friends, Laura Glauser and Martin Morlock, who gave me the support and encouragement necessary to start and finish this dissertation, and who suffered with me and had to suffer because of me during times of dissertation-related crises. I owe a great deal to my parents Karin and Bernd and to my sister Lisa who always believed in me and gave me the confidence to follow my aspirations in life. Thank you for your trust and your unconditional support!

Laura, we have come such a long way since our first meeting as anthropology students in Hamburg and it is incredible how closely our paths to becoming 'real anthropologists' have been interwoven. I am so happy and grateful for all that we have shared during this time!

Martin, I thank you and I truly admire you for your patience, your tolerance and your emotional support particularly during the last months of my work. I am grateful for the road we have traveled together - with all its bumps, unexpected turns and crossroads - and I am looking forward to the post-dissertation future!

Göttingen, April 2014

\section{Note on Research Context and Sponsors}

I wrote this dissertation while being employed as a Wissenschaftliche Mitarbeiterin at the Institute of Social and Cultural Anthropology, Georg-August-University Göttingen. During my field research in Uganda, I was affiliated with the Institute of Peace and Strategic Studies of Gulu University, where I also taught as a part-time lecturer. My research in Uganda was partly financed by a scholarship from the German Academic Exchange Service (DAAD). I would like to thank all of these institutions for their financial, administrative and logistical support without which my research would not have been possible. 



\section{Introduction}

This study is based on eleven months of field research carried out in Gulu Municipality, Northern Uganda, between August 2009 and February 2011. Since 2006, Northern Uganda has been recovering from a 20 -year war. In the current post-war phase, different social actors are trying to 'rebuild'1 Acholi society and 'normalize' societal relations, which they believe have been heavily disrupted through the war and particularly the war-related, large-scale displacement of Acholi people into refugee camps. Imaginations of a post-war society are contested and negotiated between youth and elders, men and women as well as local and international actors. While some try to re-establish former practices and conventions, others attempt to establish new social structures, values and norms. Discourses and debates on

1 Throughout this book, I use quotation marks for a number of different reasons. I use double quotation marks to quote a) technical or analytical terms as well as longer passages of text from the literature and b) terms and expressions from the emic discourse. I use single quotation marks to denote so-called scare quotes, i.e. to emphazise that I use a word or expression in an unusual, non-standard way or to imply skepticism or disagreement with the quoted terminology. 
Julia Vorhölter: Youth at the Crossroads

retraditionalization versus modernization and "Westernization" 2 are widespread, and, depending on the issue discussed, the context, and the power constellations involved, speakers switch between different positions.

My research project studies these ongoing negotiations and discourses from the perspectives of urban youth. I analyze how members of the generation that was born and grew up during the years of the war perceive and evaluate the socio-cultural changes Acholi society is seen to be undergoing, how they imagine their future society and how they picture their role in this future society. By discussing aspirations and agency, predicaments and problems of the young people in Gulu, my study contributes to the growing field of youth research in Africa.

In this introduction, I will outline my key research questions and explain my approach to studying youth and discourses on socio-cultural change. In order to contextualize my research, I give some background information on the war and post-war situation in Northern Uganda and the state of the art of youth research in anthropology with particular focus on contemporary debates on youth and sociocultural change in Africa. I explain how my research contributes to these fields of study. Finally, I discuss my analytical framework and present an overview of the chapters which make up this book. First, however, I would like to introduce the reader to my 'field' and my topic of research by presenting a short anecdote from my field notes.

\section{Prolog: Barbra's Dream}

I will start by telling you a dream. It is not my dream, but the dream of Barbra, a 13-year old Acholi girl, the daughter of a friend of mine. We, that is Lioba, Florence, her four children Barbra, Eunice, Solomon and Elizabeth ${ }^{3}$ and me, are sitting at our favorite pork-eating place, locally referred to as "pork joint", at the outskirts of Gulu town centre. It is the first day of the long school holidays and we have decided to treat the children to a pork dinner. It is already dark. The moon and the faded lights from the pork grill are shining over to where we are sitting, on an open

2 Throughout this book, I use terms like "Westernization", "Western" and "the West" in the way they are commonly applied in Uganda. "The West" usually refers to (Northern) America and (Western/Central) Europe. More important than the spatial references, however, are the ideological implications of the terms. "Western" is often used as analogous to modern, and as antonym to traditional. As Ferguson (2006: 6) argues for the concept of "Africa", the "West" marks both a location in space and a rank in a system of hierarchical social categories. I have put "Western" (etc.) in quotation marks only in those cases where I quote a particular expression from the emic discourse or the literature (double quotation marks) or to emphasize that the application of the term should be treated with caution (single quotation marks).

3 I have listed and provided some background information on my most important interlocutors in the appendix. 
meadow, surrounded by trees, in wooden chairs. Some few other guests are scattered across the place.

Pork joints are widespread throughout Gulu town. They are not only popular eating places, but important urban spaces for social gatherings. In pork joints, people from all segments of urban Acholi society come together: men and women, local elites and underpaid workers, students and out-of-school youth. They are especially popular among the younger generation. Most of the pork joints in the town centre have TV screens, where videos, usually Western action films or Nigerian movies and sometimes also music clips, are shown from morning to night. One often finds customers seated in rows in front of the TVs, watching videos while eating pieces of roasted pork and fried cassava with chopped raw cabbage and slices of tomato.

Throughout my stay in Gulu, I spend many hours hanging out in local pork joints - to meet friends for food or drinks, to visit youthful interlocutors who work there, or simply to observe the town life. Nearly every time I make valuable discoveries for my research, learn important aspects about social life in Gulu, and experience thought-provoking conversations and debates. It is in the informal setting of pork joints that people tell me about their life stories and family biographies, about the time of the war, and about the challenges they face today. It is where I learn about Acholi names and their meanings, about rituals and proverbs and fables and songs; where I try to converse in the local language; where I discuss hip hop, record studios and the local music scene; and where I am confronted with local peoples' perceptions of munu (colloquial Acholi term for white people) ${ }^{4}$, who are working in Gulu as 'development experts' or researchers.

Our local pork joint in Pece, the quarter of town where I live, does not have a TV screen. Lioba, Florence and I often meet here in the evenings since we all live close by. If the children are not at school, they always come along. Meat is not part of the boarding school diet and thus always appreciated as a special treat. Tonight, while we are waiting for the food to arrive, we talk about the dreams we had last night. It is Barbra's turn. She is a good and confident story teller. After a small intro, she starts recounting her dream:

"I dreamt I was at school. All the students in my class had just finished their exams and we were enjoying some free time on the school premises. Suddenly I see Alfred, the shortest boy in our class. He is running around the schoolyard, wearing a miniskirt. I am surprised and a little bit shocked. I walk up to him and shout: 'Alfred, are you crazy? What do you think you are doing putting on that miniskirt?' But instead of being intimidated or ashamed Alfred just answers matter-of-factly: 'We are now living in a globalized world and so I can wear miniskirts just as I like!'" (field notes 04.12.2010; my interpretation of exact wording).

A list of the Acholi terms used throughout this book and their English translation is provided in the appendix. 
This anecdote of Barbra's dream captures many of the themes I will discuss in this book. I will talk about perceptions of socio-cultural change, about images of tradition and modernity, about generational and gendered conflicts, about various interpretations of Western influences, and about negotiations in the (urban) postwar Acholi society with regard to the future and the ideal society. I believe that the miniskirt as reflected in Barbra's dream is an emblem for change in Gulu - as I will show later in my text it is referred to in many different contexts. The miniskirt represents not only a modern way of dressing. Depending on the speaker it can stand for the emancipation of girls and young women, the loss of elder's control over young people, a symbol of Western influences in Uganda, a sexual icon and sign of moral degeneration and indecency. Above all, it stands for the loss of "traditional Acholi culture" 5 . This discourse on cultural loss and the various perceptions and interpretations of socio-cultural change among the Acholi will be the main focus of my analysis in the following chapters.

Barbra's dream is also relevant to my theoretical reflections on discourse, power and agency. In the dream, Alfred, the shortest and therefore probably one of the less powerful boys in his class, draws upon the discourse of a "globalized world" to emphasize his right to wear a miniskirt. Discourses, while reflecting existing power structures, can also be a means to challenge them. Drawing on a particular discourse can be a source of agency. According to both Foucault (1990 [1976], 2002b) and Ortner $(1997,2001,2006)$, whose theories I outline in more detail below, social power relations are neither fixed nor all-encompassing, and agency can be exercised even by the seemingly least powerful. Alfred, who in the dream might represent a subordinate student, implicitly uses his knowledge of discourses on globalization, personal freedoms and human rights, to challenge established gender ideologies and dress conventions. In this sense, Barbra's dream illustrates, in a very peculiar way, a point that I argue in the following: that global und local influences as well as changing norms and practices are negotiated at all levels of society, and that discourses, power and agency are central concepts which help us to understand processes and perceptions of socio-cultural change in contemporary Acholi society (and elsewhere).

The research for this study took place between 2009 and 2011 in Gulu Municipality, Northern Uganda. Gulu Municpality is the biggest town in Northern Uganda. It was the main site of my field research, which lasted a total of eleven months. I first came to Gulu for a preparatory study in August/September 2009. From March 2010 until January 2011, I lived in Gulu for a period of ten months in which I collected the main data for my research.

Throughout this book, I speak of ("traditional") Acholi culture in the emic sense, i.e. in the way it is imagined and referred to in local discourses. I outline in great detail in chapter 4 what the term entails and what people mean when they talk about Acholi culture. In chapter 4, I also refer to anthropological debates on the concept of culture and delineate what I understand by the term culture. 
Northern Uganda has been affected by severe armed conflict since 1986 and only the beginning of peace talks in 2006 has brought about a lasting end of the fighting. The 20-year insurgency has caused massive ruptures in the cultural and social life of the Acholi, the majority population in the Northern districts ${ }^{6}$, who were worst affected by the conflict. Continuous insecurity and forced resettlement are seen to have caused changes in norms, values and social practices, and have led to a perceived breakdown of Acholi culture. In the faltering post-war phase, different social actors try to 'rebuild' society by either re-establishing former practices and conventions, or by attempting to establish what is referred to as a "modern" lifestyle. In this book, I analyze different perceptions and interpretations of socio-cultural change in Northern Uganda, which manifest themselves, among other things, in gender and generational conflicts. I particularly focus on the perspectives of young people and analyze how they position themselves between conflicting notions of retraditionalization and modernization when imaging their future - as individuals and with regard to Acholi society as a whole. I also analyze the different roles attributed to Acholi youth in discourses on socio-cultural change. On the one hand, they are seen as bearers of hope for the future and preservers of "traditional culture", on the other hand they are blamed for "losing Acholi culture" and for "westernizing" Acholiland. In this sense, I argue that Acholi youth are being discursively placed at a crossroads: between past and future, tradition and modernity, Acholi culture and Western culture.

Before I further elucidate my key research interests, I consider it important to give a brief summary of the war and the recent post-war situation in Northern Uganda in order to contextualize the contemporary discourses on socio-cultural change. After my synopsis of the recent history, I will discuss how it impacted on the life of Acholi youth, who grew up during the war and who were the prime focus of my research.

\subsection{The War in Northern Uganda: Insecurity, Displacement \& 'Cultural Breakdown'}

Between 1986 and 2006 Northern Uganda was affected by one of the longest and most convoluted armed conflicts in Africa. Different rebel groups, parts of which later united to become the Lord's Resistance Army (LRA), fought against the Ugandan army (National Resistance Army (NRA), later renamed to Ugandan Peoples Defence Force (UPDF)). The complex causes of the war and the many different actors involved (on the local, national and international level) have been controversially discussed by many authors and I analyze this literature in detail in chapter 3 .

6 As of 2011, the Acholi sub-region, sometimes referred to as "Acholiland", was comprised of seven districts: Gulu, Kitgum, Pader, Amuru, Nwoya, Lamwo and Agago (see appendix, figure 1). 
Julia Vorhölter: Youth at the Crossroads

In the course of the war both the rebels and the Ugandan army committed severe human rights abuses and the local population bore the brunt of the suffering. Thousands of people lost their lives, either through violence, starvation or warrelated diseases and epidemics. The LRA abducted tens of thousands of children and young adults, looted food and other belongings from the Acholi population, burned down their huts and massacred local people suspected of supporting the NRA/UPDF. Until 2006, the fighting between the LRA and the UPDF continued, sometimes with longer intervals in which no attacks were launched. Several peace initiatives failed. In August 2006, a first peace agreement was signed between the LRA and the Ugandan government, followed by further peace agreements in April and June 2007 and February 2008 which brought about a tentative end to the fighting. The peace talks, held in Juba, Southern Sudan, did not however lead to a final resolution of the conflict as leading commanders of the LRA refused to sign the final peace deal. Since 2006, Northern Uganda has experienced relative peace while the LRA is continuing its attacks in the DR Congo and the Central African Republic (ICG, 2010; 2011).

From 1996, the government started forcibly displacing the people of Northern Uganda into so-called "protected villages", also commonly known as IDP $^{7}$ camps. Over the next ten years, up to 1.8 million people (IDMC, 2010) ${ }^{8}$ - the great majority of the Acholi population - were forced by the NRA/UPDF to leave their local villages and resettle in camps which were established around local trading centers, allegedly to protect the people from the LRA attacks in the villages. The living conditions in the camps, however, were extremely poor, leading prominent social scientists to accuse the Ugandan government of "social torture" (Dolan, 2009) and of "displacing human rights" (Branch, 2011). Several thousand Acholi people are said to have died as a result of the encampment due to lack of food, low health, sanitation and housing conditions, physical and psychological disorders and violence. In local perception, camp life is furthermore seen to have caused a breakdown of Acholi culture, i.e. formerly established economic practices, political orders, social relations, norms and values. This perceived loss of Acholi culture and the various contemporary attempts to reconstruct it will be discussed in depth in chapter 4 .

Most of the people who did not stay in the camps, usually those who had better financial means and/or relatives in town, moved to urban centers. Gulu Municipality, the biggest town in the North, grew from around 40,000 people in the early

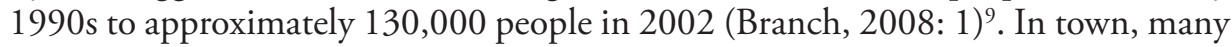
of the new settlers experienced living in a large-scale monetary economy and gained

Internally Displaced Person

8 Estimates vary between one million and 1.8 million displaced people (Branch, 2011; RLP, 2004: 21ff.; OCHA, 2006; IDMC, 2010).

9 According to estimates attributed to the Ugandan Bureau of Statistics (2012), the population of Gulu has developed as follows: 18,170 inhabitants in 1969; 14,958 inhabitants in 1980; 38,297 inhabitants in 1991; 119,430 inhabitants in 2002, and 154,000 inhabitants in 2011 (cf. appendix, figure 4). 
access to new technologies such as mobile phones, national and international media, and popular culture through TV and internet for the first time. They also lived in a 'multi-cultural' setting, in which they interacted with people from other countries and other ethnic groups on a daily basis (ibid.: 7ff.). While people enjoyed greater freedom and safer living conditions in town, they also suffered from economic hardships. Since no food aid was given out in town people had to struggle to provide for their families. And although there was an increase in the number of jobs and income opportunities due to the presence of humanitarian organizations (especially from 2000 onwards), many people were un- or underemployed and salaries were exceedingly low (ibid.: 5 ff.).

Due to forced displacement and the subsequent change of social, cultural and economic practices and routines, Acholi - particularly those in the camps, but also those in town - increasingly perceived the war situation as a situation of 'cultural breakdown'. According to common perception, displacement implied a radical change in lifestyle: in camps and in town people were confronted with new norms, values and morals. Discourses on the rights of children and women promoted by many humanitarian NGOs, for instance, were seen to thoroughly challenge former Acholi social hierarchies (Branch, 2008: 7ff.). Images and behaviors (particularly those regarding dressing styles and sexual practices) exposed in Western films, which were (and still are) widely shown in video halls in the camps and in town, were seen to clash with Acholi ideas of morality and decency. To this day, a frequently voiced claim is that Acholi culture has been lost due to the war and its social consequences, and that Acholi society is experiencing a profound "moral degeneration".

While this discourse can be found among all segments of Acholi society, it is particularly pronounced among the older generations. Elders often blame young people for abandoning "their culture" and engaging in a lifestyle copied from the West instead. In the current post-war situation the benefits and detriments of "tradition", and the extent to which former cultural practices should be 'revived' and reinstated, are matters of fierce debate. Urban youth, while appreciating the value of "tradition", are frequently attracted to a more global, "Western" (youth) culture. Inspired by the media which conveys images of a glossy modern future, young people dream of a prosperous life in urban Uganda or abroad, and do not want to return to a life of rural farming as practiced by previous generations before the war. At the same time, they yearn for the communality and stability of "traditional life", which they know from romanticized narratives about the past. In this sense, they are caught between conflicting notions of retraditionalization and modernization.

\subsection{Growing up in Times of War: Acholi Youth}

The historical events I described above had a great impact on the life of my interlocutors. Most people I worked with during my research were born shortly before or during the early years of the war (i.e. roughly between the mid-80s and early 
1990s). They had spent their childhood and early youth in a time and place that was characterized by great insecurity, confusion and despair. Members of this "war generation", as I argue in more detail in chapter 5, experienced the instability caused by the war and the post-war situation in a specific way, which was different from members of older (pre-war) or younger (post-war) generations. During the war, they faced a particular situation of insecurity, for instance because young people of their age group were a prime target of LRA abductions (cf. Spitzer and Twikirize, 2012: 70ff.). Nearly all of my interlocutors had friends, siblings or class mates who had been forcefully recruited by the LRA, and some of them had also been abducted themselves. War-related displacement also affected members of the war generation in specific ways. Unlike their parents and grandparents, most of them had not or only very briefly experienced pre-war village life and the social, cultural, economic and political practices related to it, which shaped older people's imagination of a 'normal', i.e. stable and regulated social life and provided them with a source of stability and orientation. I gained the impression that young people's lack of a sense of normality had in some ways made it easier for them to adapt to the new circumstances in the camps or in town than for members of the older generation.

Most of my interlocutors had come to Gulu during the years of the war, either with their families or to stay with relatives in town. As described above, urban life differed significantly from life in the camps. Children and youth in town had better access to education and other services (e.g. health and counseling, leisure activities, media) which were provided or supported by international development organizations, particularly during the last years of the war. Although the overall humanitarian intervention, particularly the distribution of food aid, concentrated on the people in the camps, urban children and youth were an important target group of aid agencies and thus became very exposed to Western development discourses and practices (cf. Verma, 2012).

During the time of my research, I gained the impression that my young interlocutors had not only experienced the time of the war quite differently from members of older generations, but were also confronted with specific challenges in the contemporary post-war period. Some of these directly resulted from the war context (for instance being exposed to an extremely high rate of HIV, having to cope with traumas resulting from abduction, displacement and violence, or being orphaned $\left.{ }^{10}\right)$. Other factors such as the lack of quality education, unemployment, political and economic marginalization, were challenges faced by other young people in urban Africa and beyond.

Acholi youth in Gulu also gained new opportunities and means to exercise agency compared to older generations. In some regards these were related to recent developments in Gulu which was in the process of becoming a rapidly growing ${ }^{11}$

10 Spitzer \& Twikirize (2012: 72) give estimates according to which 22 percent of the children in Northern Uganda are orphaned.

11 Gulu now ranks third in the list of most-populated towns in Uganda (cf. appendix, figure 4). 
and globalized economic center with promising business opportunities due to its reestablished and newly emerging national and international trade connections. With the opening of Gulu University in 2003, Gulu had also become a centre for higher education and attracted students from all over the country. Although many of my interlocutors did not immediately profit from Gulu's economic or educational progress, they welcomed the increased access and exposure to international media and material culture (particularly music and films, clothing and phones) and often used this access in creative ways.

It is crucial to point out that there were important differences among youth living in Gulu, particularly regarding class and educational background, family situation and gender, which affected the ways they experienced the war and post-war situation. I will discuss these differences in greater detail in chapter 5 . The information provided so far suffices to describe the setting of my research and to contextualize the key research questions, objectives and hypotheses which I outline in the following.

\subsection{Key Research Questions, Objectives \& Hypotheses}

Branch (2008: 7) states that

"[a]lthough there [are great] controversies over what Acholi society was like before displacement, the actual changes that have occurred are, especially now, twenty-one years since the beginning of the war, of minor importance relative to the perceived changes that have occurred in the eyes of the displaced population itself. The differences between different perceptions of pre-war, pre-displacement Acholi culture and of its current changes are allimportant, for these different perceptions will guide and legitimate the different projects put into place after the end of displacement."

This statement only hints at the pervasiveness of current discourses on socio-cultural change in Northern Uganda and at the importance the contestations of a 'true' Acholi culture might have for the restoration and renovation of post-war society. Branch rightly remarks that in this context it is less relevant to try to reconstruct actual changes which have occurred in Acholi society. Rather, one should take seriously people's perceptions of what has changed because these perceptions fundamentally shape, and thus have very real consequences for, future developments. During my stay in Gulu, I was confronted with discourses on socio-cultural change daily. Everywhere I went and whomever I talked to, at some point the topic of "cultural change" 12 and the differences between pre-war and post-war Acholi society came

12 My English-speaking interlocutors in Gulu used the term "cultural change" rather than sociocultural change to refer to the changes they perceived in Acholi cultural, social, economic and political life. I have opted to use the term socio-cultural change as a more encompassing term to 
Julia Vorhölter: Youth at the Crossroads

up: in the local market when talking to vendors or tailors, in restaurants selling Acholi food, in family contexts when visiting people at home, and at the university, when chatting with colleagues or students ${ }^{13}$.

Originally, my main focus of research was only on perceptions of changes in gender relations. However, during the course of my fieldwork I learned that gender relations were only one of the many topics discussed in the context of analyzing and interpreting socio-cultural change. I further learned that an important reference in discourses of change was not only the imagined 'authentic' pre-war Acholi society; just as relevant were imaginations of a 'prototypical' Western society, which people encountered in films, in development discourses, and by observing and/or interacting with expatriates currently living in Northern Uganda. I will elaborate the discourse on Westernization in more detail in chapter 6 .

At this point it is enough to declare that discourses on socio-cultural change are highly complex matters. They are comprised of and interlinked in multiple ways with local, national and global discourses, political, economic and moral discourses as well as colonial and post-colonial discourses. As stated above, discourses reflect and at the same time challenge existing power structures. They reveal different positionalities individual actors have in Ugandan society. They enable and constrain agency. In my analysis, I have thus chosen a discourse-analytical approach to study the ways people perceive and talk about socio-cultural change in post-war Acholi society. My research is guided by two main questions and their respective sub-questions:

On a general level, I look at discourses on socio-cultural change and the various imaginations of post-war Acholi society conveyed in these discourses:

$\rightarrow$ How do different social actors define, perceive and interpret socio-cultural change? What are their future aspirations both individually and for their society as a whole?

- How are values, norms and cultural practices negotiated in a society which has experienced severe disruption due to war?

- What are matters of debate and conflict?

I specifically focus on the perspectives of urban members of the generation that was born and grew up during the years of the war:

talk about the perceived changes in these various but closely interconnected fields of Acholi life. In my analysis, I am less interested in the 'real' changes which occurred in recent history (in fact, when speaking from a Foucauldian standpoint, the 'real' cannot be separated from the discourse and as such is always already an effect of power). Instead, I focus on the perceived changes and the way these are represented and discussed in local discourses.

13 During the second half of my stay (August 2010 to January 2011) I worked as a part-time lecturer at the Institute of Peace and Strategic Studies (IPSS) of Gulu University (cf. Chap. 2). 
$\rightarrow$ How do they perceive changes in Acholi society and (how) do they position themselves as agents or 'victims' of these socio-cultural changes?

- How have their life experiences influenced their understanding of Acholi culture and values?

- How do they picture their individual futures and the future of Acholi society?

- How do they react to the expectations directed at them by older members of Acholi society?

These research questions are discussed with regard to three key sets of relations: 1) generational relations, 2) gender relations, and 3) local-global relations, especially between Acholiland (respectively Uganda and Africa) and the West as they are imagined in local discourses. All three themes are closely interconnected. They are of crucial relevance for my analysis not only because they recur throughout my data, but because all three areas are especially dense fields and transfer points of power relations and thus interesting and suitable to study by means of a Foucauldian discourse-analytical approach (see below). Throughout my analysis I will show that generational relations, gender relations, and (imagined) relations between Uganda and the West are currently major fields in which power relations are established, maintained and contested. It is in these fields that all the different types of discourses I mentioned above - local, national and global, political, economic and moral, as well as colonial and postcolonial discourses - become closely intertwined.

Throughout my study, I place Acholi youth, specifically those who grew up during the time of the war, in the centre of my analysis. My key argument is that members of this war generation are faced with a particular situation of uncertainty ${ }^{14}$ and ambivalence. This is linked, on the one hand, to their experience of protracted war and the profound changes people attribute to the war. On the other hand, it is related to the expectations and hopes placed on Acholi youth as the "pillars" of the future ${ }^{15}$ and the preservers of Acholi culture. I argue that the war generation occupies a specific in-between position. It is seen as the link between the war-torn past and a prospective peaceful future, but also between tradition and modernity, Uganda and the West. As 'beacons of hope' for Acholi future, members of this generation face an enormous amount of societal pressure. Figuratively speaking, they are placed at a crossroads at which they feel that they have to choose whether they

14 In my understanding of uncertainty, I loosely draw on Reiter (2010: 8), who defines the concept of "biographical uncertainty", which has been applied in different sociological studies, as "the weakening of [the] linkage of experience, expectation and projecting due to an erosion of intersubjectively shared certainty in a special social situation". According to this definition, uncertainty is linked to the difficulty to establish a coherent link between past experiences and future actions.

15 According to Cheney (2007: 3) the Ugandan national youth anthem even refers to young people as "the pillars of Uganda's tomorrow". 
Julia Vorhölter: Youth at the Crossroads

want to be 'breakers with' or 're-makers of' the past. It is their burden but also their chance to decide whether these seemingly conflicting notions can be reconciled or whether they are, as often suggested, mutually exclusive.

My study seeks to make a contribution to the growing field of youth research and generational change in Africa. I assume that in societies which recently experienced prolonged war, such as in Northern Uganda, the dynamics of and debates on change are even more pronounced than in other contemporary African societies. I thus believe that my research can provide specific insights into the complex ways change is negotiated by youth and between youth and elders, men and women, local and international actors.

The origins of youth research in anthropology go back to the early years of the discipline, but approaches to studying youth have rapidly changed over time. Therefore, it is necessary to first give a brief overview of the historical development of the anthropology of youth before I discuss recent developments in this field with particular regional focus on Africa. Subsequently, I will elaborate my standpoint, and propose how my research contributes to current debates.

\subsection{State of the Art: Past \& Contemporary Debates in the Anthropology of Youth}

In the last 20 years, youth and youth culture have (again) become popular fields of research in anthropology. Studies of childhood and adolescence, both in Western and non-Western societies, have a long history in anthropology, but their focus has greatly changed over the years (for a good overview, see Bucholtz, 2002; Dracklé, 1996a; Hodkinson, 2007; Luig \& Seebode, 2003b; Wulff, 1995).

\subsubsection{History of Youth Research in Anthropology}

A foundational work in the field of youth research, which subsequently inspired many studies in anthropology, was Stanley Hall's Adolescence: Its Psychology and Its Relations to Physiology, Anthropology, Sociology, Sex, Crime, Religion and Education, first published in 1904. Hall analyzes adolescence as a process of becoming, a transitory life stage marked and to some extent determined by physiological changes. Due to the bodily changes during puberty, Hall regards adolescence as a universal period of uncertainty, existent in all societies. Adolescent sexuality and delinquency are two of the topics discussed at length by Hall, and, as I will show in the following, have been taken up by sociologists and anthropologists as key themes of youth research until today (Hall, 1911; cf. Dracklé, 1996a: 19ff.).

In the 1920s and 1930s, anthropologists became interested in studying adolescence in cross-cultural perspective (Benedict, 2008 [1938]; Malinowski, 2001 [1927]; Mead, 1949 [1928]). Margaret Mead's Coming of Age in Samoa is one of the pioneering books of early cultural anthropology and an essential reference in 
its emerging Culture and Personality School. In her study among adolescent girls in Ta'ū, Mead analyzes the passage from childhood to adulthood in Samoan society by looking at family, gender and sexual relations and related social norms, and compares them to adolescence in the U.S.A. (Mead, 1949 [1928]). Her findings, although later disputed by Freeman (1983), challenge Hall's assumption of a universal and biologically determined phase of adolescence, and instead emphasize the culturally-determined particularities of growing up in different societies.

For a long time after these early works, anthropologists continued to study adolescence as a phase of transition, as passages from childhood to adulthood. Adolescents were regarded as no longer children but not yet adults. They were thus seen as 'incomplete' and studied from an adult perspective, rather than taken as self-determining and mature social actors. A prominent, albeit very narrow focus of the anthropology of adolescence were rites de passage and initiation rituals (e.g. Richards, 1956; Turner, 1967), which were seen as the most crucial transition points from childhood to adulthood (for an overview and critical analysis of these studies see Dracklé, 1996a; Lauser \& Bräunlein, 1996: 152ff.; Müller, 1992; Schlegel \& Barry, 1980; 1979).

A separate strand of research on youth and adolescents was situated at the crossroads between anthropology, sociology and cultural studies, and was largely focused on urban youth and youth (sub)cultures ${ }^{16}$ in Western societies. Starting in the 1920s, the Chicago School produced some famous monographs which particularly focused on (criminal) urban youth gangs (e.g. A. Cohen, 1967 [1955]; Whyte, 1955 [1943]). The deviant behavior of youth, often second generation immigrants, was discussed in relation to racial segregation and economic destitution in the USA, and can be seen as important antecedents to more recent works on social marginalization in inner-city America, most prominently those by Bourgois (2003; with Schonberg, 2009). The Chicago School also greatly influenced the foundation of youth cultural studies, particularly in Birmingham (Bucholtz, 2002: 536).

In the 1960s, the Birmingham Centre of Contemporary Cultural Studies (CCCS) started to analyze youth "subcultures" in Great Britain. The studies by different researchers mainly concentrated on male (for an exception see McRobbie \& Garber, 1991 [1975]), white, urban, working class youth. They applied a Marxist framework to discuss the perpetuation of class dynamics across generations, and were particularly concerned with "cultural style" as a basis for class identity, and with resistance against hegemonic, mainstream culture (Hebdige, 1988 [1979]; Hall \& Jefferson, 1991 [1975]). With the prominent exception of Willis' study of working class "lads" (1977), the CCCS researchers did not base their studies on participant observation, but rather on textual and semiotic analysis. Nevertheless, their studies greatly influenced later youth research in anthropology and beyond. A good example is Stanley Cohen's concept of moral panics (Cohen, 2002 [1972]), which is still frequently cited and referred to (cf. Buchholtz, 2002: 536ff.; Valentine et al.,

16 The term youth culture was first introduced by Talcott Parsons in 1964 (Wulff, 1995: 3). 
Julia Vorhölter: Youth at the Crossroads

1998: 10-19). Furthermore, many contemporary studies which focus youth's resistance to and contestations of race-, class-, gender- or ethnicity-based discrimination, often in the context of globalization, build on the works of the Birmingham School (Cole \& Durham, 2008b: 4; Bucholtz, 2002: 540f.).

During the 1980s and early 1990s, research on youth and youth culture lost some of its former popularity in anthropology (and sociology). But in the past two decades, a new focus on youth has emerged (Luig \& Seebode, 2003b: 9). Although topics discussed throughout its early stages - like sexuality, deviancy, crisis etc. - are still important today, youth research has undergone a significant shift. Newer approaches to the subject have regional foci and theoretical premises which largely differ from older approaches.

For a long time, youth were mainly studied in the context of Western, industrialized societies (Wulff, 1995: 2). Anthropologists did study adolescents in non-Western societies, but, as outlined above, with the aim of comparing adolescence in Westernand non-Western societies, and/or with an often exoticizing focus on initiations. Nowadays, social scientists study youth in the context of globalization and analyze the interplay between local and global youth cultures, prominently in the fields of music, film, clothing and recently also computer-based social networking (Furlong \& Cartmel, 1997; Hodkinson \& Deike, 2007; Skelton \& Valentine, 1998). In anthropology, youth research relates to a range of broader popular themes (e.g. post-modernism, media, consumerism, ethnicity, gender, sexuality) and analytical concepts (e.g. agency, space, resistance, identity, performance) which are related to contemporary process of socio-cultural change across the globe (e.g. the volumes by Amit-Talai \& Wulff, 1995; Cole \& Durham, 2007a; 2008a; Luig \& Seebode, 2003a). As Wulff (1995: 1) states in her often-cited introduction: "The analysis of youth cultural production raises questions which are at the very heart of contemporary debates in anthropology". She further argues that "[w] hen it comes to globalization or transnational connections youth cultures are in the forefront of theoretical interest; youth, their ideas and commodities move easily across national borders, shaping and being shaped by all kinds of structures and meanings" (ibid.: 10).

\subsubsection{Defining Youth: Conceptual Challenges \& Debates}

The broader, global focus in studying young people has exposed some conceptual problems in defining youth. In their introduction to a volume on globalization and the temporalities of children and youth, Cole and Durham (2008b: 5) claim that "[c]hildhood and youth are notoriously difficult categories to define". The challenge arises not only from the fact that conceptions of life stages differ vastly across cultures and societies, but also because, very broadly speaking, rapid changes in all societies across the globe, particularly throughout the second half of the $20^{\text {th }}$ century and until today, have called into question formerly established assumptions of 'normal' life courses and have led to a disjuncture of biological age and the expected correlating life stage. 
For a long time in anthropological writings, concepts of childhood, adolescents, youth, or adulthood were based on Euro-American understandings of the life cycle as a "developmental teleology" (Cole \& Durham, 2008b: 5) and clearly separable, successive stages, based primarily on biological age. As stated above, more recent works fundamentally challenge these assumptions (Baller, 2010: 25ff.). Cole and Durham (2008b: 6ff.), for instance, point out that adolescence as a distinct life stage only came to be recognized in Europe and the USA in the course of the $19^{\text {th }}$ and $20^{\text {th }}$ century and was particularly shaped by the introduction of capitalism. Condon (1990) argues that among the Canadian Inuit he studied population changes, increased economic security, and increased exposure to "southern" value systems led to the recognition of adolescence as a prolonged life stage - albeit substantially later than in Western societies - which was non-existent in the pre-contact period. Thus, definitions of social categories like youth or adulthood, are always determined by social circumstances rather than being biologically determined. What exactly it means to be a child, a youth, or an adult, and whether these are relevant categories at all, changes over time and greatly varies across cultures and genders.

In recent decades, however, social categories, their boundaries and definitions have undergone significant and somewhat paradoxical shifts across the globe. On the one hand, there has been a global move towards standardized definitions, usually based on biological age, for statistical reasons, legal purposes and social planning. This trend must be seen in connection with the global establishment of the nation state (cf. Scott, 1998). In international or regional conventions such as the Convention of the Right of the Child (1989) or the African Youth Charter (2006), definitions of "child" or "youth" have even been homogenized beyond the level of the nation state. On the other hand, locally established, i.e. emic markers of social categories and their boundaries have become obscured for various reasons. Initiations, for instance, which formerly served to mark the transition from childhood to youth in many societies, are no longer experienced collectively by all or even the majority of boys and/or girls in these societies - because young people are in boarding schools or their families have moved to towns, or because initiation rituals have been discontinued due to the introduction of Christianity. Similarly, 'status symbols' like marriage and the establishment of an independent household, which formerly marked the transition from youth to adulthood in many cultures, are no longer attainable for a large number of young people for a number of reasons: young men cannot find employment and lack the resources to pay the brideprice; young women therefore cannot find a husband in their age group and often turn to older men or simply remain unmarried. Furthermore, due to processes of urbanization and neoliberalization new conventions and social relations are emerging which differ considerably from existing patterns and norms (Hansen, 2005: 14; Honwana, 2012: 89ff.).

In any case, the discrepancy between ideal type and reality poses an analytical challenge. For how can social scientists still operate with the term "youth" if in fact a considerable proportion of young people remain "youth forever" (Hansen, 
Julia Vorhölter: Youth at the Crossroads

2005: 5)? And even beyond the analytical level, the emergence of new social actors who fit neither the standardized, formal categories nor the emic ones, constitutes a very real concern. A prominent example are 'child soldiers', a category of social actors, which challenges definitions of child, youth, and adult, and deeply confounds behavioral expectations, social roles and hierarchies associated with these social categories (Baines, 2009).

Anthropological studies have increasingly become confronted with a gap between ideal life stages and lived realities and the uncertainties and confusion which result from this incongruity (Cole, 2011: 82). Honwana (2012: 19ff.), in her comparative analysis of African youth, uses the concept of "waithood" to analyze this phenomenon and states that "[f] or many, being young in Africa today is synonymous with living in involuntary waithood" (ibid.: 6). The problem of conceptualizing youth has become a central concern and issue of debate in anthropology in the last two decades. In the following, I will briefly sketch some of the most important 'solutions' anthropologists have found to deal with the problem of conceptualizing youth, and outline some of the ongoing debates carried out concerning this matter.

\section{Adolescence}

As already stated above, in its earlier stages, the majority of anthropological research on 'young people' was highly influenced by Western psychology and its postulations on adolescence. Adolescence was seen as a universal process and life stage, throughout which physical and social transitions occurred, and which was thus experienced by the individual as a period of uncertainty and crisis. Although some anthropologists working with the concept of adolescence acknowledged that 'context' had different effects on the way individuals in different cultural settings experienced adolescence, the concept as such was not generally questioned. The definition of adolescence was based largely on biological age and biological measures, i.e. the years of puberty, and therefore did not constitute a major analytical concern (Bucholtz, 2002: 528ff.).

Conceptually and etymologically, the word adolescence, derived from the Latin word adolescere, to grow, implies a sense of incompleteness, a state of becoming, and thus of not yet being a full social actor (Bucholtz, 2002: 532). Accordingly, anthropologists have tended to view adolescents "as not to be taken very seriously" and many studies depicted them "as objects of adult activity" (Wulff, 1995: 1). Adolescents in anthropological studies were often represented by others - by adults in their community or the anthropologist speaking about and for them rather than with them - often with an educational intent. These studies were thus often more about the way adults guide and socialize young people to become full members of the society and not about the many informal ways young people socialize themselves. Due to their often comparative design, many studies on adolescents were shaped by the anthropologists' own assumptions about adolescence in their coun- 
tries of origin, and this bias was rarely openly reflected upon (Bucholtz, 2002: 529; Dracklé, 1996a).

Bucholtz (2002), Dracklé (1996a) and Wulff (1995) thus all call for a different approach to the study of young people, one which discards the concept of adolescence and the premises associated with its study, and which instead focuses on youth as cultural agents.

\section{Youth as Cultural Agents}

As an alternative to the "anthropology of adolescence", Bucholtz advocates an actorcentered approach, the "anthropology of youth", which she believes can help to overcome some of the shortcomings she associates with the former. She delineates this approach as follows:

"More recently, (...) an anthropology of youth has begun to take shape, sparked by the stimuli of modernity and globalization and the ambivalent engagement of youth in local contexts. This broad and interdisciplinary approach revisits questions first raised in earlier sociological and anthropological frameworks, while introducing new issues that arise under current economic, political, and cultural conditions. The anthropology of youth is characterized by its attention to the agency of young people, its concern to document not just highly visible youth cultures but the entirety of youth cultural practice, and its interest in how identities emerge in new cultural formations that creatively combine elements of global capitalism, transnationalism, and local culture" (Bucholtz, 2002: 525; my emphasis).

In contrast to the concept of adolescence, which is based on "age as biological fact", Bucholtz then sees the concept of youth as based on "age as identity", and emphasizes that "the selection of either term is itself a theoretical choice", which leads to very different research approaches and outcomes (Bucholtz, 2002: 532). Bucholtz does not in fact provide a definition of youth, but is rather concerned with broader conceptual issues related to studying youth. Essential to her approach are the concepts of agency and identity. She stresses the necessity to focus on youth's own cultural agency which can be somewhat independent from that of adults. Youth are not only being formed by their elders, but also rebel against them and are often initiators of socio-cultural change. They are full cultural, social and political actors, who take conscious choices and are influenced by their peer groups just as much or even more than by adult members of their communities.

Bucholtz's approach has been criticized by Durham (2008) and Cole (2011), both prominent anthropologists of youth in Africa. They claim that Bucholtz's focus on agency is too much centered on individual actors and often aligned with a very rationalist subjectivity, which reflects the ideal of Western individualism. They argue that agency as a positively connoted concept celebrates the opposition between subjects and existing structures, but often tempts the researcher to overlook the fact 
Julia Vorhölter: Youth at the Crossroads

that many individuals, particularly in non-Western contexts, aspire to become part of and subordinate themselves to a collectivity. In this sense, Cole claims that $\mathrm{Bu}-$ choltz's approach is not very suitable for African contexts where youth seek to "be recruited into particular kinds of subject positions" (Cole, 2011: 72) which can be tied to the reproduction of patron-client relationships. She asserts that "youth seek adulthood by subjecting themselves even more intensively to the networks and social relations that provide economic and social opportunities. Theirs is not a story of standing outside existing structures of power: It is a story trying to get inside them" (Cole, 2011: 73).

Durham also criticizes that agency has become a rather arbitrary and ubiquitous concept in anthropology, which requires further specification if it is to be of any analytical value. She wonders whether youth have the same kind of agency as other people and suggests that "[w]e must ask what kind of agency they might have, how they come by it and exercise it, and how their agency relates them to others and to their society" (Durham, 2008: 153). She questions whether youth are really the initiators of socio-cultural change often envisioned in the West, and criticizes the "romance of youth agency" frequently portrayed in anthropological writings (ibid.: 164ff.; 175f.). Thus, rather than conceptualizing youth as cultural actors, Durham (2004) suggests that they are "social shifters".

\section{Youth as Social Shifters}

Durham develops her concept of youth as "social shifters" with reference to her own ethnographic research in Botswana. Drawing on linguistic concepts, Durham suggests that "youth is socially deictic or, more boldly, a social shifter" (2004: 589). Who is considered youth can only be understood with reference to temporal, spatial and social context, and it is situationally created or defined. Youth is thus a relational concept, and who is considered youth is contested and changes depending on the situation. In Durham's words:

"If one accepts that youth (or other age categories) is culturally contingent, that is relational, and that there may be more than one set of age-related frameworks available in any society, then one must explore that pragmatic dimensions through which age is invoked, the political aspect of calling someone 'youth' (or not)" (2004: 592).

In this sense, the act of labeling oneself or someone else as youth can be considered a political act (ibid.). It reflects struggles within society about defining, representing and positioning (age) groups: "To call someone a youth is to position him or her in terms of a variety of social attributes, including not only age but also independence-dependence, authority, rights, abilities, knowledge, responsibilities, and so on" (Durham, 2004: 593). The contested, dynamic and relational meanings of youth in any given society need to be taken into account by anthropologists. Rather than assuming that all youth are cultural agents, researchers need to understand 
what it means in a given society to be a 'youthful cultural agent', in which situations it may be desirable or undesirable to be labeled as such, and how young people are positioned and position themselves in the category of youth (cf. Christiansen et al., 2006b: 9ff.).

\section{Generation}

A different but related approach to studying young people, i.e. analyzing generations and generational dynamics, has recently experienced a new popularity, particularly among scholars studying African youth (e.g. Alber et al., 2008; Alber \& Häberlein, 2010; Bundy, 1987; Comaroff \& Comaroff, 1999; Kagwanja, 2005). The concept of generation, just as the concept of social shifter, is a relational one. Specifically, it designates relations in time. It does not a priori define a social category in terms of youth or adulthood, but acknowledges the relational nature of such categories. In the literature on Africa one can identify three different conceptions of generation (Whyte et al., 2008: 3ff.): a) generation as a genealogical relation of kinship; b) generation as a principle for structuring society (as in the classical example of age sets among East African pastoralists); and c) generation as historical generation or cohort, as outlined by Karl Mannheim in his classic text The Problem of Generations, first published in German in 1928. Most of the recent studies by anthropologists draw on this last conception, which I will therefore briefly summarize ${ }^{17}$.

According to Mannheim, a central characteristic of a generation is "the similarity of location of a number of individuals in the social whole" (1972: 290) ${ }^{18}$. He postulates that a "historical generation" reaches maturity in a similar cultural and historical "location", which its members are conscious of, and which offers its members a limited range of potential experiences. If, during their young ages, people of a similar age range experience major historical shifts and socio-cultural changes together, they can develop a "generational consciousness" (1972: 288ff.). However, whether a generation does in fact develop such a distinctive consciousness depends on the "tempo" of change. As Mannheim states, "not every generation location not even every age group - creates new collective impulses and formative principles original to itself and adequate to its particular situation" (1972: 309). This depends on the "realization of potentialities" inherent in the social location, and it is closely connected to the speed of socio-cultural change (ibid.). Furthermore, the perception of one's generation as a distinct group, i.e. as a "generation in actuality", only develops when a concrete bond exists between its members due to their exposure to similar social and intellectual modes of thought. These may differ between people of different classes and social backgrounds (e.g. urban vs. rural) and their subsequent

17 For a re-interpretation of Mannheim's theory in view of current sociological theory see Fietze, 2009.

18 In this book, I draw on the English translation of Mannheim's text by Paul Kecskemeti (cf. Mannheim, 1972) in order to be able to use direct quotes without having to translate them from the German original. 
Julia Vorhölter: Youth at the Crossroads

capacity to participate actively in social transformation, which results from these different positionalities in society (1972: 302ff.). The most concrete group within an "actual generation" is the "generation unit", which is not only exposed to similar modes of thought, but shares a similar ideology or "identity of responses" (ibid.: 306), i.e. shares a similar conviction how to respond to a particular historical situation. Mannheim gives the example of liberal and conservative groups in $19^{\text {th }}$ century Germany, which he sees as polar forms of generation units within an "actual generation" (1972: 304).

An important concept in Mannheim's theory which is often taken up in recent writings (e.g. Cole, 2004) is the concept of "fresh contact" (Mannheim, 1972: 293f.). Mannheim attempts to explain processes of socio-cultural change by arguing that every new generation establishes "fresh contact" with the already existing social and cultural heritage but with a different attitude than former generations. Thus every generation assimilates accumulated heritages differently and selects different cultural elements to be kept and others to be forgotten (cf. Cole \& Durham, 2007b: $16 \mathrm{ff}$., who use a similar concept which they call "regeneration").

\subsection{Defining Youth in Northern Uganda}

My own conception of youth is largely based on and combines the more recent approaches just outlined. I provide more detailed information on my regular interlocutors, interviewees and respondents in the course of my analysis and in the appendix. Here, I only want to explicate my conceptual approach and delineate who I mean when I speak of youth or the young generation.

As a label for the target group of my research in a narrower sense, I have coined the term "war generation". Thereby, I have used Mannheim's concept of "historical generation". I speak of the war generation when I want to refer to a particular 'subgroup' of Acholi youth, namely the generation which was born and grew up during the years of the war, i.e. those born shortly before or in the early years of the war (roughly between the mid-80s and early 1990s). The group thus defined can be well-described as a historical generation in a Mannheimian sense: members of this generation reached maturity in a similar location, experienced a major historical shift, i.e. the war, throughout their childhood and adolescence, and thus - one has reason to believe ${ }^{19}$ - developed a form of "generational consciousness". Throughout my field research I mainly worked with urban members of this war generation in Gulu Municipality who had spent most of their life in town (i.e. they never or only briefly experienced village life and did not spent extended periods of time in the

19 The question whether the "war generation" had developed a generational consciousness in the Mannheimian sense is, in fact, an empricial one. Although I did not gather systematic data with regard to this question, I assume that members of the war generation did possess a form of generational consciousness because in several discursive contexts they referred to themselves and were referred to by others as a distinct generation. 
IDP camps). I chose to place them in the center of my analysis, because they experienced war-related changes in Acholi society in a very particular way as I will argue in more detail in chapter 5, where I describe the specific characteristics of the urban war generation and also point out important differences between its members.

When speaking about Acholi youth in a broader, more general sense, I draw on Bucholtz's concept of youth as cultural agents. Like Bucholtz, I believe that youth represent a distinct group of social actors, which can exercise cultural agency and initiate or influence socio-cultural changes relatively independent of or even in opposition to other societal groups, namely adults and elders. This assumption also seemed to be in line with the conceptions of youth I encountered in Gulu because, as stated above, my interlocutors often spoke about youth and elders as distinct categories, endowed with different characteristics and different potentials for agency. In my research I am interested to find out under which conditions young people perceive themselves as agents and actively try to influence change processes, and in which situations they perceive themselves as subordinated members of society who cannot or do not want to question the status quo. Following Bucholtz, I do not $a$ priori want to categorize youth as agents or victims, equals or subordinated as is often been done by adult members of society and by external researchers. Rather, I focus not only on youth's perspectives on social developments, but also on their perceptions of themselves.

Based on my empirical experience, I acknowledge that youth in Northern Ugan$\mathrm{da}$, just as Durham has argued, is very much and maybe increasingly becoming a relational category. Who is categorized as youth varies from situation to situation and according to speaker and context. I can give many examples from my fieldwork, where in one situation a person was labeled youth, and in another was addressed as an adult or even an elder. One extreme case happened in the context of a group discussion in Bobbi, a rural area some 30 kilometers outside of Gulu. My research assistant had organized the interview with the help of a young woman, Alice, who was living and working in Bobbi. When telling me about her, my assistant always referred to her as "youth". He knew her because she sometimes helped the Youth Centre in Gulu where he was working to organize outreach programs in Bobbi. Alice was 25 years of age and married with one child. When we arrived at the day of the interview she had organized a number of young people between the ages of 16 and 20. She had also tried to find elders, as the interview was planned as a group discussion between youth and elders. Unfortunately, she had only managed to find two elderly men. Thus, in the course of the interview, my research assistant started to address her as a female elder. He, for instance, asked her to give her opinion on today's young generation and to judge them from her adult/elder point of view. Thus, in the brief context of the interview, Alice social position shifted to that of an elder - not because she really fulfilled the criteria for being an elder, but because relative to the other young people present, she came closest to these criteria, i.e. being married, having a child and being (relatively) older (cf. field notes 06.10.2010). 
This is a very extreme case. However, in all the interviews I conducted with mixed groups of elders and youth there was always significant variation as to who was considered youth, and who would fall in the category of elder. Sometimes youth were school children in their teenage years; sometimes they were married men and women in their late 20s. Similarly, elders were sometimes in their 50s and 60s, and at other times they were people in their 40 s and 30s. In these mixed group contexts, the relationality of categories such as youth and elder became very obvious to me.

Before I close my conceptual reflections on youth, I will briefly touch upon emic conceptions of youth among the Acholi as well as official Ugandan definitions. The Acholi word for youth is bulu. According to my interlocutors there were and are no specific initiation rituals which mark the transition from childhood to youth. Rather, a person passes the threshold from child to youth when he or she obtains a separate hut in the father's compound. Children usually sleep in their parent's hut and later in the kitchen until they are old enough to inhabit a separate hut. The information people gave me on the age of the child when he or she moves to a separate hut varied considerable. Some claimed a boy could be as young as ten, others said it was only at a later age. Whether girls also obtained a separate hut was a matter of considerable debate. The issue of having a separate hut was the most commonly mentioned single indicator of child to youth transition I encountered. Rather than referring to this Acholi conceptualization of youth, however, most of the people I talked to referred to official definitions of particular institutions or the Ugandan state when asked to define youth. These definitions were all based on age-spans, and normally ranged somewhere between 9 and 35, with sizeable differences at both end $^{20}$. The official Ugandan National Youth Policy defines youth as "all young persons (...) aged 12 to 30 years", claiming that " $[\mathrm{t}]$ his is a period of great emotional, physical and psychological change that requires societal support for a safe passage from adolescents to adulthood" (Republic of Uganda, 2001: 9). Similar arguments, which reflect an understanding of youth as a period of change and an in-between status, were also put forth by my interlocutors.

To sum up, one can state that youth both as analytical category and emic concept is a highly blurred one which is nevertheless relevant and frequently used in academic writing as well as in quotidian conversations. What is clear is that terms like youth and elders are always relative to some degree. Abstractly, they can be used to refer to distinct groups, but who is included in this group is highly contextspecific. In order to define my target group in a narrower sense, I have therefore used the Mannheimian concept of "historical generation", which allows for the definition of distinctive groups in relation to a particular event in history, in my case the war. However, throughout this book I also often (and interchangeably) use comparative

20 In interviews I conducted with members of CBOs and NGOs working in the field of youth, the following different age spans were named by my interlocutors: 18-35 (INT Rocki, 16.03.2010); 12-35 (INT Ojara,17.03.2010); 9-24 (INT Faith, 18.03.2010); 15-30 (INT Zipparoh, 23.03.2010); $12-24$ or 12-35 (INT Henry \& Bangi, 27.04.2010). 
terms like youth and elders, the young(er) and old(er) generation or young(er) and old(er) people. By doing so, I do not imply that these categories are fixed or homogenous. Rather, I consider them to be relative categories and use them to emphasize different tendencies between these 'groups', for instance with regard to a particular topic of debate. Unless otherwise stated, I use these comparative terms in the way they were also used by my interlocutors in the context or situation I refer to.

The question of conceptualizing of youth, and thereby taking into account etic, emic as well as situational understandings, remains a central concern in all contemporary studies of youth. In the following, however, I want to turn from general reflections to the field of youth research which is specifically relevant for my research: current studies on youth with a regional focus on Africa.

\subsection{State of the Art: Contemporary Debates on Youth \& Socio-Cultural Change in Africa}

Studying youth and socio-cultural changes has emerged as one of the major preoccupations of Africanist scholars as the following quotes by leading researchers reveal. Diouf (2003: 2), for instance, states that

" $[\mathrm{t}]$ oday, young people are emerging as one of the central concerns of African studies. (...). Undoubtedly, the centrality of this subject is connected to the extraordinary turnaround over the last three decades in the way African societies see themselves."

Durham (2000: 113) argues that

"[y]outh are an increasingly compelling subject for study in Africa (...). To pay attention to youth is to pay close attention to the topology of the social landscape - to power and agency; public, national and domestic spaces and identities, and their articulation and disjunctures; memory, history and senses of change; globalization and governance; gender and class."

Similarly, and more recently, Honwana (2012: 3) in her book The Time of YouthWork, Social Change and Politics in Africa has emphasized that

"[y] outh are a critical indicator of the state of the nation, of its politics, economy, and social and cultural life. Studying youth involves not only studying the lives of young people themselves, in all their diversity, but also understanding the social, political, economic, and cultural concerns of adults. The two generations are entangled in complex processes of construction and reconstruction, the making and remaking of society."

And Abbink (2005: 3) proposes that "there is a need to integrate the youth factor as a necessary element in any social analysis of African societies" (my emphasis). Anthropologists, in particular, have discovered youth and generation as central 
concepts to analyze contemporary African societies and to understand the rapid socio-cultural changes these societies have experienced in the past decades. ${ }^{21}$ There are several reasons for this increased interest.

The first is that young people make up such a large proportion of contemporary African societies. The World Population Data Sheet for 2011 indicates that 43 percent of the population in Sub-Sahara Africa is below 15 years of age. Only three percent are above 65. All top-ten countries listed in the World Population Report as those with the youngest population worldwide are in Sub-Saharan Africa. In contrast, with the exception of Japan, all of the top-ten countries with the oldest population are in Europe. Here, only 16 percent of the population is below 15, the same percentage as those above 65 (Population Reference Bureau, 2011). Therefore, as the majority of the population in most African countries falls under the category 'young people', it seems plausible that they are widely represented in current studies of African societies.

Second, youth and generation have become such prominent concepts in African studies because they can be well combined with other currently fashionably concepts and research interests in anthropology such as agency, identity, globalization, modernization etc. as the above quotations suggest. The perceived rapidness of social, cultural, economic and political change in postcolonial Africa over the past decades and, related, the changing context in which youth grow up (due to urbanization, economic liberalization, HIV/AIDS, access to education and global media, to name but a few factors), has inspired much of the recent research. Debates about tradition and modernity - in the literature but even more so among Africans themselves - have inspired reflections about how young people engage and come into "fresh contact" (Mannheim, 1972: 293f.) with the so-called "traditional" cultural heritage of their societies, and how they are on the other hand increasingly drawn to adopt and appropriate foreign cultural elements transmitted through global markets and the global media (e.g. Adogame et al. 2008a; Appadurai 1996; Loimeier et al. 2005a; Ferguson, 2008; Geschiere et al., 2008a; Comaroff \& Comaroff, 2005; cf. Diouf, 2003: 2). Burgess (2005: xi) has claimed that in many African contexts of generational change "youth came to possess conflicted associations with modernity and all of its attendant blessings and ills". As these points illustrate, youth, directly or indirectly, have been placed at the heart of current debates on socio-cultural change, both in Africa and within the scientific discourse.

A third reason for the increased interest in youth and generational relations is that conflicts - which for a long time have been a major research concern among Africanists - increasingly occur along generational lines. As Jean and John Comaroff, speaking about South Africa, state: " $[R]$ ather than the more familiar axes of social division - class, race, gender, ethnicity - the dominant line of cleavage here

21 See, for instance, Honwana, 2012; the volumes edited by Abbink \& van Kessel, 2005; Alber et al., 2008; Honwana \& De Boeck, 2005; Christiansen et al., 2006a; and the special issues in Anthropological Quarterly Vol. 73, No. 3 (Part I \& II), cf. Durham, 2000. 
has become generation" (Comaroff \& Comaroff, 1999: 284). The same might be said about other African societies. Generational conflicts are not only a popular concern of researchers but are experienced and frequently discussed by young and old Africans in their everyday lives (as I will subsequently show in my case study of Northern Uganda). The closely interwoven family ties and social networks often associated with African societies have recently experienced fundamental ruptures along generational lines. Conflicts between children, parents and grandparents often revolve around issues like education ${ }^{22}$ (Cheney, 2007; Sharp, 2002), morals and values (Boden, 2008; Roth, 2008), lifestyle and consumerism (Ringsted, 2008), carerelations and responsibilities in extended family networks (Alber, 2004; Nyambedha et al., 2003; Nyambedha, 2008; Whyte et al., 2004; Whyte \& Whyte, 2004), access to leadership positions (Le Meur, 2008; Mwangola, 2007), and other aspects which are closely related to the socio-cultural changes pointed to above.

For these and other reasons, research projects concerned with African youth have mushroomed over the past decade, particularly in anthropology, and a number of key debates have emerged. I will briefly summarize the debates which are of particular relevance to my research in the following.

\subsubsection{Victims or Agents? Makers or Breakers?}

There are currently two important, far-reaching, and closely-related debates in contemporary studies of Africa's young generation. The first concerns the question whether African youth are victims or agents of change. The second explicitly focuses on youth as agents and revolves around the question whether African youth are to be considered vanguards and makers, i.e. positive agents of change, or rather vandals and breakers, destructive forces that pose a danger to their societies (cf. Honwana \& De Boeck, 2005; Abbink \& van Kessel, 2005).

The debates, of course, are more nuanced than these two questions would suggest. On a very general level, one can differentiate between pessimists, who delineate African youth as precarious or "lost generation" (Cruise O’Brian, 1996), and more optimistic voices, which emphasize and celebrate the creativity of African youth. The former include those who see young Africans largely as victims of their crisisridden environments. In these writings, rather than looking at the agency of youth, the focus is on structural conditions and constraints which they face such as poverty, unemployment, bleak education opportunities, violent environments, HIV/AIDS,

22 Young people, inspired by NGO campaigns, see access to schooling as their right. Parents often struggle to acquire the necessary means to send their children to school, others cannot or do not want to let their children be away from home for a prolonged period every day, because they need their assistance on the fields or at home, or because they fear their children will be exposed to unwanted influences. The large-scale spread of 'Western' school education by governments and international organizations has furthermore led to an 'education gap' between children and their parents and grandparents as the former sometimes feel their knowledge to be superior to that of their elders (Cheney, 2007; Sharp, 2002). 
forced marriages and forced recruitment into armed forces. The discourse on African youth as victims is very prominent in development discourses (e.g. World Bank, 2008; IRIN, 2007; UNDP, 2006: 19f.; 26f.), which often imply that African youth need the help of external development actors. To a lesser extent this discourse also resonates in the anthropological literature, which is less paternalistic but does not generally question the fact that African youth grow up in a situation of profound crisis (e.g. De Boeck \& Honwana, 2005: 1f.; Abbink, 2005: 1; Cruise O’Brien, 1996; Boothby et al., 2006; cf. Cole, 2011: 61).

On the other end of the pessimistic spectrum are those authors who do not see youths as victims but actually blame them, at least partly, for the current crisis in many African states, and who construct them as "threats" (cf. Diouf, 2003: 3). This discourse is more pronounced in popular science and media representations of Africa (cf. Kaplan, 1994 as a prominent example) than in academic writing. But it can also be identified in texts by social scientists, who point to the destructive nature of youthful rebels in armed conflicts, or violent, criminal youth gangs in African cities. They see youth as agents, albeit as destructive ones, whose actions are detrimental to their communities and to positive developments on the African continent as a whole (e.g. Abdullah, 1998, 2005; Bangura, 1997; Barker \& Ricardo, 2005: 24ff.; Simonse, 2005; cf. UNDP, 2006: 21f.).

Most anthropologists take a more nuanced approach to the subject by looking both at the structural constraints faced by many African youth as well as their agency in dealing with these constraints, which can be very destructive. A prominent example is the debate on children and youth in armed forces, so-called "child soldiers", who are at the same time victims and agents of violent conflict (Baines, 2009). Faced by bleak future opportunities - unemployment, lack of access to schooling, inability to marry, start a family and gain a respectable status in their communities - young people may resort to violence, or are more vulnerable to be recruited into fighting forces. This 'grievance-approach' to explaining violent behavior among youth has been supported by many anthropologists working in war zones, in which fighting forces included a large number of children and youth, e.g. in Sierra Leone (Richards, 1996; Richards \& Krijn, 1998), Liberia (Utas, 2005), Northern Uganda (Finnström, 2003; 2006b; 2010), Angola and Mozambique (Honwana, 2005), Sudan (Jok, 2005) and more generally (McEvoy-Levy, 2006; Boyden \& Berry, 2004).

The 'grievance-approach' can also be found in the literature on youth revolts, i.e. situations in which youths have protested, sometimes violently, against their political marginalization in African politics and for more democratic and equal political systems (e.g. Kagwanja, 2005; Mwangola, 2007). Prominent examples here are the youth uprisings in South Africa during the years of apartheid (Bundy, 1987; Johnson, 1988), or, more recently, the 'revolutions' in Northern Africa and the Middle East (INAMO, 2011; Honwana, 2013).

Among the more 'optimistic' scholars are those who give illustrative example of positive, non-violent youth agency. A UNDP report alerts its readers to the fact that the focus on violent reactions to crisis in much of the literature on African youth 
should not "lead us to argue that involvement in violent conflict is the only - or even the main - response to a youth crisis" and that "[r] esponses to such a youth crisis are not necessarily violent" (UNDP, 2006: 27). The report, somewhat superficially, mentions urbanization, South-North migration and involvement in religious movements as the main non-violent strategies of African youth to deal with or escape inauspicious environments (UNDP, 2006: 27-29). In a similar vein anthropologists often emphasize and celebrate the creativity and 'robustness' of African youth and their inventive ways of dealing with situations of crisis and marginality in order to avoid the Afro-pessimism and escape the victim narratives so widespread in the literature (Chabal, 2009; Ferguson, 2005: 172ff.). Different researchers have analyzed forms of resistance and social critique found in popular arts, especially hip hop (Stroeken, 2008; 2005; Ntarangwi, 2009; Weiss, 2005), films (Larkin, 1997) and popular drama (Lange, 2001), or in sport (Baller, 2010). Others have looked at the creative ways youth participate in and adapt Western consumer culture, for example with regard to clothing and style (Hansen, 1999; Hendrickson, 1996; Friedman, 1994). And again others have studied more ambivalent forms of 'sexual liberation' such as "transactional sex", whereby mostly young girls have sex with older and/ or richer men in exchange for money and consumer goods (mostly phones and clothes), which offer new (economic) opportunities, particularly for young women, but at the same time expose them to new risks and constraints (Cole 2004; Honwana, 2012: 89ff.; Hunter 2002: 100f.; Mills \& Ssewakiryanga, 2005). As pointed out above, agency figures as a pivotal concept in these debates, and its proponents stress that even youth in the most marginalized positions can exert agency to a certain degree and are thus not only passive victims. In one way or another, all these different studies show how African youth engage with global, mostly Western cultural and economic trends, which they criticize and ridicule at the same time as admiring and wanting to imitate them (Ferguson, 2006). However, 'creative chaos', 'cultural hybridity' and 'alternative modernities' resulting from youth's desire to participate in what they refer to as global modernity are not always just aspects to celebrate. As Ferguson (2005: 179f.) warns:

"[A]nthropologists have lately tended to focus on (...) happy stor[ies] about plurality and non ranked cultural differences - to the neglect of (...) relatively fixed global statuses and a detemporalized world socioeconomic hierarchy. In this way, the application of a language of alternative modernities to the most impoverished regions of the globe has become a way of not talking about the non-serialized, detemporalized political economic statuses of our time - indeed a way of turning away from the question of a radically worsening global inequality and its consequences".

Thus, studies of youth agency should not overlook the fact that many young people grow up in situations of inequality and marginalization - within their societies, but also in relation to 'global society'. Different researchers have turned to analyze how youth in Africa deal with and react to their real and perceived relative marginal- 
ization. One particular focus in these studies has been the way young people give meaning to concepts like tradition and modernity and thereby position themselves in relation to spatial and social categories like Africa and the West.

\subsubsection{Tradition \& Modernity, Africa \& the West}

Afro-pessimism, i.e. seeing Africa mainly as a place of crisis, is not only prevalent outside Africa. It is in fact a very real sentiment among many African youth, who experience their countries as being behind the rest of the world and distinctively non-modern (Ferguson, 2005: 174; Honwana, 2012: 90). The idealized images of the West young people gain from TV, internet and films, and by witnessing the luxurious lifestyle of expatriates and tourists staying in their countries, sometimes leads them to question their own societies and cultural identities. Subsequently, many dream of leaving their countries and migrating to the West - for educational purposes, to find (lucrative) employment, or to escape poverty in their home communities (cf. Ferguson, 2006: 151f.).

On the other hand, and as a reaction to what many consider the detrimental aspects of a Western, capitalist lifestyle such as inequality, individualism, and voracious consumption, an increasing number of youths seems to seek solutions to contemporary problems by drawing on 'local traditions' or an "invented" form thereof (cf. Hobsbawm, 1983). Instead of idealizing the West, they demonize its 'modern' influences, and propagate a return to 'African traditions' and an 'unspoilt' pre-colonial past. Particularly in the literature on HIV/AIDS 'retraditionalization discourses' are commonly described (for an imposing example, cf. Geissler \& Prince, 2010 and Prince, 2008 \& 2009; cf. also Reis, 2008). AIDS is regarded as a modern disease and often blamed on young people's 'immoral' behavior, which is associated with living a Western lifestyle and disregarding 'cultural' rules and conventions (cf. Dilger, 2003, 2005). Subsequently, reviving these rules is proposed - both by elders and youth as a solution to mitigate the adverse effects of AIDS and 'modernity' as a whole. What is desired in these discourses, then, is a return to an often idealized past.

One particular contested and well-researched field in which discourses on tradition and modernity, Africa and the West play a prominent role are gender and sexual relations (for a good overview see Arnfred, 2004a; Baerends, 1998; Cornwall, 2005; Tamale, 2011a). Different authors have critically noted how Western interventions and related discourses on African gender and sexual relations have historically shaped and continue to influence gender- and sex-related practices and perceptions among Africans (cf. Arnfred, 2004b; Mamdami, 2004: 91ff., $121 \mathrm{ff}$.; Tamale, 2011b: 14ff.; Lewis, 2005). Both in popular discourses and in the academic literature, one still commonly finds the assumption that a) there are significant differences between 'African' and 'Western' gender, kinship and sexual relations and b) 'African' gender and kinship system have undergone drastic changes over the past 100-150 years, which have caused fundamental disruptions and redefinitions and have been significantly influenced by the West (cf. Appiah, 2008: 88). These changes 
have been linked to, among other things, Christian proselytism and colonial policies (e.g. Bennett, 2011: 80f.; Silberschmidt, 2001: 660ff.; cf. also texts of African classic literature such as Ngugi Wa Thiongo'o, 1965 and Okot p'Bitek, 1989), colonial and post-colonial labor migration and urbanization (Ferguson, 1999: 170ff.; Mamdani, 2004: 218-285), structural adjustment policies following the economic and debt crisis of many African states in the 1980s and subsequent socio-economic changes (e.g. Silberschmidt, 2004; O'Laughlin, 1997; Cleaver, 2002: 3f.), as well as Western development discourses (e.g. Cornwall et al., 2004; Cornwall \& White, 2000; Pala, 2005).

In recent years, studies focused on African gender, kinship and sexual relations have paid increasing attention to the influences of the mass media, global capitalism and consumer culture, especially among youth. Following Appadurai (1991: 197), these studies argue that (gender) images and ideologies conveyed through the mass media have influenced the dreams and expectations of people around the world, and represent "a peculiar new force to the imagination in social life today" (ibid.). Films and TV series, which convey "images of modernity" (Hunter, 2002: 115) related to fashion, beauty, romantic love and consumer goods, are regarded as very influential in transforming conceptions of gender and sexual relationships in Africa, particularly among the younger generation (cf. for instance Larkin, 1997 and Masquelier, 2009). Many recent case studies show that sexual behavior and images of relationships and love among youth have changed profoundly as a result of media influences (e.g. Bochow, 2008; Cole, 2004, 2008, 2010). Others have studied how, in different African societies, alterations of what are considered 'traditional' gender and sexual norms and practices have become a major cause of intergenerational conflict and debate (e.g. Silberschmidt \& Rasch 2001; Ringsted, 2008). Ideas of 'traditional African' and 'modern Western' forms of gender relations and sexuality are often linked, in complex and sometimes contradictory ways, to moral notions of right and wrong (cf. Vorhölter, 2012). What is considered traditional and whether tradition is seen as something outdated and harmful or as something desirable and appropriate can vary significantly between speakers and according to context. The differences between 'African' and 'Western' gender, sexual and kinship relations that have been historically constructed in various popular and academic discourses will be analyzed in greater detail in chapter 6 , where I relate them to contemporary debates in Ugandan society.

In the literature on youth in Africa, notions of modernity and tradition, African and Western culture found in local discourses are frequently dissected and linked to broader debates in postcolonial studies on contemporary African identities (for an overview see Eriksson Baaz, 2001; Appiah, 2008; Mbembe, 2008; Werbner \& Ranger, 1996). It is interesting to note that although many authors emphasize the interdependence and relational construction of these categories, in local discourses they are still perceived as dualistic, even antagonist categories.

Drawing on my own experience in Uganda, debates on tradition and modernity are ever present in discourses on socio-cultural change, and revolve around com- 
Julia Vorhölter: Youth at the Crossroads

plex and profound questions of identity and cultural authenticity. As I will show throughout this book, positionalities in these discourses vary greatly among youth and are often dependent on context. Most young Ugandans I encountered switched between celebrating 'African traditions' in one situation and longing for 'Western modernity' in others. Hereby, the majority expressed difficulties in reconciling the two sides, and thus experienced being 'caught in between' as a burden rather than as a chance.

To summarize, the challenge of writing about African youth is to pay attention to the creativity and the crisis, the agencies and the structural constraints, as well as to the dualisms and eclecticisms inherent in discourses on modernity and tradition, African and Western identities. In short, one has to take into account the ambivalent and heterogeneous experiences of African youth and the dialectics of generational change "as characterized by the conjuncture between young people of coming of age, on the one hand, and existing social, cultural and economic arrangements on the other" (Cole, 2011: 64).

\subsection{Specific Contribution of my Research}

My research contributes to the above-outlined debates by providing a differentiated analysis of intergenerational negotiations of socio-cultural change and the multilayered positions which youth take on in these negotiations and related discourses. Rather than labeling them as makers or breakers, agents or victims, modernizers or traditionalists - categories which fail to address the complexity and diversity of social relations/positions and which often reflect an outsider and/or adult perspective of youth - I focus on young people's perceptions of themselves in processes of socio-cultural change, specifically those which are seen to have taken place in Acholi society since the beginning of the war in the mid-1980s: How have Acholi youth experienced these processes of change? Do they believe they can effectively shape these processes? How do they see themselves in relation to older and younger members of society? How do they use and relate to discourses about Acholi youth? I will address these questions by adopting a specific theoretical approach in which I identify youth's perceptions of agency and victimhood in local discourses. My theoretical approach, which I elaborate below, also enables me to analyze the diversity and complexity of intergenerational debates about socio-cultural change by studying the discourses and power relations which shape these debates.

Furthermore, and as outlined above, the regional focus on Northern Uganda distinguishes my analysis from other recent studies of African youth in the context of socio-cultural change. This is due to the specific post-war setting: in addition to the introduction of mass schooling ${ }^{23}$, increased media exposure and HIV/AIDS - factors, which are discussed in many recent studies on youth and socio-cultural

23 Universal Primary Education (UPE) was introduced in Uganda in 1997. 
change in Africa - young people in Northern Uganda have experienced 20 years of war and thus a situation of extreme instability and 'disorder'. As stated above, the combined effects of war, displacement and "internal crisis" (Branch, 2011: 61ff.) have placed Acholi youth in a special situation of cultural uncertainty and have led to the fact that discourses on socio-cultural changes are particularly relevant and wide-ranging in the current post-war situation ${ }^{24}$.

The war in Northern Uganda has recently become a major focus in different social science disciplines dealing with war, displacement and its effects on society (cf. Chap. 3). Many of these studies touch upon the situation of youth as well as the discourses on socio-cultural change, which are the focus of my study. Especially in the literature dealing with the situation in the IDP Camps, the reintegration of former 'child soldiers', and recent peace-building measures, the issue of 'cultural revival' and restoration of cultural practices is extensively discussed. These studies provide important background information to my analysis. However, they are largely based on research that was conducted while the war was still ongoing, and their predications for post-war society are largely speculative. Furthermore, the reports produced or commissioned by NGOs in particular are often written from a positivist standpoint. They neglect the constructed nature of culture, take historical narratives about the past as given facts, and overemphasize the homogeneity within societal 'subgroups' such as youth, women, or male elders. Some of these reports as well as the more populist writings (and films) on the war (e.g. Eichstaedt, 2009; Green, 2009; Invisible Children, 2006; 2012a,b; McDonnell \& Akallo, 2007) reproduce colonial discourses about Africa as the 'dark, dangerous and uncivilized' continent - for example by depicting the LRA rebels, and especially their leader Joseph Kony, as irrational barbarians (cf. Chap. 3). In a different vein, some of the reports produced by or for development organizations invoke colonial discourses by postulating that "in some parts of the world [e.g. in Uganda] the most important, authentic identities are cultural identities, particularly traditional, customary, or tribal identities", which are patriarchal and "illiberal", as has been critically noted by Branch (2011: 154). Particularly NGOs working in the fields of gender and children's rights often

24 This, once again, became obvious to me when I presented some preliminary findings of my research at a colloquium at Gulu University shortly before I finished my fieldwork. The audience was made up of students as well as staff from the university. There were also some visiting anthropologists from Denmark and the U.S.A. In the discussion, comments by the external researchers addressed conceptual problems in my research outline. They also suggested further analytical tools for my data analysis and referred to texts which might be interesting for me to read. The Ugandan students, on the other hand, focused largely on the content of my presentation. They affirmed that the loss of Acholi culture was a major societal problem and thus a topic of great concern to them. Some of the older students (many were already in their late 30 s or early $40 \mathrm{~s}$ and were studying part-time while working) started to explain to me how the young generation was responsible for the loss of values and morals; one student particularly blamed youth for their "project of modernity". Another student asked me whether I had any practical suggestions as to what could be done to stop this loss of culture. To me, these statements indicated how all-encompassing the discourse on socio-cultural change and loss of culture was (field notes 01.12.2010). 
implicitly or explicitly suggest that 'vulnerable groups', i.e. women, children and youth, need to be protected against 'harmful cultural practices' because 'traditional' Acholi gender roles and child rearing practices are not in line with Western discourses on women's and children's rights.

My analysis contributes to the growing number of studies that deconstruct such conceptions of Acholi culture and people. I apply a discourse-analytical approach to point out the fuzziness and complexity of concepts like "Acholi culture" and "Western culture" and to analyze how such labels are strategically used and filled with meaning in local discourses. I am interested in the ways various social actors engage with international discourses on women's and children's rights, post-conflict peacebuilding and "traditional culture" in their negotiations of socio-cultural change. I explicitly focus on power relations, both within Acholi society, specifically those based on age and gender, and between the local and the global level, specifically between Uganda and the West. In summary, my research makes a contribution both to the recent debates in the study of African youth as well as to the vast and growing literature on the war in Northern Uganda and in particular the immediate post-war situation. A specific feature of the study is its analytical approach, which I outline in the following.

\subsection{Analytical Framework}

As already stated, my study follows a discourse-analytical approach which is largely based on the works of Foucault ${ }^{25}$. In this section, I first give an overview of discourse analysis as it is currently applied in anthropological theory and two of its major concepts - discourse and power - as understood by Foucault. I explicate how I make use of these concepts and outline different elements, which I refer to in my analysis of discourses on socio-cultural change, specifically binary oppositions and agency.

\subsubsection{Foucauldian Discourse Analysis}

Over the past three decades, discourse analysis has gained widespread prominence in anthropology (Dracklé, 1996b: 24). Among German anthropologists, however, it is still regarded quite ambivalently in some institutes toda ${ }^{26}$ (the same applies to

25 In chapter 3, I also draw on the discourse theory of Reiner Keller (2008; 2007; 2006; 2005; 1997), who has adopted some aspects of Foucault's theory and integrated them into the framework set by Berger and Luckmann's sociology of knowledge.

26 During my time as a student at the Institute of Social Anthropology in Hamburg (2003-2008) I was once told by a professor that "some anthropologists today believe that discourse analysis could be applied in anthropological research" but that "at this institute we do not consider discourse analysis as anthropology". Haller (2012: 326f.) notes that in recent years German anthropology has (again) turned towards studying "social reality" rather than its discursive production, 
postcolonial theory, cf. Castro Varela \& Dhawan, 2005: 8f.). This is somewhat surprising because discourse analysis has much to offer for anthropology (cf. Birkhan, 2012). It can address the complex relationship between individual and society, agency and structure, and can thus capture the dynamics inherent in studying socio-cultural change. Hence, it can also contribute to the development of theoretical concepts in anthropology (Dracklé, 1996b: 24ff.). Essentially, discourse analysis is an instrument for studying power relations as reflected in societal practices and speech. It aims to discern what is said, how, by whom and under which effects of power (Dracklé, 1996b: 28).

Foucault has not provided a singular and finite definition of discourse. Rather, he has tried to explain in different texts and speeches how discourses are structured and produced and how they can be identified and analyzed. An often cited 'definition' of discourse is taken from The Archeology of Knowledge, first published in 1969, in which Foucault states that " $[\mathrm{w}] \mathrm{e}$ shall call discourse a group of statements in so far as they belong to the same discursive formation" (Foucault, 2002a: 131). According to Foucault, one can speak of a discursive formation " $[\mathrm{w}]$ henever one can describe, between a number of statements, such a system of dispersion, whenever, between objects, types of statement, concepts, or thematic choices, one can define a regularity (an order, correlations, positions and functionings, transformations)" (ibid.: 41). In The Order of Discourse, Foucault's inaugural lecture at the Collége of France given in 1970, he outlines how discourses are "controlled, selected, organized and redistributed" (Foucault, 1981b: 52) through procedures of exclusion, internal procedures and a "rarefaction (...) of the speaking subjects" (ibid.: 61). He proposes to analyze discourses either from a critical perspective, i.e. by focusing on procedures of exclusion, limitation and appropriation, or from a genealogical perspective, i.e. by looking at the historical formation and changes of discourses (ibid.: 70ff.). Hall (1992: 295) summarizes Foucault's concept of discourse as follows:

"Discourses are ways of talking, thinking or representing a particular subject or topic. They produce meaningful knowledge about that subject. This knowledge influences social practices, and so has real consequences and effects. Discourses (...) operate in relation to power - they are part of the way power circulates and is contested. The question of whether a discourse is true or false is less important than the question whether it is effective in practice. When it is effective - organizing and regulating relations of power (...) - it is called a 'regime of truth".

Thus, rather than focusing only on language and text as is common in linguistic approaches ${ }^{27}$, discourse analysis rooted in a Foucauldian tradition also looks at

and quotes Preisendörfer (2008) who states that "Die (postmodernen) Diskursgletscher ziehen sich zurück, und die (soziale) Wirklichkeit kommt wieder zum Vorschein” (quoted in Haller, 2012: 326f.).

27 For a discussion of linguistic versus intertextual analysis within different approaches to discourse analysis, cf. Fairclough (1992). 
Julia Vorhölter: Youth at the Crossroads

non-language practices. According to Foucault (2002a), all social practices entail meaning and thus also have a discursive effect. Discourses can thus bridge the divide between what is spoken and what is done, i.e. between language and practice (Hall, 2001: 72). Discourse analysis allows for the interpretation of text material (documents as well as interview-transcripts) with regard to the societal context in which they were produced (Fairclough, 2001: 18ff.). In applying an anthropological approach of participant observation in addition to pure linguistic procedures one can analyze how discourses develop and how they operate and become manifest in concrete situations. As Dracklé states:

"Through participant observation over a longer period in one place (...) sufficient situations arise in which discourse, its process of coming into being, and its effects can be pursued." (...) "Against the background of empirical work and the participant observation of non-discursive practices, discourse theory offers the pivotal point for an anthropology of "truth production" (1996b: 33; 36).

In Foucault's theory, the way "truths" are "produced" is closely connected to his concept of power-knowledge, which I outline below. According to Foucault, discourses link power, knowledge and truth and legitimate power relations. Based on this assumption, he formulates four rules for the analysis of discourse. First, there is no exteriority between the technologies of knowledge and the strategies of power. Second, there is a continual shift in power-knowledge relations. Third, a "rule of double conditioning" exists between strategies and tactics of power. Fourth, there is no uniform function of a discourse (Foucault, 1990: 98ff.). The last point is specifically important: Discourse is not subservient to power; it can produce but also undermine it.

\subsubsection{Power-Knowledge}

The relationship between power, knowledge, discourse and truth is essential to Foucault's theories. Unlike in Enlightenment epistemology according to which power distorts truth but truth can be unraveled through knowledge, Foucault argues that power and knowledge are not oppositional but mutually constitutive and that there is no such thing as absolute truth because our perception of the world is only a reflection of a particular set of social relations in a historical context (Foucault, 1990: 97ff.; cf. Haugaard, 2002: 181ff.). What follows from this is that each historical epoch has its own specific relationship between knowledge and power, which is both, constantly reproduced and constantly challenged. Power in a given society is also always related to historically-specific types of discourses, which define what is considered relevant knowledge in a given time and place. For example, in contemporary Northern Uganda discourses on post-conflict peacebuilding sustain the power of international 'development experts', because they are seen to possess a certain type of knowledge which is discursively established as relevant. 
In Discipline and Punish, first published in 1975, Foucault argues that since the $19^{\text {th }}$ century a new form of power has developed in Europe, which is no longer based on obedience to the law or a sovereign but on knowledge and the knowledge-based disciplining of individuals. Knowledge, for example how to behave according to the current social rules, can be used to individualize power, as is done in the Panopticon. In this prison, designed by Jeremy Bentham in 1791, power does not have to be enacted in the form of (physical) punishment. As the inmate feels that he is being constantly exposed to (potential) observation he automatically behaves the way it is expected of him. Foucault (2002b: 197) speaks of a "fictitious" power relationship, which is based on subjection. Thus, rather than being a "property", power becomes a "strategy" (ibid.: 191), a whole set of mechanisms and technologies, which can be used to regulate the behavior of individuals. What is important is that power is not marked by repression but by positive technologies of power. This means that power is productive, it produces social realities and must therefore always be seen in a spatial and historical context (Foucault, 2002b: 191-203).

In the History of Sexuality, first published in 1976, Foucault further outlines this understanding of power as a "complex strategical situation in a particular society" (Foucault, 1990: 93). He argues that power is decentral and omnipresent and that it consists of a multiplicity of force relations which constitute an overall strategy or system of power. Decentral means that power evolves from below. At the bottom level it is intentional but because of the multiplicity of force relations the overall strategy has an unintentional outcome. Hence, it is not possible to calculate the consequences of power and it becomes nonsubjective. Omnipresent denotes that there is power in every unequal relation. Foucault understands power as strictly relational in character. Thus, inherent in every power relation is the possibility of resistance. Just as there are multiple generators of power there is also a multiplicity of points of resistance. Just as there cannot be a society without power relations, there cannot be a societal power regime in which no resistance is possible (Foucault, 1990: 92ff.).

In the History of Sexuality, Foucault argues that since the late $17^{\text {th }}$ century, sexuality has, in various ways, become an important transfer point for power relations. He notes that

"Sexuality (...) appears rather as an especially dense transfer point for relations of power: between men and women, young people and old people, parents and offspring, teachers and students, priests and laity an administration and the population. Sexuality is not the most intractable element in power relations, but rather one of those endowed with the greatest instrumentality: useful for the greatest number of manoeuvres and capable of serving as a point of support, as a linchpin, for the most varied strategies" (Foucault, 1990: 103).

According to Foucault, the reason why sexuality comprises such a dense node of power relations relates to it being an intersecting point between the individual body and the population as a whole. It is thus a target point for a disciplinary "bio- 
Julia Vorhölter: Youth at the Crossroads

power", "whose task [it] is to take charge of life [and which] needs continuous regulatory and corrective mechanisms" (Foucault, 1990: 144). According to Foucault (ibid.: 146), technologies of sex combine "in varying proportions the objective of disciplining the body and that of regulating populations." I relate to this argument throughout my analysis, and particularly in chapter 6 , by revealing how in contemporary Acholiland and Uganda, discourses on sexuality have become a way to discuss a whole range of societal developments, which are seen to be problematic and in need of regulation.

In Scientia Sexualis, the third part of his book on the History on Sexuality, Foucault (1990: 53ff.) further elaborates his argument that sexuality has become a focal point of societal discourses and power relations. He describes how from the 19th century onwards a confessional science of sex was created by bringing together confession and scientific discourse. Sex started to be regarded as a "cause of any and everything" (ibid.: 65), as an explanation of all sorts of different behaviors, and thus, indirectly, also for many societal developments and problems. Due to the "interplay between sex and truth" (ibid.: 57), talking about sexuality came to be discovered as a way of revealing certain truths which had less to do with sex itself than with the discourses around it. In this sense, Foucault suggests that

"in this 'question' of sex (...), two processes emerge, the one always conditioning the other: we demand that sex speak the truth (...), and we demand that it tell us our truth. Or rather, the deeply buried truth of that truth about ourselves which we think we possess in our immediate consciousness. We tell it its truth by deciphering what it tells us about that truth; it tells us our own by delivering up that part of it that escaped us. (...). [T]he project of a science of the subject has gravitated, in ever narrowing circles, around the question of sex. (...) Not, however, by reason of some natural property inherent in sex itself, but by virtue of the tactics of power immanent in this discourse" (Foucault, 1990: 69f.).

The different ways sexuality is used in Ugandan discourses to establish certain "truths", for instance about tradition or the West, and the power dynamics which surround these discourses offer an interesting perspective for my analysis and I will take up this point in my discussion of my findings in the concluding chapter.

\subsubsection{Discourse \& Power as Analytical Concepts}

In this book, I apply a discourse-analytical approach to study the power dynamics inherent in discourses on socio-cultural change in Northern Uganda. I examine the linkages between competing normative orders and states of knowledge. Following Foucault, my approach is based on three assumptions: 1) Discourses serve to establish certain interpretations of reality as truths; 2) Discourses reflect positionalities and power differences within society; 3) Discourses can be resources for and expressions of agency and resistance. 
These assumptions are based on the premise that power, knowledge and truth are intimately linked. Truths, such as the idea of an 'authentic' pre-war Acholi culture, are constructed through discourses, whereby the production of such truths must follow certain rules which are determined by the discourse (cf. Foucault, 2002a: 34ff.; Mills, 1997: 51ff.). One always has to keep in mind that discourses must be seen in their historical and cultural context - in my case the immediate post-war setting in Northern Uganda. Different discourses will arise in different times and in different historical settings and thus produce new truths on socio-cultural change (Hall, 2001: 74). Furthermore, discourses are never singular but multiple. Thus, one must also pay attention to contradictions within discourses as well as to interdiscursive effects (Dracklé, 1996b: 38).

In my analysis of discourses on socio-cultural change in Northern Uganda, I refer to the following elements ${ }^{28}$ (cf. Hall, 2001: 73f.; Dracklé, 1996b: 37f.):

- Statements, for example about past, present and future, or about different groups/clusters of people such as youth, white people (munu) etc.

- (Implicit) rules which define who is allowed or not allowed to say what on the topic of culture in a given situation - in a mixed group of elders and youth, for instance, only elders would have the authority to speak about "traditional Acholi culture".

- Subjects who personify the discourse and possess certain characteristics typical for the discourse - for example the prostitute, who sells her body in order to be able to afford consumer goods and accessories required for a 'modern' town life; the sugar daddy, who stands for the corruptive nature of modern life; the lazy and disrespectful youth as opposed to the respected and knowledgeable elder; or the muno (white person).

- Authorities who people refer to if they want to manifest specific opinions on culture and socio-cultural change such as elders, religious leaders, or in some cases Western development workers.

- Practices within institutions, for instance those involved in 'post-conflict peace-building', who initiate certain ideas of culture - for instance by 'inventing' certain rituals for the reintegration of former LRA soldiers (cf. Verma, 2012: 443ff.), or by postulating simplistic ideas about "traditional reconciliation and justice" (cf. Branch, 2011: 154ff.).

- Continually repeated terms - in my case for example Westernization or culture.

- Myths - for example why women were or are prohibited to do certain things according to "traditional Acholi culture".

28 I have used these elements as a guide in my analysis, but I have not dissected each of them in greater detail, which is also due to the fact that they are often overlapping. 
- Symbols - for instance the miniskirt, which symbolizes negative Western influences, or video halls, which stand for the 'downfall' of the young generation of Acholi.

I have placed particular emphasis on studying binary oppositions and (expressions of) agency in local discourses and will thus discuss these elements more comprehensively.

\section{Binary Oppositions in Local Discourses}

Binary oppositions are a consistent feature of discourses on socio-cultural change in Northern Uganda (and elsewhere), and thus a very relevant aspect to analyze. The study of binary oppositions in language goes back to the French linguist Ferdinand de Saussure. Saussure argued that making difference is essential to the production of meaning. Signs have meaning not because they refer to real objects, but because of their oppositions to other signs. Binary oppositions are the simplest and most radical way of constructing difference ${ }^{29}$. Hereby, meaning is never fixed but always produced in context. Saussure's approach was later heavily criticized by poststructuralist scholars and in the context of postcolonial theory. They argued that there are many other, less simplistic and less dualistic ways of establishing difference, which cannot be captured by focusing merely on binarisms ${ }^{30}$. They further criticized that Saussure's concept neglected the fact that there are always "violent hierarchies" implied in binary thinking on which imperialist thinking is based and perpetuated (Hall, 1997a: 30ff.; 1997b: 258; Ashcroft et al., 1998: 23).

These criticisms are very valid and my analysis should thus not be mistaken as an application of Saussure's theory. Rather, I am interested to find out how, when and for what purpose binary oppositions are used within local discourses. Thereby, I concur with Baumann (2004: 31) who argues that grammars, i.e. classificatory structures like binary oppositions, can be "argumentative tools" which "provide a repertoire of structures through which to put forward arguments about self and other". He stresses that "all grammars are always at the disposal of all social actors, and it is precisely the constantly shifting invocations and revocations of each grammar that matter in the social processes of selfing and othering as we can observe them emprirically" (Baumann, 2004: 31). Furthermore, he points out (and convincingly demonstrates by giving various concrete examples) that each binary grammar always implies a ternary grammar (ibid.: $37 \mathrm{ff}$.). I found numerous examples of such ternary

29 However, as Baumann and Gingrich (2004), among others, have comprehensively demonstrated, there are further, more complex ways to create and 'order' difference. In their edited volume Grammars of Identity/Alterity, they identify three major "classificatory structures or schemata" (ibid.: $\mathrm{x}$ ) which are used in processes of selfing and othering, namely orientalization, segmentation and encompassment.

30 Even structuralists themselves, for instance Levi-Strauss, acknowledged that binarisms cannot capture the richness and sophistication of social actors' taxonomies and engaged in debates about what Baumann calls the "ternary challenge" (Baumann, 2004: 35ff.). 
implications in statements that were framed in binary terms by my interlocutors, although they did not constitute an explicit focus of my analysis.

The most common examples of binary oppositions in discourses on socio-cultural change in Northern Uganda revolved around distinctions between Africa and the West, modern and traditional as well as local and global. The high prevalence of such binary oppositions or "cultural dualisms" (Ferguson, 1999) in speaking about social change is not specific to Northern Uganda, but has been observed in other studies of perception of socio-cultural change. James Ferguson, for example, conducted research on perceptions of modernization and decline and related associations with "the urban" and "the rural" among mineworkers on the Zambian Copperbelt. He observes:

"A pervasive and familiar dualism structured the way that most Copperbelt dwellers spoke about such matters. Contrasting styles of urban dress and comportment, workers said, reflected a fundamental difference between 'town ways' and 'village ways'. But what they described in one breath as a difference between urban and rural might in the next become a contrast between 'modern' and 'traditional', 'European' versus 'African', or even 'educated' versus 'uneducated"” (Ferguson, 1999: 83).

He further reflects:

"The puzzle in all this (...) is that my fieldwork with Zambian mineworkers in Kitwe revealed (...) a cultural bifurcation remarkable similar to those that Wilson (1941), Epstein (1958, 1981) and Mitchell (1956a, 1987) had described for an earlier era. We might well reject the terms in which these authors described this duality (primitive/civilized [Wilson]; tribal/urban [Epstein]; low urban commitment/high urban commitment [Mitchell]), but the ethnographic fact of a certain cultural duality remains to be explained" (Ferguson, 1999: 91, my emphasis).

Like Ferguson ${ }^{31}$, I will treat binary oppositions in local discourses as "ethnographic facts", which shape people's experiences and interpretations of their lives, and thus have real effects not only on everyday thinking but on social life more generally. I will show how binary opposition in local discourses in Northern Uganda both reproduce and invert colonial discourses ${ }^{32}$. In particular, I will focus on the discourse on Westernization and its inherent representations of African/Ugandan/Acholi culture as opposed to Western culture. As I will show, this discourse is central to analysing and deciphering discourses on socio-cultural change in (Northern) Uganda.

31 I will further draw on Ferguson's concept of cultural styles, which I outline in Chap. 5.

32 Binary Opposition were and are a crucial component of colonial discourses and racialized regimes of representation (cf. Hall, 1997b: 243ff.; Hall, 1992). 
Julia Vorhölter: Youth at the Crossroads

\section{Perceptions of Agency in Local Discourses}

A further aspect that I focus on in my analysis of discourses is agency. In my understanding of agency, I loosely draw on the works of Sherry Ortner (1997, 2001, 2006). Ortner's concept of agency is concerned with the mediation between conscious intentions and actions of the individual and the structures he or she is embedded in, and which influence these actions and intentions (Ortner, 2001: 77). Ortner argues that there are two inseparable meanings of agency - "agency of intentions" which she relates to Geertz's interpretative approach of studying the meaning of human activities, and "agency as power", which she relates to post-structuralist approaches of studying power and domination (1997: 136ff.). According to her

"[i]n one field of meaning 'agency' is about intentionality and the pursuit of (culturally defined) projects. In the other field of meaning agency is about power, about acting within relations of social inequality, asymmetry, and force... [Hereby] power itself is double-edged, operating from above as domination and from below as resistance" (Ortner, 2006: 139).

Ortner explains the difference between these two meanings as follows:

"In the contexts of questions of power, agency is that which is made or denied, expanded or contracted, in the exercise of power. It is the (sense of) authority to act, or of lack of authority and lack of empowerment. It is that dimension of power that is located in the actor's subjective sense of authorization, control, effectiveness in the world. (...) [O]n the other hand, agency represents the pressures of desires and understandings and intentions on cultural constructions. Much of the meaning uncovered in a cultural interpretation assumes, explicitly or implicitly, an actor engaged in a project, a game, a drama, an actor with not just a 'point of view' but a more active projection of the self toward some desired end. In the first context, agency (...) is both a source and an effect of power, in the second (...), it is both a source and an effect of 'culture'" (Ortner, 1997: 146).

To summarize her idea, one can say that "agency as power" refers more to the conventional meaning of agency: agency as a form of power, which can be used by the powerful, but also by the seemingly powerless in order to keep up the status quo or to invoke changes ${ }^{33}$. It is a form of reactionary agency as it is directed against another individual or societal group, i.e. it can be used to influence actions and events, but it also entails the capacity to control one's own life (Ortner, 2006: 143f.). According to Ortner, the "agency of power" is defined to a great extent by people

33 I am aware that Ortner, whose work is positioned in the realms of practice theory, has a different conception of power and understanding of the subject or individual actor than those commonly applied in discourse-analytical approaches based on Foucault. Nevertheless, I regard certain aspects of her approach to agency as useful for my analysis. 
in positions of power. In her 1997 article Thick Resistance: Death and the Cultural Construction of Agency in Himalayan Mountaineering, she gives the example of international, mostly Western mountaineers in Nepal who - due to their privileged (economic and world-political) position - can impose their terms and conditions on the local Sherpa people who they employ as climbing assistants. However, she convincingly shows that the Sherpa are not only dominated by the mountaineers, but use local constructions of agency and power to give meaning to their actions and to integrate their (religious) beliefs into the mountaineering operations.

Ortner refers to this later form of agency as "agency of intentions". It designates the ability to imagine, plan and exert one's own projects by drawing on personal and cultural resources. Ortner claims that it is important to study this form of agency by applying a Geertzian interpretative framework in order to better grasp and understand local assumptions about what counts as agency in a given cultural and historical context. In this way, one can identify how social actors give meaning to their actions within existing relations/systems of power and how they formulate and pursue their plans, goals and desires.

In order to clarify the relevance of these elements for my analysis I will give some examples. On the one hand, I look at agency in the context of unequal power relations - agency as a "source and effect of power". I analyze implicit or explicit statements about power relations and social structures, and the ways individuals position themselves within these power relations, e.g. as agents or 'victims', as members of the dominant or of the inferior group. I also observe, how power relations manifest themselves in daily practices, for instance in the family setting. I specifically focus on three different forms of power relations which I frequently encountered throughout my research: relations between youth and elders, between men and women and between Uganda and the West.

On the other hand, I use the meaning of "agency as projects" to focus on perceptions of agency in (youth's) discursive practices. Thereby, I place special emphasis on the analysis of my interlocutor's future aspirations. Do they have visions for the future or "projects" at all? If yes, where do ideas and inspirations for these projects come from? What meaning do they give to their actions and (how) do they try to establish their systems of meaning in a larger social context? How do they perceive their social situation and their chances to act within this situation? These questions will be particularly interesting because there are many young people in Northern Uganda who perceive themselves to be confronted by very bleak future opportunities.

I will further elaborate some of the concepts mentioned here in the chapters where they become relevant for my analysis. I will conclude my introduction by outlining the structure of this book. 


\subsection{Structure of the Book}

This book is divided into seven chapters: the introduction, a field chapter, four analytical chapters and a concluding chapter. I introduce each of the chapters (with the exception of chapter $3^{34}$ ) with an extract from my field notes in order to convey a better feeling and understanding for my research setting in Northern Uganda. The lengthy extracts intend to illustrate some of the general points I talk about in the respective chapter.

I begin the following second chapter with an extract from my field notes in which I outline my impressions of 'field' and 'fieldwork' when I travelled to Gulu for the very first time in August 2009. Subsequently, I discuss the progress of my research, the various methods I applied and the 'biases' entailed in my research approach. I also introduce the reader to some of my field sites and groups of interlocutors in Gulu, which I will refer to throughout this book.

Chapter 3 and 4 comprise a historical analysis of discourses on the war in Northern Uganda and of discourses on Acholi culture. The background information provided in these chapters is necessary to contextualize my analysis of contemporary discourses on socio-cultural change in the two following chapters.

The third chapter takes a discourse-analytical approach to studying Ugandan history. I trace different narratives and interpretations of events in Ugandan history, which entail different analyses of the root causes of the war in Northern Uganda. I demonstrate that there are different versions of history, which are contested among Ugandans and social scientists alike. I point out how certain interpretations of historical events have become established as "truths" (in a Foucauldian sense) and show how these "truths" have had a profound effect on subsequent historical developments, in particular the war in Northern Uganda, and their interpretations. Chapter 3 is intended to help the reader to grasp the complexity of the war in Northern Uganda and the scientific and popular debates that have been fought about it. This is necessary to understand my discussion of discourses on (war-related) socio-cultural change in the subsequent chapters.

Chapter 4 serves to expound the contemporary, hegemonic discourse on Acholi culture, propagated by both local and international actors, who proclaim that "traditional Acholi culture" as it was in "those days" has been lost through war and displacement. Thereby, I refer to the literature as well as to my ethnographic material. In order to give the reader an impression of contemporary representations of Acholi culture, I begin the chapter with an extract from my field notes in which I describe the "Miss Acholi Contest". I then delineate elements of Acholi culture that are commonly associated with pre-colonial and/or pre-war times. I try to reconstruct the image of this proclaimed ideal and 'authentic' Acholi society by linking com-

34 Chapter 3 comprises a discourse-analysis of the literature on the war and is not based on my ethnographic data. 
mon expressions by my interlocutors to older and newer ethnographic accounts of the Acholi. By doing so, I reconstruct how contemporary notions of an 'authentic' Acholi culture have been and are being discursively produced. In the subsequent part of the chapter, I focus on the widespread contemporary impression that Acholi culture is "getting lost". In local discourses this loss of Acholi culture is blamed on the war, particularly the displacement of the majority of the Acholi population to IDP camps, and the effects of war-related foreign influences. In the final part of the chapter, I briefly discuss contemporary attempts to reconstruct 'traditional', 'authentic' Acholi culture, which are pursued in different ways by rural communities, urban elites and international development actors.

Based on the general analyses of the discourse on Acholi culture and its proclaimed loss in chapter 4, I then turn to analyze more specifically how the young people I worked with in Gulu position themselves in this discourse and how they evaluate ongoing processes of socio-cultural change. I argue that due to the specific situation they have been confronted with in the past, and the specific challenges and opportunities they face both with regard to the present and the future, their position is somewhat different from that of the adult/elder population.

In chapter 5, I discuss youth practices and discourses against the backdrop of shifting social expectations, different power influences as well as local and global discourses. The chapter focuses on the ways members of the "war generation" experience and evaluate the changes Acholi society is seen to be undergoing, and on the strategies they adopt in dealing with the post-war situation of perceived cultural flux and uncertainty. I first provide an ethnographic insight into contemporary youth culture in Gulu and give a general description of the generation of urban young people, who were born and raised during the war years and who live in Gulu Municipality today. In the subsequent part of the chapter, I discuss youth practices and behaviors with regard to Ferguson's (1999) concept of "cultural styles". Thereafter, I focus on discourses on socio-cultural change and future visions of Acholi society and delineate four 'prototypical' positions young people adopt regarding this subject: a desire to retraditionalize Acholi society, a desire to modernize Acholi society, ambivalence and creativity. Chapter 5 intends to illustrate how youth in Gulu strategically react and contribute to contemporary discourses in post-war Acholi society in very different ways depending on their individual characteristics, the situational context and changing power constellations.

Chapter 6 deals with notions of Westernization and neocolonialism in Ugandan discourses on socio-cultural change, particularly those concerned with gender, kinship and sexuality. It is based on my observation, derived from my analysis of statements by my interlocutors and in the Ugandan media, that the West constitutes an important, spatial and symbolic reference point in contemporary discourses. Westernization is generally regarded as a major source of the ongoing changes in Acholiland (and beyond), and its implication and desirability were strongly debated among my interlocutors. In my analysis I aim to understand why the West is such a frequent point of reference and comparison and why and in which con- 
Julia Vorhölter: Youth at the Crossroads

texts Ugandan actors respectively establish positive or negative associations with the West. I argue that one can differentiate between two different types of discourses: "neocolonialism discourses" which mainly reflect negative perceptions of 'Westerninfluenced' change and are used to blame the West for interference in Ugandan internal affairs, and "Westernization discourses", which echo more ambiguous views of Western influences and are concerned with Ugandan society itself. In the first part of the analysis, I examine general discourses on Westernization which are related to aid dependency, NGO intervention and generational change, all of which are much-debated topics in contemporary (Northern) Uganda. In the second part of the analysis, I place special emphasis on representations of the West in contemporary debates on gender, kinship and sexuality, where binary oppositions between local and global, modern and traditional and African and Western are particularly widespread and contested. In the third part of the analysis, I contrast the formerlyoutlined discourses on Westernization with a neocolonialism discourse - the current national debate on homosexuality - and show that the motives, arguments and strategies behind it are very different from the discourses on Westernization. Finally, I draw attention to the highly sexualized dimension of discourses on socio-cultural change in Acholiland and Uganda generally and analyze the way these discourses are closely interwoven with power dynamics at the local, national and international level.

The concluding chapter summarizes the major themes and insights discussed in the previous chapters with regard to the question how perceptions of socio-cultural change and imaginations of post-war Acholi society are contested and negotiated in the context of generational, gendered and globalized power dynamics. It takes up my hypothesis that, in these negotiations, members of the war generation are placed in a specific in-between position - between past and future, tradition and modernity, Acholi culture and Western culture - which they perceive as a cause of uncertainty, but also as a source of agency. The concluding chapter furthermore serves to link my findings from Northern Uganda to broader debates on youth and socio-cultural change in Africa. 


\section{2. 'My Field' - Changing Perceptions of Research in a Post-War Setting}

This chapter serves to introduce and reflect my research approach and fieldwork experience, including my research setting in Gulu, the various research methods I applied, the course and evolution of my research and the biases entailed in my research approach. I introduce the reader to some of my 'field sites' and interlocutors in Gulu, which I will refer to throughout this book ${ }^{35}$. Drawing on the work of Gupta and Ferguson (1997a,b,c), I briefly dissect the problematic notion of 'field' and expound how I conceptualize 'my field' beyond the conventional sense of the term. I begin my reflections by describing the feelings and expectations I had about my research when I first travelled to Uganda for a four-week exploratory study in August and September 2009. In the following, I discuss how my perceptions of my research and my 'field' changed over time and how my change of perceptions affected my research approach.

35 A complete list and description of all of my major interlocutors can be found in the appendix. 


\subsection{Entering 'The Field'}

In August 2009, I left Germany for a one-month preparatory trip to Northern Uganda. I had studied the literature on Northern Uganda which was largely focused on the 20-year conflict which had come to a tentative end in 2006. I had talked to people on the ground, mainly foreign researchers and development workers, who assured me that the situation was stable and safe. I had read many books focusing on gender and conflict - which was my original 'theoretical frame' for my research. With regard to methodology, I had contemplated about the nature of ethnographic fieldwork, about self-reflectivity of the anthropologist, about trying to learn from the people on the ground, about having a 'blank mind' and entering the 'field' as un-biased as possible.

But despite all my 'scientific engagements' with region, theory and methodology and my critical reflections, in retrospective I must admit that my mind was full of stereotypes: stereotypes about war-stricken and dangerous Northern Uganda, about victimized and marginalized women and youth and their patriarchal counterparts. I also had a rather inadequate vision of 'doing ethnography' which corresponded largely to the "Malinowskian archetype" (Gupta \& Ferguson, 1997a: 11) of getting settled in a bounded 'field' and to provide a comprehensive ethnography of 'modern Acholi' and the changes which had taken place and affected Acholi culture, particularly gender relations, as a result of the war. Resulting from all the contradictory and confusing images in my mind and the high expectations I had of me as an ethnographer, my predominant feelings when I entered the plane to Uganda were doubt, fear and uncertainty. I had many doubts about my 'dangerous field', feared the post-war traumas I might be confronted with, and felt uncertain about the methodological and personal challenges of fieldwork.

After spending a few preparatory days in Kampala, the Ugandan capital, I felt it was time to explore my 'field-to-be'. I took the bus to Gulu, the biggest town in the North, which would become my main base for a longer stay in 2010/2011. In the bus, I was lucky to sit next to a friendly young man. The conversation with him helped me to temporarily forget some of my fears and doubts about my research endeavor. His name was Komakech and it turned out that he was an Acholi from Gulu, a student, pursuing his secondary education in Kampala, going for a home visit during the school holidays. I was naively excited to have the opportunity to speak to a 'representative' of my envisioned target group - Acholi youth - even before having entered 'the field'. This is what I wrote about the encounter in my field notes:

"We exchange some introductory words. Proudly, he shows me his student ID card and tells me that he is currently doing his A-level, the last two years in the Ugandan school system, which will enable those who graduate to study at university. We talk about school and this and that. Then, I start to 'interview' 
him about the present situation in Northern Uganda and about the reason why he had decided to study in Kampala. I ask him whether his family is still in Gulu and whether he will be visiting them now during the holidays. He becomes quiet, his face expression changes and all of a sudden he looks very serious. He tells me that he will be seeing his sister and brother who are still in Gulu. His mum, he says, has also moved to Kampala. After a pause he tells me that his father is dead. I don't know what to say and feel stupid at having asked such an insensitive question. There is silence between us. I imagine how his father died in the war, how Komakech and his mother fled to Kampala, how the family is trying to cope now. And for the first time I feel what it can mean to do research in a former war zone" (field notes 22.08.2009).

In the situation described above, I never considered that Komakech's father could have died of cancer, AIDS, old age or in a car-accident; that his mum might have had a well-paid job in Kampala which enabled her to provide a good education for her son; that his brother and sister might have decided to stay in Gulu to run a family business. My image of Northern Uganda as a war-zone blinded my interpretation, or, to quote the brilliant speech by the Nigerian novelist Chimamanda Adichie (July 2009) ${ }^{36}$, I only had a "single story" of Northern Uganda in my mind. Most of the things I had read about Northern Uganda had been about the war, the victims, 'child soldiers', the rebels. And despite my intended theoretical focus on the agency of the people in a post-war setting, my mind was full of victim narratives. In the first days of my stay (and even later, during my second stay), I often saw daily life in Gulu only through the 'war lens'. When I saw a teenage girl carrying a baby child I thought that she must have been raped by the rebels; when I saw young people hanging out in the streets I often wondered whether they had been abducted and were former 'child soldiers'. I expected everyone, everywhere to be always thinking and talking about the war.

What I actually found in Gulu, however, was very different and much more multifaceted. Most people in town seemed to be living in the present rather than in a 'traumatic' past. Men and women were working hard on their fields or in small businesses, struggling to provide for their families. Young people were going to school or hanging out with their friends. Boys and girls were supporting their families at home, helping with household chores or taking care of their younger siblings. Gulu Municipality was a vibrant place, one of the fastest growing towns in Uganda, and one in which people seemed to have a vision for their future. Construction work was going on everywhere, the local markets were full of stalls selling all types of products, and the streets were bustling with life. If I had not known that only three years ago Gulu, and more particularly its surrounding areas, had been a war zone, I could not have guessed it. Only the numerous signs pointing to the headquarters of humani-

36 Adichie, Chimamanda. 2009. The Danger of a Single Story. TED, July 2009: http://www.ted. com/talks/chimamanda_adichie_the_danger_of_a_single_story.html (accessed 10.10.2013). 
tarian NGOs, which had 'flooded' Gulu mainly in the last phase of the conflict, still provided some evidence of the conflict-ridden past. Daily reality in Gulu hardly conformed to my expectation of a dark and dangerous field site.

Of course, upon closer inspection, there were also problems and impediments: many people were still suffering from the consequences of war and did not profit from the 'development boom'. Children were out-of-school because their parents lacked the means to pay school fees, unemployment was widespread and poverty remained a big challenge, especially for youth. In the rural areas, new conflicts about land were erupting as people returned from internal displacement camps. And of course, when discussing these issues, the war sometimes came up as a topic of conversation and especially older people lamented that in the past everything had been better. However, the war did no longer occupy such a central position in the daily lives of the people as I had expected.

There was only one group of people who were still primarily focused on the war: the foreign researchers. And they were many. Although I had known beforehand that Gulu had become a major 'hub' for conflict researchers from various disciplines, especially since the war had ended, I had not expected the researcher community to be so large - and so well-known. Whenever I told local people in Gulu about the purpose of my stay - research - they seemed to have a very precise idea of what exactly I was planning to do and sometimes they smiled at me knowingly. I often felt awkward and I sensed (and sometimes my interlocutors explicitly stated) that they were wondering why all these foreigners came to do so much research, and why all research topics seemed to focus on the same thing, namely the war in Northern Uganda. I sometimes encountered situations where people seemingly randomly came up to me and, after confirming that I was a researcher, offered to be interviewed by me. In other situations, I was told that my topic of research had already been covered, but that nevertheless it would be no problem to find volunteers for a group discussion. "Mobilizing" people for focus groups, taking people to "the field" (usually a rural area outside Gulu Municipality), and being "research assistants" were tasks and positions actively sought by some of the Gulu locals. Just as I had my stereotypical expectation of a post-war community, this very same community had a very clear (and also stereotypical) understanding of what it meant to do research or be a researcher.

To most people I encountered in Gulu, research meant that white people (usually young, often university students, and mostly female) from the US or from Europe would stay in Gulu for some weeks or months. They would look for former LRA rebels or victims - preferably 'child soldiers' - and conduct interviews or 'visit' the camps for internally displaced persons (locally known as IDP camps), which had already been closed by the time I settled in Gulu. In common perception, research was understood to be applied research, aimed to provide 'solutions' to current 'problems', which could then be taken up by the NGOs working in Gulu. In this sense and understandably, most people expected some short- or mid-term (personal and communal) benefits to come out of all the research, and, as a result, were happy 
to (re)produce and reinforce the victim narratives and the images of Gulu as a war zone, which the foreign researchers wanted to hear and see (cf. Verma, 2012; for a similar situation in West Nile cf. Bogner \& Rosenthal, 2012: 124ff.). This is not to say that people intentionally lied about their situation or exaggerated their problems (although this sometimes also happened), but that they presented only "a single story" of their lives as war victims, which left large parts of their daily routines unnoticed and served to manifest the dominant discourse on Northern Uganda as a crisis zone.

I often felt awkward being confronted with the stereotypical image of the foreign researcher, probably because it was in many ways quite an accurate representation of the situation on the ground ${ }^{37}$. Reluctantly, I had to admit to myself that I not only was a part of the researcher community, but was actually not as different from the stereotype as I pretended and would have liked to be. During my second stay in Gulu (March 2010 - January 2011), and over time, I became more confident in my role as a researcher, especially after I started working as a part-time lecturer at the local university. The people I worked with for my research also became more accustomed to my research style which was less focused on formal interviews and rather based on establishing relationships and having informal conversations (see the discussion of my research methods below). They eventually believed that I would stay longer than many of the student short term researchers and that I was interested in getting to know the different facets of their lives and their opinions on a whole range of matters, including but by no means limited to the war experience. Over time, my own perception of the situation in Gulu also changed dramatically from my first impressions.

Today, after having spent nearly a year in Northern Uganda, I sometimes look back to that first bus ride to Gulu to remind myself of my changing perceptions which now offer me an important guideline for my interpretations. As I changed, my 'field' changed - not as a physical "space", but as a "place"38. The way I will come to represent it in the following chapters are strongly related to the personal changes I underwent during my time in this 'field' and the way I came to understand it as a "political location" rather than a "spatial site of difference" (cf. Gupta \& Ferguson,

37 Together with my colleagues from IPSS, I often wondered about the influx of foreign researchers and "well-intentioned Western teenagers" (cf. Perrot, 2010: 190), some of whom had very superficial observations and assumptions about Northern Uganda. We met and talked to quite a few of the international students and researchers, because they came to IPSS to collect information on the war and post-war setting and were sometimes quite surprised and shocked by the naïve, unreflected and paternalistic approach to studying and 'helping' the people in Northern Uganda some of them proposed (cf. field notes e.g. 23.03.2010; 29.03.2010; 15.04.2010; 18.11.2010).

38 "Space" refers to a physical, geo-political and seemingly natural unit whereby "place" refers to something which has acquired an identity and social meaning. Gupta and Ferguson (1997c: 36) claim that "by always foregrounding the spatial distribution of hierarchical power relations, we can better understand the processes whereby a space achieves a distinctive identity as place." For anthropological debates on space and place cf. also Low \& Lawrence-Zúñiga (2003) and Coleman \& Collins (2006). 
1997a: 5; 35ff.). I will briefly reflect on the changes my notion of field underwent throughout my research.

\subsection{Reflecting the Notion of 'Field'}

At the start of my research, I still had a rather classical notion of fieldwork and the 'field' - being far away from 'home', generating a specific form of ethnographic knowledge, and following a rite of passage which turns the anthropological student into a "real anthropologist" (cf. Gupta \& Ferguson, 1997a: 12-18). This perception changed when I came to realize not only the differences but the similarities between 'field' and 'home', when I came to understand both the ordinary and the extraordinary aspects of life in the 'field', when I discovered my role not only as a knowledge seeker and generator but as an ignorant and naïve learner and visitor, and through these realizations gained a somewhat different, much more fuzzy notion of what it means to be a "real anthropologist".

The representation of my field which I present in this book takes into account the critique of Gupta and Ferguson $(1997 \mathrm{a}, \mathrm{b}, \mathrm{c})^{39}$, who in their often-cited essays called into question anthropology's long-established and uncritical understandings of field and fieldwork ${ }^{40}$. Following their appeals, I address the interrelationship between "culture, power and place" (Gupta \& Ferguson, 1997b) and dissect how understandings of community, locality and region have been formed and how they are now lived. In chapters 3 and 4, in particular, I analyze the ways different groups of people, both insiders and outsiders, have historically and politically constructed the places (e.g. "Acholiland"), peoples (e.g. "the Acholi") and events (e.g. the "LRA war") which I discuss as part of my research, and thereby try to uncover the unequal power relations and various forms of knowledge inherent in these constructions.

In their chapter on Discipline and Practice: 'The Field' as Site, Method and Location in Anthropology (1997a), Gupta and Ferguson summarize their vision of a reformed and relevant ethnography as follows:

"Instead of a royal road to holistic knowledge of 'another society', ethnography is beginning to become recognizable as a flexible and opportunistic strategy for diversifying and making more complex our understanding of various places, people and predicaments through an attentiveness to the different forms of knowledge available from different social and political locations" (Gupta \& Ferguson, 1997a: 37).

I hope that the insights I present throughout this book can live up to this vision.

39 I exemplary draw on the essays by Gupta and Ferguson, but am aware that similar ideas have been put forth by many other anthropologists, who reflect on the changing nature and assumptions of anthropological fieldwork since Malinowski.

40 Having pointed out the problematic implications as well as my understanding of the term 'field', I will use it without quotation marks in the following text. 


\subsection{Fieldwork in Gulu: Basic Overview of Research Methods}

As I already stated above, my findings are based on a one-month preliminary study in 2009 and ten months of fieldwork between March 2010 and January 2011 in Gulu Municipality. The main part of the research consisted of participant observation and regular conversations with urban youth, their families and friends. It involved visiting and participating in training sessions of different youth groups (e.g. hip hop, break-dance, "traditional dance" or sports), participating in discussions with and about youth at Gulu Youth Centre and watching competitions such as song contests, dance competitions or debate tournaments in which young people performed. I interacted with youths from very different backgrounds (regarding their family situation, educational level, economic situation etc.) and with very different life experiences (cf. Chap. 5). I developed closer relationships and met with some of them outside of the institutional settings described above. I visited their homes, got to know their families and 'hung out' with them in their free time - in dance clubs, movie halls, record studios and several other places. The majority of my interlocutors belonged to what I would call the 'ordinary', i.e. non-elite population. Most had a basic level of education and were able to speak English, but only a few had finished high-school or gone to university. My regular informal encounters and conversations, which I recorded daily in my field notes, constitute the most important basis of my data.

In addition to my participant observations, I also conducted a number of semistructured interviews with male and female urban youth (20), staff from NGOs, CBOs and the local government (9), an Acholi elder (1), and mixed groups of youth and elders in selected rural areas $(6)^{41}$. The interviews were based on a set of broad and very loosely structured questions, and focused on perceptions of the socio-cultural changes which had occurred in Northern Uganda over the past 25 years. All interviews were conducted in English with the exception of the group interviews in the rural areas, which were carried out in Acholi with the help of three research assistants $^{42}$ : John Omara, Ruth Lagen and Kenneth Oyet Odong ${ }^{43}$.

41 A list of all the interviews including date, location and biographical information on the respondents is provided in the appendix.

42 I did not have a fixed research assistant at any point of my research, but relied on the help of various people in various contexts. I tried to reward their help by inviting them for food and drinks, or by equally assisting them in material and non-material ways in situations where they could use it (for instance in interactions with organizations and institutions or when they needed volunteers for projects and activities organized by them). The only situations in which I worked with research assistants in the conventional sense of the term, i.e. as paid 'employees', were the group interviews I conducted in the rural areas in the Acholi language.

43 I met John and Ruth through my work at Gulu Youth Centre, where they both worked as youth counselors. Kenneth was a Master student at the Institute of Peace and Strategic Studies (IPSS), where I worked as a part-time lecturer. 
In some instances of my fieldwork, I worked with a "bio-ethnographic approach" (Roberts, 2005), in which ethnographic and biographical methods overlapped. I carried out participant observation with a strong biographical focus and asked the young people about their life stories in the semi-structured interviews I conducted. I spent significant time hanging out with my interlocutors and, after a while, a situation of trust and normality emerged between us. I was no longer seen primarily as a foreign researcher but as a member of the group - albeit a special one. The young people started sharing information about their lives with me which they had never mentioned during the interviews. Furthermore, by observing the behavior of my interlocutors in different settings I got a more complex picture of their lives and could relativize the self-images people had presented of themselves in the interviews. The interviews provided an important complementary source of information. Here, my interlocutors could reflect on and explain why they behaved in certain ways. They could also clarify aspects which might have been misleading for me when only observing their behavior. In one instance, for example, I was observing a session of the hip hop project, in which the participants were asked to write a hip hop verse talking about their life story. One of the participants wrote a verse about his life on the streets. He rapped about living without his parents and how he had to cope on his own. I later interviewed the young man and asked him about his lyrics. He laughed and then clarified:

"My song portrays my life, but it is not a true life. I wrote it just to shame my father, because one time he annoyed me, so I wrote it to shame him. He didn't want me to do the music project, so I wrote the song to shame him. That's why I put so much interest on my parent's life" (INT Nura, 21.04.2010).

In addition to resolving such misinterpretations, the combination of interviewing and observing exposed how youth strategically conjured different facets of identity depending on the setting they were in. This was especially evident when comparing how youth presented themselves among fellow youth in town (and also in the interview) as opposed to their behavior at home or when visiting relatives in the village.

After the first five months of my stay, and based on an intermediary data analysis of my field notes and interview transcripts, I developed a short questionnaire and distributed this to youth in Gulu Municipality in order to get a broader picture on some of the topics I had discussed with my interlocutors in the interviews and daily conversations. The questionnaire was distributed by two of my research assistants to youth at Gulu Youth Centre and in cultural groups. The target group was approximately 100 youth between the ages of 16 and 26. I received a total of 94 response forms. The average age of the respondents was 19 (age range: 13-33) and the sex ratio was 36 percent female and 64 percent male youth. The selection of respondents was based on a convenience sample (Bernard, 2006: 191f.) and is thus statistically not representative for any larger part of the population of urban youth beyond the sample. Nevertheless, the findings provide some interesting additional insights and 
represent a larger number of youth than those which I interviewed personally and in more depth. I present some findings from the questionnaire throughout my analysis, especially in chapter $5^{44}$.

Throughout my stay, I collected newspaper articles and other documents which focused on discourses of socio-cultural change in Northern Uganda and Uganda more broadly. I regularly perused the two main Ugandan daily newspapers: the Daily Monitor which is the leading independent and government-critical newspaper, and the New Vision which is largely government-owned and sympathetic to the NRM regime. Furthermore, I read and collected several issues of Straight Talk, a newspaper which discusses "issues raised by adolescents" and aims to carry out comprehensive sex education and which was distributed to youth at Gulu Youth Centre ${ }^{45}$. These additional data helped me to better contextualize my own experiences and perceptions and relate them to wider discourses. I will draw on the various newspaper articles I assembled throughout my stay particularly in chapter 6 , where I discuss notions of Westernization and neocolonialism in local and national discourses.

In my research and data analysis I combined elements of ethnography and grounded theory (Glaser \& Strauss, $\left.2005[1967]^{46}\right)$. Charmaz and Mitchell (2001) have described the benefit of such a mixed approach as follows: "Grounded theory methods preserve an open-ended approach to studying the empirical world yet add rigor to ethnographic research by building systematic checks into both data collection and analysis" (ibid.: 162). In their article, they outline how the strengths of ethnography (i.e. thick description of and an open-minded frame of mind towards everyday life) and grounded theory (i.e. flexible but none the less systematic approach to theory development) can be combined, and develop an approach to grounded theory, which "builds upon a symbolic interactions theoretical perspective and constructivist methods that assume the existence of multiple realities, the mutual creation of knowledge by researchers and research participants, and aims to provide interpretative understanding of the studied world" (ibid.: 160).

Throughout my research, I approached my topic from various angles and observed and participated in very different aspects of Gulu everyday life. After some weeks of relatively unstructured ethnography, I started to preliminary code and analyze the data I had hitherto collected and thus to follow a more systematic approach to data collection and analysis as envisioned by grounded theory. I began to approach my field more systematically and - by engaging in a cumulative cycle of collecting and coding data - tried to work out core themes and thus increase the focus and depth of my research.

Shortly after I returned from the field, I started a second round of coding my data in which I confirmed and refined already existing codes and identified new

44 All original response forms can be consulted upon request to the author.

45 Straight Talk is published by the Straight Talk Foundation, a Ugandan, internationally funded NGO that specializes in communication for adolescent health (cf. www.straighttalkfoundation. org/, accessed 14.01.2013).

46 For a critical discussion and summary of grounded theory cf. Denscombe (2003). 
Julia Vorhölter: Youth at the Crossroads

themes ("open coding"). I then categorized and compared all of my codes ("axial coding") and selected the most important themes ("selective coding"; cf. Denscombe, 2003: 119ff.; Charmaz \& Mitchell, 2001: 165ff.). Based on this analysis, I developed a basic outline of my book and defined the broad topic of each chapter. I then carried out a further, more detailed and pronounced data analysis with regard to the topics of the respective chapters. In most stages, writing and analysis phases overlapped or were deeply intertwined. In the written account that emerged, I again combined elements of ethnography and (grounded) theory by mixing narrative accounts and detailed description with conceptual analysis (cf. Charmaz \& Mitchell, 2001: 169ff.).

In the following, I will briefly reflect on the process and different stages of my research in order to elucidate how I practically applied the different methods and concepts I outlined in this section and also to give a reflexive account of the ways I experienced fieldwork.

\subsection{Progress of Fieldwork}

Chaudhary (2006: 24f.) writes that "the main emphasis of reflection lies in clarifying the transfer process of the fieldwork experience into an anthropological text, the idea being that the fieldwork experience offers information on the background and the individuality of the researcher as a very important determinant of anthropological knowledge." In a similar vein, Hastrup (1992: 117) argues that "[f]ieldwork is situated between autobiography and anthropology" and that this "connection itself is of generative impact upon the reality of anthropology". Thus, as part of my reflexive account, and in line with an interpretative epistemology, I believe that it is imperative to discuss not only the methodological but also some of the personal implications of the fieldwork process. I will do so in the following by sketching different stages I underwent during fieldwork.

Based on a review of fieldwork literature, personal exchanges with colleagues over a 40-year period and his experiences as a director of field schools in cultural anthropology and linguistics, Bernard (2006: 378-384) has developed a typology of seven different stages of participant observation: 1) "Initial Contact", 2) "Culture Shock", 3) "Discovering the Obvious", 4) "The Break", 5) "Focusing", 6) "Exhaustion, Second Break and Frantic Activity", and 7) "Leaving the Field". I found Bernard's typology very helpful to reflect on the course of my fieldwork, both on a personal and a methodological level, and will loosely relate to it in the following description of the different fieldwork phases I experienced.

\section{March-July 2010: Initial Contact, Culture Shock \& Discovering the Obvious}

During the first four months of my fieldwork, I was concerned with getting settled in Gulu (on the personal level) and setting out my field (on the professional level). 
Although this phase was very challenging and exhausting as I struggled with alternating feelings of euphoria and shock, understanding and ignorance, frustration and optimism, I did not experience any profound set-backs. In the first weeks in Gulu, I tried to talk to as many people as I could about my research topic. I spent a lot of time at the Institute of Peace and Strategic Studies (IPSS) of Gulu University, where I had already established some contacts during my first visit to Gulu. I also made interview appointments with people who were working for $\mathrm{NGOs}$ and $\mathrm{CBO} s$ involved in youth work and used the interviews to get a general overview of my research field and my envisioned target group. At the same time, I started to visit different youth groups, which were involved in music, sports or "cultural activities" and which I had heard about. Soon, I decided to work with two of these groups more closely. The decision was based on two aspects: first, both groups were very open towards me as a researcher. Secondly, I believed they were situated in very different fields of youth culture, one being a group of so-called "traditional dancers" and the other being a group of hip hop performers.

The first group called themselves the "Gulu Theatre Artists" (GUTA). They were a "cultural group", consisting of male and female children and youth between the ages of roughly ten to thirty who met regularly to practice and perform "traditional Acholi dances". Throughout my stay in Gulu, I visited their dance practices and their performances in public venues and at dance competitions on a regular basis. I also conducted interviews with a number of the GUTA's members and some became regular and important interlocutors.

The second group I got involved with was engaged in a hip hop project called "Gulu Talking Straight", which was loosely connected to Gulu Youth Centre and coordinated by an international volunteer and an Acholi (self-proclaimed) music artist and producer. Approximately 20 young people (in their late teens and early twenties), among them only one young woman, had qualified to participate in the project. They had been promised that they would be taught in creative writing and other basic music skills and would be able to record a song in a record studio after their training. The predefined style of music was hip hop and the predefined topic of the songs was "my life story". Apart from these basic specifications, the project turned out to be very unstructured and unorganized. The bi-weekly training sessions were held during school hours, which forced the in-school participants to decide between their 'hip hop career' and their education. Sometimes, one or both of the coordinators who also took the role of the trainers did not show up, came late or unprepared. The long waiting hours before and in-between sessions enabled me to establish closer contacts to the group and after some weeks I also used these 'breaks' to conduct interviews with many of the participants. Two of them, Akello and Simon, became very important interlocutors and 'field guides' and Akello became one of my closest friends in Gulu. In the first months of my research, I spent a lot of time with the people from the project and even after the project had officially ended I maintained sporadic contact with many of the young hip hoppers. 
Julia Vorhölter: Youth at the Crossroads

Towards the end of the start-off phase, I started to 'experiment' with my methods and conducted a group interview with youth and elders in Kapedopong, a settlement on the outskirts of Gulu, with the help of a research assistant and translator. I also started a preliminary reflection and analysis of the field notes and interview transcripts I had produced during the first four months and wrote a paper for a conference presentation in mid-July (see below). I felt I had become well-settled in my field and that my research was progressing well. At the same time I felt exhausted and was happy to take a break from field work.

\section{July-August 2010: The Break}

In July, I travelled to Sweden for the World Congress of Sociology in Gothenburg (11. -17.07.2010), where I presented some of my preliminary findings (cf. Vorhölter, 2010a). Afterwards, I returned to Uganda with my parents. I invited them to Gulu and introduced them to some of my friends before travelling through the country with them for twelve days. I only got back to my field in the beginning of August.

\section{August-September 2010: Focusing}

When I returned to Gulu, I was eager to follow-up on my research and catch up with the people I had not seen for a month. I intensified my participant observation and for a couple of weeks got very involved in the Gulu hip hop scene. I spent a lot of time hanging out in record studies, talking to music and video producers and even ended up participating as a 'guest rapper' in two songs myself. In addition, I also spent time at Gulu Youth Centre where in the meanwhile I had become well-known as a researcher and occasional volunteer. I helped to chair the youth talks and continued (as I had done before) to come along on outreach trips for VCT (Voluntary (HIV-) Testing and Counseling) to the rural areas. Based on my preliminary data analysis, I developed a questionnaire and, with the help of two research assistants, distributed this to youth in Gulu (see above). By this time, I felt that the relationships I had developed in the first months of my research were intensifying. I spent the greater parts of many days (and some nights) out with my interlocutors and friends and thus gained insight into many new aspects of Gulu life.

\section{September-December 2010: Frantic Activity ${ }^{47}$}

In September, I started my position as a part-time lecturer in the Post-GraduateDiploma Program at IPSS ${ }^{48}$. Every Saturday, I taught the course Ethnic Identity

\footnotetext{
47 Bernard has labeled this phase "Exhaustion, Second Break and Frantic Activity", but for me it was mainly a period of "frantic activity".

48 Because there was a lack of teaching staff and because I was an affiliate to the institute, the director of IPSS had offered me to teach a course in the program.
} 
and Conflict Transformation. This made me feel even more at home in Gulu and I thoroughly enjoyed the teaching experience. I sometimes used the seminar sessions to discuss issues which were also relevant to my research and I asked my students about their opinion on some of the topics I was working on. On December $1^{\text {st }}$, I presented my research at the IPSS colloquium, which was attended by several Post-Graduate and Master students as well as a number of foreign anthropologists and gave me the chance to receive a critical feedback on my work.

In addition to my regular participant observation activities during this period, I also had the chance to observe and take part in some important festivities such as Independence Day (on October $9^{\text {th }}$ ), Christmas and New Year's Eve, which I spent with friends and their families in Gulu. The last months of the year also marked the start of the pre-election campaign (elections took place in February 2011) and I watched the rallies by President Museveni and FDC $^{49}$ opposition candidate Kizza Besige, which provided me with some new, interesting insights into political life in Uganda.

Throughout the month of October, with the support of two research assistants and translators, I carried out five group interviews with youth and elders in selected rural areas outside of Gulu.

Between September and December, I also undertook some short trips to other parts of Uganda in order to visit the home regions, friends and families of people I had met in Gulu: to Arua in the West Nile Region, to Busia in Eastern Uganda, and to Palabek in Lamwo District (cf. figure 2 in the appendix). These trips not only gave me short breaks from "frantic fieldwork", but helped me to establish even closer contacts to my interlocutors and also gave me the opportunity to compare life in Gulu with other places in Uganda.

\section{January 2011: Leaving the Field}

Although my return flight to Germany was only on the $31^{\text {st }}$ of January, I already left Gulu in early January in order to participate in an evaluation of a ZFD ${ }^{50}$-Project ("Promotion of Peaceful Co-existence between the Iteso and the Karimojong") in Teso and Karamoja, Eastern Uganda, with three colleagues from IPSS. Before I left, I visited all of my regular interlocutors to say farewell and to thank them for their support. I exchanged contact details with those who had become close friends and to this day I am still in touch with some of them. Bernard (2006: 383) writes that " $[\mathrm{t}]$ he ritual of leaving a place in a culturally appropriate way will make it possible for you to go back and even to send others" and I tried as best as I could to live up to this statement.

49 Forum for Democratic Change

50 Ziviler Friedensdienst. The ZFD supports projects which aim for the peaceful resolution of conflicts (cf. http://www.ziviler-friedensdienst.org/de, accessed 30.01.2013). 
Julia Vorhölter: Youth at the Crossroads

\subsection{Biases Inherent in my Research Approach}

It seems unnecessary to say that despite the relatively long time I spent in the field and the different research approaches I applied, I only gained a temporal insight into some aspects of youth life in Gulu. The accounts I present in the following chapters of experiences and life situations youth face in Gulu are based on my impressions and the information which was reported to me by my interlocutors. Thus, they are selective and subjective and only hint at the manifoldness and complexity with which youth - collectively and as individuals - deal with and interpret sociocultural change in contemporary Acholiland.

My 'personal attributes' as a relatively young, white, educated woman from Germany affected the way people in Gulu interacted with me in multiple ways. On the one hand, these characteristics made it easy for me to gain access to various places and people: firstly, because they granted me a privileged position in the local social order, and secondly (and related to the first point), because people were generally enthusiastic about interacting with типи, albeit for different reasons. Many were simply interested in exchanging and discussing ideas with someone from a different social and cultural context, others thought that "having a white friend" was a symbol of status, and some expected financial or social benefits from encounters with whites. On the other hand, being young, white and female sometimes also had some rather annoying 'side-effects' such as having to deal with offensive approaches by men on quite a regular basis, being 'harassed' by children in the street and having to explain and justify my behavior in many situations, especially when it collided with local gender ideologies.

Apart from the biases resulting from my 'personal attributes', language had a restricting impact on the kind of people I interacted with. Due to my very limited understanding of Acholi, I mostly interacted with people who could speak English, i.e. those with at least a basic level of education. In urban Gulu, this was the great majority of the population, at least among the young generation and among male elders, and most spoke a fairly high level of conversational English. However, although English was widely used ${ }^{51}$, it was only the second language for my interlocutors and this probably had an effect on the conversations and interviews. In the rural areas or when talking to non-English-speakers in Gulu, I was usually aided by research assistants or friends who translated for me. In everyday situations, for instance in the local market, I usually managed to have very simple 'conversations' in Acholi, and my language skills did improve to some extent throughout my stay.

Lastly, my data has a slight male gender bias, particularly with regard to the interviews I conducted with youth, but also with regard to the unplanned personal

51 English is the official national language in Uganda. The only other national language is Swahili, which was not spoken by the majority of my interlocutors and is, generally, not commonly used in the Acholi sub-region. 
exchanges and daily encounters, which make up a significant part of my field notes. This bias can be attributed to a number of reasons: (young) men were more forthcoming and actively sought contact with me. I was often approached by (young) men in the street and used this as a chance to talk to them and 'informally interview' them on topics I was interested in. Among my close friends and the people I interacted with regularly, the number of men and women was relatively equal (see list of most important interlocutors in the appendix). The insights I gained from the regular encounters with these close interlocutors produced some of my most important data and reflect both male and female perspectives.

The male bias is most obvious in the individual interviews I conducted with male and female youth. Throughout my research, it proved to be extremely difficult to interview young women and to get them to talk in front of a voice recorder. It seemed, maybe due to established gender roles, that girls were not used to and thus very shy to figure as 'experts' and express their opinion in a formal (interview) setting. Even girls like Akello, who I interacted with regularly, seemed to feel very uncomfortable in the interview situation (cf. field notes 26.11.2010). In the end, I decided to conduct the interviews with female youth in a more informal manner and without recording, for instance by deliberately discussing and asking their opinions on certain issues in seemingly 'ordinary' conversations. Interestingly, in the group interviews with youth and elders, I observed that elderly women were usually the most outspoken and often took the lead in the discussion. This illuminates that it is not gender as such, which produces certain socially-accepted speaker positions and subsequent 'research biases', but a combination of gender, age, social status and, possibly, other factors - both on the side of the researcher and the research participants.

In this 'field chapter', I have outlined and reflected my research approach and have thus provided some guidance to the reader as to what he or she can expect in this book. The following chapters are based on an analysis of both the literature and my ethnographic material, which I have gathered by applying the above-cited research methods. 



\section{The War in Northern Uganda - Conflicting Interpretations}

This chapter takes a discourse-analytical approach ${ }^{52}$ to studying events in Ugandan history which are important in order to understand the war in Northern Uganda and its root causes. I point out how certain interpretations of historical events have become established as "truths" (in a Foucauldian sense, cf. introduction) and how these "truths" have had a profound effect on subsequent historical developments as well as their interpretations. This chapter provides important context and background information, which is needed to grasp the complexity of the war in Northern Uganda and the scientific and popular debates that have been fought about it. This information is relevant to understanding my discussion of discourses on

52 Originally, the chapter was intended only as a historical excursus. However, upon closer inspection of the literature, I found that many aspects of Ugandan history and the war in Northern Uganda were so contested that I opted for a discourse-analytical approach. 
Julia Vorhölter: Youth at the Crossroads

(war-related) socio-cultural change in the rest of the book ${ }^{53}$. My analysis is based mainly on an extensive review of the literature and not on my own ethnographic data, which is less concerned with the history of the war as such.

\subsection{Different Accounts of Ugandan History from the Perspective of the Sociology of Knowledge}

The war in Northern Uganda cannot be understood without giving at least a general overview of the political developments Uganda underwent during colonialism and after independence. This is not an easy endeavour as historical accounts, just like social reality in more general terms, are collectively negotiated and constructed, and different versions or orders of knowledge may be contested among different societal groups (cf. Bogner \& Rosenthal, 2012: 120ff.). As Keller (2006: 121) states:

"Gesellschaftliche oder gruppenspezifische Wissensvorräte und symbolische Ordnungen stehen untereinander mitunter in Konkurrenzbeziehungen. Sie bilden keine harmonische Gesamtordnung. Treten solche Sinnwelten zueinander in Konkurrenz, entscheiden Interessen konkreter Personengruppen bzw. Machtverhältnisse über ihre relative Geltung. "“54

A typical Acholi perspective on Ugandan history often differs quite substantially from the 'mainstream version', which dominates public and to a lesser extent academic discourses. Since colonial times - and for reasons I will explicate later - the Acholi have been viewed as an uncivilized, dangerous, martial tribe and this view still persists among many Ugandans today. Misrepresentations of the Acholi and their involvement in the political past continue in the daily newspapers, in academic writings and in popular discourses (cf. Finnström, 2008: 74f.; 78ff.; Leopold, 1999). As Finnström (2006a: 204) states, "[i]t is still common today for people in Central Uganda to regard people from Northern Uganda as backward, primitive and warlike".

The young Acholi I met in Gulu, some of whom had gone to school in other parts of the country during the war, often told me about their experience of being called "Kony" 55 and being feared by their non-Acholi classmates. The following statement by a university student, who had gone to high school in Western Uganda, is a typical example:

53 Readers who are sufficiently familiar with the debates on the war might only want to skim over my analysis.

54 "Societal or group-specific pools of knowledge and symbolic orders can occasionally compete with each other. They do not constitute harmonious total orders. In the case that such symbolic worlds compete, the interests of concrete groups of persons or power relations respectively decide over their relative standing and validity" (Translation J.V.).

55 Joseph Kony is the name of the notorious LRA leader. 
"The first two weeks I had a lot of problems, in fact people, the whole school feared me, the only word they call you is Kony, they relate you to the real rebel leader (...), everywhere you go 'Kony, Kony, Kony. See that Kony?' They thought everybody from here is too rough and too tough (...). Sometimes, in those places like Central Uganda, Kampala (...) people still call you a Mukoko, which means animal in their language. They call us from the North an animal...” (INT Ojok, 31.03.2010).

The image of the Acholi as barbarous and irrational people has been reinforced and intensified through statements by the Ugandan government and media reporting on the LRA rebels and particularly their leader Joseph Kony. Thus, in conversations with non-Acholi Ugandans, I often found that they blamed the Acholi for much of the postcolonial violence in Uganda generally, and the war in Northern Uganda in particular. Among the Acholi, on the other side, I often experienced that people tried to teach me the 'real' history of Uganda according to which the Acholi were largely the victims of the colonial and postcolonial state. Sometimes people encouraged me to tell other Ugandans about my positive experiences among the Acholi, and asserted that my research would surely contribute to rectifying the negative image of the Acholi (personal conversations in Gulu; cf. RLP, 2004: 23; Kuster \& Santchi, 2006: 158ff.).

Different versions of the war and Ugandan history more generally are not only found in people's minds and reflected in daily conversations. They are also reproduced in the social science literature, albeit to a lesser extent (cf. Bogner \& Rosenthal, 2012: 137). While the major historical occurrences are not disputed, the devil is in the details. Only after returning from the field and rereading some of my writings on Ugandan history I had produced before entering the field - which were mainly drawn from social scientists, who had not carried out extensive research in Northern Uganda - did I notice how they differed not only from popular Acholi perceptions of Ugandan history (cf. Dolan, 2009: Chap. 3), but also from articles on Ugandan history by Acholi social scientists (see for example the texts in the Accord volume edited by Lucima, 2002) and by ethnographers of contemporary Acholiland (see below). The difficulty of reconstructing Ugandan history based on oral and written sources is captured in the following statement by Vincent (1999: 123):

"I have referred several times to the difficulty of finding or trusting either written or oral sources relating to war in postcolonial Uganda. Experience has taught the people of Uganda that the powerholders of today may be overthrown by the powerholders of yesteryear, and, without the dangerous courage of an ideological commitment to speak out, journalists and those interviewed carefully and deliberately fashion their words, I would suggest, with double tongues. One may read what one will into their messages".

With regard to the war in Northern Uganda more specifically, different authors have recognized the various framings of the armed conflict and its root causes - by 
Julia Vorhölter: Youth at the Crossroads

the conflict parties as well as by the media and other outside analysts - not only as a 'scientific challenge' but also as a practical problem to ending the war (Leopold, 1999; Westbrook, 2000: 7). A report by the Refugee Law Project (RLP, 2004: 7) states:

"The absence of a consensus on the core causes of the war partly explains why there is no consensus on how to end the war. (...) [C]ompeting analyses [of the root causes] paralyze conflict resolution efforts, as key actors lack a firm consensus on which issues to address in resolving the conflict."

Thus, when trying to summarize the major historical events which led to the armed conflict in Northern Uganda, I have tried to highlight relevant discrepancies I found in the literature between different versions of Ugandan history. I have taken a sociology-of-knowledge approach to discourse analysis ("wissenssoziologische Diskursanalyse”, cf. Keller, 1997; 2005; 2006; 2007; 2008). According to Keller (2006: 115), "wissenssoziologische Diskursanalyse” implies reconstructing the processes of social construction, objectivation, transmission and legitimation of structures of interpretation and action at the level of institutions, organizations and social actors, and, secondly, discerning the societal effects of these processes. This can include analyzing the emergence of specific discourses (including their power-knowledge constellations), their changes over time, the topics and audiences they address, the latent and manifest contents and convictions they convey, as well as the relationships between different, competing discourses (Keller, 1997: 318f.). Sociologists of knowledge, like Keller, understand discourse as

"Formen der Wissenskonstruktion und Vermittlung (...), die sich von der Ebene konkreter situativer Konstruktions- und Aushandlungsprozesse basalen Allerweltwissens unterscheiden. D.h. es geht um die Wissensproduktion in wissenschaftlichen Disziplinen bzw. in unterscheidbaren institutionellen Feldern der Gesellschaft: etwa im Recht, in der Politik, in der massenmedialen Öffentlichkeit. (...) Diskurse sind abgrenzbare übersituative Zusammenhänge von Äußerungsformen (Praktiken der Artikulation) und Inhalten (Bedeutungen), die mehr oder weniger stark institutionalisiert sind" (Keller, 2006: 130f.)..$^{56}$

This understanding is based on the ideas of Foucault but also includes everyday usages of the term. Keller adopts some aspects of Foucault's theory and integrates them into the framework set by Berger and Luckmann's sociology of knowledge (Keller, 2005: 5; cf. Berger \& Luckmann, 2011 [1966]). I have chosen to work with

\footnotetext{
"Forms of knowledge construction and transmission (...), which differ from the level of concrete situational processes of construction and negotiation of basal everyday knowledge. I.e. it is about the production of knowledge in scientific disciplines or respectively in discernible institutional fields of society: for instance in law, in politics, in the mass media (...). Discourses are definable meta-situational combinations of forms of articulation (practices of articulation) and contents (meanings), which are more or less institutionalized" (Translation J.V.).
} 
Keller's approach in this chapter, because, more than Foucault, he acknowledges the role of actors in the social production and circulation of knowledge and offers a theory, which is specifically situated to study the "historical and collective dimensions of knowledge and knowledge-making practices" as well as "social regimes and politics of knowledge" (Keller, 2005: 4).

As a conceptual approach, Keller (2005: 9f.; 2007: 10ff.) has suggested four categories for the analysis of societal knowledge relations and politics of knowledge: interpretative schemes ("Deutungsmuster"); classifications ("Klassifikationen"); phenomenal structures ("Phänomenstrukturen"), and narrative structures ("Narrative Strukturen"). In the following chapter, I will analyse the discourses on the war in Northern Uganda based on the conceptual approach suggested by Keller, which I will briefly outline.

Interpretative schemes emerge over time and are interactively produced. They are the result of the social construction of reality. They help social actors to interpret worldly phenomena, and provide practical orientation in daily life - to solve problems, in interactions with others, or in understanding and reacting to social processes, happenings and events. Interpretative schemes are transmitted through socialization processes, but also, for instance, through the media. In discourses, different interpretative schemes of social phenomena are combined in specific ways. In my example of the war in Northern Uganda, I will show how certain events in Ugandan colonial and postcolonial history have gained high symbolic relevance, and how hegemonic interpretative schemes of these events have emerged. These not only serve to produce a dominant narrative of Ugandan history, but have in fact heavily influenced the actions and practices of social actors and thus fundamentally shaped and continue to shape historical developments in Uganda.

Classifications, according to Keller (2007: 12f.), not only structure reality, but help social actors to experience reality in the first place. Classifications in this sense have a performative effect. Keller names the common example of ethnic categorizing, which can fundamentally shape self-perception as well as the perception by and of others. In my example, I will outline how classifications of the war in Northern Uganda are heavily contested between different, competing discourses, and how different classifications, for instance of the war's root causes or its major conflict parties, have had profound effects on suggested interventions and solutions to end the war.

Phenomenal structures establish causal connections between different elements of a discourse. They are necessary to convincingly construct an issue as a problem or concern and to place it on the public agenda. Different argumentative, dramatizing or evaluating statements can serve to define a topic in a particular way, establish certain interpretations of cause and effect, ascribe responsibilities and subject positions, and suggest possible courses of action. In my analysis, I discern two major and competing discourses on the war - what Finnström (2008: Chap. 3) and Dolan (2009) have called the "official narrative" and the "counter narrative". I will present a detailed analysis of the phenomenal structure of these two major discourses, 
and demonstrate that they frame their responses to key analytical dimensions (for instance origin of the war, possible solutions, positioning of key actors, value attributions etc.) very differently when interpreting the war.

Lastly, narrative structures serve to establish a coherent story line of a discourse over a longer time span. Keller (2007: 16) states that narrative structures are those structuring moments of statements and discourses, which are related to each other in specific ways through patterns of interaction, classification and phenomenal structures. In making use of narrative structures, discourses become stories with a coherent plot, which can be convincingly communicated to a broader audience. Keller argues that collective actors (for instance social scientists, journalists, NGOs) may form a coalition to raise public awareness of a problem by using a common basic story line. In my analysis of discourses on the war in Northern Uganda, I outline different narrative structures used by proponents of competing discourses. I further show how the discourses and their story lines have developed and been altered over time due to shifts in power structures and interpretation hegemonies, and in order to accommodate recent events.

For my analysis, I selected the most relevant, i.e. the most commonly cited texts, most of which were written by social scientists (commonly cited popular texts, books and films were also included, albeit to a minor extent $)^{57}$. Social scientists and academic institutions, among many other social actors, produce knowledge, which - depending on the economic and political constellations - may be accepted as truths. According to Foucault (cited in Keller, 2006: 126f.), knowledge is always a form and effect of power, a power to establish one version of reality or truth, while excluding others. In my analysis, I was interested to find out not only how different narratives and types of interpretation of the war varied, but also how hegemonies of interpretation changed over time ("dispositive analysis", cf. Keller, 2007: 25ff.).

In the following, I will first reconstruct the elements of Ugandan history which are necessary to understand the war in Northern Uganda. Thereby, I will present the hegemonic version, i.e. relatively uncontested historical facts, but also point out those aspects, which are highly disputed ${ }^{58}$. I will start my analysis by tracing the (proclaimed) origins of the war to the times of British colonial rule in Uganda ${ }^{59}$, and end by looking at the most recent debates, which directly concern the armed conflict and its impacts on Northern Uganda.

57 In recent years, there has been an explosive increase in research and literature dealing with the war in Northern Uganda, not all of which could be sighted for the analysis.

58 The analysis of all the contested elements would be enough material for a study of its own. As my main focus lies elsewhere, I will concentrate on the major points of debate, which are relevant to understanding interpretations of the war in Northern Uganda.

59 At this stage I will not focus on the precolonial era - for a summary of precolonial developments in Northern Uganda see Finnström, 2003: 87ff. and Girling, 1960: 135ff.; cf. also Chap. 4. 


\subsection{Colonial Times: Dominant Interpretative Schemes}

1884 marked the beginning of the British Protectorate in Uganda. It is generally undisputed that the colonial rule by the British laid the foundation for many of the subsequent conflicts in postcolonial Uganda - particularly along ethnic and regional lines. Branch (2011: 45) states that "ethnicity and the state have been in a dynamic, mutually dependent relationship ever since the establishment of indirect rule in the early twentieth century". Similarly, Ndikumana and Nannyonjo (2007: 17) remark that postcolonial antagonisms "were the outcomes of a colonial system of political control that transformed ethnicity from a latent factor into a primordial determinant of access to power and economic advancement".

In the literature on Northern Uganda, the origins of the contemporary conflicts are often traced back to colonial times. The dominant interpretative scheme suggests that from the beginning, the British privileged the Southern ethnic groups. In colonial discourses, ethnic groups in Northern Uganda like the Acholi were seen as inferior to the ethnic groups in Southern and Central Uganda, particularly the Baganda. This was largely due to their different form of political organization (Finnström, 2006a: 203f.). While the Baganda and other ethnic groups in the South like the Bunyoro, Batoro, Ankole and Busoga (cf. Tripp, 2010: 42) were organized as centralized kingdoms - which thoroughly impressed the British (Vincent, 1999: 111) - many groups in the North had only very loose and decentralized forms of political organization beyond the level of the lineage, and some did not even perceive themselves as members of one ethnic group at all. Under British colonial rule the Buganda Kingdom was given a privileged role in governing the country - Vincent (1999: 109) even goes as far as to say that "colonial sovereignty rested on Baganda sub-imperialism" - which has led to a complicated role of Buganda in the postcolonial state until today. As Tripp (2010: 42) asserts, this legacy of privileged treatment under and collaboration with the British during colonialism has made Buganda "a thorn in the side of every post-independence Ugandan government". ${ }^{60}$

According to the dominant interpretative scheme, the decentralized political systems of the Acholi and other Northern groups were not as easily adoptable to the colonial system of indirect rule as the more centralized kingdoms. Therefore, instead of relying on lineage heads and local chiefs (in Acholi: sg.: rwot, pl.: rwodi), the British installed their own 'government chiefs' who were responsible for collecting taxes and organizing communal labour in Acholiland on a central level, i.e. beyond the lineage. A common interpretation is that this policy eventually led to a disintegration of the different subgroups throughout Acholiland, and the importance of organizing in lineages decreased. At the same time, the central administration of Acholiland and the decreasing importance of the individual subgroups resulted

${ }^{60}$ On the special role of Buganda during colonialism and subsequent Ugandan politics see for instance Low \& Pratt (1960), Apter (1967) and Karlström (1996; 2004). 
in the emergence of an "Acholi consciousness" (Girling, 1960: 201), which has led some authors to conclude that the Acholi as an ethnic group were only created by the colonial administration. I will discuss this point in more detail below.

A further, commonly emphasized aspect in the literature is that the colonial administration effectuated massive changes in the local economic organization, mainly through the monetization of the economy and the introduction of cotton as a cash crop. The Acholi population, which formerly relied on subsistence farming, was forced to cultivate cotton in order to be able to pay taxes. For the same reason, the colonial state encouraged labour migration of Northerners to the South, where the main economic developments were centred. According to Branch (2011: 50), many Acholi were also recruited to become civil servants, and an educated Acholi elite started to emerge - a factor that is often neglected in the literature (see discussion below). After some initial hesitation the Acholi were also recruited in large numbers for the King's African Rifles (particularly with the onset of WWI) and semi-military services of the police and prison department (Finnström, 2006a: 204). This fact is always mentioned (and sometimes overemphasized) in the literature dealing with the war in Northern Uganda. In a typical vein, a report by the International Crisis Group notes that "[ $t]$ he Acholi in particular had been told by their colonial masters that they were born warriors, effectively transforming them into a military ethnocracy" (ICG, 2004: 2).

Some authors point out that after the Second World War, when the anti-colonial struggle started to emerge mainly in the South of Uganda, soldiers from the North including many Acholi were also deployed by the British to fight anti-colonial revolts (Tripp, 2010: 133). Mamdani (1983: 10) writes that "[ $t$ ] he colonial view that northerners were 'martial' peoples was simply racist hogwash; the simple truth was that northern peasants were put in uniform to crush the resistance of the southern peasantry."

In any case, the North-South divide of the country installed under the colonial administration (and the narrative, which constantly reemphasizes this fact) has had long-lasting consequences for the political history of Uganda and still plays a major role in the conflicts (and their interpretations) of the country today (Mamdani, 1976: 133; Ndikumana \& Nannyonjo, 2007: 16ff.). Similarly, ethnic classifications and ascriptions given to certain ethnic groups - such as claims that the Acholi are a militant ethnic group - have their origins in colonial ideologies, but have since profoundly shaped social relations in Uganda. As Vincent (1999: 109) states:

"Imperial times bred colonial places and the hegemonic moment reified languages and cultures, tribes and bounded districts, and codified them. In Uganda, this lasted for the first sixty years of the twentieth century. Not precolonial animosities but modern state formation bred ethnic and regional conflict."

In most points, the accounts of Ugandan colonial history converge. The dominant interpretative scheme acknowledges the devastating effects of colonialism and 
the basis it provided for subsequent ethnic tensions and conflicts. Ndikumana and Nannyonjo (2007: 16) summarize the three main channels through which the British colonial administration "sowed the seeds of ethnic antagonism": first, the division of Uganda into several ethnically demarcated areas and the privileged status given to the Baganda as collaborators in the administration of the country; second, the promotion of racial theories according to which some ethnic groups (i.e. the Baganda) were taken to be superior to other ethnic groups; and third, the concentration of economic and educational development in the South and the military power in the North of Uganda.

\subsection{Critical Debates on Colonial History}

In this section, I will point out debated matters and incongruities in the academic literature (and popular accounts) of Ugandan colonial history, which are relevant to understanding different analyses of the war in Northern Uganda. The first matter of debate concerns the origins of an 'ethnic consciousness' among the Acholi, the second concerns the origins and the extent of Acholi marginalization in the colonial (and later the postcolonial) state. Both ethnicity as well as the regionally uneven development in Uganda are often singled out as root causes of the war in Northern Uganda, which originated in colonial times. Evidently, both factors have shaped conflict realities and processes, and the way they are dealt with. However, as Vincent (1999: 110ff.) has pointed out in her analysis of the Teso war (in the Eastern part of Northern Uganda), one must always carefully dissect how these explanations have been constructed and culturally produced in academic as well as in public discourses (cf. Keller, 2006; 2007).

The first point of contestation concerns the question, whether the Acholi existed as an ethnic group before colonial times at all. This point is important because contemporary imaginations and interpretative schemes of a 'typical Acholi society' and of 'traditional Acholi culture' are frequently related to a pre-colonial past, and instrumentalized in national political debates (e.g. on cultural institutions) and in peace-building discourses, where 'cultural revival' is seen by some humanitarian organizations as a means to recreate social stability by reconstructing 'traditional cultural practices' (cf. for instance Pain, 1997 and Liu Institute for Global Issues, 2005). I will further discuss this point in chapter 4 .

Historians and anthropologists working in Northern Uganda have long debated whether the Acholi existed as a distinct ethnic group before colonial times. Some researchers (e.g. Allen, 2006: 26; Behrend, 1993: 23; Schäfer, 2008: 332; Vincent, 1999: 109) argue that the Acholi as an ethnic group were only created or reified by the colonial administration. Others, notably Atkinson $(1994,1999)$ as well as Dwyer (1972: 12) and authors in the Onyango-Odongo and Webster edition 1976 (the two latter both cited in Finnström, 2008: 52), trace the origins of the Acholi to 
precolonial times and claim that Acholi collective belonging is not (just) a colonial intervention.

The debate is partly about classifications and collective terms (e.g. when the ethnonym Acholi was first used and by whom), and about the related question, when a collective Acholi self-consciousness first began to emerge. Girling (1960: Chap. 9) claims that before colonial times, lineages and domains were the most relevant categories of social organization. With the arrival of the first missionaries and the onset of colonial rule, these bonds started to dissolve, while the individual household became the most important formation. At the same time, he argues, something like an overall "Acholi consciousness" was born (ibid.: 201f.). Finnström (2003: 63f.) explains the missionaries' role in creating this Acholi consciousness:

"The missionaries encouraged the production of various vernacular texts dealing with Acholi history and culture, in which Acholi writers played an important part along with the missionaries. (...) [A] variety of localized Acholi myths and histories were systemized, standardized, printed and distributed widely, with the potentiality of promoting a higher degree of cultural coherence throughout Acholiland."

It is not possible and also not necessary to come to a final conclusion as regarding the 'true' origins of the Acholi. What is important is to acknowledge, on the one hand, that today a (however-defined) collective Acholi identity exists and has powerful effects (cf. Chap. 4). Allen (1994: 115) expresses a similar thought when he argues that "in spite of their limitations as analytical devices, these old [ethnic] labels have the advantage of being categories used by actors themselves". On the other hand, one always needs to bear in mind that ethnic classifications like "the Acholi" imply static, primordial identities and disguise the fact, that these labels were - at least to some extent - reified as distinct categories only by the colonial administration (Allen, 1994: 113ff.; cf. Lentz, 2006). Particularly, when using ethnicity as an explanatory variable to explain the roots and processes of armed conflicts, differentiated analyses which go beyond emic conceptualizations are crucial (cf. Schlee, 2006; Turton, 2002; Nielsen, 2008). As I will later discuss, different discourses on the war in Northern Uganda attribute different relevance to ethnicity as a root cause of the conflict. While the official discourse reinforces the dominant interpretative scheme and primordial classification of the Acholi, the counter discourse is concerned to deconstruct and contextualize Acholi ethnicity, and opposes classifications of the war as an "ethnic conflict"

A second point of incongruity in the literature on colonial history, which to date has not gained much recognition, concerns the role of the Acholi in the colonial

${ }_{61}$ The official discourse largely reflects the NRM perspective and blames the war primarily on the LRA, while the counter discourse takes as more nuanced and critical stance and sees the war as the outcome of a complex political crisis (for a further differentiation of the two discourses, see Table 1 and discussion below). 
state. According to the dominant interpretative scheme, the Acholi were marginalized by the colonial administration and used only as cheap labour and as soldiers for the army (see for instance Finnström, 2008: 101f.; Schäfer, 2008: 331; Mamdani, 1983: 10; Doom \& Vlassenroot, 1999: 7f.). The resultant and still continuing economic and political marginalization of the North is commonly mentioned as a root cause of the conflict(s) in Northern Uganda (Vincent, 1999: 110ff.).

Branch (2011: 50), however, drawing on the works of Leys (1967), Sathyamurthy (1986) and Kasfir (1976), contends that the Acholi were not marginalized by the colonial state as has frequently been asserted. Instead, he argues that they were in fact overly included in the state, particularly in the civil service, and that it was thus their privileged position which led to the problems they faced later in postcolonial history. According to Branch (2011: 50),

" $t$ t]he Acholi ended up being overrepresented in both [i.e. in the civil service and the military/police], because of a British policy of recruiting northerners to put down southern rebellions and of the lack of profitable unskilled employment opportunities in Acholiland. This situation thus belies the oftenheard narrative that describes the Acholi as having been marginalized under colonialism, with their role restricted to providing military recruits; although the Acholi were indeed found in the security services, more important was their incorporation into the civil services and access to state resources. Marginalization cannot explain the roots of the conflicts in northern Uganda: instead, it is necessary to consider the particular way the Acholi were included in the state all the way until the purges undertaken by Idi Amin. For this reason, the exclusion of the Acholi in recent decades has to be seen in the context of the degree of privilege that they formerly enjoyed" (emphasis in original).

Branch's point is rarely taken into account in most analyses of the war. The dominant interpretative scheme - used both by social scientists (e.g. Shaw \& Mbabazi, 2008) and the Acholi population - reinforces the picture that Northern Uganda, and Acholiland in particular, have been marginalized since colonial times, and thus lag behind other regions of the country today (with regard to economic development, political representation in national politics, quality of school education etc.). The common contemporary classification of a war-torn and underdeveloped Northern Uganda and a prosperous, peaceful Southern Uganda has fundamentally shaped the perceptions of the Acholi people, and has (further) alienated them from the Museveni government ${ }^{62}$. The narrative of Acholi marginalization has also been

62 There are certainly many indicators, which suggest that economic developments and political representation have been and still are distributed very unevenly across Uganda. The IDP politics of the NRM government during the war, rumors of subsequent land grabbing by politicians from Kampala, which had been enabled through IDP policy, as well as the de-stocking of cattle by the army and the Karimojong in the 1980s and early 1990s have further reinforced this perception (van Acker, 2004: 344). 
Julia Vorhölter: Youth at the Crossroads

taken up by the LRA, which argues that the political and economic exclusion of the North has been one reason for its insurgency.

The hegemonic interpretation of Uganda's postcolonial history as an ongoing North-South conflict is a good example of a narrative, which has fundamentally structured Ugandan realities and which has caused tangible societal effects. Van Acker (2004: 342f.) brings this idea to the point, when he writes that " $[\mathrm{t}]$ he fact that the pattern of economic differentiation is more complex than a straightforward north-south antagonism does not deny its perceived existence". He further argues that

"Acholi perceptions of marginalization evidently present a picture of differentiation in Uganda that is not necessarily complete or accurate. (...) Rather than debating the accuracy of various arguments, however, what matters are the insights they offer into people's perceptions and the type of latent mobilizing power they convey for an entire generation spoon-fed on them" (ibid.: 344).

Ethnicity and marginalization along regional and ethnic lines are two themes which also dominate the narrative accounts of and have shaped Ugandan postcolonial history. I will turn to these in the following section. Again, I will present the dominant interpretative scheme, which is reflected in the literature I cited. Afterwards, I dissect how different discourses follow different argumentative schemes and narrative structures when analyzing postcolonial developments in the context of the war in Northern Uganda, and how different story lines emerge in the interpretation of the events, particularly after the fall of Amin.

\subsection{Postcolonial Developments: Dominant Interpretative Schemes \& Critical Debates}

In 1962, British colonial rule ended and Uganda became an independent African state. However, independence did not bring stability to the country. On the contrary, ethnic (and religious) antagonisms, widely agreed to have been created by the colonial rulers, manifested themselves in post-independence politics and divided the country (Branch, 2011: Chap.2; ICG, 2004: 2; Rubongoya, 2007: 19ff.; Ogenga Otunnu, 2002: 11f.). According to the dominant interpretative scheme, "ethnification" 63 was a central component of the political developments in Uganda between 1962 and 1986 (and until today). However, one has to bear in mind that

63 Finnström (2003: 98) defines ethnification as "the process of fragmentation, especially at play in situations of social unrest, social inequality and political turmoil, in which expressions of collective belonging are limited to a dominant discourse of more or less fixed stereotypes. Ideological constructions are institutionally reproduced, and ethnic categories unavoidably become politicised categories." 
ethnification alone cannot explain the complexities of the actual political processes in post-independence Uganda ${ }^{64}$ (Finnström, 2003: 98; 101f.). Some authors acknowledge that there were in fact many attempts by postcolonial Ugandan governments to prevent anti-sectarian politics, which, however, largely failed in practice and are thus not always acknowledged in public and academic discourses (Tripp; 2010: 43ff.; Mamdani, 2004: 200-217; Vincent, 1999: 111, and Van Acker, 2004: 341f.).

Upon independence, Milton Obote, a Langi from the North, became the first prime minister of Uganda and in 1963 the King of Buganda, Edward Mutesa II, became the first president of the state, demonstrating the privileged political status the Baganda had gained under the colonial administration. His rule, however, only lasted until 1966 when Obote abolished all kingdoms and Uganda became a one party state under the rule of Obote and his Ugandan People's Congress (UPC). Obote's break with Buganda is commonly interpreted as an attempt to weaken the power of Baganda and install a government and army dominated by Northerners. Ndikumana \& Nannyonjo (2007: 19), for instance, argue that Obote discriminated against the Buganda region "as a means of shifting the balance of power to the North", and thus perpetuated the ethnic tensions and the political divide between Northern and Southern Uganda, which had existed during colonial times. Tripp (2010: 43ff.) and Rubongoya (2007: 33ff), however, demonstrate that the reasons and courses of action behind the 1966 crisis were much more complicated than explanations based on simple ethnic or regional sectarianism would suggest (cf. also Branch, 2011: 53ff.). Among other things, both point to and offer a differentiated analysis of Ugandan party politics as a reason for the crisis.

In 1971, Obote's regime was overthrown by Idi Amin, an army officer of Kakwa origin from the West Nile Region. According to the dominant interpretative scheme ${ }^{65}$, Amin was initially welcomed by the majority of the population due to the increasing dissatisfaction with the Obote regime. However, he soon began to systematically oppress the Buganda as well as the Langi and Acholi who had made up the largest percentage of Obote's army. He also expelled the prosperous Asian business community (and all other Asians) from the country and institutionalized an economic system in which access to commodities depended on the religious and ethnic background of a person (Rubongoya, 2007: 51). The rapidly evolving corruption and nepotism, and the random killings of political opponents and people

${ }^{64}$ Mamdani (1976). for instance, offers a Marxist analysis of class formation in Uganda and its influence on the political developments.

65 The widespread interpretative scheme of Amin's regime - in Ugandan but even more in international (scholarly and popular) discourses - is often shaped by sensationalist accounts of his gruesome dealings with political opponents, his fanatical personality, and his devastating political decisions. Mamdani criticizes that the picture is more complex than these accounts would suggest. He writes: "[Their] sensational twist hides the ideological content. The trick is quite simple: a book on the Amin regime becomes a book simply on Amin, and instead of political analysis, we get an anecdotal biography" (Mamdani, 1983: 1). 
not belonging to Amin's ethnic group or not adhering to his religious beliefs (Amin was a Nubi Muslim) led to a fundamental breakdown of the Ugandan political, economic and social system. According to some estimates, up to 500,000 people died during his eight-year regime and several thousand fled the country (Schäfer, 2008: 333f.; Rubongoya, 2007: 45ff.). The literature on the war on Northern Uganda commonly mentions that the Acholi specifically suffered from a series of ethnic purges by Amin's troops. Branch (2011: 57) estimates that tens of thousands of Acholi (and Langi) civilians were killed during the time of the Amin regime, and that several members of the Acholi political elite fled into exile.

In April 1979, Amin was driven from office by the Tanzanian army supported by the Ugandan National Liberation Army (UNLA), which had been formed by exiled Ugandans who opposed the Amin regime. After short interim-governments by Yusuf Lule, Godfrey Binaisa and Paulo Muwanga (Tripp, 2010: 43), Milton Obote returned to power, claiming to have won the parliamentary elections in 1980. From the beginning, there was massive opposition against his regime as he was accused of having manipulated the elections, a claim which is widely accepted in most historical accounts. According to the dominant interpretative scheme, Obote then established patronage networks based primarily on Langi and Acholi loyalties, which had already served as an important cornerstone of his first regime. But in the 1980s, as there were less state resources to be distributed to loyal supporters, these clientalist structures were considerably weaker. Due to the resultant instability right from the beginning of his regime, the military became of foremost importance to Obote's hold on power. According to widespread perception, Langi and Acholi troops became overrepresented in the UNLA $^{66}$ (cf. e.g. Tripp, 2010: 134). Branch (2011: 58) reflects on the role of the Acholi in the newly formed government:

"Although certain prominent Acholi were incorporated into the new, Obote II, government, there was no return to the massive patronage machine of the Obote I regime, and there was no wide-scale political revival of the Acholi middle class. Indeed, given the years of economic ruin under Amin, the destruction wrought by the Tanzanian invasion, and the newly imposed International Monetary Fund (IWF) austerity measures, there was much less to distribute. Instead, Acholi were brought into the state principally through the military, and the UNLA officer corps again became heavily weighted toward the Acholi and Langi."

In 1981, Yoweri Museveni founded the National Resistance Army (NRA) and started to wage a guerrilla war against the Obote Government. The bulk of the fighting was carried out in the Luwero Triangle in Central Uganda. Museveni, a Munyankole from South-Western Uganda, sought the support of the local population. It is often stated that, throughout the course of the fighting, more and more

${ }^{66}$ Again, as in other accounts of postcolonial Ugandan history, one finds that ethnicity is singled out as the decisive factor in the analysis of army recruitment patterns. 
people willingly joined the NRA, and Museveni managed to build an alliance between Baganda and Banyarwanda migrant workers, indigenous peasants from other ethnic groups and refugees of Rwandan origins (Mamdani, 2004: 200ff.; Branch, 2011: 58f.). Some authors, for instance Mamdani (2004), classify Museveni's strategy as an effort to mobilize support for the NRA without appealing to ethnic identities, and thus as an attempt to overcome sectarian politics in Uganda. Others contest this interpretation. Branch (2011: 59f.), for instance, argues that the NRA framed its mission as a struggle against Northern ethnic power in the national state. According to Branch (ibid.: 60),

"the rebels also built support in Luwero by putting forth, not tribal ethnic commonality, but common ethnic regional identity, as Bantu southerners united against Nilotic northerners. The rebellion became the crucible in which the north-south divide took a central place in national politics."

The fighting in Luwero Triangle lasted until 1985. According to the dominant interpretative scheme, an estimated number of 250,000 to 300,000 people were killed by the UNLA, the national army under the command of Obote, and severe human rights abuses were committed including rape and torture (Schäfer, 2008: 335). It is commonly cited that the profound humiliations against the local population and NRA soldiers committed by Obote's army, believed to be largely consisted of Acholi and Langi, further deepened the antagonisms between Northern and Southern ethnic groups. Several authors therefore argue that the Luwero conflict and the ethnic hatred it conjured among Southerners particularly against the Acholi laid the cornerstone for the war in the North. In the words of Doom and Vlassenroot (1999: 9), "Luwero is the ghost that haunts the Acholi".

The accusations of having killed and raped thousands of innocent civilians during the Luwero fighting are heavily contested among the Acholi until today. In 2010, Olara Otunnu, an Acholi and the president (and later presidential candidate) of the UPC (Uganda People's Congress) party, caused an uproar in the media, when he demanded an independent inquiry into the killings in Luwero and thus called into question the taken-for-granted culpability of the Acholi (and Langi) from the North ${ }^{67}$. In a similar vein, critical social scientists like Ogenga Otunnu (2002: 12) have remarked that "[a]lthough the UNLA was a national and multi-ethnic army, the NRM/A held the Acholi exclusively responsible for the atrocities committed, and this disputed perception was to shape subsequent attitudes toward the conflict".

The events during the Luwero war, but also the repeated reporting of the proclaimed Acholi responsibility for the war crimes and the constant framing of the war as an ethno-political conflict, have profoundly influenced post-1986 social relations and politics in Uganda. As a report by the International Crisis Group states, " $\mathrm{t}]$ he effects of massacres on the psyche of all protagonists are central to the failure

67 See for instance: Khisa \& Nalugo (2010), Ngabirano (2010) and N.N. (2010b). 
Julia Vorhölter: Youth at the Crossroads

to overcome the cycle of ethnic retaliation after the NRA came to power" (ICG, 2004: 2). The discourse on Luwero is thus an example of how profoundly discourses and the dominant interpretative scheme they propose can shape reality. ${ }^{68}$

\subsection{Critical Debates on the Lead-up to the War}

In 1985, a split occurred within the UNLA when high-ranking Acholi generals initiated a military coup. It is generally uncontested that the Acholi accused Obote of favouring the Langi within the army. Rubongoya (2007: 55) writes that Obote "sought to purge the army of the Acholi elements while elevating his fellow Langis (...) Obote's commanders disproportionately deployed the Acholis to the frontline to face a strengthened guerilla force in the name of the National Resistance Army (NRA)." This eventually led to the coup commanded by Brigadier Bazilio Okello and General Tito Okello. In 1985, they took over Kampala and Tito Okello became the first Acholi president - however, only for a very brief period of time.

The events following Okello's rise to presidential power are heavily debated both, in the literature and in public discourses. Some authors, especially those with a proAcholi stance, claim that the Okello regime tried to unite different fighting factions and political parties and engaged in protracted peace negotiations with the NRM/A. They blame the NRA for the failed implementation of the peace agreement, which was signed between all fighting factions in Nairobi in December 1985, and accuse Museveni of having used the peace talks only as a means to prepare his own takeover of Kampala (Ogenga Otunnu, 2002: 12; Kiplagat, 2002; Allen \& Vlassenroot, 2010b: 9). As Ngoga (1998: 104) concedes, "the NRA had little interest in peace negotiations for anything but tactical purposes, when it was in any event on the brink of victory." To this day, the Acholi blame Museveni for having betrayed the peace agreement and for having unlawfully taken power from Okello who remains the only ever Acholi president ${ }^{69}$ (cf. van Acker, 2004: 340).

Other authors describe the situation prevailing in $1985 / 6$ very differently. They claim that Okello was unable to control his troops, had no clear political program, and was thus driven from office by Museveni and his NRA in January 1986 (Ndikumana \& Nannyonjo, 2007: 21; Rubongoya, 2007: 53ff.; Schäfer, 2008: 336f.). Contrary to classifying Museveni as the spoiler of the peace talks, these authors celebrate him as the 'savior' of a war-torn country. Schäfer (2008: 337), for instance, argues:

68 This is also reflected in public discourses. In one discussion I had with two students from Gulu University, for instance, my interlocutors claimed that Museveni and his supporters had rewritten Ugandan history to make it sound that Obote committed "so many" crimes in Luwero Triangle (field notes, 10.03.2010).

${ }^{69}$ This topic often came up in personal conversations about politics and the (illegitimate) rule of the current NRM government with my interlocutors in Gulu, who blamed Museveni for having taken power from the Acholi. 
"General Tito Okello hatte nur kurzfristig die Macht im Lande inne, denn bereits Ende Januar 1986 eroberte die NRA Kampala und Museveni übernahm offiziell die politische Führung. Die Acholi Soldaten gingen u.a. gegen Langi und Männer aus dem West Nil Gebiet vor, marodierende Truppen zogen durch Kampala (...) Okello konnte nicht einmal die in Kampala stationierten Streitkräfte unter seine Kontrolle bringen. Museveni wollte seine Visionen von neuen ökonomischen und politischen Entwicklungen in Uganda verwirklichen, wozu neben ehrgeizigen Wirtschaftsreformen, die politische Konsolidierung und Stabilisierung sowie die Befriedung und Demokratisierung zählten." ${ }^{0}$

Similarly, the media and the international community lauded Museveni's ascent to power, and for many years celebrated him as a new type of African leader, who respected human rights and followed Western development imperatives (Hansen \& Twaddle, 1991: 1). Omara-Otunnu (1992: 446) reflects on the different perceptions of the post-Obote phase:

"The reaction of the population to the defeat of Okello's junta varied according to geographical regions, thereby reflecting in large measure the main structural imbalances in the country. However, the occasion was widely hailed as marking the dawn of a new era by the intelligentsia and the media: they announced that Museveni would usher in genuine democracy and the enjoyment of human rights for the majority of Ugandans, and it was their views that certainly helped to shape international opinion about the character and purpose of the new regime."

While it is generally accepted that Museveni's rule brought an end to the fighting in Central and Southern Uganda, one also has to acknowledge that it marked the beginning of the long lasting armed conflict in Acholiland, as well as in other 'peripheral' regions of Uganda such as West Nile, Karamoja, Teso and Western Uganda $^{71}$, which is often ignored in uncritical accounts of the Museveni regime. The events surrounding Museveni's ascent to power (and their interpretations) are of crucial importance in order to understand and analyze the conflicts arising in

70 "General Tito held power only for a short while, because already at the end of January 1986 the NRA seized Kampala and Museveni officially took over the political leadership. The Acholi soldiers attacked Langi and men from the West Nile Region, among others, marauding troops moved through Kampala (...) Okello was not even able to control the troops stationed in Kampala. Museveni wanted to realize his vision of new economic and political developments in Uganda, including ambitious economic reforms, political consolidation and stabilization as well as pacification and democratization." (Translation: J.V.)

${ }^{71}$ For more details about these other armed conflicts see for instance Finnström (2003: 105f.), Schäfer (2008: 352 ff.), Bogner \& Rosenthal (2012: 118ff.), Behrend (2007), Knighton (2003), Leopold (2005), Beyond Juba Project (2008). 
Julia Vorhölter: Youth at the Crossroads

Northern Uganda in the mid-1980s and the subsequent 20-year war in the North, which I will turn to in the following.

In my analysis, I will first outline the historical developments since 1985, and briefly point out those 'facts', which are debated in the literature. In a second step, I will then introduce the two major, competing discourses which exist on the war in Northern Uganda in greater detail.

\subsection{The War in Northern Uganda}

For people in the North, the time after Museveni's National Resistance Movement/ Army (NRM/A) took over the government in 1986 "was a strange time of holding one's breath while preparing for the worst" (Dolan, 2009: 43). While some of the former UNLA soldiers demobilized and resettled in their homes, others refused to disarm and accept the new Museveni government and started to regroup. The latter withdrew to Southern Sudan where they formed the Ugandan Peoples Democratic Movement /Army (UPDM/A). In the course of 1986, fighting resumed in Northern Uganda between the NRA and the UPDA. This marked the beginning of the subsequent war, which was to last more than 20 years.

Again, the events following Museveni's ousting of Okello and the withdrawal of the Acholi from Kampala are disputed in the literature. Some authors claim that many of the Acholi soldiers who had served in the previous government forces found it difficult to adjust to a peaceful life back in their villages and felt alienated towards their former communities. Due to the long and brutal fighting in Luwero these soldiers had become "internal strangers" (Behrend, 1993: 23f.), or as Schäfer (2008: 339) puts it more drastically, had become "brutalized". Due to their unwillingness and inability to reintegrate themselves into their communities and start a life as farmers, many of these soldiers joined the UPDA. Schäfer (2008: 338) depicts the situation of the returnees as follows:

"[I]hre Verrohung durch die von ihnen verübten Gewaltakte und die Perspektivlosigkeit trieb zahlreiche Demobilisierte in die Hände der Uganda Peoples Democratic Army (UPDA), die geflohene Acholi-Soldaten im SüdSudan kurz vorher gegründet hatten. Mit Gewaltexzessen versetzte die UPDA die Bevölkerung Nordugandas bald in Angst und Schrecken." ${ }^{72}$

\footnotetext{
"Their bestialization through the violent crimes they had committed and their lack of future prospects drove many of the demobilized soldiers to join the Uganda Peoples Democratic Army (UPDA), which had been newly founded in Southern Sudan by Acholi soldiers, who had fled Northern Uganda. The UPDA soon began to terrorize the population in Northern Uganda with acts of excessive violence" (Translation: J.V.).
} 
The brutal behavior Schäfer (and also Behrend) attribute to the newly formed UPDA is not confirmed in other accounts which claim that the UPDA was well respected and generally supported by the local population (e.g. RLP, 2004: 5). ${ }^{73}$

Instead, some authors paint a very different picture of the situation which unfolded in Northern Uganda in 1986. Ogenga Otunnu (2002: 13), for instance, claims that the majority of Acholi soldiers "heeded the appeal by the government to hand over their arms and demobilize". He and others blame the escalation of the situation in Northern Uganda on Museveni's troops, who followed the withdrawing Acholi soldiers to the North - officially to counter the burgeoning insurgencies and pacify the country. Ogenga Otunnu (2002: 13) writes that

"anxieties escalated when the NRA began to commit human rights abuses in the name of crushing a nascent rebellion. Over time NRA soldiers plundered the area and committed atrocities, including rape, abductions, confiscations of livestock, killing of unarmed civilians, and the destruction of granaries, schools, hospitals and boreholes escalated. These atrocities were justified by some as revenge for the 'skulls of Luwero."

It is widely accepted that the conduct of the NRA which had been a relatively well-disciplined army during its guerilla war in Luwero deteriorated severely when its soldiers reached Northern Uganda and were confronted with their former enemies $^{74}$. Revenge killings, also against non-combatants, and cattle looting occurred on a large scale and created mistrust of the new government and its troops among the local population (ICG, 2004: 3). Some authors (e.g. Finnström, 2003: 104ff.; 2005: 100) claim that it was the misbehavior of the NRA that actually led the Acholi people to support and thus strengthen the UPDA and other emerging rebel groups (see below). A report by Human Rights Watch quotes an eye witness of the happenings by the name of Nyeko as follows:

"'National Resistance Army soldiers would do all they could to make things difficult here [in Gulu and Kitgum]. They would defecate in water supplies, and in the mouths of slaughtered animals. They would tie people's hands behind their backs so tightly that people would be left paralyzed. They went into villages, and took guns by force. They looted Acholi cattle, and did nothing to prevent [cattle raiders from the Karamajong district] from stealing the rest. Over three million head of cattle were soon lost, and it made the people embittered"' (cited in HuRiWa, 1997: 32).

73 In personal conversations I had with my interlocutors (esp. with Florence and Lioba), I was often told that the UPDA is generally remembered by the Acholi as a well-behaved army which warned the civilian population before it launched its attacks on the NRA.

74 This claim is frequently voiced particularly with regard to soldiers belonging to the FEDEMU unit, a former anti-Obote insurgency comprising many Baganda from the Luwero triangle, which committed severe human rights abuses including massacres of the civilian population (Doom \& Vlassenroot, 1999: 14ff.; Gersony, 1997: 23ff.). 
Nyeko further explains how many ex-soldiers feared ethnic purges similar to those carried out by Idi Amin:

"One further event sparked the beginnings of the Acholi rebellion: the National Resistance Army high command issued a directive over Radio Uganda, calling on Acholi ex-soldiers to report to Mbuya army headquarters within ten days. Nyeko observes that to many Acholi, this order was frighteningly reminiscent of the radio order that presaged one of Idi Amin's massacres of Acholi soldiers, and it inspired many additional Acholi ex-soldiers to leave Uganda to join their comrades who had fled to Sudan: 'The order was just like in Amin's days,' says Nyeko. 'The Acholi boys said to each other, 'This time we are not going to die like chickens. Let us go to Sudan and join our brothers, and fight to save the Acholi'”' (ibid.).

Whatever happened exactly and whoever is to blame, what one can unanimously derive from the above accounts is that the period particularly between August 1986 and May 1988 was one of great turmoil in Northern Uganda (cf. Dolan, 2009: 41). This was also due to the emergence of different rebel groups which managed to mobilize popular support by combining political aspirations with spiritual motivations.

In August 1986, a religious movement - the Holy Spirit Mobile Forces (HSMF) had been founded by Alice Auma, the spirit medium of the ghost Lakwena ${ }^{75}$. There are various accounts of the HSMF, ranging from meticulous academic analyses to sensationalist media depictions, which I will not present in detail here. The following is just a summary of the most essential and relatively uncontested 'facts' as maintained by the dominant interpretative scheme. According to this scheme, the HSMF were opposed not only to the NRA/M but also to the proceedings of the UPDA. Their original aim was to overthrow the government of Museveni and establish a new moral order in Uganda. Apparently founded as an egalitarian, non-ethnic and gender-equal movement, which combined Christian doctrines with local beliefs, the HSMF managed to attract many followers. Up to 10,000 people - men and also some women from different ethnic and social backgrounds - are said to have joined the "March on Kampala" (Behrend, 1993: Chap. 6) where the government was to be taken over. Before reaching Kampala, however, the HSMF were defeated by the NRA in Jinja in November 1987. During the march, thousands of the HSMF fighters lost their lives. After the defeat of the HSMF, Alice Auma's father Severino Lukoya set up a rebel movement based on the ideas of the HSMF but never attracted as many followers (Behrend, 1993; Finnström, 2003: 109ff.; Schäfer, 2008: 339ff.).

It appears that around the same time, Joseph Kony, a former UPDA fighter, founded another spiritual military movement which was later to become the Lord's

\footnotetext{
75 The HSMF, and especially the spiritual beliefs and the role of ghosts within the movement, have been thoroughly analyzed by Behrend $(1991 ; 1993 ; 1998 ; 1999)$ and will not be further elucidated in this book.
} 
Resistance Army (LRA). There is some debate regarding the overlapping of the different rebel movements and the extent of commonalities they had. What is relatively uncontested is that in 1988, the UPDA signed a peace agreement with the NRA, so that Kony's movement eventually remained as the main opposition force to the NRA. Some of the former UPDA rebels who refused to abide by the peace agreement joined Kony (Dunn, 2004: 140). Different narratives exist about the events that took place after the 1988 peace agreement, which I analyze in detail below. The smallest common denominator of these narratives on the developments from 1988 until today might be summarized as follows.

Over time, Kony's LRA resorted to tactics more and more atrocious and which were no longer solely directed at the NRA but also affected the local population. The LRA forcefully recruited children, youth and adults, looted food and other belongings from the Acholi population, and massacred local people suspected of supporting the NRA. The NRA/UPDF ${ }^{76}$, on the other side, also committed severe human rights abuse, among other things by forcibly displacing the people of Northern Uganda into so-called "protected villages" (see below). Over the next two decades, the Acholi population suffered from a protracted war situation in which periods of physical violence alternated with periods of relative $\mathrm{calm}^{77}$. Different peace initiatives failed (for a detailed description, cf. ICG, 2004, 2010; Finnström, 2003: 124f.; Rodriguez Soto, 2009; Lamwaka, 2002; O'Kadameri, 2002; Obita, 2002; Otto, 2002; Allen, 2010; Brubacher, 2010; Atkinson, 2010).

In August 2006, a first peace agreement was signed between the LRA and the Ugandan government, followed by further peace agreements in April and June 2007 and February 2008, which effectuated a tentative end to the fighting. The peace talks, held in Juba, Southern Sudan, did not however lead to a final success as leading commanders of the LRA refused to sign the ultimate peace deal (Allen \& Vlassenroot, 2010b: 17ff.). Especially the involvement of the International Criminal Court (ICC), which was called upon by Museveni in 2003 to "investigate the situation concerning the Lord's Resistance Army" (press release ICC, 29.01.2004 cited in Allen, 2006: 1), was taken by many to have had a negative effect on the peace talks (e.g. Mamdani, 2012: 20). Somewhat contrary to the former policy of the Ugandan government to grant amnesty to LRA returnees if they agreed to cease all insurgencies, the ICC had issued arrest warrants against Joseph Kony and four other high-ranking LRA officers in 2005 (for an in-depth discussion on the debates surrounding the involvement of the ICC in Uganda see Allen, 2006).

Since 2006, Northern Uganda has experienced relative peace while the LRA is continuing its attacks in the DR Congo and the Central African Republic (ICG, 2010; 2011). The 20 years of war have had devastating effects on the Acholi popula-

76 With the introduction of the 1995 Constitution, the NRA was renamed to Uganda Peoples' Defense Forces (UPDF).

77 Dolan (2009: 41ff.) distinguishes between seven distinct phases of the war between 1986 and 2006 involving an overall gradual intensification of violence with periods of relative calm in between. 
tion and the region of Northern Uganda as a whole. Thousands of people have been killed, several thousand abducted and well over a million displaced ${ }^{78}$. The economy has been ruined and health, education and other social services have broken down. However, it is generally acknowledged that due to the heavy presence of national and international development organizations, post-war rehabilitation in Northern Uganda has proceeded quite rapidly, at least in the urban centers of Gulu and Kitgum. The IDP camps have officially been closed and many of the people who had been forced to settle there have returned to their original villages (IDMC, 2010: $74)^{79}$. Although generally the situation is quite calm and people are relieved that the security situation has improved, there are also several challenges which could lead to a large scale eruption of new conflicts in the medium-term (Allen et al., 2010). The most pressing issues currently affecting Northern Uganda are land wrangles among the returning population, the continuing (perceived) economic, social and political marginalization of the North compared to the rest of Uganda, which was intensified through the long period of war, and the growing, nationwide political tensions and dissatisfaction with the regime of Museveni throughout Uganda (ICG, 2012).

\subsection{Critical Debates on the War: Official Discourse versus Counter Discourse}

In the preceding pages, I have summarized important dates and events in Ugandan political history from colonial times until today. I have pointed out both relatively uncontested interpretative schemes as well as disputed matters, which are relevant to understanding the war in Northern Uganda and its various interpretations. I will now look more closely at these various interpretations. Following Finnström (2008: Chap. 3) and Dolan (2009), I differentiate between two different meta-narratives ${ }^{80}$ about the war in Northern Uganda ${ }^{81}$ : The official discourse is propagated by hu-

78 It is impossible to provide exact figures. Estimates vary heavily depending on the discourse and the speaker.

79 Some have also decided to stay near the trading centers, i.e. the former camps, because they have better access to services there. Others did not, in fact, have the option to return to their villages, especially elderly people, who lost their family and thus have no one to take care of them and no place to return to in the villages.

80 Finnström and Dolan both use the term "narrative" to refer to the two conflicting interpretations of the war in Northern Uganda. In my analysis, however, I have decided to use the term "discourse" instead as it better captures the complexity and scope of the two positions. Both, the official and the counter discourse are made up of several sub-discourses, which I reconstruct in my analysis to show how they come to form a larger discourse.

81 In doing so, one needs to acknowledge that different positions taken by different authors concerning the analysis of the conflict do not always neatly map out onto coherent discourses. There are several sub-discourses, and not all authors can clearly be assigned to one of the two discourses on the war at all. 
manitarian organizations, the Ugandan NRM government as well as large parts of the Ugandan population outside of Northern Uganda, and for a long time has also featured prominently in academic publications. Typical examples of the official discourse are the texts by Schäfer (2008), Eichstaedt (2009); McDonnell \& Akallo (2007), De Temmerman (2001), Green (2009) and the films by Invisible Children (esp. Rough Cut (2006) and Kony 2012 (2012)). In a modest version, the official discourse is also reproduced by Gesony (1997) and Shaw \& Mbabzi (2008).

The counter discourse, on the other side, has recently gained acknowledgement through the voices of Acholi politicians and intellectuals as well as through several recent publications by critical scholars who have carried out extensive field research in Northern Uganda. The most prominent academic representatives of the counter discourse are Sverker Finnström, Chris Dolan, Adam Branch and most of the authors in the edition by Allen \& Vlassenroot (2010a). Some aspects of the counter discourse are supported by Westbrook (2000) and Van Acker (2004). After having studied the literature on the war in great detail, I regard the latter discourse as more substantiated and convincing. As this is reflected in my analysis of the two discourses, the reader should be aware of my own standpoint and take it into account.

Following Keller (2007: 14ff.), I have analyzed the phenomenal structures of the two competing discourses. Thereby, I have differentiated between central analytical dimensions or categories which come up in both discourses, and their contents, i.e. the perspective the respective discourse represents and the arguments it puts forth. The results of my analysis are summarized in the following table and discussed more extensively in the following text. 
Table 1: Contrasting Perspectives on the War in Northern Uganda

\begin{tabular}{|c|c|c|}
\hline \multirow{2}{*}{ Dimensions } & \multicolumn{2}{|c|}{ Contents: Conflict Analysis } \\
\hline & Official Discourse & Counter Discourse \\
\hline $\begin{array}{l}\text { 1. Causes / Origin } \\
\text { of the War? }\end{array}$ & $\begin{array}{l}\text { - Ethnicity } \\
\text { - North-South antagonism } \\
\text { - Spiritual/religious beliefs }\end{array}$ & $\begin{array}{l}\text { - Political and economic griev- } \\
\text { ances } \\
\text { - Complex historical develop- } \\
\text { ments }\end{array}$ \\
\hline 2. Who is to blame? & - Mainly the LRA & $\begin{array}{l}\text { - Multiple actors on the local, } \\
\text { national and international level }\end{array}$ \\
\hline $\begin{array}{l}\text { 3. Need for Action? } \\
\text { Solutions? }\end{array}$ & $\begin{array}{l}\text { - Military solution, i.e. defeat of } \\
\text { LRA } \\
\text { - Humanitarian intervention to } \\
\text { help the Acholi 'victims' }\end{array}$ & $\begin{array}{l}\text { - Political solution, i.e. peace } \\
\text { talks and peace agreement } \\
\text { - Sustainable changes in Ugan- } \\
\text { da's political landscape }\end{array}$ \\
\hline $\begin{array}{l}\text { 4. Interpretations } \\
\text { and value attri- } \\
\text { butions? }\end{array}$ & $\begin{array}{l}\text { - Moralizing approach } \\
\text { - Conflict as a humanitarian crisis }\end{array}$ & $\begin{array}{l}\text { - Analytical approach } \\
\text { - Conflict as a political crisis }\end{array}$ \\
\hline $\begin{array}{l}\text { 5. Major repre- } \\
\text { sentatives / pro- } \\
\text { ponents of the } \\
\text { discourses? }\end{array}$ & $\begin{array}{l}\text { - NRM/UPDF } \\
\text { - US Government } \\
\text { - Aid industry } \\
\text { - Large parts of the Ugandan } \\
\text { population outside of Northern } \\
\text { Uganda }\end{array}$ & $\begin{array}{l}\text { - Critical scholars } \\
\text { - Acholi intellectuals and politi- } \\
\text { cians on the local and national } \\
\text { level } \\
\text { - Acholi diaspora } \\
\text { - Acholi population }\end{array}$ \\
\hline $\begin{array}{l}\text { 6. Positioning } \\
\text { of key actors: } \\
\text { a) Museveni } \\
\text { (as head of NRM } \\
\text { Government \& Chief } \\
\text { Commander of UPDF) }\end{array}$ & $\begin{array}{l}\text { - 'Savior' of war-torn Uganda } \\
\text { - 'Developer' } \\
\text { - Ally in the "war on terror" }\end{array}$ & $\begin{array}{l}\text { - Spoiler (of peace talks) } \\
\text { - Profiteer of the war - political } \\
\text { and economic incentives to } \\
\text { continue fighting }\end{array}$ \\
\hline $\begin{array}{l}\text { b) LRA } \\
\text { (Motives/ldeology? } \\
\text { Extent of popular } \\
\text { support? Extent of } \\
\text { child abductions?) }\end{array}$ & $\begin{array}{l}\text { - 'Irrational barbarians' } \\
\text { - Army of 'child soldiers' } \\
\text { - No political agenda } \\
\text { - No support by Acholi popula- } \\
\text { tion }\end{array}$ & $\begin{array}{l}\text { - Complex political, religious and } \\
\text { spiritual motives } \\
\text { - Army of abductees and volun- } \\
\text { teers; fewer 'child soldiers' than } \\
\text { commonly assumed } \\
\text { - Political agenda, which reflects, } \\
\text { to some extent, the grievances } \\
\text { of many Acholi }\end{array}$ \\
\hline
\end{tabular}


The official discourse labels the war as a result of ethnic conflict in Uganda since colonial times as well as a result of 'irrational, brutal, spiritual rebels', which emerged in Northern Uganda in the 1980s (cf. Finnström, 2006a: 202f.; 2008: 68; Leopold, 1999: 221f.). In Finnström's words, "the typical depiction has been a one-sided and sometimes eroticizing focus on the various Holy Spirit rebel movements, and thus on the religious, even pseudocultural, aspects of the war" (2008: 63). By overemphasizing factors such as ethnicity and spiritualism, and by blaming the war primarily on the LRA, it is de-politicized and the 'real grievances' by the Acholi population are ignored. The official discourse furthermore conveys a highly moralized image of the conflict, which concurs with more general, international perceptions of Africa as a continent of crisis, war and human suffering. According to Branch (2011: 45/2012), this has led to equally moralized interventions by the international aid regime with largely harmful consequences. Proponents of the official discourse favour a military solution to end the war. They encourage the attempts by the US government and army to support the UPDF in their fight against the LRA (cf. Atkinson et al., 2012). Unlike most proponents of the counter discourse, they still regard Museveni as a trustworthy partner and an ally of the West in development initiatives and the "war on terror", and not as one of the prime conflict actors. In sum, the official discourse pinpoints the roots of the conflict in ethnic divisions, depicts the crisis as humanitarian rather than political, views the Acholi populace as helpless victims rather than political agents and citizens, and looks mainly at the LRA and to a lesser extent the Ugandan government and army as conflict actors, thereby failing to ignore the broader complexities of the war.

In contrast, the counter discourse argues that the war in the North is highly complex, essentially politically motivated, and must be historically contextualized. It cannot be reduced to an ethnic conflict, or to a rebel insurgency led by a mad and barbarous leader. Rather, one needs to look at a range of different conflict actors with very different (and sometimes changing) motives. In order to understand the length and complexity of the war, one has to consider not only the local and national, but also the regional and international dimension of the conflict. Relevant aspects include the role of the Sudanese government in supporting the LRA and, more generally, the proxy wars fought between Uganda, Sudan and Congo; the global "war on terror" and the labeling of the LRA as a terrorist organization by the USA and the Ugandan government, which legitimated the extensive (military) support the US government provided to the Ugandan government army in their fight against the LRA; and the internationalization of the conflict resolution and the subsequent involvement of the UN, Western states, and international humanitarian and development organizations ${ }^{82}$. In this spirit, the counter discourse frames the LRA as a political (rather than irrational, spiritual) actor, and blames the war in

82 For a more detailed analysis of the regional and international dimension of the conflict see Prunier, 2004; ICG, 2004: 24ff.; ICG, 2010; Dunn, 2004; Mwenda, 2010; Perrot, 2010; Branch, 2011; Finnström, 2008: 112ff.. 
the North not only on LRA violence, but also on the irresponsible and intentional warfare by the Ugandan government and its uncritical support by the international community (cf. Branch, 2011; 2012). Rather than lamenting the humanitarian crisis and lauding the efforts by humanitarian organizations to stop it, the counter discourse takes a critical stance on the complex and politically-intended reasons for the massive human suffering, which Chris Dolan (2009) has labeled "social torture". He summarizes his idea of "social torture as counter narrative" as follows:

"Social Torture is a counter-narrative which embraces complexity and rejects oversimplification. The range of local, national and international actors involved, the intersection of multiple economic and political motivations with psychological needs arising from cycles of oppression and subordination, and the transnational nature of justificatory public discourses and value systems, cannot be easily accommodated in the depoliticizing binary oppositions (such as 'internal-external', 'greed-grievance' and 'rational-irrational') which underpin the mainstream discourse of internal war" (Dolan, 2009: 252).

The counter discourse favors a political solution to end the war. It argues that only sustainable changes in Uganda's political landscape will prevent further violence in the long run.

The official discourse and the counter discourse are exemplary for the many controversies on and conflicting interpretations of the war in Northern Uganda, not all of which can be neatly assigned to one of the two discourses. In the growing amounts of literature on the war, debates have become increasingly blurred. The most contested issue is the role and image of the LRA/LRM ${ }^{83}$. As Dolan (2009: 74) states,

"[a]nyone attempting to assess the role of the LRA in northern Uganda is faced with a number of ambiguities, particularly concerning its composition and the extent of civilian support and link with the LRM. They are also faced with a media which fuels rather than resolves these ambiguities."

I will turn to this matter in more detail in the following section.

\subsubsection{The Role of the LRA}

Different accounts of the role of the LRA reflect different understandings of the war, its root causes and the reasons for its continuation. Therefore, I want to discuss this matter in more detail. When assessing matters such as the political or spiritual motivation of the LRA, the magnitude of its child abductions, the extent of local civilian support, and the (in)sanity of its leader, diverse images of the rebel organi-

83 Some authors, notably representatives of the counter discourse, who want to stress the political character of the LRA, refer to the organization as LRM - Lord's Resistance Movement - which is the self-designated name of the political wing of the LRA. 
zation emerge. In the following, I will summarize the major debates surrounding these matters and thereby give an overview of the different positions taken by different authors on the war.

The first matter of debate concerns the proclaimed motives of the LRA for its insurgency in Northern Uganda. Some authors (for a typical example see Eichstaedt, 2009), especially the local and international media as well as some human rights organizations have portrayed the LRA as an irrational and absurd rebel organization led by a mad leader, which is fighting for no comprehensible goal at all (cf. van Acker, 2004: 336). This image is also conveyed in films, most prominently those by the US-American organization Invisible Children (see below). Others claim that the LRA is a Christian fundamentalist organization which wants to rule Uganda on the basis of the Ten Commandments (cf. Finnström, 2008: 108ff.; HuRiWa, 1997: 31). Sensationalist portrayals of the LRA also like to point to its spiritual elements, which can be traced back to its origins or more correctly other spiritual movements such as the HSMF, and which still serve as a signboard for the LRA. In this regard, uncritical analysts often do not differentiate between the different rebel groups which existed in Northern Uganda in the first phase of the war, and the diverse motives and tactics they each pursued. In recent years, several critical scholars have argued convincingly that the LRA is by no means an irrational and mad movement (see for instance Titeca, 2010). As a report by the Refugee Law Project maintains,

"[a]lthough the LRA is often portrayed as a band of criminals, such a characterisation is clearly inaccurate for a group that has wreaked havoc in northern Uganda for the past 17 years. Not only are its tactics appallingly effective, but the LRA also has significant military ability" (RLP, 2004: 21).

Sophisticated historical analyses of the insurgencies point to the differences between the spiritual and political movements (Finnström, 2006a) which responded to two different crisis faced by Acholi - an internal crisis (cf. Behrend, 1993: 36ff.) and a national crisis (Branch, 2010: 25). They also differentiate between the extents to which the different rebellions were supported by the local population (Behrend, 1993; 1999; Omara-Otunnu, 1992: 455ff.). In this regard, the UPDA and HSMF rebellions are clearly distinguished from the LRA and seen as having been supported by the majority of Acholi as they addressed their grievances and fears. This is also stated in a report by the Refugee Law Project which argues that

"[i]n retrospect, both the UPDA and HSM were similar in that they tried to mobilise popular grievances in a struggle against the new government. Although the former was more about capturing political power and the latter more about rejuvenating Acholi society, they both articulated reasons for rebellion that most Acholi sympathised with at the time. These popular causes can be summarised as follows: they feared reprisals for what many perceived to be Acholi led massacres in the Luwero Triangle during the early 1980s; they were upset at their loss of political and economic power as a 
result of Museveni's breaking of a 1985 power-sharing agreement and destructive cattle raids that they believed were sponsored by the NRM; they were afraid the new government - believed to be controlled exclusively by Western Ugandans - would marginalise them after their dominance in the national army; they were defending themselves against atrocities committed by certain battalions of NRA troops in 1986-7; and they saw violence as the only means to address these grievances after witnessing Uganda's successive violent power struggles since independence. Since they were trying to gain popular support, neither the UPDA nor the HSM committed significant atrocities against its own civilians" (RLP, 2004: 5).

The existence and scope of a political ideology within the LRA is one of the greatest controversies in portrayals of the LRA, and arguably a very complex matter (RLP, 2004: 15). As stated above, many analysts simply refuse or fail to grasp even the possibility that the LRA could be motivated by a political agenda. The violent tactics the LRA has adopted, which have caused inexplicable suffering among the civilian Acholi population, have led many to refuse to try to understand possible reasons behind it. This dominant attitude is captured very well in the following statement by the International Crisis Group (2004: 5): "The LRA is not motivated by any identifiable political agenda, and its military strategy and tactics reflect this".

In fact, it is not easy to pin down the motives behind the LRA's fight ${ }^{84}$ (Doom \& Vlassenroot, 1999: 20). However, different authors have recently tried to unravel the "myth" behind the LRA (Allen \& Vlassenroot, 2010a), and take seriously the political aspects of the war, which reflect real grievances and concerns by the Acholi population and which have been addressed - however defectively and untransparently - by the LRA. Social scientists such as Sverker Finnström, Chris Dolan, Adam Branch, and Tim Allen have convincingly demonstrated that it is important to acknowledge that, besides its spiritual and religious agenda, which have been overrepresented in the official discourse, the LRA also pursued a political agenda (Dolan, 2009: 90ff.). Against the common claim that, even given the existence of a political program, the LRA has been unable or unwilling to communicate it (Doom \& Vlassenroot, 1999: 26), these authors have described various attempts by the LRA to disseminate their political program, for instance via radio messages and village meetings (Branch, 2010: 41). Dolan (2009: 85) writes that "[ $t$ ]hese broadcasts belie the claim that the LRA lacked any political position and had no interest in communicating with the civilian population - clearly they wished to, but were suppressed at the first sign of success."

Finnström (2001; 2003: Chap. 4; 2008: Chap. 3; 2006a; 2006b; 2010; cf. also Allen, 2006: 43) has gone even further and claimed the existence of "political manifestos", which according to him had been distributed among the Acholi population,

${ }^{84}$ This is even more the case since the LRA has left Northern Uganda and is continuing its random and brutal attacks on civilians in the DR Congo and the Central African Republic. 
and which reflect the political issues the rebels wanted to address. He repeatedly refers to the frustration communicated to him by his interlocutors about the fact that the issues, which were of real concern to the people, have been left without commentary in the public arena (Finnström, 2008: 99; 2006b: 207). In an article, Finnström (2001: 247f.) summarizes the main points communicated in the manifestos:

"The Acholi of Gulu, Kitgum and Pader districts in northern Uganda seem to share a mistrust - created by this uneven development - with the LRM/A rebels. The criticism is outlined in a recent manifesto distributed by the rebels. (...)The manifesto takes a critical stance against 'the New World Order', as it is described by the globalization sociologist Zygmunt Bauman (1998: 5576). Furthermore, the LRM/A claims to be fighting for multi-party politics, a key issue in contemporary Ugandan politics. Most government officials dismiss this and previous rebel manifestos as diaspora creations disconnected from Ugandan realities. However, regardless of the origin of the manifestos, it must be noted that the LRM/A rebels pinpoint the issues relevant to most people in northern Uganda."

It is frequently claimed, by scholars and political actors alike, that the political manifestos of the LRA are mere diaspora creations, which have little to do with the motivations of those fighting on the ground. The Lord's Resistance Movement (LRM), allegedly the political wing of the LRA, is seen by many skeptics to be largely a group of London-based Acholi in the diaspora, who are extremely critical of the Museveni government and its role in the war, but who are not as close to Kony and his leading commanders as they claim to be (Dolan, 2009: 76f.).

The debate about the political aspirations of the LRA is still ongoing. However, since the LRA has concentrated its attacks on the civilian population in the DR Congo and Central African Republic, skepticism of the sincerity of their political motivations is even more widespread than before.

The extent to which the local population supported the LRA is another matter of considerable debate (Dolan, 2009: 75). The majority of analysts postulate that only a very small minority of the civilian Acholi population supported the LRA. They argue that due to the excessive violence committed by the LRA, the movement lost all the support it might have enjoyed in the initial years of fighting (Behrend, 1998: 117; Gersony, 1997: 68; Westbrook, 2000: 3, van Acker, 2004: 352; HuRiWa, 1997: 36). This and the fact that Acholi elders accused the LRA of having broken 'traditional' conventions and rules of Acholi warfare soon diminished the local support for the LRA.

Finnström, most prominently, opposes this general opinion and claims that the LRA has enjoyed more support among the local population than is widely acknowledged. He writes: 
" $[Y]$ oung informants were often careful when they expressed their views on the public arena, and it took quite some time for me to gain their confidence so that they could freely share their feelings, views, and ideological standpoints. Again without being able to provide any proper or final statistics, I want to question the conclusion by Gersony (1997: 59) that of the Acholi people "more than $90 \%$ do not respect, welcome, encourage, support or voluntarily assist the LRA"' (Finnström, 2008: 105).

In a similar vein, a report by the International Crisis Group argues that

"Although few are willing to say that the LRA is fighting to rectify historical Acholi grievances, these grievances do exist, and many see the LRA, for all its faults, as the only group that is effectively confronting Museveni. This feeling is likely to be strongest amongst the Acholi diaspora, which is not directly affected by either the LRA's actions or by any positive deeds of the government" (ICG, 2004: 9).

The issue has still not been resolved and debates on the extent of LRA support continue. However, since the LRA has not been active in Uganda since 2006, and the aims they supposedly fought for have been taken up and made public by politicians from the North such as the charismatic DP presidential candidate Norbert Mao or UPC president Olara Otunnu, this question is no longer such a pressing issue.

The debate on the extent of support is closely intertwined with the question about the extent of (child) abductions and violence actually committed by the LRA. International human rights organizations, the media as well as other proponents of the official discourse on the LRA have frequently portrayed the LRA as an army of 'child soldiers'. They derive their main motivation for intervention on the moral ground that the abducted children need to be rescued. In discourses on military support for the Ugandan army as well as in debates on humanitarian interventions the issue of 'child soldiers' always figures high on the list of arguments which legitimate intervention (for an extreme example see the recently released film "Kony 2012" by Invisible Children (2012), which I discuss in more detail below). Several figures exist on the supposed numbers of child abductees, most are based on the number of returnees which have gone through reception centers. High estimates suggest that over 30,000 children were abducted by the LRA (World Vision, 2005: 4) ${ }^{85}$. Shaw \& Mbabazi (2008: 230) state that "the LRA reportedly consists of more than 80 percent abducted children". Testimonies of children who returned from the bush are often used to underline the general perception of the LRA as barbarous and irrational (e.g. HuRiWa, 1997) ${ }^{86}$. As Dolan (2009: 75) writes, "The vision of an organization built on abduction of children was linked to notions of its irrationality and lack of education."

85 Cf. Invisible Children, http://www.invisiblechildren.com/history.html (accessed 28.03.2012).

86 For a critical discussion of these processes of "story-making" see Verma (2012). 
Dolan (2009) and others (e.g. USAID \& UNICEF. 2006: vi), however, have questioned the assumption that the majority of fighters in the LRA have been abducted children. Based on extensive interviews and long term research in Northern Uganda, Dolan (2009: 75) summarizes his fieldworkers' accounts. They suggest "that more than half of the abductees were adults, and thus did not confirm the image of an organization which focused primarily on abducting children."

Blattman and Annan (2010, cf. also Annan et al. $2006 \& 2008$ ) have conducted an in-depth investigation of the magnitude, incidence, and nature of the violence of LRA abductions. Based on an extensive survey of hundreds of former abductees they try to present a more balanced and accurate picture of the subject than generally presented in the often sensationalist accounts. They state:

"The phenomenon of abduction is (...) poorly understood. While we know that many youths met terrible fates - whether killed, forced to commit unspeakable acts or taken as slaves for combat or sex - we have little sense of what experiences are exceptional and which are the rule. (...) In the absence of a public face and (until very recently) an active political arm, the LRA's activities, motives and structure have been defined by external actors, most of all journalists, human rights groups and the Ugandan military and government. One thus worries that the most sensationalist rather than the most common experiences have found their way into discourse" (Blattman \& Annan, 2010: 132).

Based on their data, they come to the conclusion that

"the LRA appears to be a much more strategic and conventional military organization than often supposed, however terrible its violence. (...) On the one hand, abduction is seemingly more widespread, more focused on adolescents and (on average) less grotesquely violent than often imagined. On the other hand, what is more common and broad based than previously supposed is the emphasis on political ideology in the group, as well as the level of cooperation and allegiance to the rebel cause reported by abductees..." (Blattman \& Annan, 2010: 132f.).

These and other controversies about the LRA have only recently been openly debated in the literature on the war in Northern Uganda. The fact that the motives, practices and tactics of the LRA are more complicated than is generally portrayed by the official discourse should not belie their brutal abductions, killings, mutilations and the suffering they have caused in Northern Uganda for a period of 20 years. However, one needs to keep in mind that just as the position of the LRA has been more complex than assumed, the role of the Ugandan army and government also needs to be critically re-examined. 
3.7.2. The Role of Museveni, the NRM Government \& the UPDF

Different evaluations regarding the inability or unwillingness of the government to end the war, and its potential motivations to continue it, can lead to various conclusions about the nature of the conflict. Many authors are surprisingly uncritical of Museveni's politics in Northern Uganda and the fact that his government and army have been unable - for more than 20 years - to defeat an army of 'insane rebels' and 'child soldiers' (for instance Hansen \& Twaddle, 1991; Schäfer, 2008: 337; 343ff.; 358; Eichstaedt, 2009: 13; Ndikumana \& Nannyonjo, 2007; Mamdani, 2004; Gersony, 1997). Museveni's labeling of the armed conflict as a military rather than a political struggle, his long-lasting refusal to engage in peace talks and his IDP politics have led critical scholars (e.g. Omara-Otunnu, 1992) to question his motives and his willingness to end the war. As a report by the International Crisis Group analyses,

"[t]he war has been a disaster for Uganda but it has allowed him [Museveni] to maintain an unreformed and corrupt army as a key pillar of the regime. It stands in the way of thorough security sector reform and gives him the arguments with which to resist mounting international pressure to reduce defense spending drastically. It also gives him pretexts to maintain the political status quo by denying the opposition a power base and curtailing freedom of expression and association in the name of 'the war against terrorism"' (ICG, 2004: 10).

Besides these political motivations to continue the war, there have also been economic incentives for the UPDF, especially its top commanders (Ogenga Otunnu, 2002: 13). Van Acker (2004: 353f.) mentions large scale cattle theft, different forms of corruption, as well as the use of "ghost soldiers" as means by some people in the army to enrich themselves (cf. RLP, 2004: 27ff.). Only in very rare cases were these forms of misbehaviour by UPDF soldiers recorded and punished (Dolan, 2009: 148f.). Proponents of the counter discourse have often criticized that legal measures to punish war crimes committed during the armed conflict in Northern Uganda have only been directed against the LRA and that the UPDF, despite its known gross human rights violations, has never been indicted. In this regard, the most frequently cited example is the investigation by the International Criminal Court, which charged the top LRA commanders with crimes against humanity while refusing to investigate the crimes committed by the government forces (Mamdani, 2012; Kalinaki, 2012).

To summarize the complex debates on the LRA and the Ugandan government, I will quote Chris Dolan, who, in his chapter Reconsidering the LRA-Government Dynamic concludes his analysis with the following words: 
"The LRA was more motivated and organized than it was made out, and the GoU [Government of Uganda] less committed to finding a solution than concepts of wars as something you fight to win would have us believe. Indeed, for the GoU winning seemed to lie in keeping the opponent alive for as long as possible, in particular by using humiliation tactics to provoke him into reacting whenever the situation became calm for too long. In this interpretation the Government's behaviors, whether in military or non-military interventions, were not driven by political immaturity, but rather aimed to achieve the opposite of what was stated - namely to bring the situation back to the broil rather than to find a solution" (Dolan, 2009: 102).

\subsection{Concluding Remarks - Changing Hegemonies of Interpretation}

In this chapter, I have demonstrated how different historical realities are constructed in different discourses on Ugandan history. At different times, different social actors have had different degrees of influence to establish their version of history as the dominant interpretative scheme in public and/or academic discourse (cf. Keller, 2006: 121, 124). I have further shown how, once established, dominant interpretative schemes of key events in Ugandan history and their consolidation in coherent story lines (cf. Keller, 2006: 133f.) have had a profound effect on subsequent historical developments and their interpretations.

My aim, more specifically, was to analyze different narratives of the war in Northern Uganda and the way they were based, at least partly, on different versions of Ugandan history. On a macro level, two major opposing discourses can be singled out: one official discourse, which takes a very moralizing approach in its conflict analysis, blames the war primarily on the LRA and its ethnic and spiritual fanaticism, and favors a military solution to the war; and a counter discourse, which acknowledges the LRA as a political actor, points to the devastating effects not only of LRA violence but also of the government policies on the war and the complicity of the international community, and calls for a long-term political solution to overcome the root causes of the conflict. Each of the two discourses interprets historical events before and during the war in different ways, and builds different story lines to legitimate its interpretation of the war.

Since the beginning of the war, discourses and interpretations of the war have been repeatedly altered due to the necessity to accommodate recent events. Hegemonies of interpretations have also changed due to changes in discourse coalitions and societal power structures and relations. In the beginning of the war, and for quite a long time thereafter, the official discourse was the only one which resonated in national, international and even in academic discourses. This was due to the widespread image of Museveni as the 'savior' of Uganda after the troubled years un- 
der Amin and Obote, which made his rhetorics on the war in the North sound credible. It was further affected by chaotic events in Northern Uganda in the mid-1980s, which were hard to comprehend for outside observers, and the gruesome reporting of the crimes, which the LRA began to commit particularly after the failure of the 1994 peace talks.

In recent years, the counter discourse has gained more influence, and has begun to challenge the dominant interpretative schemes set by the official discourse. This, among other reasons, is due to the fact that prominent and influential Acholi politicians like Olara Otunnu (President of the UPC) and Norbert Mao (President of the DP) have started to change the image of Northern Uganda and the Acholi in national discourses. Furthermore, Gulu is increasingly becoming an important economic centre and is no longer seen as the capital of a war region. Another important aspect is that the general political atmosphere in Uganda and also attitudes among the international donor community have become very critical towards the Museveni Government (cf. ICG 2012). In academic circles, the counter discourse has, in fact, become the hegemonic line of interpretation. Today, there is hardly a serious scholar working on Northern Uganda, who does not cite the major works by Finnström, Dolan and others, and takes a more critical look at the government and international involvement in the war.

In Uganda (with the exception of Acholiland), the official discourse long dominated public perceptions of the conflict. In line with established colonial and postcolonial classifications, it was blamed on the 'barbarous' and 'martial' Acholi people, while the accountability of the NRM government was rarely taken into account. Over the years, however, and especially since the end of the war, critical press reports (especially in the Daily Monitor) and the voices of prominent intellectuals and influential Acholi politicians have managed to establish a more differentiated picture of the conflict in Ugandan public discourses. With rising criticism of the Museveni government in all parts of the country, especially since the elections in 2011 (ICG, 2012), and the recent outrage over the Kony 2012 video (cf. for instance Mamdani, 2012; Kalyegira, 2012; Tabaire, 2012; Kalinaki, 2012; see discussion below), many aspects of the counter discourse have in fact become hegemonic.

In international media and political circles, however, the official discourse is still widely recited. For many years, the war was largely ignored, and was famously described in 2003 by Jan Egeland, the UN Secretary General's Special Representative on Humanitarian Affairs, as the world's worst neglected humanitarian crisis (Dolan, 2009: 55f.). Afterwards, relief efforts rapidly expanded, and reportings of child abductions and 'child soldiering' by the LRA as well as the plight of thousands of night commuters, children who fled their villages at night to sleep in protected areas in town for fear of attacks, spread through the international media. In the U.S.A., the films by Invisible Children reached ten thousands of (predominantly) young people, and convinced them that Northern Uganda needed to be rescued from the 'evil and mad' Joseph Kony with the help of the U.S.A. (cf. Finnegan, 2013). This 'propaganda' culminated in the documentary "Kony 2012", which was spread via Face- 
book und YouTube and was watched by millions of people worldwide within days after it was first uploaded ${ }^{87}$. Kony 2012 represents the bluntest version of the official discourse; it distorts historical facts ${ }^{88}$, and is based on the most sensationalist and moralizing images. In an article about the video, Finnström (2012: 127) notes:

"The global success of the film KONY 2012 by Invisible Children, Inc., manifests far greater magical powers than those of Joseph Kony and his ruthless Lord's Resistance Army, which it portrays. The most prominent feature of the Invisible Children lobby is the making and constant remaking of a master narrative that depoliticizes and dehistoricizes a murky reality of globalized war into an essentialized black-and-white story. The magic of such a digestible storyline, with Ugandan rebel leader Joseph Kony as a global poster boy for evil personified, not only plays into the hands of the oppressive Ugandan government but has also become handy for the US armed forces as they seek to increase their presence on the African continent."

Even the Ugandan Government, generally a stern promoter of the official discourse, has criticized the video for its misrepresentation of historical facts and its patronizing attitude. A press release states:

"[W]e note with concern the gross misrepresentation created by the documentary. The documentary is in essence, an erroneous attempt to rewrite the history of Uganda regarding the conflict in the Northern part of the country. (...) The documentary is also patronizing in as far as it portrays Uganda as helpless in the face of the conflict and cuts out Ugandans as people incapable of solving their own problems" (Okurut, 2012: 28).

Internationally, there have been mixed reactions to the video. While the extreme emotional and patronizing measures the film adopts to convey its message, and the motives behind the film and the organization Invisible Children have been widely criticized, few of the uninformed viewers of the film are capable or willing to challenge the story behind it. As is well-known from other examples (e.g. Schomerus, 2010), there is a general reluctance by the international media and its consumers to accept less sensationalist accounts of the war and its main actors as the presentation

87 On March 5th, 2012, Invisible Children released the film as part of a campaign to call attention to the LRA and its leader Joseph Kony and to lobby for a large-scale military intervention to capture Kony. In the 30-minute film, American Jason Russel, founding member of Invisible Children and director of the film, talks to his five-year old son Gavin about the war in Northern Uganda and the "bad guy" Joseph Kony. Using very emotional language and images, the film contrasts Gavin's life as a child growing up in the U.S.A. with the life of Jacob, a Ugandan friend of Russel, who grew up in Northern Uganda during the war and experienced terrible suffering due to Kony and the LRA. Russel states that his motivation for the campaign is that children across the globe should grow up in a better world and calls upon the international internet community to support his mission.

88 The most drastic distortion, which has been pointed out by several critiques, is that the video gives the impression that the war is still ongoing in Northern Uganda. 
in the video fits too well the common notion of Africa as the dark, dangerous and irrational continent. As a columnist in the Daily Monitor writes:

"International media has long perfected the reductive art of trying to explain a complex, foreign story to an uninterested domestic audience in the traditional 90 seconds or three minutes of a television news clip. (...) The biggest concern shouldn't be the inaccuracies or the lack of context in the video - that is to be expected - but that there are few, if any, alternative realities to correct them. We are simply not telling enough of our own stories. Mzungus [common Swahili term for white people] have written most of the books I have read on the LRA war. (...). Fifty years after independence, one can count less than that number of good, insightful books written by Ugandans telling the story of our nation and the men (and women) who built it" (Kalinaki, 2012: 11).

Thus, while Kony 2012 has certainly achieved to put the conflict in Northern Uganda (back) on the international agenda ${ }^{89}$, at least for a brief period of time, the notion it conveys of the war, its root causes and its main actors, is one-sided if not completely wrong. The video is therefore a manifestation of the official discourse on the international level, and it remains to be seen whether critical commentators will be able to correct the interpretative scheme it has established ${ }^{90}$.

The debates about the Kony 2012 video are an extremely telling example of the fights about defining history, and the power inherent in the capability to do so, which I have referred to in this chapter. I will end this chapter with a quote from another Daily Monitor columnist, who captures this idea very well when he writes:

"But, finally, here we are - in the twenty-first century. Africa is pushing back in real time on (somewhat) equal platform. Everyone is free to define and redefine Africa in his or her own image. That definition, however, shall no longer go un-interrogated. Swiftly and robustly. The fight is fully joined" (Tabaire, 2012).

89 As a reaction to the video, the African Union now plans to deploy 5,000 soldiers to the countries in Central Africa currently affected by the LRA attacks to defeat Kony and his rebel army (Tagesschau, 2012).

90 Some weeks after the release of the first video, Invisible Children published a second video "Kony 2012 - Part II. Beyond Famous" (2012b), in which they try to react to some of the criticisms voiced against the first film. They make clear that Northern Uganda is no longer a war zone and focus more on the actions of the LRA in the DR Congo and the Central African Republic. Generally, however, the film is just as patronizing as the first. 


\section{4. “Our Culture is getting lost!" - Pre- \& Post-War Representations of Acholi Culture}

This chapter represents the starting point of my main analysis and consists of a mix between literature review and a discussion of my ethnographic material. The chapter serves to expound the contemporary, hegemonic discourse on Acholi culture, propagated by both local and international actors, which proclaims that "traditional Acholi culture" as it was in "those days" has been lost through war and displacement. I will introduce the reader to contemporary representations of Acholi culture by presenting a lengthy extract from my field notes which describes the "Miss Acholi Contest". Afterwards, I will turn to a detailed analysis of the ways Acholi culture has been historically and discursively produced and how it is under- 
stood today ${ }^{11}$. The proclaimed loss of Acholi culture is one of the main features of contemporary discourses on socio-cultural change and thus of great relevance for my analysis. The way different people - elders and youth, men and women, local and international actors - talk about and give meaning to it reveals the complex role of culture in linking and understanding past and future of Acholi society. In order to give the reader an impression of the contemporary discourse, I have decided to present numerous and sometimes lengthy quotes throughout this chapter.

\subsection{Acholi Culture 2.092}

I first learned about the Miss Acholi Contest in August from Simon. Simon was one of my regular interlocutors. I got to know him in the first month of my research as a participant of the "Gulu Talking Straight" Hip Hop Project (cf. Chap. 2), but we stayed in touch even after the project was finished. In August, Simon was working for Kwach Academy (http://www.kwachacademy.net/, accessed 29.05.2012), the $\mathrm{CBO}$, which was responsible for the organization of the Miss Acholi Contest, and whenever we met he would tell me about the event. When I first heard the name "Miss Acholi" I had to think of a beauty competition or a fashion show, but Simon explained to me that the Miss Acholi Contest was by no means a conventional "modern" fashion show, but that the event was "all about tradition" (cf. field notes 09.08.2010). On the official website, the Miss Acholi event is described as follows:

"The Miss Acholi Cultural Festival is not the normal conventional beauty pageant. This is very much to celebrate the rich culture and traditions of the Acholi people. This is a platform where we become students and learn something new. The event is a family event for both children and adults to learn. This year the events will consist [among other things] of the following:

- Miss Acholi - showcase of the beauty of the Acholi women (...) each will have to demonstrate knowledge of the Acholi Cultures and current affairs.

- Cultural Dances (...)

91 When I use the term Acholi culture without further specification I refer to this contemporary understanding.

92 Acholi Culture 2.0 alludes to the term "Web 2.0.", which has been used to designate new developments in the World Wide Web since the late 1990s. Web 2.0 is a concept that stresses the interactivity and interoperability of the internet, in which users no longer only passively consume web contents, but become actively involved in shaping and creating web contents, for instance through social network and blogs. I have appropriated the term to designate not only the inventiveness and creativity in current discourses on Acholi culture but also the multiplicity of different actors, who are involved in the 'creation' of Acholi culture as it is understood today. 
- Panelist [sic] - which consists of cultural leaders, academics and teachers to talk about Acholi culture and traditions. There will be a question and answer time from the audience.

- A Showcase of forgotten Acholi, e.g. food, fruits, craft - you name it, and we will have it!"

(Miss Acholi, cf. http://missacholi.com/aboutus.php, accessed 14.05.2012).

According to the website, the main purposes of the event are "cultural revival" and "empowerment through culture". It states: "The Miss Acholi Cultural show acts as a platform for cultural revival after the 23 years of war which ravaged the region and caused devastating impact on the community and families in the area" (Miss Acholi, cf. http://missacholi.com/faq.php, accessed 14.05.2012).

Ever since I first heard about Miss Acholi, I waited for this event, hoping that it would provide me with a new perspective on contemporary representations and negotiations of Acholi culture. In a very peculiar way, the event did indeed provide me with a new perspective on Acholi Culture 2.0. And it reinforced my perception of the ubiquitousness of static and highly flexible elements commonly associated by Acholi people in Gulu with Acholi culture.

In the following chapter, I will first present an extract of my field notes on the Miss Acholi Event to give the reader an impression of the hybrid ${ }^{93}$, multiple and sometimes contradictory contemporary images of Acholi culture. I will use this ethnographic example to address a question which is of central concern to my research: What is Acholi culture? Or, more concretely: What do people mean when they speak of Acholi culture? The answer to this question is by no means straightforward and critical anthropologists, including myself, would probably answer that Acholi culture as a monolithic whole does not exist at all. Nevertheless, there does seem to be a 'prototypical' understanding of the term. People remember the "real Acholi culture of those days", elders lament the "loss of Acholi culture", and cultural leaders and foreign organizations aim for the "revival of Acholi culture". Expressions like these suggest that to some degree there is a shared notion of Acholi culture, and in the following chapter I will try to dissect this notion.

Before I do so, however, I will briefly elaborate my own understanding of and approach to the term culture which has been controversially debated ever since the beginnings of anthropology and, more especially, since the first anthropologists started "writing against culture" (Abu-Lughod, 1991) in the 1980s. In recent times, culture has become a buzzword not only in anthropological but also in public debates - as the Acholi case prominently shows - and this has sparked further controversies. Trouillot (2003: 98), for example, argues:

${ }^{93}$ For a discussion of the concept of cultural hybridity see Weißköppel (2005) and Ashcroft et al. (1998: 118ff.). 
"As the explanatory power of culture increases, many anthropologists react negatively to what they see as an abuse of one of their favorite categories by the general public, journalists and especially colleagues. (...) Occasional and acute irritation aside, most academic anthropologists have a limited awareness of both the extent of this abuse and the extent to which it now serves politically conservative causes. (...) The narrative and the solutions sketched here are valid only to the extent that we have both a conceptual problem and a public - therefore political - problem, that these problems are intertwined and urgent, and that the massive exportation of essentialized and racialized views of culture(s) (...) increases both their theoretical and political urgency. (...) Culture is out there, but anthropologists have no control of its deployment" (emphasis in original).

I share Trouillot's criticism of the "essentialized and racialized views of culture(s)" one finds in popular discourses today. Equally, I perceive the diffuse usage of culture as an analytical concept in anthropological writings as highly problematic. However, I would not go as far as to call for the complete abandonment of the term culture as Trouillot and others have done. I believe that in a time where everyone talks about culture, anthropologists cannot simply abandon the word or the concept behind it and ignore how and why it has become so common in popular debates. Rather than engaging in endless debates about essentialist vs. constructivist concepts of culture, plural or singular understandings of culture, and the benefits and detriments of abandoning culture (for a good overview of these debates see Lentz, 2009 and Sahlins, 1999), however, I suggest that it is more relevant to engage with and analyze the different contemporary emic understandings of the term culture as used by the people who are studied by anthropologists. Anthropologists need to shift their focus from abstract conceptual debates to ethnographic analysis and understand (discourses on) culture as an ethnographic fact ${ }^{94}$. As Sahlins (1999: 403) has pointed out, emic conceptions of culture are by no means stable but in fact highly negotiable, manipulable and instrumental. Taking up his argument and drawing on Foucault's analytics of power and discourse (cf. introduction), I argue that what is considered as culture in a given society is always related to time-andplace-specific types of discourses which derive from a complex interplay of knowledge and power relations. Culture is discourse in the sense that it is a way of creating order which subjects social actors and disciplines them to behave and believe in certain ways. Culture as discourse operates in relation to power - it is constantly reproduced as it serves to manifest societal power relations and to maintain social order, but it can also be resisted and challenged.

In this chapter I concentrate on hegemonic representations of Acholi culture and the multiple voices and authorities involved in its construction. I analyze how a shared meaning of Acholi culture has historically evolved and how it is constantly

94 The same applies to debates on tradition and modernity which will be discussed in Chapter 5. 
reproduced without ignoring, however, the ways this shared meaning is also undermined, altered and contested. My aim, in this and the following chapters, is to gain a deeper understanding of how the hegemonic discourse on Acholi culture and the various reactions to it shape past, present and future imaginations of Acholi society.

The contemporary hegemonic discourse on Acholi culture, propagated by both local and international actors, proclaims that "traditional Acholi culture" as it was in "those days" has been lost through war and displacement. I argue that this discourse is hegemonic for two reasons. Firstly, it reflects the perspective one most frequently encounters if one asks people in Gulu (and presumably also other areas of Acholiland) about Acholi culture today. Secondly, and related to the first point, it captures the perspective on Acholi culture that is most commonly depicted in contemporary writings on Northern Uganda. However, as I will show more explicitly in the following two chapters, the discourses on and conceptions of Acholi culture are more contested and complex than it may seem initially ${ }^{95}$.

In the first part of my analysis, I will delineate elements of Acholi culture which are commonly associated with pre-colonial and/or pre-war times. In different ways, both the pre-colonial and pre-war period (in common discourse often referred to, without distinction, as "those days") are seen as the time when Acholi society was still intact and 'authentic'. I will try to reconstruct the image of this ideal Acholi society not only by giving examples of common expressions by my interlocutors, but also by referring to frequently cited ethnographic accounts of the Acholi. I have decided to adopt this dual approach because both, the older and the more recent ethnographies written by social scientists and local ethnographers influence contemporary discourses in multiple ways. To this day, they are cited as authentic accounts of the past - in school education on 'traditional culture', by local organizations and NGOs involved in 'cultural revival', and by academics working on Acholiland - and thus shape contemporary imaginations of the past. Girling (1960: 202f.) furthermore argues that Acholi ethnographies in fact contributed to the emergence of an overall Acholi consciousness in the middle of the twentieth century. Both, contemporary discourses and older ethnographies adhere to a largely essentialist notion of culture as a social system. In their characterization of Acholi culture they both depict similar elements (political, social, economic organization, local beliefs etc.). Due to the pervasiveness of these categories, I have decided to follow their pattern in my analysis despite criticisms of such fixed representations of 'cultures' in contemporary anthropological debates.

In the second part of my analysis in this chapter, I will focus on the widespread contemporary impression that Acholi culture is "getting lost". In local discourses

95 In chapter 5, I show how, among the young generation, very different understandings of Acholi culture and its role in future Acholi society exist. In chapter 6, I further analyze how imaginations of Acholi culture are contrasted to a "westernized lifestyle" and demonstrate that the proclaimed loss of Acholi culture is attributed not only to the war but also to Western influences, which can be regarded both positively and negatively depending on the context and the speaker. 
this loss of Acholi culture is blamed on the war, particularly the displacement of the majority of the Acholi population to IDP camps, and the effects of war-related foreign influences. Again, I will link findings in the literature on Acholiland with expressions from my interlocutors in Gulu.

In the final part of my analysis, I will briefly look at contemporary attempts to reconstruct 'traditional', 'authentic' Acholi culture, which are pursued in different ways by rural communities, urban elites and international development actors.

With this chapter, I intend to show continuities and discontinuities, differences and similarities in discourses on Acholi culture. The eclecticism inherent in contemporary understandings of Acholi culture is best exemplified by the Miss Acholi Contest. In the following, I will present an extract from my field notes to characterize this event, and use this example to introduce my analysis of contemporary understandings and representations of Acholi culture.

\subsection{The Miss Acholi Contest - Extracts from my Field Notes}

$18^{\text {th }}$ December, 2010, Saturday night, Acholi Inn, Gulu. It is $6 \mathrm{pm}$ and I am sitting with a group of friends at the Acholi Inn, one of the oldest, most well-known and expensive hotels in Gulu. Tonight the infamous "Miss Acholi Contest" will take place, which I have been hearing about for months.

We are a mixed group of people: both locals and foreigners, and of different ages and occupational backgrounds. We have bought our tickets at the entrance and are now awaiting the show, which is supposed to start at $5.30 \mathrm{pm}$. But apart from us no other guests have arrived yet.

I sit with Akello, a good friend and one of my closest research interlocutors ${ }^{96}$. While waiting, we chat and observe the preparations for the show going on around us. We greet Simon who is busy running around organizing. As usual, he looks like a 'gangsta rapper' - he is wearing sun glasses, a big cap and baggy pants. He greets us enthusiastically in his usual 'hip hop style' - a casual hand shake and a fist bump. Besides being a rapper Simon is also a passionate supporter and performer of "traditional dance", and I always wonder how he manages to combine these two facets of his identity. For him, there does not seem to be a contradiction - even on an event like today, which he is attending as a representative of the organizing team, he does not consider it necessary to drop his 'gangsta habitus'. (...)

I look around as the crowd keeps gathering. There are families with small children, elderly men and women, youths - really all segments of society (but predominantly those, who are a little bit better off and who can afford the entrance fee of 10,000 UGX, approximately 3.2 Euro $^{97}$ ). Most of the young people are members of the cultural

96 For more information on my most important interlocutors cf. appendix.

${ }^{9}$ According to a statistical survey by Pham \& Vinck (2010, cf. figure 3 in the appendix), the average weekly income in Gulu District in 2010 was 23.157 UGX (approx. 7 Euro). Presumably, the 
groups which will perform in the dance competition. A DJ has started to play music. The very adventurous mix includes "traditional Acholi music" (locally also referred to as "Suk style"), Ugandan and Western hip hop tunes, as well as international Christmas songs. One hip hop song consists nearly exclusively of the word "motherfucker" - I find it quite out of place in this event which explicitly aims to "revive traditional culture", and I think many people in the audience, especially the older, more conservative ones, think likewise, but no one complains.

At $10 \mathrm{pm}$ the show finally starts. The presenter, a radio $\mathrm{MC}$ from the local radio station Choice FM, welcomes the audience and introduces the event. He says that Miss Acholi is an annual event which aims to preserve Acholi culture. "Today", he continues, "the young children should see and learn about Acholi culture". He remarks that the Miss Acholi contest is not so much about beauty, but about knowledge of Acholi culture, and that the eight contestants will have to prove their knowledge of Acholi culture by answering questions raised by the jury. The winner of the contest, he announces, will receive a scholarship for Gulu University.

The presenter also introduces the rest of the program. There will be more than ten cultural groups from all over the Acholi region which will be performing "traditional dances" and competing against each other ${ }^{98}$. The winner, who is selected by the jury, will receive a prize money. In addition to the two contests, there will be other entertainment and music acts.

The presenter apologizes that the expected chief guest, the Acholi Paramount Chief Rwot David Onen Acana II, will not be able to attend the event. Ker Kwaro ${ }^{99}$ has sent his secretary as a representative instead. (To me it seems that Ker Kwaro does not take the event very seriously despite the fact that "cultural revival" and "cultural education" are two of its primary concerns). The second guest of honor is the speaker of the local government who is welcomed briefly. Then the presenter introduces the jury which is made up of three older men. Akello explains to me that all of them are well-known

average income in Gulu Municipality was slightly higher. In order to put the above figure in a broader (national) perspective, one could look at the average income for teachers in Uganda. According to a New Vision article (N.N., 2011a), the average monthly salaries for primary teachers at the time was 260.000 UGX (approx. 78 Euro) and 450.000 UGX for secondary teacher (approx. 135 Euro).

98 "Traditional dance" competitions, which I discuss in more details below, are very popular in Acholiland and throughout my research I witnessed several of these competitions. The performing groups are often comprised of children and youth who meet regularly to practice. Some groups also have adult members. The most common dances performed in the competitions include courtship dances like Larakaraka or Ajere, the "royal dance" Bwola, as well as age- and gender-specific dances (such as Dingi Dingi for young girls, and Apiti for older women). The performances are judged by a jury and the winners usually win various amounts of prize money (and sometimes other prizes). "Traditional dance" is the established emic term and as such I will use it without quotation marks in the following. (However, I am aware of the problematic notion of the term "traditional").

99 Ker Kwaro is the official (but controversial) Cultural Institution of the Acholi (cf. Paine, 2011), which I will further discuss in the course of this chapter. 
experts of Acholi music and traditional dance who regularly judge music and dance competitions.

After all the announcements the program finally begins. First, the Ker Kwaro cultural group is called on stage to sing the "Hymn of the Acholi", which praises the rwot, i.e. the Paramount Chief. I have never heard of this hymn before, and when I ask Akello about it, she says she has not heard of it either. I wonder whether it might be a very recent invention.

Next, the eight women, who will be competing to become Miss Acholi briefly present themselves to the audience by walking and dancing across the stage. Afterwards, the cultural group of the hosting organization Kwach Academy presents Bwola Dance ${ }^{100}$. (...)

The dance competition starts. Each group has nine minutes performance time. As in other traditional dance contests I have observed, most of the groups have powerful costumes and perform with great passion and professionalism. The boys and young men are bare-chested and often only wear something like feather skirts to cover their private parts. Most of the ladies and girls wear short skirts and something to cover their breasts, sometimes just conventional bras. Akello and some of the other young people in the audience find the costumes very amusing and there is some laughter. These young people are probably not the only ones who wonder why in the name of tradition so much bare skin can be shown, while in other contexts it is condemned as something Western and morally disgraceful. One performance, in particular, by a dance group made up only of elderly and very corpulent women, who are all wearing black bras, causes some uproar in the audience. (...)

Akello really enjoys watching the dances and is intrigued by their swiftness and powerfulness. She tells me that she once used to perform traditional dances when she was still at school, but that unfortunately she does not know the great majority. She is happy that today, at least, she is seeing and learning some new dances, which are part of her culture ${ }^{101}$.

In between the dance performances, the Miss Acholi Contest continues. One by one, the eight contestants are called on stage. I guess that most of the women are in their twenties. They enter the stage by dancing to a 'traditional tune'. When the music stops they step before the jury to introduce themselves. The women are asked to state their names, their region of origin and the names and origins of their parents - probably to establish that they are 'real' Acholi. Every time, the people in the crowd, who are from the

${ }^{100}$ Bwola is the "royal dance" of the Acholi. According to custom, it was performed during the crowning or the burial of a chief, or to welcome and entertain respected elders on festive occasions. Today it is one of the most popular dances performed by youth cultural groups in dance competitions and other public events (cf. Nzita, 1997: 94; Acholi Heart Beat, cf. http://ugta.org/ acholi_heart_beat.php, accessed 29.05.2012).

${ }^{101}$ I often encounter similar expressions by young people, who regret that they do not know the dances and other traditions of their forefathers and mothers. In this sense, events which aim to promote cultural education like Miss Acholi are something very much welcomed by the younger generation, despite the fact that they do not agree or accept all aspects of "traditional culture" as I will further discuss below. 
same area as the contestant, cheer and clap. The conversation between the contestants and the jury is only in Acholi so that I do not understand much. But in many ways it seems awkward to me: some of the women are very loud and their answers do not seem to please the jury. I ask Akello about it, and she thinks that some of the women might be drunk. (...)

After a further round of dances, the Miss Acholi contestants appear on stage for the second round. This time they wear some kind of 'traditional clothing', usually a skirt and something to cover their breasts. The jury asks them to tell the audience about the cultural meanings of the clothes and accessories they are wearing. Some of the ladies give lengthy and very sophisticated answers (according to Christopher, another Acholi friend of mine, who is sitting close by). Others seem to know nothing and embarrass themselves.

The evening continues, with dance competition and Miss Acholi contest alternating. It is already long past midnight, but there is still so much program to come. As it is very cold, many of the spectators begin to leave, and if it were not for research purposes, I would probably leave as well.

All of a sudden, the presenter announces a hip hop act, and Simon appears on stage. He performs a hip hop song with Acholi lyrics. He later tells me that he has written the song just for the Miss Acholi event. Together with him, many young guys, all in baggy pants, and also some girls, dressed in casual clothes, come on stage and dance. Some young people from the audience come up and put money in Simon's pockets to show that they are enjoying his music. To me, the performance seems very much out of place when compared to the preceding program. (...) Later in the show, more rappers perform, who seem similarly out of place when compared to the rest of the 'cultural program'. I look at the audience. The young people enjoy the hip hop performance, while the older people seem relatively indifferent. Some also seem annoyed, but I think mainly because it is getting so late and they want the contests to move on. I really wonder about the eclectic conception of this event. Is this Acholi Culture 2.0? (...)

It is already past 3am and of our group only Akello, Lioba, Christopher and me are left. Christopher, an Acholi man in his 40s and a stern supporter of 'Acholi traditions', is the one who is making us stay as he wants to see who wins the Miss Acholi Contest. But there is always some other program mixed into the contest so that it is getting later and later. Alpha Otim, a well-known local artist for popular Acholi music, comes on stage to perform one of his "Suk style" songs. All of a sudden the stage is full of people - young and old, traditional dancers and rappers, men and women - who are all dancing to Alpha Otim's tune. It is a crazy sight, seeing elderly ladies in bras dancing together with rappers in beanies and baggy pants. Despite the coldness and the late hour, I have to smile and feel somehow happy that we stayed this far. Nevertheless, Akello and I decide to leave shortly after the performance, since it is already $3.30 \mathrm{am}$ and it will probably take some more hours until the contest will be over (field notes 18.12.2010).

The Miss Acholi Contest raises several questions about the notion of Acholi culture and the way it is currently being promoted. Acholi culture, on the one hand, seems 
Julia Vorhölter: Youth at the Crossroads

to imply something bounded and fixed, something which can be grasped by interrogating contestants about 'cultural facts' or by judging the authenticity and correctness of a dance performance. On the other hand, Acholi culture blends in with other elements - in case of the Miss Acholi Contest international popular music, fashion and dance - and thus seems to be an inherently hybrid concept. In this chapter, I will concentrate largely on the first aspect, the official discourse on Acholi culture, and will turn to the more dynamic and hybrid aspects of Acholi culture in the following chapters.

\subsection{Pre-war Ethnographies: Representations of the Ideal Acholi Society}

In this section of the chapter, I analyze widespread imaginations of pre-war Acholi society. I give a systematic account of different elements, which are regarded as fundamental parts of Acholi culture. Many of these elements are reflected in early ethnographic studies of the Acholi such as those by Crazzolara (1950; 1951; 1954), Girling (1960) and Onyango-Odongo \& Webster (1976) as well as the later publications by Atkinson (1989; 1994; 1999), Ocholla-Ayayo (1980), Nzita (1997), Behrend (1993) and Finnström (2003) ${ }^{102}$. These ethnographies not only reflect contemporary notions of Acholi culture, but have in fact contributed to their production and construction by inscribing and thus consolidating ethnographic data as 'historical facts'. I focus on those facets of Acholi culture, described in these ethnographic accounts, which I also encountered in contemporary popular imaginations of "traditional Acholi culture". I will summarize the insights provided by the different ethnographers on commonly discussed aspects such as origin, social, political, economic and religious/spiritual life of the Acholi, and relate them to expressions by my interlocutors in Gulu. Reconstructing the way Acholi culture has been discursively produced and is seen to have evolved is important in order to understand contemporary discourses on socio-cultural change.

\subsubsection{The Origin(s) of the Acholi}

Different ethnographic studies claim that the Acholi are part of the Luo ${ }^{103}$ and originally stem from Southern Sudan, from where they started to migrate into the

102 Other prominent examples of Acholi ethnography, which I did not cite for this section because I did not have access to the texts, include Dwyer, 1972 as well as the local ethnographies by Reuben Anywar, Alipago Latigo, Noah Ochora, Laito Okech und R.M.Nono (cf. Behrend, 1993: 14).

${ }^{103}$ Luo is a Western Nilotic Language spoken by different peoples in Southern Sudan, Uganda and Tanzania and the umbrella term under which the Acholi dialect is subsumed (Atkinson, 1994: 3; 1999: 62; Crazzolara, 1938). 
area now referred to as Acholiland ${ }^{104}$ sometime between the $15^{\text {th }}$ and $17^{\text {th }}$ century due to several calamities such as diseases, conflict and overpopulation (Behrend, 1993: 23f.; Nzita, 1997: 87; for a more nuanced analysis cf. Crazzolara, 1950; 1951; Atkinson, 1999: 61ff.; Onyango-Odongo \& Webster, 1976: 25ff.). According to Nzita (1997: 88), they moved into different areas in Uganda where they intermarried with the local people. The Acholi as we know them today "are said to have been the offspring of the intermarriages between the local people and the Luo arrivals" (ibid.: 88).

When talking about the origins of the Acholi with my interlocutors in Gulu, both older and younger people frequently referred to the founding myth according to which two brothers split up over a bead and one went to West Nile and became the founder of the Alur and the other became the father of all Acholi (personal conversation cf. field notes 31.03.2010; INT Faith, 18.03.2010; cf. Finnström, 2008: 47f.; Crazzolara, 1950: 62ff.; Girling, 1960: 158; Onyango-Odongo \& Webster, 1976: 106f.). In conversations, the issue of origin sometimes came up when discussing the differences and similarities between the Acholi and their neighbouring ethnic groups. Some interlocutors emphasized the differences that had existed (and still exist) between different Acholi clans or between Acholi from different regions in Northern Uganda. A common claim, for instance, was that there is a fundamental difference between Acholi from the Gulu and Acholi from the Kitgum region (e.g. INT Okello, 26.09.2010; personal conversation cf. field notes 06.09.2010) ${ }^{105}$.

Nevertheless, the existence of a collective, overall Acholi (ethnic) identity was never disputed. When I asked my interlocutors what being Acholi meant to them, most of them answered that it was an unchangeable part of their identity. The following statement by one of my interviewees is typical: "I just found myself born in it - they call us Acholi, so there is no way I can run away from it. I prefer some people's culture to mine, but there is nothing you can do, I have to love my culture and my tribe" (INT Martin, 21.04.2010).

When I further inquired, what being Acholi meant in practice, many of my interlocutors stated that it implied living according to Acholi traditions and following 'typical' cultural practices related to social, political, spiritual and economic life. The popular descriptions of the different spheres and aspects of Acholi life correlate in many ways with ethnographic accounts I found in the literature. Behrend suggests that these correlations may not be coincidental and argues that contemporary rep-

${ }^{104}$ The geographical area of Acholiland (approx. 28,400 square kilometres, cf. Atkinson, 1999: 46) consists of a series of huge terraces rising from West to East with some isolated mountains. Rolling grass plains, small bushes and scarcely scattered trees (Ficus, Albizzia, Shea-Butter-Nut Trees etc.; nowadays also fruit trees such as Mango and Citrus) comprise the main features of the vegetation (Girling, 1960: 13f.). A map showing the districts which make up Acholiland today is included in the appendix (figure 1).

105 The (historically grown) regional differentiation between different Acholi groups has also been discussed at length in the literature, cf. Atkinson (1999), Onyango-Odongo \& Webster (1976) and Crazzolara $(1950,1951,1954)$, but will not be further discussed here. 
resentations of Acholi culture have in fact been influenced by ethnographic studies. She writes:

"Als ich mit einigen Acholi-Ältesten im Norden Ugandas Gespräche führte, musste ich feststellen, dass meine Gesprächspartner Bücher und Artikel, die von Missionaren, Ethnologen und Historikern über ihre Kultur und Geschichte geschrieben worden waren, bereits gelesen hatten und mir daraus berichteten. In ihren Antworten begegnete ich also nicht so sehr einem authentischen Wissen, als vielmehr meinen eigenen Kollegen, in gewisser Weise also mir selbst. Auch fand ich heraus, dass es bereits eine Anzahl lokaler Ethnographien und Historiographien gab, die von Acholi wie Reuben Anywar, Alipago Latigo, Noah Ochora, Laito Okech und R.M.Nono, um nur einige zu nennen, geschrieben worden waren. In diese indigenen Texte sind auch die Texte von Europäern eingegangen, vor allem die von Missionaren der Comboni-Mission, die von Crazzolara über die Geschichte der Lwo (1937) und von Pelligrini über die Geschichte und "Tradition' der Acholi (1949)" (Behrend, 1993: 14) ${ }^{106}$.

During my research I encountered similar situations and responses. When I questioned my interlocutors about Acholi culture, they sometimes referred to books which had already been written on this subject. One interlocutor even showed me the book Living with Bad Surroundings by Sverker Finnström (2003) which he was reading because he was planning to make a movie based on two chapters in the book (field notes 14.04.2010).

In the following, I will draw on both sources - popular and ethnographic accounts of Acholi culture - and will summarize those aspects of Acholi political, economic, social and religious/spiritual life which both sources consider important.

\subsubsection{Socio-political Organization}

In ethnographic descriptions of the Acholi, different levels of their socio-political organization have been identified ${ }^{107}$. Girling (1960) differentiates between four levels: the household, the hamlet, the lineage/village and the domain. Crazzolara

106 "When I talked to some Acholi elders in Northern Uganda, I noticed that my interlocutors had already read and recited to me books and articles, which had been written by missionaries, anthropologists and historians about their culture and history. Thus, their statements did not primarily reflect an authentic knowledge; rather, I encountered my own colleagues, and in some ways myself. I also discovered that there were a number of local ethnographies and historiographies, which had been written by Acholi like Reuben Anyway, Alipago Latigo, Noah Ochora, Laito Okech and R.M.Nono - to name just a new. These indigenous texts also reflect the accounts of Europeans, especially those by the Comboni missionaries, by Crazzolara on the history of the Lwo (1937) and by Pelligrini about the history and 'tradition' of the Acholi (1949)" (Translation J.V.).

107 The inclusion in the political and administrative system of the British colonial state heavily impacted on the Acholi socio-political organization and will be further discussed below. 
(1954: 325ff.; 1938: ix f.) also mentions three segments above the household, which he refers to as clan group, tribal group and rwotship group. However, this typology is not maintained in all descriptions of the Acholi. More recent publications discern only three segments: the household, the localized lineage and the chiefdom (e.g. Atkinson, 1994: 5; Behrend, 1993; for a detailed account of the development of Acholi chiefdoms, cf. Atkinson, 1999).

According to the ethnographic literature, the lineage constituted the most fundamental socio-political unit in Acholi (Atkinson, 1994: 5). It was comprised of different households headed by agnatic kinsmen, who lived in the same area (i.e. what Girling refers to as "village"). The lineage members believed in the idea of a common ancestor and shared common traditions, taboos and totemic observances. Members of the same lineage were thus considered (distant) relatives and forbidden to marry one another (exogamy rule). A lineage collectively owned agricultural land and hunting grounds. Ritual authority was exerted by a lineage elder (ladit), whose main functions involved the supervision of moral rules and the regulation of the internal and external relations of the lineage (Girling, 1960: Chap. 5).

According to the literature, the chiefdom (or "domain", cf. Girling, 1960: 8) constituted the next higher social unit above the lineage. Atkinson (1999) dates the emergence of the first Acholi chiefdoms to the late $17^{\text {th }}$ century. According to Girling (1960: Chap. 6), a "domain" was made up of aristocratic lineages whose members were kinsmen of the ruler, and commoners who were unrelated to the ruler. It was ruled by a chief (rwot) who organized the agricultural production of the domain and was responsible for rain-making. The rwot was the ritual and political authority. However, his political power was rather limited, especially when compared to those of the kings among the more centralized and stratified groups in Southern Uganda. He did not possess a "coercive machinery for enforcing his decisions" (Girling, 1960: 100). Rather, his main task was to mediate between potentially antagonistic individuals, households and villages in order to achieve internal cohesion of the chiefdom. It is often mentioned that some rwodi of the larger domains did acquire substantial political influence, such as the rwot of Payira, however the nature and extent of their influence is highly contested ${ }^{108}$.

108 The proclaimed "paramount role" of the Payira rwot is especially debated, both in the literature and in popular accounts. Some authors and members of the Payira clan claim that he hailed from an ancient royal hierarchy and originally fulfilled the role of a paramount chief from the 18th century onwards (cf. Atkinson, 1999: 121ff.; 234ff.). They use this argument to legitimate why to date the 're-invented' post of the Paramount Chief has always been held by a Payira rwot (cf. Liu Institute for Global Issues, 2005: 30). Others (e.g. Girling, 1960: 156; 201; Allen, 2006: 149ff.) say that the Acholi never used to have a Paramount Chief and that this post was only invented by the colonial administration. Crazzolara (1954: 481) states that "Payiira (...) was perhaps the largest Rwootship of old Acooliland; its superiority however, was merely numerical. (...) It is, therefore, a plain deception to attribute to any of the former Payiira Rwoots the position of paramount chief in the Acooli country." 
The main purpose of the domain, according to Girling (1960: 97ff.), concerned the common organization of defense, of agriculture and of some rituals and ceremonies. Sometimes war was declared on another domain in order to loot women and cattle. Generally, however, the chiefdom constituted a relatively unstable political structure whose unity was continuously threatened by internal conflicts. It was not uncommon for a household or even a whole lineage to leave the domain and join another (Crazzolara, 1954: 327).

When comparing older ethnographic accounts with contemporary popular representations of the socio-political organization of the Acholi, it seems that the terms used to refer to different segments have changed. In conversations (in the English language) I had with people in Gulu, I never encountered the use of terms like "lineage", "chiefdom" or "domain". The only common term people used when referring to the socio-political organization of the Acholi beyond the level of the individual household was "clan". I had the impression that people mainly used the term "clan" to refer to lineage in the anthropological sense. According to Ker Kwaro (2010b: 2) "Kaka", the Acholi word for clan, "is an extended family unit comprising of a generational line including grandfather father's son (sic) and immediate next of kin". In this sense, $k a k a$ would be closer to the meaning of lineage than to the meaning of chiefdom/domain. Girling (1960: 196) writes that kaka "are social formations, which I have termed village-lineage in my analysis. They are known to the [colonial] Administration as 'clans"'.

In some contexts, however, people also used the term clan to designate larger social units, i.e. chiefdoms. 52 "chiefdoms" (often referred to as clans) are formerly recognized by Ker Kwaro Acholi, the "traditional institution" of the Acholi since 1995 (cf. Constitution of Uganda, 1995: Chap. 16, Art. 246; Liu Institute for Global Issues, 2005: 30f.).

Most of my interlocutors considered clans to still be relevant today. However, according to some elders I spoke to the knowledge about clans and clan membership was declining among the young generation, which seems to be a recent phenomenon and is also related to the massive displacement and break-up of families and clans during the war. In a group interview (in Paicho, 17.10.2010, translated from the Acholi original by John Omara), an elder lamented this loss of knowledge by saying: "These days people don't know their cousins, uncles and aunties... That is why sometimes there is a lot of incest". I often encountered similar statements which reflected a fear of incest as a result of the dispersion of families and clans and the lack of knowledge about kinship relations among the younger people. In fact, I even witnessed a particularly dramatic example of an 'incest case', when one of my interlocutors found out by coincidence that the man she had been dating for years was too closely related to her (field notes 20.-21.12.2010).

According to the literature, in former times knowledge about clan membership had been common knowledge. Crazzolara (1950: 109f.), describing the situation in the 1940s, writes that 
"[i]f one asks any Acooli, man or woman, about their clan membership, one can be certain that (...) the (sic) know and state without the least hesitation that they belong to such and such clan. (...) [T] bership is common knowledge in the district (...) and no knowledge is more general than (...) distinctions and divisions [between clans]. (...) [A] group, as a whole knows moreover very well about the existence of separated groups of their own clan in possibly distance parts of the country and beyond, and consider them as 'brother' clans in which one could not marry".

Some 40 years later, Atkinson (1994: 4) writes that "[over] the twentieth century, chiefdoms in Acholi have become vestigial institutions". When I asked my interlocutors about clans, both older and younger people usually talked about the functions of the clan and thereby differentiated between intra-clan and inter-clan relations. The internal function of a clan was most commonly related to two aspects: land ownership ${ }^{109}$ and the performance of certain rituals such as the last funeral rite for so-called "big people", for which all clan members would come together (personal conversations cf. field notes 10.05.2010).

Inter-clan relations were related to marriages which serve to establish bonds between different clans, and conflicts which create divisions between clans. When talking about marriages, people always stressed the ongoing importance of exogamy, i.e. the rule to marry someone from a different clan. People explained to me at length how marriage relations were established in the past, and how the marriage between a man and a woman not only affected the two individuals and their immediate families, but their two clans as a whole. Many stressed that to this day some of the long established marriage principles such as the payment of a brideprice are valued (cf. Ker Kwaro Acholi, 2010a/b $\mathrm{b}^{110}$ ). This is also reflected in the continuing importance and widespread practice of "traditional marriage" (which usually takes place before church marriage) throughout Acholiland (personal conversations cf. field notes 10.05.2010, 10.09.2010; INT Okello, 26.09.2010). In addition to marriage relations, which served to establish peaceful bonds between clans, my interlocutors also mentioned conflicts between clans which still occurred today, especially in the rural areas. A commonly mentioned reason for inter-clan conflicts was murder, i.e. when a member of one clan murdered a member of a different clan. In such a case, the

${ }^{109}$ In Uganda, there are currently different, parallel existing forms of land ownership. In Northern Uganda, much of the land which is not privately owned is clan land. Particularly, when discussing the resettlement process after the closure of the camps, people would often debate issues relating to clan land: Who was entitled to clan land? Where were the former boundaries? Could clan land be sold if people decided to stay in town? The issue of land and the conflicts related to it are currently a matter of great debate in Northern Uganda, which, however, I cannot pursue any further at this point.

110 The reports by Ker Kwaro Acholi describes Acholi marriage traditions in detail with the aim of defining and codifying "cultural principles" relating to courtship, the marriage process, brideprice, obligations, divorce etc. 
performance of certain rituals as well as compensation payments would be required in order to appease the clan relations (field notes 26.09.2010; group interview Wii Aweng, 26.09.2010).

In conversations and interviews about clans and the socio-political organization of the Acholi, my interlocutors always came to talk about the role of the chiefs. The chiefs constituted the most important representatives of the clan, both in symbolic and practical terms. It seemed to me that the term "chief" was used to refer to both 'local chiefs', i.e. lineage elders (ladit) and 'traditional', i.e. 'chiefdom chiefs' (rwot) depending on the context. To further complicate matters, "chief" could also be used to refer to government officials ${ }^{11}$.

As stated above, Ker Kwaro Acholi, the "traditional institution" of the Acholi since 1995, officially recognizes 52 Acholi "traditional chiefs" (rwodi moo), who are headed by one "Paramount Chief" (Liu Institute for Global Issues, 2005: 30f.). Whenever I asked about these "traditional chiefs", my interlocutors stressed that they (still) played an important role in Acholi society today - as cultural role models for the young people and preservers of cultural norms and rules, as mediators in community conflicts and as political and spiritual authorities (group interviews Bobbi, 06.10.2010; Bungutera, 03.10.2010; Wii Aweng, 26.09.2010; INT Okello, 26.09.2010). One of my interlocutors, who lived in Palabek, a rural area in Lamwo District ${ }^{112}$, summarized the current role of the chiefs as follows:

"Their most important role is in solving conflicts between clans, for example when a man from one clan murders a member from another clan. Then the big chief steps in to arrange for reconciliation and compensation so the relations between the clans are restored. Chiefs also play an important role in land wrangles. Another important function of chiefs is their role in dealing with evil spirits. Due to the war, many people have died outside their homeland and were not buried properly. Thus, people now fear that the spirits of the dead are disturbing them. Chiefs have to go to these areas and perform some rituals so that the spirits are appeased and no longer disturb the people" (field notes 20.12.2010, my interpretation of exact wording).

When comparing popular representations of the chiefs and the (older) ethnographic literature, it seems that the relevance of chiefs has increased in recent times. Chiefs have become key representatives not only of their clans, but of Acholi culture as a whole. A report by El-Bushra and Sahl (2005: 14f.) explains the potential reasons behind this:

${ }^{111}$ In Acholiland today, the term "chief" could mean different things. Besides the 'traditional' clan chiefs, there are also county, subcounty and parish chiefs, who are elected state officials in the Local Council system (cf. Tripp, 2010: 113) and have nothing to do with Acholi clan structures. Girling (1960: 195ff.) describes how these new 'government chiefs' were first introduced by the colonial administration.

${ }^{112}$ Cf. map (figure 2) in appendix. 
"From the 1930s onwards, the Acholi (like other Ugandan societies) were not allowed to anoint new chiefs. Instead, people were expected to hold allegiance to the Ugandan state and central government. However, in the 1990s, government liberalised its policy towards traditional authorities, and in 2000 Acholi started to revive the institution by holding anointment ceremonies for chiefs of all the clans. This was a controversial decision: some people (especially women and young people) felt that it was inappropriate to put the clock back, while others saw the chiefship as an integral part of Acholi identity. The revival of the chiefship was widely viewed as a positive step towards peace. This was partly because the chiefs would be able to carry out conflict resolution within their communities, but also because the anointments would reaffirm Acholi identity after decades of it being devalued, both by the Acholi themselves and by others" (my emphasis).

This interpretation suggests that chiefs, while not undisputed, are important symbolic figures, and serve as markers of Acholi identity both internally and externally.

The office and role of the chief have undergone significant historical changes, which partly account for their increased relevance today. The British colonial administration initiated this process in an attempt to centralize the Acholi political administration and render it more similar to that of the central Ugandan kingdoms, particularly that of Buganda. The British 'uplifted' the status of the chiefs and were the first to officially install a Paramount Chief. Atkinson (1999: 5f.) describes this restructuring of political authority in Acholiland:

"First, the imported Buganda-style council of chiefs, with a new 'paramount' chief, was further entrenched. Second, many formerly independent chiefdoms were amalgated, thereby extending the authority of some chiefs over peoples they had never previously ruled while demoting or removing others. Third, even those chiefs remaining in office were controlled much more than before (...). Finally, the administration 'jettisoned [their policy of following] a rigid adherence to the Acholi law of succession in the appointment of chiefs' in favour of a much more ad hoc process."

While most people I spoke to did not principally contest the authenticity and relevance of the clan chiefs, a matter of substantial debate was the office and role of the Paramount Chief. The post of the Paramount Chief, first installed by the British, was revived under the 1995 Constitution which lifted the ban on cultural institutions that had been put up by the Obote II administration. My interlocutors often asserted that in former times the Acholi had only had different clan chiefs, but never an overall paramount chief. Some told me that this post had just been invented to have a representative figure similar to that of the Baganda (personal conversations; cf. Finnström, 2008: 44ff.; Paine, 2011; Atkinson, 1999: 5; Liu Institute for Global Issues, 2005: 30f.). One informant gave another reason for the introduction of the 
Paramount Chief, namely the need for a political authority, which could solve conflicts between the Acholi people:

"Ah, this one was just introduced politically. This one has been bought because certain clans were fighting one another like that, always quarreling, killing, killing, always waging wars against one another, so they have brought people who decided that they should put a paramount chief, like the governor, if he can govern all, so that we have a small constitution which can guide them. (...) So people have a government now, to get that peace, you don't misbehave, because if you misbehave, people have their traditional constitution there, they will just come together with the paramount chief, then they will act accordingly" (INT Okello, 26.09.2010).

In summary, one can say that with regard to the socio-political organization of the Acholi there are some disparities between (and within) the ethnographic literature and contemporary popular representations. This is due to political changes, which have occurred throughout the $20^{\text {th }}$ century, but also due to discursive effects, i.e. that for reasons hinted at above some elements of Acholi political organization have been discursively constructed as more relevant than others (I will come back to this point in the third part of my analysis). The same can be said for the representations of social organization and family life, which I will turn to in the next section.

\subsubsection{Social Organization \& Family Life}

Both ethnographic and popular accounts of Acholi culture devote significant attention to the individual household, which can be comprised of a nuclear family or an extended family depending on the context and the definition. In the Acholi language, one can differentiate between " 'Ot' (household), [which] means the smallest family unit consisting of a man, wife (or wives) and their children" and "Paco dogola' (family), [which] is a collection of two or more households who are related and headed by a family head" (Ker Kwaro, 2010b: 2). Some major issues can be discerned which are commonly discussed with regard to the household and Acholi social life:

- the formation of the household through marriage

- the household as economic unit

- the household as a place and institution for the socialization of children.

In the ethnographic literature, the household is described as the smallest unit of Acholi social organization which was headed by an adult man. Girling (1960: 21f.) describes the typical formation of a household as follows: upon marriage, a wife was expected to move into her husband's hut, whereby the union was not fully 
acknowledged until the birth of the first child ${ }^{113}$ (cf. Nzita, 1997: 92). Marriage constituted a central criterion for both men and women to achieve their full status as adults (Onyango-Odongo \& Webster, 1976: 209f.) and it followed culturally defined rules, which Girling (1960: 65ff.) has outlined in great detail ${ }^{114}$. Polygyny was allowed and considered as ideal among men. A man could increase his number of wives (and thus his status) through different forms of marriage and also through inheritance of wives from his father or brothers. According to the literature, arranged marriages comprised the most common form and required the payment of a brideprice by the family of the husband. Among my interlocutors, the question whether marriages in the past were arranged (and whether this meant that the marriage partners had no free choice) was a matter of considerable debate. Most of them believed that the right to select a marriage partner had existed for both the man and the woman and was the most common basis for marriage. However, most acknowledged that arranged forms of marriage or "forced marriage" had also occurred in the past, and still occurred in the rural areas today (personal conversation cf. field notes 14.03.2010; INT Okello, 26.09.2010).

The literature states that the amount and the form (cattle, goats, cash...) of the brideprice was to some extent determined by the overall economic situation and thus varied considerably over time. According to both Girling (1960: 72) and Schäfer (2008: 332) the obligation to pay brideprice and especially the monetarization of the brideprice in the course of the $20^{\text {th }}$ century has always prevented men from poor families to marry women of higher status (for instance the daughter of a rwot), or to marry polygamously. Atkinson (1994: 5) states that divorce was not uncommon in former times and in some cases involved the refunding of the brideprice to the man's family (for a contrary depiction see Onyango-Odongo \& Webster, 1976: 210).

According to the literature, often written from a functionalist perspective, the household served both social and economic purposes and was spatially arranged accordingly (Ocholla-Ayayo, 1980: $21 \mathrm{ff}$.) ${ }^{115}$. Girling (1960: 25ff.; 61ff.) describes the 'normal' household ${ }^{116}$ as a unit of production. All family members, i.e. father and mother as well as the children, when they reached a certain age, were involved in

113 The Acholi are generally classified as a localized patrilineal descent group, although, as Finnström (2003: 56f.) points out, the principle of matrifocality is (inofficially) recognized in some instances. Girling (1960: 68) writes that patrilocal residence often proved difficult for the young women at first. They were treated as strangers with no rights and eyed with suspicion until the marriage and the birth of the first child.

114 There have been recent attempts to codify these principles of Acholi marriage (cf. Ker Kwaro Acholi, 2010a/b).

115 Ocholla-Ayayo (1980: 21) writes: "Housing has a close functional relationship to the habits of social organization and of the cultural system of the people. (...) This is represented in the layout of the positions of the houses in a village, or general patterns of settlement of the society".

116 In his chapter on the Acholi household, Girling (1960: Chap. 3) first describes a typical Acholi household and then mentions other types of households, for instance mature and immature households, royal households etc. 
agricultural work which provided the main base for subsistence. A division of labor existed within each household and was gender-based. Men carried out the heavy agricultural work (such as clearing the fields), participated in hunts and were in charge of the protection of the household. Women were also involved in the cultivation of the fields and, furthermore, were responsible for raising the children and for other household tasks such as collecting and preparing food and fetching water and firewood. In polygamous households, each woman had her own fields, granaries and a hut with her private belongings for which she was responsible (Girling, 1960: 27f.; Ocholla-Ayayo, 1980: 34f.). Inheritance of land and other important household belongings (cattle, for instance) followed patrilineal principles. Atkinson (1994: 5) writes that "apart from land, the rights to which were passed on equally to all sons, the eldest son was traditionally the designated heir of his father's property, although he was supposed to provide for his younger brothers". Wife inheritance among the Acholi, i.e. the inheritance of the wife of one's deceased father or brother, is also described in the literature (Girling, 1960: 62ff.).

It is widely believed that in pre-colonial and pre-missionary times, the household was the main site for the socialization of children. According to the literature, differences along the lines of gender were of high relevance in Acholi society and played an important role throughout the whole process of socialization (OchollaAyayo, 1980: 37ff.; cf. Ssekamwa, 2000: 2f.). Atkinson (1994: 5) writes:

"Form early on, girls and boys learn gender-appropriate behaviours and activities, and these are reflected in both their play and their chores and other responsibilities. Sons have traditionally learned about farming, hunting, herding, and lineage and chiefdom traditions from their fathers and other lineage males; girls learn farming and domestic duties from their mothers".

Girling (1960: 22f.) describes sex-specific rituals which were already performed during the birth ceremony. For example, the umbilical cord of the new-born baby was cut with an instrument specific to its sex: a spear or an arrow if the child was a boy and a piece of thatching grass if it was a girl. Furthermore, during the birth ceremony, the baby was encircled by articles it would need in his/her later working life as a man or as a woman. For girls, these articles included millet stirring sticks, grinding stones for making millet flour, a winnowing basket and a small waist knife. Typical boy-items included a hoe, spear and shield or a bow and arrow.

The descriptions of a "traditional household" by my interlocutors in many ways resembled the accounts in the literature. According to popular descriptions, an ideal Acholi household was made up of a polygamously extended family and headed by an adult man. His wives would each have their separate hut and fields, but in the evening everyone including the children would come together to eat and share educative stories at the fireplace, the wango-o (see below). As one of my interviewees described: 
"We used to have homesteads like that, so people in that homestead gather together, they eat together, the children are taught together, cultural activities, the fathers used to tell us riddles, short stories like that, and the stories would just have meanings..." (INT Okello, 26.09.2010).

Generally, it seemed that many of my interlocutors had a very 'romanticized' understanding of family relations in the past. Marriage relations were seen as more stable and the relationships between all household members - between men and women, parents and children and even between co-wives (although this was a matter of much debate ${ }^{117}$ ) - were described as harmonious. My interlocutors explained that this was because marriage partners were more carefully selected in the past. According to their accounts, marriage had formerly been a long procedure, in which several meetings and negotiations between the families and clan members took place before a couple could get married and establish their own household. When asked whether marriages were forced in the past, older people usually stressed that they were not so much forced, but more embedded and controlled by the family and that young men and women could not just choose anyone as their marriage partner. I discussed this matter in an interview (INT Okello 26.09.2010) with Samuel (25) and his father Okello (in his late 70s):

Samuel: "What I understand is that a girl and a boy first, after meeting, they had to agree first before telling the parents, because you cannot tell the parents if there is no agreement (...) So after they had come into agreement, then the parents would come in. You cannot do it alone without the parents, so after telling your father, the father will go and negotiate"

Okello: "There was no forced marriage. It may take two or three years before the boy marries that girl, the whole process, because it goes very very slowly. It goes back to asking about the history of the clan: 'How are they behaving there? Are there people, who are also involved in killing people?' - Ah, no no no, then I don't like my daughter to go there. And these people: 'Are they magicians? Do they have local herbs to kill people?' - No no no no, my daughter cannot go there! The relatives can get all those stories. Only after understanding that things were good, that the clan was good - no misbehavior, no killing...- then they would say: 'Yes, my daughter can go'. That is why all those marriages were fixed."

As will be discussed in the next section, today, most living arrangements did not resemble the ideal homestead, neither in the village nor in town, and this point was often stressed by my interlocutors and linked to the time of displacement. There

117 Some of my interlocutors claimed that relationships between co-wives had always been conflictridden and that polygamous marriages were inherently conflictive (personal conversations cf. field notes 04.09.2010; 07.09.2010; 10.09.2010). 
was a general decline in polygamous marriages, and in most of the still-existing polygamous families (at least in town), the women and their respective children would not stay together, but would have separate residences. Often violent quarrels between the co-wives erupted (personal conversation, e.g. field notes 02.01.2011; cf. Tibatemwa-Ekirikubinza (1999) for a general analysis of violence between co-wives in Uganda) and most of my interlocutors, who had grown up in polygamous families told me that this type of marriage and co-residence was no longer working in an urban, 'post-traditional' society. The following quotation is typical:

"Currently life is not fine, because there are a lot of conflicts within the family, conflicts among the children and the elders, and especially in polygamous marriages. So in the past, some children would be very happy and grow up with their stepmothers. Co-wives would just be very happy among themselves, because people would follow culture. Culture says it is very normal for a man to have multiple wives and the women should be in good terms. And elders would tell their children 'your stepmother is just like your mother, so respect your stepmother the way you respect your mother.' This is not the situation now, people don't respect stepmothers, co-wives just fight all the time..." (elderly man, group interview Bobbi, 06.10.2010, translated from the Acholi original by John Omara).

Gender relations were often described as having been complementary in the past, and this was generally seen as something positive. While the normative model of Acholi masculinity (which has been analyzed by Dolan, 2002 and El-Bushra \& Sahl, 2005), emphasizes and historically legitimates the subordinated role of women in Acholi society, my interlocutors - both men and women - took a more nuanced stance on this matter. They agreed that "traditional Acholi culture" discriminated against women regarding some aspects such as inheritance laws, but some also stressed that women had had a better standing and more influence in the past than is generally acknowledged. A female interviewee, who was working in a project on gender-based violence conducted by Ker Kwaro Acholi, told me:

"Traditionally, women elders were there and played an important role in the traditional councils. Also, traditionally men had to consult their women when making decisions for the household. So for example if they wanted to sell a goat they had to ask the women and if they refused, they couldn't sell the goat. Or if they sold it without a woman's approval she might apply witchcraft and in many cases the men died or were injured. So in a way women were very powerful and respected in Acholi society" (INT SK, 23.03.2010).

Another interviewee, Okello (INT 26.09.2010), explained:

"In the clan, these elderly women were also having status, some of them were called rwot okoro, or rwot mon - that is the head of the women in the clan. 
They would be just put in charge of that one, so all the women would just respect one elderly woman there, who has the knowledge to teach the young ladies how to manage their affairs. So they have very big roles, and if there is anything, like marriage, women would have to be consulted first, because everything was controlled by women. Even if you have a small chicken like this, you can't take the chicken without asking the woman, if she says no, it is no, you don't force it. If it is a goat, the goat belongs to that woman, if she agrees, it can be slaughtered, or it can be taken as part of the dowry. Women were the ones who were controlling our wealth, even when those ordinary coins came, the money... Like cotton, we were growing cotton, if cotton is sold and the money is brought you give it to mummy, the mummy would know how to keep it, keep it in a small pot there, put it in the ground, hide it and seal it well. Money was not taken to the bank, because they fear men could go hunting and they can be killed, so the wealth would be lost, so if the woman keeps it there at home... So that was their biggest role - control of money was on women."

The same interviewee stressed that "traditional Acholi society" was much more gender equal than today, despite all the recent talk of women's rights in Uganda:

"Many of the men of these days are not familiar with the knowledge our bigger parents were giving at the wango-o, so they tend to deprive the women, they say 'ah, this mere woman, how can you keep my money, no I keep the money myself...' Then they go drinking, they spend it and say: 'I am the one who married you, how can you come across and say you are the manager of my property'..." (INT Okello, 26.09.2010).

The gendered division of labor and learning was often referred to when people talked about Acholi family life. Akello once told me that even at school they were taught "what girls and boys are supposed to do in Acholi culture". In history classes, they learned how in the past Acholi girls would be taught how to behave respectfully and be good housewives, while boys would learn how to control a family well (field notes 28.10.2010). My interlocutors always stressed that in the past gendered learning also took place at the wango-o, the fireplace, where everyone gathered in the evening. In the words of one interviewee: "Initially, just from the wango-o, girls and boys would be told their roles. So they would stick to their roles, from boyhood to manhood, from girlhood to womanhood" (participant in the group interview in Bobbi, 06.10.2010, translated from the Acholi original by John Omara).

In fact, the wango-o was the single most important aspect people mentioned when talking about the household or homestead "in those days". I always asked my slightly older interlocutors whether they themselves had ever experienced the wango-o when they were young - and those who had always remembered it with much nostalgia. Samuel (25 at the time of the conversation), for instance, reminisced: 
"I remember that when I was very young and still in the village there used to be a wango-o every night and that it was so beautiful. The children used to sit in one circle around the fire surrounded by the adults so they wouldn't get cold. Then the elders would tell educative stories. (...) The best stories would always come from the hunters - about how they had to perform certain rituals when they killed a lion or a leopard, how they protected themselves from wild animals, how there were different types of hunting, mainly in the dry season and how it was mainly young men but sometimes also women who would go for hunting. I never went hunting because I left the village, when I was still young, about six years, in 1989, and then grew up in town. Today hunting is banned in many areas in order to protect the wildlife for tourists" (field notes 10.05.2012, my interpretation of exact wording).

Interestingly, in the older ethnographic literature the wango-o is only mentioned briefly, if at all. Girling (1960: 45), who conducted his fieldwork in the 1950s, writes that "the wang-o (...) is found more rarely today. But it was at one time a feature of every hamlet, and all the authorities from Baker onwards have mentioned it." However, in recent attempts to 'rebuild' Acholi culture the wango-o has been singled out as the "foundation of Luo culture and family values" as has been described by Cagney (2011: 22). She also states that

"Wang'oo is already being used by various Ugandan and non-Ugandan organizations in the community setting, and they are also adopting the concept for use in rehabilitation and community centers. (...) With the myriad of social restructuring, hybridizations, and tension amongst social groups, fully reviving wangoo can be a very powerful tool, as it opens up a safe space for dialogue in which communities can discuss their traditions, their issues, and their reactions to globalization's effects on their communities" (ibid.: 53).

While my interlocutors talked about many different aspects of "traditional Acholi culture" in "those days" with much nostalgia, the mutual solidarity inherent in Acholi family and social life, symbolically represented by the wango-o, was among the things most positively remembered. The perceived loss of this communal life was always mentioned when people discussed socio-cultural changes in Acholiland as will be further analyzed below.

\subsubsection{Economic System}

The ethnographic literature states that in pre-colonial times the Acholi relied on a mixed economy. Subsistence farming was complemented by large dry-season hunts, the gathering of wild foods and the tending of small stock. Home-grown staple foods included millet, sesame, sweet potatoes, ground nuts, cassava, peas, beans and maize (Girling, 1960: 16; Atkinson, 1989: 20f.; Nzita, 1997: 96). Furthermore, 
ironworking is mentioned by different authors as an ancient profession among the Acholi for which they were well-known (Girling, 1960: 17f.; Atkinson, 1994: 4). According to the literature, the Acholi relied largely on their own subsistence until the 1920s, when the British colonial administration introduced money as a form of payment and cotton as a cash crop to be grown for the exchange economy. Precolonial trade focused mainly on obtaining iron ore and later, in the late $19^{\text {th }}$ century, also on ivory, slaves and cattle (Girling, 1960: 16f.; 190ff.; Atkinson, 1994: 4).

There is some debate regarding the importance of cattle in the Acholi economic system. While many authors (for instance Ocholla-Ayayo, 1980: 31ff.) assume that all Luo are principally pastoralists, Atkinson (1989: 21; 1999: 61f.; cf. also Onyango-Odongo \& Webster, 1976: 212f.) states that among the Acholi cattle seem to have been a significant economic and occupational factor only for those groups living in the dry areas in the East and in the North of Acholiland ${ }^{118}$. However, as will be discussed below, in popular recollections of "those days", cattle are always mentioned as a very important form of economic and symbolic capital as they constituted a central part of the brideprice (cf. Girling, 1960: 71f.).

According to the literature, a low diversification of the early economic system of the Acholi accounted (among other things) for a low stratification of Acholi society. Mamdani (1976: 21) states: "The relations of production under the communal mode of production were cooperative, not antagonistic. (...) This was a poor and fundamentally egalitarian society. Material distinctions between families were of little importance."

Ethnographic sources describe that land rights were vested in localized patrilineages, which assigned small patches of land to each household. Everyone was required to help in the cultivation of the fields. Therefore, working parties (awak) were formed. Only the rwot was exempted from communal work. To him all members of his domain had to pay customary tribute in form of agricultural labor (Atkinson, 1994: 4; Girling, 1960: 21).

Girling (1960: 174ff.) analyzes how the organization of labor gradually changed after the arrival of the British colonizers. More and more land was privately owned and working groups were no longer organized among kin. Instead of relying on a system of mutual support and communal labor, wealthy Acholi started to pay workers to cultivate their land (cf. Mamdani, 1976: 133f.).

When people today talk about economic life in "those days", they usually remember it with great nostalgia. The past is envisioned as a time of economic prosperity, when every household had fertile land and was able to harvest enough to feed the family. "Digging", i.e. cultivating the fields, is still seen by many as the embodiment of "traditional" Acholi identity and lifestyle. Most of my interlocutors described the Acholi of the past as proud, successful and responsible farmers, as in the following quote by Innocent, a university graduate:

${ }^{118}$ He speculates that this may be due to the heavy tsetse fly infestation in large parts of Acholiland. 
"In those days, people were more responsible and it was the prime aim of everybody to ensure food security and make a good living for the family. The men would try very hard to take good care of their wives and children and no one had to go hungry because people were really committed to digging in the gardens" (field notes 05.05.2010, my interpretation of exact wording).

While farming was by far the most important occupation attributed to the Acholi, other economic activities like dry season hunts and animal rearing were also mentioned frequently by my interlocutors. The widespread prevalence and important role of cattle were often emphasized as in the following two quotations:

"Our fathers were having hundreds of heads of cattle, the land was vast..." (INT Okello, 26.09.2010).

"Acholi were rich in the past - so every household had at least some goats and cattle so boys would also learn to take care of them" (male elder, group interview Kapedopong 28.06.2010, translated from the Acholi original by Kenneth Oyet Odong).

In a similar fashion, my interlocutors often reminisced about the economic success of past days which enabled men to marry many women, while today many struggled to pay the brideprice for just one woman, as in the following quotations:

"Polygamism was rampant in the past, because people could dig, you could even have ten wives, so you give them gardens, they can dig on their own, they can look for food. Not like these days whereby people depend on the salaries. You depend on a salary from only one point - how can you serve ten women?" (Samuel, INT Okello, 26.09.201)

"Long time ago, people kept cattle, so if it comes to [brideprice] payment you just pick cattle from your Kraal, then you go and pay" (INT Henry \& Bangi, 27.04.2010).

Economic activity in the past was described as a communal task, which served to unite the people who lived close to each other, and some of my interlocutors lamented that the communitarian spirit of past days had disappeared in today's society. The following quotations are good examples:

"People used to live a communal life in the villages, share many good things, a lot of animals...There are changes, so that those things are no longer there. (...) Now that poverty has come, everyone is only for himself and for the family" (INT Ojara, 17.03.2010).

"We used to have community work, we call it awak - that is community work. One day, everybody, all the men, go to serve in his garden, so if we 
have 40 men, we can work on two gardens in one day, finish it all for you. Then the next day for me and my wife, the next day for him [points to Samuel, who is sitting next to us]. So everybody will have the same garden. In time of weeding - do it together, rotating; during harvesting - also rotating like that. So food is harvested and put in the granary, everybody must have five granaries, so we all have enough food. How can you quarrel now? You want simsim [local term for sesame] - you go and get it from the granary. So there was peacefulness in the family..." (INT Okello, 26.09.2010).

One interviewee, who was working for SPRING (Stability, Peace and Reconciliation in Northern Uganda), a development program, told me about a project which aimed to revive (the knowledge about) communal farming and storage of past days. He explained:

"In those days the Acholi used to farm together. This is why the project is a little bit unique - people get interested in knowing the old old things (...) We decided to produce a corporative bilo for this farmer's group (...) People used to dig together during the old days, it is a communal type of farming, now when you look at the cover of the bilo itself, it talks about those old days and how the Acholi used to farm (...) So when people look at it, they say 'this is part of the culture", so they tend to respect it (...) and they start mutual respect between the farmer's groups..." (INT Mike, 23.03.2010).

In Acholiland today, farming is still considered an important economic activity even for those employed in the monetary economy. Most people in town either have a small patch of land close to their homes or larger plots of land in their home villages which they use to cultivate different food crops for their own consumption. During my research, children and youth often told me that they spend their school holidays in the village to help their families with farming. Some youths even managed to pay their school fees by selling part of what they harvested from the fields in the local markets (INT Ajoka, 08.05.2010). Most young people in town, however, could not imagine relocating to a village to start a life as farmers. As one of my interviewees put it:

"I don't fit in a village, because - what I want in life is not there in the village. The village is fit for the farmers. Well, for me I don't look like somebody who can hold a hoe, for me to survive I use my head, I don't use much of my energy..." (INT Joseph, 14.12.2010).

Although a complete change to a lifestyle as farmers was not an option for the majority of my urban interlocutors, farming was still seen by many as the embodiment of Acholi identity and one of the most characteristic elements of Acholi culture. 


\subsubsection{Religious \& Spiritual Beliefs}

Much has been written about Acholi religious and spiritual beliefs, especially due to the emergence of different 'spiritual' (military) movements in the 1980s, which gained international prominence due to their 'spectacular' resistance against the new NRM government. The Holy Spirit Mobile Forces founded by Alice Auma at the beginning of the war in Northern Uganda are probably the most well-known of these (cf. Chap. 3). In my summary of the ethnographic literature, I will only recapitulate the most commonly mentioned and important aspects of Acholi spiritual life.

According to ethnographic accounts, the Acholi believe in several different spirits, usually referred to by the term jok (pl. jogi), which can take possession of animals and humans and which live in the wilderness, i.e. in mountains, rivers and lakes (Behrend, 1993: 120; cf. Okot p'Bitek, 1980: 71 cited in Behrend, 1993: 120; Girling, 1960: 80f.). Atkinson (1994: 6) differentiates between three types of spirits: the spirits of known relatives, mainly lineage ancestors, non-ancestral spirits related to a chiefdom, and spirits of unknown persons and dangerous beasts. While the two former are described as beneficial spirits, which bring health and fertility, the latter are classified as hostile spirits, which cause sickness and misfortune and are dealt with through processes of spirit possession.

Behrend (1999: 22) depicts the power of jok as deeply ambivalent and explains:

"It could be used for good and bad purposes, for healing, and for killing. Thus, in precolonial times, the chief (...) would use the power of the chiefdom jok to advance the well-being and the fertility of the land and its people. However, he would use the same power to wage a war against a neighboring chiefdom. The chiefdom jogi were guardians of the moral order. A more or less immoral state of society would make them angry and would result in their sending social or natural catastrophes. Thus the jogi were held responsible for misfortune and catastrophes which hit the chiefdom and, at the same time, were a power against them."

Atkinson (1994: 6) portrays different religious specialists among the Acholi. Lineage heads and elders were most knowledgeable about spiritual matters and therefore most involved with the spirits. Spirit mediums (ajwaka) who used their spiritual powers for the general good could be consulted in cases of sickness or disaster. By contrast, witches and sorcerers worked for evil and destructive purposes (cf. Behrend, 1991; 1993: 127f.; 1995; 1999; Onyango-Odongo \& Webster, 1976: 211f.).

Different ceremonies, associated for instance with birth, death, harvest or hunting, which served to worship and appease the spirits, are commonly mentioned in the literature. During these public events, small offerings were provided to the spirits at the ancestral shrines (abila), so that they would exercise their power to fight evil spirits which could negatively influence the planned events (Atkinson, 1994: 6; Nzita, 1997: 92f.; Behrend, 1993: 121ff.). 
Behrend (1993: 123ff.; 1999: 22f.) has analyzed how in the course of history, and especially due to political developments since the end of the $19^{\text {th }}$ century (e.g. the arrival of the British, the increase in local warfare, the war in Acholiland) several new spirits appeared among the Acholi, which she labels "free jogi" (Behrend, 1995: 55; 1993: 123ff.). She proposes that in this way external influences and contacts with foreigners were incorporated into the local cosmology and mythology:

"Zu Beginn der Kolonialzeit, aber vielleicht auch schon davor, erschien eine Anzahl neuer Geister in Acholi, die von außerhalb des Landes kamen. Diese waren mit Attributen ethnischer Fremdheit versehen, die bestimmte Erfahrungen der Acholi in dieser Zeit zu Hypostasen verdichteten. Anhand der Bilder, die die Geister entwarfen, ließe sich eine Geschichte der Fremderfahrungen aus der Perspektive der Acholi rekonstruieren."119

The first Christian missionaries arrived in Northern Uganda in the context of the insetting colonialism at the end of the $19^{\text {th }}$ century (Ssekamwa, 2000: 27ff. ${ }^{120}$. According to Behrend (1993: 129f.) the missionaries were met with scepticism at first, among other things because the local people regarded them as collaborators of the colonial administrators, especially since they supported the collection of taxes and exerted influence on the local political administration. However, as in many other African contexts, the missionaries were the first to instate formal education which quickly gained importance among the local population. Up until the 1950s, more and more Acholi joined one of the Christian churches. Behrend (1993: 128ff.; 168f.) asserts, however, that Christianity did not completely supplant local spiritual beliefs, but rather that elements of both systems of belief were combined or coexisted (cf. Girling, 1960: 187).

During my time in Gulu, I did not conduct any systematic research on religious and spiritual beliefs among the Acholi ${ }^{121}$, although the topic often came up in discussions of cultural practices which had been forbidden by the Christian churches. Most of my interlocutors were members of a Christian congregation (i.e. Roman

119 "At the beginning of British colonial rule, or maybe even before, several new ghosts appeared in Acholi, which came from outside the country. These were associated with 'foreignness', and they reflected certain experiences of the Acholi during this time ('hypostasis'). Based on the images of these ghosts one could reconstruct the experiences of foreign influences throughout history from an Acholi perspective" (Translation J.V.).

${ }^{120}$ Ssekamwa (2000: 29ff.) describes that the Muslim Arab traders also tried to spread their faith through the establishment of educational institutions, and that subsequently severe conflicts erupted between Muslims and Christians in Uganda. These conflicts about religious and educational hegemony, however, were centered in the Buganda region and revolved around who would gain influence over the Kabaka and his followers. The ethnographic literature does not mention any substantial Islamic influence on Acholi beliefs. Some recent writings discuss the existence of Islamic influences within Joseph Kony's LRA (cf. e.g. Doom \& Vlassenroot, 1999: 25ff.).

${ }^{121}$ In fact, I tried to avoid the topic, because I did not want to discuss my own religious convictions. People, especially those with strong religious convictions, often expressed surprise and irritation when I admitted to them that I was not a member of any Christian church or other faith group. 
Catholic, Protestant or one of the many Pentecostal churches) $)^{122}$. While some of them actively practiced and 'preached' their religion, others did not actively follow religious traditions at all, although they asserted that their religious association was an important part of their identity. When I asked about Acholi spiritual beliefs and practices, many people were quite ambivalent. At first, they usually emphasized that "traditional beliefs" were an outdated idea which had been practiced by former generations but were no longer applicable today because they had been ousted by Christianity. This interpretation is reflected in the following quote by a male interviewee (20 at the time of the interview):

"They used to have a very local generation, because..., maybe I start with their belief: Their belief was not on the issue of God or maybe Allah or whatever, but they used to believe in things like big mountains and hills or big trees. They believed that their ancestors had gone there, that their spirits hung around that place. So when they want to beg for rain, maybe when the rain has delayed, they go there, beg for it, pray, pray over the big mountains. They say the ancestor has gone with the rain. If they ask them, then they will bring the rain, they go, celebrate the thing, maybe they slaughter [an animal for sacrifice] and do many things... Their culture was quite different from ours. Nowadays, things like funeral rites, it is not done nowadays due to this idea of Christianity. They [Christians] take it as a bad act nowadays, if you do it..." (INT Nura, 21.04.2010).

However, many of my interlocutors also expressed uncertainty when I asked them whether they believed in jok. Some tried to avoid the topic, others acknowledged that there could be something like spiritual powers, and admitted that there had been situations in their lives, where they had felt the power of jok (personal conversations cf. field notes 09.10.2012; 07.09.2010; 15.08.2010; group interview Bungutera, 03.10.2010). It seemed that some of my interlocutors could integrate their acknowledgment of jok with their Christian beliefs, while others, especially those, who were very active church members, were radically opposed to everything connected with 'traditional religion' and the idea of jok. The following is an extract from my field notes about a conversation I had with a pastor of a Seventh Day Adventist Church in Palabek:

"We also briefly talk about jok as he tells me about the mountains near Palabek which mark the border to Sudan. I ask him whether people go there to make sacrifices to the ancestors. At first he seems a bit reluctant to talk about this issue. He says that he isn't sure whether people go to these mountains here, but that there are certainly mountain places where people, who believe in jogi, go. Then he says that he as a Christian does not believe in these things and that he sometimes

${ }^{122}$ Islam is also present in Acholiland, and - according to popular perception (personal conversation cf. field notes 28.10.2010) - the number of Muslims is on the rise. However, none of my closer interlocutors was a Muslim. 
has trouble with other people because of that. He gives an example: his wife had twins three times and each time people would tell him that they should perform the twin ritual. Each time he refused. He says he also doesn't make sacrifices to the shrine and that he opposes the practice of traditional funeral rites, which is still widespread. He adds that nowadays most people accept his behavior..." (field notes 20.12.2012).

Funeral rites and the ritual performed to celebrate the birth of twins ${ }^{123}$ were the most common examples of spiritual practices mentioned by my interlocutors (personal conversations cf. field notes 23.08.2010; 07.09.2010). People often stressed that these practices had been forbidden by the Christian churches, whereby some felt that this was a good thing, while others lamented that it contributed to the erosion of "traditional culture" (cf. e.g. group interview Pabbo, 23.10.2010). Sometimes my interlocutors also mentioned that they feared the spirits of the dead, especially of those who had died during the war and who had not been buried properly, when I asked them about spiritual beliefs. The following is an extract from an interview in which this subject is discussed:

"Samuel: The belief [in spirits] is still there (...) Do you hear about what NUTI [Northern Ugandan Transition Initiative - a peace-building program by USAID] is doing? They are reburying, they are collecting the bones [of the dead]...

Okello: They are exhuming the dead which were not buried, they slaughter goats, they rebury it [the bodies] again, do the necessary part...

Samuel: And they also still do sacrifices to the hills, they sacrifice things...

Okello: Because, especially during the time when people were beginning to go back home, when they go to certain places where they had been [before the war], where their ancestors had been, people get mad, they shout... The ghosts would just come and scare people...

Samuel: ... when you are digging in the gardens, you can hear very many soldiers singing, but you cannot see them...

${ }^{123}$ Nzita (1997: 92f.) states that the Acholi attributed any "abnormal" birth to the gods, and twins constituted the most common form of abnormal or godly births. Thus, when twins were born, various ceremonies were conducted. My interlocutors explained to me that these rituals are performed to honor the twins and the parents because people believe twins have supernatural powers and thus must be honored and appeased. They also pointed out that the Acholi believe that without the rituals the twins may die or have a bad life (field notes 07.09.2010; 23.08.2010). 
Okello: ... or at times you hear guns - bumbumbum - people get scared, they run, although you don't see anything... So that spirit - you know it is there. So the Paramount chief is going to places like that, giving sacrifices to certain mountains, in certain hilly places, to just cool things...

Samuel: But the belief is there!

J.V.: $\quad$ So is that what you call $c e n^{124}$ ?

Okello and Samuel: Yes, cen!"

(INT Okello, 26.09.2010).

To conclude, one can say that knowledge about jok and certain spiritual practices are still widespread in Gulu even among the younger generation. However, it seemed to me that in public most Acholi, at least those living in the urban centers, only disclose their association with one of the 'official religions', which they regard as an important part of their identity. The belief in jok is rarely discussed in public, and when I directly confronted people with the topic, many of my interlocutors expressed quite ambiguous attitudes towards Acholi spiritual beliefs. Thus, while the supposed decline of 'traditional' social and economic practices is bemoaned by many, the perceived fading of 'traditional beliefs' is regarded with greater ambivalence.

\subsubsection{External Influences \& Socio-Cultural Changes before the War}

All the ethnographic accounts I consulted acknowledged that Acholi culture was by no means static and had undergone substantial shifts over the course of the past centuries - through migrations, internal dynamics, but most importantly through contacts with foreigners and external influences.

The first major external impacts, which have been extensively documented in the literature, occurred in Acholiland in the middle of the $19^{\text {th }}$ century through the slave and ivory trade. Acholiland was positioned in the middle of two large trading systems - Zansibar in the South and Egypt/Sudan in the North - which both attempted to control the slave and ivory trade on the East African coast. According to Mamdani (1976: 20), the kingdoms in the South of Uganda were able to control and profit from the trade to some degree, while the peoples in the North were fundamentally exploited as slaves, and cattle and ivory were raided from them on a large scale (cf. also Onyango-Odongo \& Webster, 1976: 163). Girling (1960: 131)

\footnotetext{
${ }^{124}$ According to Finnström (2008: 159ff.), cen are the spirits of people, who died violently (cf. Behrend, 1993: 124f.).
} 
states that by the mid-1860s most of the Acholi cattle had disappeared. Atkinson (1989: 35), however, maintains that the Acholi suffered to a lesser degree from these raids than their neighbouring ethnic groups and even assisted the foreign invaders. According to Girling (1960: 131), the interests of the Arabic speaking traders were mainly economic, therefore neither the traders form the North nor those from the South tried to gain direct political control of the area and thus interfered relatively little in the political organization of the Acholi.

Coastal trading is seen to have caused major changes in the relationships between different Acholi groups. Atkinson (1994: 6) states that the introduction of small firearms and attempts by different Acholi domains to profit from the trade led to a massive increase of cattle raids and a drastic intensification of local conflicts. Behrend (1993: 26) speaks of an insetting endemic war in the North which lasted until the arrival of the British colonial power at the end of the $19^{\text {th }}$ century (cf. Onyango-Odongo \& Webster, 1976: 164ff.). Crazzolara (1951: 239ff.) and Girling (1960: 129ff.) have furthermore described how the loss of Acholi cattle resulted in changes in the economic and social system of many Acholi groups. The bridewealth, for example, could no longer be paid in cattle and thus had to be paid in goats.

According to the literature, the first contacts with Europeans also occurred during the 1860s when different European explorers led expeditions into North East Africa. The two most important of these were the Englishmen Samuel Baker and Isaak Eduard Schnitzer, a German known as "Emin Pasha". Both occupied the post of governor-general of the Equatorial Nile Basin - Baker from 1869 till 1874 and Emin Pasha from 1878 till 1889. They were installed in this office by the Khedive Ismail of Egypt (pressured by England) with the order to abolish slavery and establish a system of regular commerce in the area (Girling, 1960: 135ff.). Although both recognized the local Acholi chiefs and did not interfere with their powers, they adhered to racist ideas and used massive violence against the local population in the pursuit of raw materials, new markets and the 'civilizing project' as has been discussed by Finnström (2008: 55ff.). Atkinson (1989: 36) argues that through the contacts with the Arabic-speaking traders and the European explorers new forms of wealth were introduced in Acholiland, which for the first time led to a significant social stratification of Acholi society and caused effects which were felt in the social, economic and political spheres. He explains that

"the most important feature [of this new wealth] was its extremely unequal distribution in Acholi society. The main beneficiaries belonged to one of two categories: the rwodi and the interpreters for the outsiders (...) The inequality in the distribution of new wealth took on special importance because for the first time in Acholi significant amounts of wealth began to be accumulated over time" (ibid.).

1884 marked the beginning of the British Protectorate in Uganda, whereby Acholiland was only annexed in 1898. The colonial rule by the British is seen to have brought massive changes to the political and social organization of the Acholi al- 
though, as Atkinson (1989: 20) points out, one must bear in mind that there is an inherent "danger" in the "tendency [of many authors] to divide sharply the precolonial and colonial pasts, [and] to focus on the unique and discontinuous rather than the many patterns and processes of change that link and overlap the two periods". In the following, I will only briefly mention some examples of colonial influences on Acholi lifestyle and cultural practices, which are commonly cited in the literature.

Girling (1960: 84f.; 107ff.; 195ff.) analyses the changes in the political sphere. He states that instead of relying on the local lineage heads and rwodi, whom the colonial administration found unsuitable for collaboration, the British installed "County chiefs" who were responsible for collecting taxes and organizing communal labour. According to Girling (1960: 201f.), this policy eventually led to a disintegration of the different subgroups throughout Acholiland and the importance of organizing in lineages and domains decreased. Furthermore, he states that the assignment of new political leaders through the British disrupted local power structures and led to a change of hierarchies among men. Elders lost some of their former authority whereas young men could use the new opportunities provided to them through access to education and jobs in the cash economy to access more influential positions in the colonial administration (Girling, 1960: 188f.).

As already mentioned above, the colonial administration is also seen to have caused massive changes in the local economic organization, mainly through the monetization of the economy and the introduction of cotton as a cash crop. Girling (1960: 176) describes how the local population, who formerly relied on subsistence farming, was forced to cultivate cotton in order to be able to pay taxes. Mamdani (1976: 133f.) emphasises that for the same reason, the colonial state encouraged labour migration of Northerners to the South where the main economic developments were centred.

The changes in the political and economic order are also seen to have affected other parts of Acholi culture. Girling (1960: 89ff.) analyses that the former cooperation in the organization of agricultural labour, including the customary tribute for the rwot, was no longer practiced. Instead, wealthy families with a lot of land paid workers to cultivate it and thus supported the colonial system of wage labour. Poorer families formed private working cooperatives which were no longer based on kinship.

According to Schäfer (2008: 332), Girling (1960: 174-195), Dolan (2002: 63f.) and El-Bushra \& Sahl (2005: 14ff.), British colonial rule brought some alterations of gender and generational relations among the Acholi. They attribute these to different factors. Changes in the labour organization forced several men to migrate to and work in Southern Uganda, so that they could no longer fulfil their roles as household heads and lost their political influence in the community. Subordination to the colonial administrators made Acholi men feel incapacitated, and racist stereotypes picturing Northerners as primitive and backward in comparison with people from Southern Uganda destroyed the collective self-esteem and self-respect espe- 
cially of Acholi men. Property rights changed, more property was privately owned and women and youth had more chances of accumulating own property. The introduction of Christianity and the influence of the missionaries established new moral standards among some Acholi groups and led, for instance, to an increase in monogamous households. Access to education provided to some Acholi by the missionaries increased the stratification in the Acholi society along educational lines.

All in all, when judging from the accounts in the literature, it seems that societal conflicts, especially along the lines of age, gender and socioeconomic status increased in Acholi society after the first major contacts with foreign regimes and especially after the inset of colonial rule. Interestingly, the wide-ranging changes attributed to external 'invaders' before the 1980s in the ethnographic literature were not a topic of much debate among my interlocutors. The negative (and positive) influences of British colonialism were sometimes mentioned, but generally it seemed to me that in contemporary discourses the major reason for changes in "traditional culture" were ascribed to the recent war and the forced displacement of the majority of the Acholi population by the NRM government. This discourse on the war-related loss of Acholi culture will be discussed in greater details in the next section. A further (and related) reason for the change and loss of Acholi culture was seen in "westernizing" and "neo-colonial" influences (cf. Vorhölter, 2012), which will be further discussed in chapter 6 .

\subsection{The Situation in the Camps \& the Perceived Effects on Acholi Culture}

In the discourses on loss of Acholi culture and socio-cultural change a key role is attributed to the displacement situation. I will briefly recapitulate the most important key data on the displacement situation which I already summarized in the introduction.

In the years between 1996 and 2006 an estimated 1.8 million ${ }^{125}$ people in Northern Uganda - in Gulu District over 90 percent of the population - were forcibly displaced into huge refugee camps, commonly known as IDP camps, by the Ugandan government allegedly to protect the people from the LRA attacks in the villages. The Acholi of whom the majority had before lived in rural homesteads and villages were coerced, often with military force by the UPDF, to leave their local villages and resettle in camps which were established around local trading centers. Branch (2011: 92) describes the formation of the camps in September 1996 as follows:

${ }^{125}$ Estimates vary between one million and 1.8 million displaced people (Branch, 2011; RLP, 2004: 21ff.; OCHA, 2006; IDMC, 2010). For more details on the formation and development of the camps as well as data on the increasing numbers of refugees cf. Dolan (2009: 109ff.). 
"The UPDF drove hundreds of thousands of Acholi peasants out of their villages and into camps through a campaign of intimidation, murder, torture, and bombing and burning entire villages (...). After the formation of the camps, the UPDF announced that anyone found outside of the camps would be considered a rebel and killed."

Dolan (2009) has depicted the situation in the camps as a form of "social torture", involving fundamental violations of human rights, humiliation and cultural and economic debilitation of the Acholi refugees. According to him and others, the situation in the camps caused more suffering and more fatalities than the actual war. Branch (2011: 92; cf. Finnström, 2008: 133) cites statistics according to which the excess mortality levels in the camps reached 1,000 per week - due to diseases, epidemics and lack of access to health care (Dolan, 2009: 139ff.), rapidly rising HIV/ AIDS infection rates (ibid.: 178ff.), killings by the LRA or UPDF ${ }^{126}$, and suicides committed out of despair (ibid.: 165f.; 207ff.). Contrary to the proclaimed protection the camps were to provide to the displaced, they seem to have lacked everything necessary for a humane livelihood: sufficient and nutritious food, proper living space, and physical protection, which the UPDF failed to provide (ibid.: 144ff.). A commonly stated claim is that over night, a whole people, who had formerly been independent subsistence farmers, became dependent on food and relief aid by the World Food Program and other international NGOs (ibid.: 124ff.; cf. also Branch, 2012).

Most of the people who did not move to the camps - usually those who had better financial means and/or relatives in town - moved to urban centers like Gulu and Kitgum as has been analyzed by Branch (2008; cf. introduction). The most fortunate and economically well-off Acholi left Northern Uganda altogether and moved either to the Ugandan capital, Kampala, or abroad ${ }^{127}$. Due to the experience of forced displacement and the subsequent radical change of social, cultural and economic practices and routines, Acholi, particularly those in the camps but also those in town, increasingly perceived the war situation as a situation of 'cultural breakdown'.

To this day, a frequently voiced claim, especially among the older generations, is that Acholi culture has been lost due to the war and its social consequences, and that

${ }^{126}$ It was not always clear whether attacks on the camps had been committed by the LRA or the UPDF. Dolan (2009: 147ff.) refers to attacks on the camp inhabitants by government soldiers disguised as LRA rebels. Furthermore, the UPDF is accused of being indirectly responsible for many deaths, for instance because it encouraged the civilian population to form "Local Defense Units" to counter attacks by the LRA rebels. The badly armed groups became major targets of the LRA who accused them of betrayal and killed several LDU members in revenge (Behrend, 1993: 196ff.; 213ff.; El-Bushra \& Sahl, 2005: 19f.; Finnström, 2003: Chap. 3\&5; 2005: 99f.; ICC, 2004: 4ff.).

${ }^{127}$ Parts of the large Acholi diaspora later played a prominent role in the peace negotiations with the LRA (Westbrook, 2000: 4; Poblicks, 2002). 
Acholi society is experiencing a profound "moral degeneration". In discourses about the war and the displacement situation the IDP camps have come to symbolically represent the loss of Acholi culture. Like nothing else they stand for a total change in lifestyle, values and social relations, and for a prolonged period of foreign occupation. A report by the Refugee Law Project describes the discourse on displacement as follows:

"[T] he impact of displacement (...) is seen to have eroded the very roots of Acholi culture. (...) There was frequent reference to the fact that cultural taboos were being broken by families having to live close together, and that social support networks within the society were being eroded. As a local businessman commented, 'We grew up with dignity. These children are not growing up as true Acholis. Our culture is being destroyed completely. The children won't know about seasons and agriculture'. A religious leader summarised the impression of humiliation that came through so tangibly in discussions about displacement: 'This community is destroyed because the culture has gone. What is a community without a culture? There is no privacy, no morality in the camps. Children die very young. (...) The whole future of Acholi people is at stake, and this will also cause problems throughout the country" (RLP, 2004: 26).

There has been extensive research on the situation in the camps and the changes in formerly established social, cultural and economic practices it assumingly caused. This literature not only documents but contributes to reinforcing the discourse that Acholi culture has been lost as a result of the camp interregnum.

Most of the camps had already been closed when I started my research in Northern Uganda. Thus, my own data only refers to the narratives I encountered about the camp situation. Furthermore, since most of my interlocutors had been displaced from their original villages to Gulu Town and had thus spent the war years there, I only rarely collected personal accounts of camp life. Notable exceptions were the group interviews I conducted in the rural areas outside Gulu Town (cf. group interviews Bobbi, 06.10.2010; Bungutera, 03.10.2010; Wii Aweng, 26.09.2010; Kapedopong 28.06.2010, Pabbo 23.10.2010; Paicho 17.10.2010). All of the groups I spoke to had stayed in the camps, most of them over many years, and had only recently resettled in their original villages.

In order for the reader to understand the importance of the camp interregnum for current discourses on socio-cultural change, I want to briefly summarize the most commonly cited effects camp life is believed to have had on Acholi cultural and social life. I will base my analysis on statements by my informants as well as on the works of Dolan (2009) and Kuster \& Santschi (2006) who have provided extensive analyses on this matter. Further, detailed accounts and critical analyses of the camp situation, the devastation and suffering it caused among the Acholi population, the political interests of the Ugandan government in setting up and maintaining the camps, and the complicity of the international humanitarian regime in establishing 
and enabling the continuance of the camps can be found in the acclaimed books by Branch (2011), Dolan (2009), Finnström (2003; 2008) and the articles and reports by ARLPI (2001), Branch (2012), Dolan (2002), El Bushra \& Sahl (2005: 11-30), HuRiFo (2002), IDMC (2010) and Whyte et al. (2012).

When discussing contemporary Acholi culture, most of my interlocutors contrasted it with "traditional culture" in "those days", usually meaning those days before the war. In the preceding section, I have described what people generally understood by "traditional culture". In the following, I will take up some of the different aspects of economic, social and political life and ethical values discussed above. I will show how - in popular imagination - the camp situation and the effects of the war more generally are seen to have fundamentally altered and negatively affected these different spheres of Acholi culture.

\subsubsection{Economic Sphere: Impoverishment \& Loss of Former Living Standards}

The literature dealing with the living circumstances in the camps has repeatedly emphasized how people were forced to live under circumstances very different from those in the villages from which they had come. Dolan (2009: 110-131) describes the loss of people's former living standards in great detail. According to his account, all of the camps were overcrowded with huts having been set up one next to the other often within a meter of each other. There were hardly any proper sanitation facilities. Economic opportunities, enabling families to provide for their own subsistence, were very limited. There were no fields within the camp, and people could only access the fields in their home areas at great risk. Thus, agricultural activity became very marginal throughout Acholiland as more and more people were resettled in the camps. Similarly, hunting activities, which had formerly served to supplement subsistence especially in the dry season, decreased due to their inherent risks. Other employment opportunities in the camps were limited and the jobs available were usually on a temporary basis. Hence, over time, and despite people's efforts to find sources of income and provide for themselves, more and more camp inhabitants became dependent on food aid.

In contemporary discourses, impoverishment and the loss of former living standards are perceived by many as having had a thorough effect on Acholi cultural practices and norms. The cramped living conditions in the camps and the lack of space and privacy were described as a serious humiliation by the internally displaced. They often emphasized that in their rural villages and homesteads, they had formerly lived in widely spaced huts, surrounded by their fields and gardens. Each family member, after reaching a certain age, would be assigned a separate living space, usually a hut of his or her own. They explained that the clear separation of living space - between parents and children, or men and women - was linked to cultural taboos, and that the housing situation in the camps, which forced extended families to sleep under one roof, led to serious breaks of these taboos, especially regarding sexual relations (Kuster \& Santschi, 2006: 134f.; Dolan, 2009: 169ff.). I also encountered these 
discourses whenever I asked my interlocutors about the camps. During a group interview (Kapedopong, 28.06.2010), for instance, a young woman explained:

"Everything changed because of the war. The IDP camps brought together so many different people who had to stay on the same compound in cramped conditions. Boys and girls were staying too close by each other so it was natural that they started to fall in love and have sex. Respect was no longer there because people were just living too close - how can you respect someone if you are always cramped together?" (translated from the Acholi original by Kenneth Oyet Odong).

During a different group interview in Bungutera (03.10.2010), a young man described not only the humiliating aspects of the living situation in the camps, but also emphasized the practical difficulties it caused. He stated:

"Life in the camp was not easy. We had to live with very many people in one house which was very cramped. The children had to stay in the same house as the parents. When the children wanted to go to school in the morning they sometimes couldn't wash because the jerry can would be in one corner of the house where some adult was still sleeping so they would have to go to school without even washing their face..." (translated from the Acholi original by Wilfried Ochieng).

In addition to the humiliating housing situation, the breakdown of farming and other economic activities was perceived as a threat to Acholi cultural identity as independent agriculturalists and hunters. Former camp-inhabitants of ten complained that they had been prohibited (or severely restricted) by the UPDF (and the LRA) to leave the camps in order to work on their fields, or to go for hunting in the dry season - allegedly for security reasons (cf. Kuster \& Santschi, 2006: 137ff.; Dolan, 2009: 118ff.). My interlocutors reported how the restrictions in the camps led to dependence and frustration. As an elderly man, for example, explained during a group interview in Pabbo (23.10.2010):

"Before the camp, we were very free, we could do anything. Even now we are really free again and there is a lot of stability. In the camp situation we were very restricted. All of us were told not to move outside the camp after $8 \mathrm{pm}$. Then, if you wanted to go to the garden the earliest time you could leave the camp officially was 9am, so you could not stay outside very long. At another time they also completely restricted us from going to the gardens, because it was not safe outside the camps, so people were just waiting for deliveries from World Food Program" (translated from the Acholi original by John Omara).

Similar statements collected by Kuster and Santschi (2006: 139) reveal that the inability to provide for themselves and the subsequent heavy dependence on food aid by the World Food Program severely affected the 'collective pride' of the Acholi. 
Kuster and Santschi (ibid.) further point out that some people took up jobs like boda boda driving ${ }^{128}$, which, however, were perceived as being badly paid and regarded as inferior and dishonorable. According to their analysis, men especially, who had always seen themselves as proud farmers and breadwinners for their families, found it difficult to accept to work in these jobs (see further discussion below). One of the most frequent claims I encountered when discussing camp life with my interlocutors was that people in the camps became idle, and out of frustration and boredom spent their days in video halls or drinking alcohol. The changed economic situation in the camps is thus also related to changes in social practices and relations among the Acholi.

\subsubsection{Social Sphere: Increase in Gender \& Generational Conflicts}

The impoverishment and economic deprivation caused through the prolonged stay in the camps is also seen to have sustainably affected social relations among the Acholi people. Furthermore, the perceived inability of the camp inhabitants to fulfill the social roles and responsibilities expected of them further aggravated the feeling that camp life caused a fundamental breakdown of Acholi culture.

One serious and often mentioned consequence of poverty and lack of social capital in the camps was seen in the inability of most families to pay brideprice (cf. Schäfer, 2008: 332; El-Bushra \& Sahl, 2005: 16ff.). My interlocutors, with whom I repeatedly discussed this topic, claimed that this led to a general decline in marriages. To this day, brideprice payments are perceived by the majority of Acholi to be a fundamental requirement in the "traditional marriage" process ${ }^{129}$. According to Dolan (2002: 72; 2009: 199ff.), the only men in the camps with access to substantial capital to pay brideprice and provide for a wife and family or to attract women for "transactional" sexual relationships (cf. Hunter, 2002: 100f.) were usually soldiers. He has analyzed, how this further reinforced conflicts between (military and civilian) men, and also contributed to an increase in rape incidents (cf. Dolan, 2009: 178ff.).

As has been discussed above, marriage is seen as one of the most important social requirements both men and women need to achieve in their lives in order to become

${ }^{128}$ Boda boda is a colloquial Ugandan term for motorbike taxis.

${ }^{129}$ Whenever I asked during the group interviews whether the brideprice should be abolished because it was preventing poorer men to get married, the majority of both young and old people, men and women, rejected this idea. The group in Wii Aweng (23.10.2010) told me of a very peculiar incident which had taken place in their community. The local rwot had suggested that the brideprice for the women should be fixed at 400,000 USh [approx. 130 Euro] in order to prevent unreasonable demands by the women's family and thus to enable more men and women to get married. But despite the fact that the severe decline of marriages in the community was perceived as a great problem, the community had collectively rejected the idea of the chief because they believed that the negotiation of the brideprice was for each family to decide. Similarly, attempts to abolish or regulate the brideprice on the national level have been rejected by the majority of the Ugandan population (INT Rocki, 16.03.2010; cf. Anyoli \& Nanteza, 2010). 
respected members of the Acholi adult society (cf. Dolan, 2002: 62f.). According to popular understanding, marriage relations establish wider social bonds between families and clans and constitute the basis for the formation of an independent household. Due to the central importance of marriage, the increasing inability of men and women in the camps to achieve marriage was perceived as a serious threat to Acholi culture. In this context, the real and symbolic importance of cattle as a source of wealth and form of brideprice payment increased. According to a widespread narrative, almost all of the cattle, which had formerly belonged to the Acholi, had been raided by the NRA/UPDF and the Karimojong since the beginning of the fighting (cf. van Acker, 2004: 354). My older interlocutors sometimes mentioned that this loss had robbed the people of an important source of social capital and now prevented them from being able to pay brideprice. During a group interview in Pabbo (23.10.2010), an elderly man explained how the war-related loss of cattle had contributed to a fundamental change in marriage practices as follows:

"In the past there were so many cattle around, so you could just go and pay for the girl in cattle. But now, because of the war, so many cattle were taken away. So in most cases, instead of paying in cattle, people are forced to pay money, to give an equivalent. But money is even scarce now and that is making most people today boycott traditional marriage. As a cause of that, girls end up living in the streets because the girls cannot get married. And there is no respect between the two families, so sometimes the girl's parents charge so highly. Then you marry a girl at a very high price and then you mistreat her... these days, marriage is just about business..." (translated from the Acholi original by John Omara).

As this quotation implies, camp life is not only seen to have caused a decline in marriages. The scarcity of resources to pay the brideprice has also made marriages to become a "business", and this in turn has led to increased conflicts within marriage relations (cf. Kuster \& Santschi, 2006: 131ff.). Like in the interview quoted above, I often heard that camp life had eroded the communal spirit which people believed had characterized former Acholi social relations because in the camp everyone had to fend for themselves. Marriages were not the only aspect of social life seen to be affected by this.

Different researchers (e.g. Branch, 2008: 10ff.; 2011: 129ff.; Dolan, 2002; 2009: Chap. 7; El-Bushra \& Sahl, 2005; Schäfer, 2008: 350ff.) have analyzed how the situation in the camps brought about significant changes in gender relations, roles, and norms. Dolan (2009: 203f.) describes a discourse according to which changes in gender roles came about through an emerging new division of labor. Women were supposedly more able and willing than men to find new (economic) roles in the camps. Many started engaging in petty trade and, for the first time, started earning an income in the monetary economy, while men did not find acceptable alternatives to their former occupation as farmers and thus lost their role as main breadwinner of the family. Furthermore, relief organizations started to involve women in the dis- 
tribution of food and other relief items as they considered them more trustworthy than men in making sure that the items would also reach the children and other family members. According to Das and Nkutu (2008: 50), this "created leadership opportunities for women in a society where leadership positions were traditionally held by men". It is a widespread belief that women gained more independence in the camps than they formerly had in Acholi society, and the increasing number of women-headed households is often interpreted as an indicator of this trend (Branch 2011: 137ff.; El-Bushra and Sahl, 2005: 20f.). However, El-Bushra and Sahl (2005: 23) point out that although the

"direct and indirect effects of the war (...) include a significant change in gender roles and norms, in which women appear to have gained and men to have lost (...), the fact that everyday behaviour has changed does not necessarily mean that attitudes and values have changed. Indeed, the changes in gender roles described by respondents seem to indicate a reinforcement of gender ideologies, rather than fundamental shifts. (...) For both men and women, the ideals of the Acholi cultural code do not seem to have changed as a result of war, but have simply become harder to put into practice."

Dolan (2002; 2009: Chap. 7) has argued in great detail how changes in gender roles caused a widely perceived breakdown of masculinities and loss of male authority at the household level. According to Dolan, men's frustration about being unable to fulfill their role as husband and father, or to get married and start a family in the first place, in many cases resulted in forms of violence against the self and others. He describes alcohol abuse and in extreme cases suicide as forms of violence men directed against themselves, while family members and other men became 'external' targets of violence. Dolan reports that incidences of domestic violence escalated in the camps, as men tried to regain the control over their wives which they felt they had lost.

The perceived changes in gender roles and relations and the effects of camp life on gender hierarchies are still felt and heavily debated in the post-war phase. Among my interlocutors the negative and positive changes in gender relations caused through encampment were a frequent topic of debate (as will be further debated in chapter 6). One interviewee in Bobbi $(06.10 .2010)$ related the changes in gender roles to the breakdown of former socialization practices. According to him,

"now the ladies are doing what the men are doing, the men are doing what the ladies are doing. In the camp things changed, because the parents were drinking all the time and no longer teaching their children like they used, so you find that a boy might do the cooking, which is not what they were originally taught to do. The girls ended up doing what the boys used to do."

Another respondent added: 
"Initially a woman would not be allowed to head a family, so there was wife inheritance where the brother would take over the wife when the husband dies. But now it [women-headed household] is there, because people are running away from inheritance. And even if you look at wills, girls nowadays are also recognized in the wills and given property to own. So there are quite a lot of changes" (both statements translated from the Acholi original by John Omara).

While most of my interlocutors still considered gendered socialization practices like those mentioned in the first quotation important and were concerned about their decline, the abandonment of wife inheritance and the increased recognition of girls in inheritance processes mentioned in the second quote were generally regarded as positive changes in gender relations and rules.

A different claim, frequently voiced by my interlocutors, was that camp life had severely affected intergenerational relations, particularly those between parents and children. According to common belief, due to fundamental changes in socialization practices the young generation never learned societal rules and norms and therefore no longer knows Acholi culture (cf. Kuster \& Santschi, 2006: 119ff.). One reason for the breakdown of former education practices was seen in the decline of the wango-o. Wango-o sessions could no longer be held in the camps because it was prohibited to light fires at nights which might have attracted the rebels. Younger people, who had grown up in the camps, furthermore blamed the adults for their lack of initiative in holding the wango-o during the encampment situation as in the following quote by a girl in Bobbi (06.10.2010):

"Wango-o is still important, because from the wango-o you learn very important facts and lessons about life. At the wango-o, the parents used to have enough time to educate their children. But in the camps, the parents were just drinking all the time, so they didn't take time to educate their children" (translated from the Acholi original by John Omara).

In a similar vein, my interlocutors in Gulu often emphasized that a mixture of disillusionment, lethargy and alcoholism had led some parents to simply leave their children to take care of themselves. They explained that as a consequence, and reinforced through the parallel breakdown of school education ${ }^{130}$, children failed to learn about their societal responsibilities and cultural norms, lost respect for

${ }^{130}$ Dolan (2009: 131ff.) has described the appalling state of formal education - if it was provided at all - in the camps: there was a lack of school buildings, learning materials, as well as of trained and motivated teachers. Secondary schools hardly existed at all, because all but two schools had been displaced to Gulu Town (cf. Kuster \& Santschi, 2006: 128ff.). The District Education Officer Vincent Ochieng, whom I interviewed in Gulu (INT 26.03.2010) described the state of camp education as follows: "They [students in the camps] were not taught properly, people were running up and down, they themselves were not in class, some children were being abducted from class, so it was totally emergency education, just to make sure that the system could be running, 
their parents and started to engage in 'anti-social behaviour' (cf. also Dolan, 2009: 168ff.; Kuster \& Santschi, 2006: 129). This widespread conviction is reflected in the following quotation, taken from an interview with the District Education Officer of Gulu Vincent Ochieng (INT 26.03.2010):

"The present generation, they grew up during the war time in the camps and in town, they didn't grow up in the villages, so they don't have so much the spirit of being self-reliant, to do work on their own. They are not self-driven even to be ambitious, to be on their own, to read and do work for themselves, that is the big problem now we are having with this new generation here. For them they feel people should do things for them; like during the war time the [development] partners would give food, give clothes, give everything you need, because people were in the camps. Now the young still want that hand-out to continue in their lives. (...) Some [who returned to their villages] have even failed to fit in the villages, they are coming back to town, because they can't dig. (...) Very few of them are trying to cope up, so you find some of them have even left their parents even now alone in the villages to dig and they are here. So there is needed quite a lot of time to reorient their mind to a system where they will know that their life is there in their villages, and they have to work for their life. Cause if we go - our generation - when we are no longer there, we don't know if many of them would take leadership."

The changes in generational relations and leadership structures mentioned by the respondent, and particularly the perceived dissolving of gerontocratic principles, were generally taken as further indicators of the breakdown of "traditional culture", especially by the older generation (cf. Kuster \& Santschi, 2006: 125ff.). Younger people sometimes positively interpreted these changes as a form of youth empowerment, but they also acknowledged that the loss of age-based respect caused instability and disorder in Acholi society. One of my interviewees, a young man in Pabbo (INT 23.10.2010), analyzed the negative influence of camp life on intergenerational relations very bluntly, when he explained:

"The insurgency forced people to live in camps. There, the young started mixing with the elderly. They became friends. There was no respect, the young would not listen to elders, elders would not listen to the young, because the lifestyle of young and old became the same: people were all drinking together, watching films..."

Similarly, a young woman in Bobbi (06.10.2010) argued:

"Camp life brought a lot of conflict because old and young people were rated at the same level. Both the old and the young went to video halls; you would find a father, a mother, a daughter and a son there. So it would be difficult

because we feared that if we had stopped completely then starting after some years would be a problem. (...) At that time there was no quality education, it was just to fill in the gap." 
for the parents to forbid their children to go there, to tell them that some of these films were not suitable for them, because they themselves were setting bad examples. And also parents did not take the time to educate their children. Young and old became too close because they were sharing the same hobbies" (both statements translated from the Acholi original by John Omara).

The quotations reveal that the equalization of members of formally distinct social categories was seen to have dissolved established authority structures. According to the interviewees, parents and elders were no longer regarded as positive role models and guardians because they behaved in ways regarded as irresponsible and typical for younger members of society.

The radical change in former social relations and hierarchies, and especially the perceived relative empowerment of women and youth, was also related to foreign, usually Western, influences. A common claim was that foreigners introduced new values and norms, for instance through campaigns on women and children's rights, through Western media programs and movies, and through the behavior of aid workers in the camps, which conflicted with Acholi social conventions and hierarchies. The general feeling of being controlled by foreigners and having lost (political) self-determination will be briefly discussed in the next section. A more thorough analysis of discourses on Westernization and neo-colonialism will be provided in chapter 6 .

\subsubsection{Political Sphere: Foreign Occupation \& Loss of Self-Determination}

Different authors (e.g. Branch, 2011; 2012; Dolan, 2009; Finnström, 2008: Chap. 4) have described how the life in the camps represented, for many, not only a situation of displacement, but also a situation of foreign occupation and determination. Branch (2011: 100) argues that the complete control and related victimization of camp inhabitants represented a deliberate strategy of the camp administration and, in fact, constitutes an underlying principle of the international humanitarian regime more generally. He writes:

"Humanitarianism is an administrative regime that combines macrolevel surveillance and direction with microlevel discipline in order to efficiently provide aid to victim populations. In order for it to efficiently distribute aid according to the humanitarian imperative of promoting statistically defined life, the humanitarian regime needs to contain, control, and discipline populations so that they passively accept that aid. In practice, this means that the aid industry not only sees people as helpless victims, but also needs people to be those helpless victims and ends up disciplining them toward that identity." 
In Northern Uganda, camp-inhabitants felt incapacitated to take even the most important decisions pertaining to their life. Their movement was controlled by the Ugandan army, the food ratios and daily diet were determined by international relief organizations, international rights discourses prescribed people how to live their lives, and the only entertainment programs widely accessible were Western movies and media programs. Even matters pertaining to cultural leadership and "traditional justice" (see discussion below) were heavily influenced by the Ugandan government as well as Western development actors ${ }^{131}$ (Dolan, 2009: 112ff.; 172ff.; Kuster \& Santschi, 2006: 122ff.).

A further, often discussed problem was that family and clan structures, which had formerly served to regulate political affairs among the Acholi, broke down in the camps, because homesteads were dismantled and communities torn apart as a result of displacement (cf. Kuster \& Santschi, 2006: 121f.) Many of my interlocutors complained, for instance, that due to the erosion of former social and political institutions and the introduction of new authority structures young people no longer knew about the functions and values of clans and chiefs and could not appreciate the important role they had formerly played in Acholi society. Furthermore, the lack of education on Acholi socio-political affairs and clan structures, which had formerly been provided by elders at the wango-o, was seen to have prevented the young generation from knowing their roots and having a sense of belonging. Okello (INT 26.09.2010) explained:

"Well, [young] people know their clan, but because there are certain misunderstandings, people are now mixed [confused] about... Like, let me say, like myself - if I cannot inform my children at the wango-o that you belong to this [clan], then the children can just be going about... Like these street children, they will not know their clan, but when they stay with their elderly people, they are always informed [where they] (...) belong..."

The feeling of having lost control of matters pertaining to Acholi political and social life was further aggravated through the perceived systematic exclusion of the Acholi in national politics. Many Acholi (as well as external observers) interpreted the encampment of large parts of the Acholi population and the failure to end the conflict as a deliberate attempt by the NRM government to keep Northern Uganda, a stronghold of the opposition against Museveni and the NRM, under control. People often referred to the North-South divide in Uganda (cf. Chap. 3) and argued that politicians from Northern Uganda were not represented in the government and other important administrative posts (cf. Kuster \& Santschi, 2006: 156f).

131 The idea for the revival of Acholi chiefs (rwodi moo) and the installation of a Paramount Chief first gained prominence through a widely cited report by Dennis Pain (1997), who suggested that the rwodi moo could help to restore 'traditional culture', which had been eroded through the camp situation. Based on this idea several international organizations including the World Bank supported the revival of these chiefs and even financed Conflict Resolution courses in the U.S and the U.K for the Paramount Chief (cf. Paine, 2011: 4ff.; see discussion below). 
Overall, the war situation seems to have caused a widespread feeling that the Acholi as a people have been deprived of the autonomy to decide over internal 'cultural affairs' and, in addition, have been excluded from decision-making processes on a national political level. The perceived breakdown of the economic, social and political elements of Acholi culture and its disastrous consequences have been discussed in the previous pages. I will now turn to the changes displacement is seen to have caused regarding ethical and moral principles and values.

\subsubsection{Ethical Sphere: Loss of Morals, Respect \& Values}

Among all the negative influences displacement is seen to have had on Acholi culture, no aspect was regarded as devastating and consequential - by my interlocutors and in the general discourse on socio-cultural change - as the perceived breakdown of morality and respect. According to a widespread narrative, the inhumane living conditions in the camp had corrupted the previously morally intact Acholi society. The typical portrayal of camp life I encountered was in many ways reminiscent of Sodom and Gomorrah and usually included references to several 'sins' like idleness, promiscuity, substance-abuse and violence, which had supposedly been committed by the majority of camp inhabitants.

The most frequently mentioned aspect, which always came up when I spoke with people about camp life, related to 'immoral' forms of sexuality. Promiscuous relationships, premarital and extramarital affairs as well as prostitution and "transactional sex"132 were believed to have skyrocketed in the camps, leading to a rapid increase in divorces, teenage pregnancies, abortions and rising levels of HIV and other sexually-transmitted diseases (cf. Kuster \& Santschi, 2006: 133ff.; Dolan, 2009: 178ff.). My interlocutors often claimed that out of boredom and facilitated by the cramped, uncontrolled living space men and women started to engage in new, "immoral" kinds of sexual relationships which had been considered taboo in "traditional Acholi culture". One of my interviewees narrated his impressions of camp life:

"You know when people were in the camp, there were so many things happening. I remember staying in a camp, just when I was for my holidays [from boarding school], I stayed for one complete month, and I saw the kind of life there. It was not all that ok (...) Those days in our culture, when it was almost approaching night, you began gathering firewood, sat round the fire, telling stories. Things changed when people were in the camp. There, you

132 The term "transactional sex" (sometimes also "something for something love" or "cross-generational sex") was used by my interlocutors to refer to sexual relations which involved both, a material dimension and an intergenerational dimension. The more common form was a girl/ young woman having sex with an older man ("sugar daddy") in exchange for material goods (e.g. phones), economic needs (e.g. school fees) or leisure time activities (e.g. going to a restaurant). Somewhat rarer was the case that boys/young men engaged in transactional sexual relationships with older women. 
found that during night a boy and a girl were moving up and down, going there and there and there... Those days we used to respect the women, but it has changed these days when people were in the camp. You find that another man is caught doing all sorts of nonsense with another guy's woman. You find that was not in the culture before" (INT Laurence, 28.04.2010).

The decline of discipline and respect is stressed by the respondent as one of the most important causes of the mayhem in the camps. The many problems and challenges resulting from the generally perceived breakdown of social order in the camps came up as in an interview I conducted with the manager of Gulu Youth Centre. She reflected:

"There are some challenges that have come as a result of the situation that existed in the North for the past 20 years. Family structures were broken down because people had to flee their homes, and they got internally displaced and had to live in camps. So because of that, this issue of auntie telling you 'be careful', mum telling you 'you're too young to be having sex' [was no longer there]..., family structures generally broke down. In the camps the kind of life was not comfortable, families had to live together under one roof, the children saw mum and dad have sex when they thought they were sleeping. Children got exposed to sex early, because, you know, young men and women were idle, and living in close proximity maybe they might have passed time together. One thing led to the other and then they had sex. And remember that in most cases health centers were far off, opportunities to test [for HIV] were limited. And remember, HIV had come in, so the spread of HIV was increasing. And remember, in the camp accessibility to condoms was limited or non-existent. And like I told you in the beginning, people were commuting, there were night-commuters ${ }^{133}$ (...) So imagine a situation in which [Gulu] town was filled with young people lying down in the street. What was happening in the night? People normally turn to each other... (...) And then remember that girls were raped, some became child mothers really early, 14 years. Others were having sex earlier, not only getting pregnancy, but also getting affected with HIV, because the men were older in some cases..." (INT Faith, 18.03.2010).

The interviewee argues that the breakdown of established family structures and spatial arrangements facilitated uncontrolled sexual behaviour, which resulted in an increase of HIV-infections and thus created fundamental problems for the postwar society. She particularly emphasized this point because in her function as the

${ }^{133}$ During the height of the war years, especially from 2003 onwards, several thousand children (and adults) left their homes in the villages and in the camps to spend the night in one of the night commuter centers which had been set up in Gulu and Kitgum. The town centers were considered safer than the rural areas where children feared to be captured or attacked by the LRA (cf. Lunde, 2006). 
manager of Gulu Youth Centre, which was primarily a VCT ${ }^{134}$ drop-in centre for young people, she had to deal with the results of the high HIV/Aids prevalence on a day to day basis.

Generally, the rise of uncontrolled or 'immoral' forms of sexuality seemed to be one of the most crucial negative and sustainable outcomes of camp life (cf. Chap. 6). My younger interlocutors reported that nowadays, due to poverty or out of desire for material wealth, it had in fact become common for many young men and women to engage in transactional sexual relationships with "sugar mummies" and "sugar daddies". This so-called "something for something love" and its inherent danger of getting infected with HIV was a constant topic in the bi-weekly group discussions with male and female youth conducted at Gulu Youth Centre. After one of these sessions, I discussed the issue with Omara, a councelor at GYC. In my field notes, I reflected on the conversation:

"He tells me that there is also the problem of sugar daddies who are rich and can pay for many things in order to convince a young girl to have sex with them. He says there are even sugar mummies these days who pay for young boys. There is one well-known lady in town who is quite wealthy and who is HIV-positive. She is well-known for paying young boys something around 800,000 USh [approx. 250 Euro] to sleep with her. He says although people know someone is infected they don't care because they are poor and if someone offers the money they don't think of the consequences. (...) He talks about the situation of girls, and that it is worse for them because they are so vulnerable. Some, especially those in the villages, have to sleep with men to get money. He says there is so much of this kind of prostitution going on in the villages. Sometimes the women even force their daughters to sleep with men for money. He says it was even worse in the camps, where people were living in cramped conditions and there was nothing to do and a lot of poverty. Soldiers who had money often came and slept with the young girls - he says that the soldiers didn't care whether they got infected with HIV because they were living such a risky life anyway because they could get killed in the bush everyday. So they tried to enjoy life to the maximum as long as they could (field notes, 20.04.2010).

Again, the explanations by Omara reflect the general conviction that certain harmful sexual practices, which had first appeared in the camps, had become established and were now common in post-camp and post-war Acholi society.

A further widely discussed long-term consequence of camp life I encountered during my fieldwork relates to the militarization of society during the camp interregnum (cf. Kuster \& Santschi, 2006: 146ff.; Dolan, 2002; 2009: 204) and a heavy rise in crime-levels and incidents of violence in post-war Acholi society. In an interview, a staff member of American Refugee Council, who was working in a project on gender-based violence (GBV), explained that GBV had been a problem before

${ }^{134}$ Voluntary Counseling and Testing for HIV/AIDS 
the conflict, but that it came to be noticed and talked-about on a big scale for the first time in the camps. According to the interviewee, levels of GBV increased because of the general frustration and the violent surrounding in the camps where men were carrying guns all the time (INT EM, 16.03.2010). In a similar vein, another interviewee, who also worked in the field of GBV, reported that the war had led to a big increase in violence although "originally Acholi culture does not condone violence". She told me that in former times there had been wars, but that violence in these wars had never been directed against women and children. In this recent war, however, things like rape and defilement had become very common. The interviewee attributed the increased violence to the cramped conditions in the camps and to poverty, which made people feel frustrated, and emphasized several times that "these are new things to the culture" (INT SK, 23.03.2010).

"Post-conflict trauma" was regarded as another devastating consequence of the militarization in Acholi society during the war. One of my interviewees poignantly described the problem and stressed the importance of dealing with war and displacement traumas in order to build a stable post-war society when he said:

"Post-conflict trauma, that is the biggest challenge, and making people go back to their normal moral way of living. The people who grew in IDP camps, they have seen a lot of bad things. An example is seen when you move to these villages, where people are settling back. You ask any kid to draw for you a picture or make a toy - what they will do number one is draw a gun shape or make a gun. So look at the situation we are entering into, we need a lot of training to the young people, so the generation we will be having in future will be a better one" (INT Ojara, 17.03.2010).

In the general discourse, the rise of violence, especially GBV, was frequently related to widespread overconsumption of alcohol, which people had become accustomed to in the camps (cf. Kuster \& Santschi, 2006: 135ff.; Dolan, 2009: 167f). Omara, the GYC councelor quoted above who also sometimes assisted me in organizing and conducting group interviews in the rural areas (cf. Chap. 2), once explained to me that alcoholism was such a big problem in the camps because people were idle, could not cultivate their fields and got all their food from the World Food Program. According to him both, men and women, would start drinking alcohol at $6 \mathrm{am}$ in the morning when they woke up and continue all day, simply because they had nothing else to do (field notes, 20.04.2010).

Alcohol abuse still constituted a severe problem in many rural communities which had returned from the camps. During a group interview in Wii Aweng (26.09.2010), I discussed the issue with my interlocutors. They reported that alcohol was still a big problem today, although it had been much worse in the camps. A woman explained: "Some men wake up in the morning and go and drink. They don't even go to dig, they send their wives and children to dig for them. For them, their work is to drink and wait for food. If you don't give them food, they cane [beat] you properly" (translated from the Acholi original by Ruth Lagen). A man 
added that even the women are "drinking seriously", although this statement was contested among the group.

Many Acholi felt that the breakdown of morality and the disrespect of formerly established norms in the camps had irreversible consequences for Acholi society, not only because 'immoral practices' continued in post-war society, but also because other institutions, most notably the Christian churches, had used the general confusion in the camps to install new moral principles and put a ban on 'pagan' cultural practices $^{135}$. Omara even claimed that nowadays there was a real conflict between religion and culture because so many cultural practices had been forbidden by the churches, especially the funeral rites (cf. Dolan, 2009: 171f.) and the twin rituals (cf. Nzita, 1997: 92f.; see above). In my field notes (06.10.2010), I noted:

"According to Omara, Born-again Churches are the strictest, but the Catholic Church and the Protestants are also becoming 'more and more strict'. I ask him why he thought this conflict [between religion and culture] was a recent one, and why the people now, all of a sudden, were so committed to the churches which had been around since the first missionaries came to Northern Uganda. He answers that during the war, especially in the camps, the behavior was really deteriorating, so that religious leaders were called in to help. They did a lot of preaching and really mobilized people to join and practice religion. That, he concluded, is why the influence of religious institutions now is much stronger than before the war."

A very similar argument, namely that religious institutions had gained influence because they were called to discipline the people in the camps, was put forward by two participants in a group interview in Bobbi (06.10.2010) who stated:

"The camp life affected the funeral rites. Because of the bad behavior and moral degeneration in the camps, the religious leaders were called in to intervene. As a result of that, people got to learn that funeral rites were not so important, because according to religion, when somebody is buried you can just finish everything there... So some people now only bury the people and everything stops there. Funeral rites are still done but it is not very common now. Most people just do the funeral and stop it there" (translated from the Acholi original by John Omara).

The decline of the funeral rites and the twin ritual which had both been 'banned' by the churches often came up in discussions on socio-cultural change (cf. Kuster \& Santschi, 2006: 122ff.). Most of my interlocutors, especially Born-again Christians, claimed that abandoning these practices was a good thing. Some, however,

135 Leaders from all major religions in Northern Uganda (Catholicism, Anglicanism, Islam) were very involved in providing support to their followers from the beginning of the conflict. Later, they started to play an active role in peace-building initiatives and gained international influence and prominence through the foundation of the Acholi Religious Leader Peace Initiative (ARLPI), see Rodriguez Soto (2002). 
admitted that they were still performing the rituals although they were Christians and it was against the doctrines of the Christian churches (cf. group interview Wii Aweng, 23.10.2010).

In summary one can say that camp life is seen to have caused a devastating, allencompassing impact on Acholi culture - in the economic, social, political and ethnical sphere - which many believe cannot be reversed. Nevertheless, since the end of the fighting in 2006 (and even before), there have been several attempts to revive 'traditional culture'. These will be discussed in the last section of this chapter.

\subsection{Contemporary Attempts to Reconstruct "Traditional Acholi Culture"}

The late 1990s brought about a change in the field of international interventions in conflict settings. After the failure of humanitarian rights interventions in Somalia and Rwanda, a new interventionist agenda, which Branch (2011: 16) has termed "total intervention", was set up with the aim of "reforming and constructing African societies, polities, economies and even psychologies and cultures toward what were considered peaceful and responsible models" (ibid.). He describes the conceptual framework underlying this agenda as follows:

"The framework begins with the consequences of conflict, arguing that violence leads to crisis and breakdown in a wide array of different domains. In the political domain, conflict leads to state weakness and failure; in the economic, it leads to poverty and underdevelopment; in the social, it leads to a breakdown of social solidarity and civil society; in the cultural, it leads to a crisis of traditional values and authority; and in the legal, it leads to a breakdown of accountability and a rise of impunity. (...) Consequently, peace will be established through the rebuilding of order in those many domains" (ibid.: 27f.).

Branch further states that in this context, the revival of 'traditional culture' (or certain elements thereof) has been discovered by humanitarian organizations and NGOs as an important component of 'post-conflict peace-building' and a means of re-creating social stability in post-war settings (ibid.: 154ff.).

In Northern Uganda, which in the 2000s was among the regions worldwide most densely populated by humanitarian organizations (Perrot, 2010: 189), the first projects aiming for 'cultural revival' emerged in the late 1990s. Starting with the Kacoke Madit conference in London in $1997^{136}$ and the subsequently commissioned

136 The Kacoke Madit (Acholi for "big meeting") initiative was started by Acholi living in the diaspora to raise awareness about the conflict in Northern Uganda and discuss opportunities for peace. The KM initiative organized a series of international conferences, which were attended by Acholi 
and published report The Bending of Spears by Dennis Pain (1997), international organizations started to engage in reviving Acholi cultural practices (especially those concerned with justice and reconciliation) as a means of peace-building. Soon, local CBOs and NGOs jumped on the bandwagon and new ones were founded which had discovered that international funding was available for 'cultural revival projects' (Allen, 2006: 130f.; 2010: 243ff.). Despite the large number of projects and organizations involved, attempts to revive Acholi culture from the beginning seemed to concentrate on a few, highly symbolic key elements. Among these were the revival of Acholi "traditional authorities", the revival of "traditional justice"137, especially the reconciliation ritual mato oput, and the revival of 'harmless cultural practices' ${ }^{138}$ such as traditional dances and the wango-o.

In the following, I give a brief overview of program interventions in these key areas and the way they are debated in academic circles and by the local population. For a more extensive discussion of this matter see Acirokop, 2010; Afarko, 2002; Allen, 2006; 2010; Baines, 2007; Branch, 2011: Chap. 5; Cagney, 2011; Harlacher, 2009; HuRiFo, 2007; Liu Institute for Global Issues, 2005; Mato Oput Project, 2009; Pain, 1997; Paine, 2011; RLP, 2005 and Wasonga, 2009.

\subsubsection{The Revival of Traditional Authorities: Rwodi Moo \& Ker Kwaro Acholi}

According to oral and written sources (see the discussion in the first part of this chapter), the traditional chiefs (rwodi moo) used to play an important role in mediating conflicts in Acholi society and had still fulfilled this role in the 1980s when the war broke out. Officially, the rwodi moo had been supplanted by the rwodi kalam, chiefs appointed by the colonial administration in 1911, but the former are said to have remained important conflict mediators on the local, informal level (Afako, 2002: 67).

There is some debate as to whether the conflict and the displacement of the Acholi population strengthened or weakened the role of the traditional chiefs. Some argue that due to the rise of conflicts within the camp communities and between the LRA fighters and the local population, the relevance of mediation and dispute settlement increased and the chiefs as 'traditional' facilitators of such processes gained recognition. Others claim that displacement weakened the power of the chiefs for

from Northern Uganda and the diaspora, as well as representatives of the Ugandan government, the government of Sudan, the LRA and the international community. The first of these conferences was held in London in April 1997 (cf. Poblicks, 2002).

137 "Traditional authorities/chiefs/leaders" and "traditional justice" have become established terms in the discourses on '(post-conflict) cultural revival'. For readability purposes, I will use them without quotation marks in the following sections, while bearing in mind the problematic notion of the term "traditional".

${ }^{138}$ I use this term as an antonym to "harmful cultural practices", an increasingly common, albeit often misleading, term in development and human rights work (4,730,000 Google hits, retrieved 13.07.2012) used to refer to practices like female genital cutting or widow inheritance. 
two reasons: first, their communities were widely scattered and people in the camps and in town became accustomed to new social practices and authority structures. And second, the insecurity and restrictions of movement within the camps prevented people from accessing ritual sites and thus led to a decline of ritual practices in which the chiefs had formerly been involved (cf. Kuster \& Santschi, 2006: 122ff.). Some influential local leaders and the international donor community (cf. especially the reports by Liu Institute for Global Issues, 2005 and Pain, 1997) favored the latter interpretation. They started to promote the argument that the breakdown of traditional leadership was an impediment to conflict resolution and peace and from this insight drew the logical conclusion that the role of the chiefs as mediators of conflict needed to be revived.

In his 1997 report, Pain therefore suggested that outside donors should actively promote the set-up of a council of rwodi moo and the revival of the Acholi cultural institution Ker Kwaro Acholi ${ }^{139}$. Pain argued that these "traditional leaders" were the best suitable local peace-building actors and the only ones, who might be able to restore social order and revive cultural norms and practices to foster peace and stability among the Acholi. The international development community quickly took on this idea and started to support "the restoration of relationships" (Roco Wat I Acholi $\left.{ }^{140}\right)$. Ostentatious anointing ceremonies for a number of rwodi moo and for the Paramount Chief as well as the rebuilding of "royal houses" were financed by international donors (Paine, 2011: 4). The following statement by Afako (2002: 67) captures well the discourse on the role of traditional leaders at the time and reflects the hopes placed on the chiefs as the chief mediators of the peacebuilding process. Afako solemnly declares:

"Today, in a project supported by the Belgian government, the rwodi of all the Acholi clans have been reinstated and the Lawi Rwodi (head chief) has been elected by the other rwodi. After years of conflict and marginalization, the chiefs, like most of their people, are poor and royal houses are in need of repair. However, the greatest asset of the chiefs - their political independence - gives them enhanced credibility in mediating reconciliation."

The reinstatement of the chiefs was seen to go hand in hand with the restoration of Ker Kwaro Acholi. Both, the donors and the traditional leaders themselves, established a discourse according to which Ker Kwaro was an ancient Acholi institution and as such had the legitimacy to represent Acholi interests. Different authors have

139 The new 1995 Ugandan Constitution allowed for traditional authorities to be officially recognized and set in motion a country-wide revival of so-called "cultural institutions". Ker Kwaro Acholi was recognized as the Acholi cultural institution, but did not gain any substantial influence until the international community took on the discourse of cultural revival two years later (Afako, 2002: 67).

140 "Roco Wat I Acholi", meaning "the restoration of relationships in Acholiland", is the title of an influential report by Liu Institute for Global Issues, 2005. 
argued that this was rather an act of 'inventing' tradition and 'myth-making' than a reconstruction of 'cultural facts'. Paine (2011: 7), for instance, writes:

"The historical narrative offered through the Strategic Plans presents KKA's [Ker Kwaro Acholi's] past as the undisputed traditional institution of the Acholi, utilising particular truths and myths to create the impression KKA is a primordial institution dating back to the fifteenth century. Even a cursory understanding of Acholi history shows this to be inaccurate."

She goes on to delineate that this 'myth-making' was crucial for Ker Kwaro because its central role in the international peace and development strategies derived from its status as 'authentic' cultural institution. In her words:

"One of the most crucial aspects of the Strategic Plans has been the way they have not only presented KKA as the natural gatekeeper and custodian of Acholi traditions and customs on the one hand and as the key to future sustainable development on the other, but that KKA has positioned itself as the key to development because it is the gatekeeper of culture" (Paine, 2011: 8 , emphasis in original).

This implies that Ker Kwaro actively sought being represented in a particular way in order to gain a new and profitable role as a development and peace-building institution.

Local perspectives on the attempts by the international community to revive traditional leadership were quite diverse. While Acholi people, especially those who had been displaced, did lament the breakdown of traditional leadership and longed for the re-establishment of former social relations, many were skeptical about the intense involvement of their traditional leaders in Western development programs. While many supported the idea of reviving and strengthening the role of traditional leaders in dispute settling, conflict mediation and reconciliation, they also feared that their clan chiefs might be instrumentalized by donors for their own agendas and thus would no longer be able to represent the interests of their clans (Paine, 2011: 12; Kuster \& Satschi, 2006: 122ff.). Paine relates to this debate when she writes:

"Although most rwodi mo in Acholiland are struggling for local recognition and respect, for reasons quite apart from donor intervention, the shaping of KKA through engagements with donors seems to be hindering any potential rwodi mo could play in the future of Acholiland. Even though a handful of academics have been very critical of KKA's 'revival', there has been a broader and more widespread foreclosing of critical reflection on whether the revival of KKA, with a Council of Rwodi mo, a newly created Paramount Chief, a cabinet of ministers and a secretariat, is, as the Ugandan Constitution stipulates it should be, in accordance with the aspirations of the people to whom it applies" (Paine, 2011: 14f.). 
The "critical academics" Paine refers to (among them Branch, 2011 and Allen, 2006; 2010) have voiced their concerns about the ways traditional authorities and especially Ker Kwaro Acholi, despite the institution's uncertain stance among the local population, have been instrumentalized by the Western donor community to fit current peace-building agendas. Branch (2011: 171), for instance, argues:

"The motivation is clear: to channel donor funding to the promotion of 'traditional authorities', who can lead a cultural revival and, through mechanisms of traditional justice, restore social order among the Acholi, as an alternative to Western systems of justice through punishment. It is an empowering, participatory project, where Acholi are empowered to participate as proper, 'responsible', Acholi under the authority of chiefs. As with all ethnoscience discourses, this is oriented principally toward a Western audience - in this case, toward donors."

This statement only implies that the merits and downsides of creating and supporting traditional authorities were heavily debated among development practitioners and academics. Even more debated, however, was the (related) question, whether peace in Acholiland could be better achieved by following 'traditional justice', centered on restorative approaches, or whether LRA combatants and collaborators should be subjected to 'Western', retributive forms of justice. In the following section, I will briefly recapitulate the debates on supporting traditional justice and especially the emblematic role of the reconciliation ritual mato oput.

\subsubsection{The Revival of Traditional Justice \& the Reconciliation Ritual Mato Oput}

In the mid-1990s, the scope and length of the conflict in Northern Uganda, the difficulty to resolve it and the failure of numerous peace attempts led to a reassessment of conflict settlement approaches. Due to the complex relationships between the LRA and the local population - many LRA perpetrators being former victims of LRA abductions (cf. Baines, 2009) - many Acholi ${ }^{141}$ supported a restorative approach to conflict settlement rather than calling for the persecution of perpetrators (Afako, 2002: 64; Peachey, 2012).

Following these debates, in 1998, a first Amnesty Act was introduced, which offered pardon to insurgents, who had given up fighting and wanted to return to a peaceful life as civilians. Offenders of especially heinous crimes (genocide, murder, kidnapping and rape), however, were excluded from the regulation. In 2000, based on the close involvement of representatives from the Acholi community (most notably ARLPI), a new and reformed Amnesty Act was introduced. This act granted

${ }^{141}$ Different sources, especially reports produced by development organizations, claim that the majority of the Acholi population favored forgiveness and reconciliation over persecution and punishment (for a moderate presentation of this argument see Peachey, 2012). Allen (2006: 138ff.) contests this claim and argues that the local population was more divided on this matter than is commonly acknowledged. 
general amnesty to all insurgents, irrespective of the crimes they had committed, including combat, collaboration and aiding rebellion (Afako, 2002: 65f.). According to Afako (2002: 65), the act was widely supported by the Acholi population because it was "building on tradition and responding to the expressed wishes of the people of Uganda - particularly those of the people of Acholi whose specific concerns were incorporated into the law".

Despite some successes of the amnesty $\operatorname{act}^{142}$ and its continuous renewal, it always remained a matter of much debate. For different reasons, neither the Ugandan government, nor senior commanders of the LRA unanimously supported the Amnesty Act (Finnström, 2008: 92; 119f.). Contrary to the idea of granting amnesty as a first step towards peace, the Ugandan government intensified counterinsurgency warfare in Northern Uganda at the beginning of the 2000s. Furthermore, in 2003, Ugandan President Museveni called upon the International Criminal Court (ICC) in The Hague to investigate the crimes and human rights violations committed by the LRA. The ICC took on the case and in 2005 issued arrest warrants against Joseph Kony and four other leading LRA commanders (Brubacher, 2010: 268ff.).

The involvement of the ICC sparked great debates among local and international actors about which form of justice - restorative as intended in the Amnesty Act or retributive as envisioned by the ICC - should be applied in dealing with perpetrators and would be more suitable to solving the conflict and establishing sustainable peace ${ }^{143}$. An influential group of local traditional and religious leaders and international development actors argued that a 'cultural approach' to justice should be taken due to the complexity of the conflict situation, particularly the fact that most of the former LRA fighters would eventually return to their communities and thus would need to be properly reintegrated in order to prevent a renewed escalation of conflicts. The claim that the Acholi have long adhered to an alternative system of justice - "Acholi justice" - based on a "special capacity to forgive" became highly institutionalized and widely regarded as a way to resolve the complex relationships between Acholi victims and Acholi perpetrators resulting from the conflict (Allen, 2006: 129). The basic argument brought forward by promoters of the traditional justice approach is probably best captured by an often cited quote from Pain's report. Pain writes (1997: 2):

"Acholi traditional resolution of conflict and violence stands among the highest practices anywhere in the world. After factual investigation, it requires acknowledgment of responsibility by the offender, followed by repentance and then payment of compensation, leading to reconciliation through mato oput, the shared drinking of a bitter juice from a common gourd. This practice of reconciliation lies at the heart of a traditional approach to 'cooling'

${ }^{142}$ According to Afako (2002: 66), by 2002 over 4,000 people across Uganda had applied for Amnesty.

${ }^{143}$ This debate has been carried out and analyzed in numerous articles and books and can only be briefly summarized in this section. For an overview see Allen, 2006 and Branch, 2011: Chap. 6. 
the situation and healing the land and restoring relationships, far beyond the limited approaches of conservative Western legal systems and a formal amnesty for offences against the state".

Thus, the key to justice and reconciliation was seen in the revival, adaptation and extension of different 'traditional' rituals designed for reconciling clans and individuals after conflict. Traditional authorities were regarded as key actors in carrying out these rituals (cf. Liu Institute for Global Issues, 2005: iif.; Afako, 2002: 67; Mato Oput Project, 2009: 8). Despite the diversity and complexity of reconciliation rituals in Acholi society (cf. Allen, 2010: 251; cf. Harlacher, 2009: 175ff.; Acirokop, 2010: 276f.), one specific ritual - mato oput - was singled out and became a synonym for reconciliation and "a sort of euphemism for healing rites or blessings performed by the rwodi moo (anointed chiefs), which promote reintegration of former LRA combatants into society by offering 'forgiveness'” (Allen, 2006: 134; cf. also Acirokop, 2010: 277; Harlacher, 2009: 186).

According to widespread opinion among the Acholi, which was also cited to me by my interlocutors, mato oput was originally a ritual to reconcile clans after a member of one clan had been killed by a member of the other clan. It centred on the principles of confession, compensation and reconciliation. Relationships between the two clans were re-established after the offender's clan had claimed responsibility for the killing and paid compensation to the victim's clan (Harlacher, 2009: 186ff.). Acirokop (2010: 277) describes mato oput as follows:

"Mato oput literally means 'drinking bitter root', as it is made from the ground, bitter roots of the oput tree, which is common in Acholi. The ceremony aims at reestablishing relationships suspended between two clans in response to a killing, whether deliberate or accidental. Participants share this bitter drink at the peak of the ceremony, at the end of a long process of confession, mediation and payment of compensation. Essential to the process is the willingness of the offender's clan (not the offender as an individual) to assume responsibility for the act committed and a readiness and ability to pay compensation."

In the evolving peace-building discourse in Northern Uganda in the mid-1990s, the ideas of reconciliation and forgiveness underlying mato oput were seen to epitomize the principle of Acholi traditional justice. Mato oput was regarded as a solution to the problem of reconciling victims and perpetrators from the same community. By the mid-2000s, mato oput rituals were being performed on a large scale throughout Northern Uganda, often accompanied, financed and promoted by Western development organizations and the Western media (Allen, 2010: 249; Peachey, 2012: 298ff.).

Many authors have pointed out, how mato oput came to be re-invented by donors and traditional authorities. In order to suit the conflict situation in Northern Uganda, the original meaning of the ritual had to be altered. The focus was no 
longer on reconciling two clans but on re-establishing relations between individuals and their communities. Compensation payments to the communities were often disbursed by Western donors, rather than by the offenders themselves, as the latter did not have the means (Pain, 1997: 3). This led some observers (e.g. Allen, 2010: 250) to conclude that the widespread acceptance of the mato oput rituals was mainly due to the availability of donations.

There have been extended debates about the benefits and downsides of the re-invention of mato oput, which are too complex to recapitulate here (for an overview cf. Acirokop, 2010; Wansonga, 2009; Mato Oput Project, 2009; RLP, 2005). Sceptics have often pointed out that it was not possible to adapt the ritual to the war context, while supporters have argued that the principles and symbolic meanings underlying mato oput were crucial to 'rebuilding' Acholi society and should thus be promoted (Liu Institute for Global Issues, 2005: iii).

During my own research, I rarely came to discuss mato oput and the 'invention' of traditional justice with my interlocutors. The peak time of these debates had been during the last years of the war and in the immediate post-war phase, and I felt that everything had been said on this issue. Among the young people I worked with the revival of other aspects of "traditional culture" - especially traditional dances and the wango-o-were considered more important and relevant to their current lives. In the remaining section, I will focus on these aspects.

\subsubsection{The Revival of Traditional Dances}

The younger people I worked with in Gulu had various opinions on the question whether "traditional culture" should be revived (which will be further discussed in chapter 5). Some idealized the past and dreamed of a return to social order, intact social relations and established cultural practices, rules and norms. Others saw the change in lifestyle, which they felt had occurred across Acholiland and especially in the urban areas in the past years, as a sign of progress and modernity and did not want to return to the old ways of life. There were two aspects of "traditional culture", however, which were nearly unanimously regarded as positive, and which nearly all young people hoped would be revived: traditional dances and the wango-o. In the following section, I will concentrate on the former, as I have already discussed the subject of wango-o earlier ${ }^{144}$.

${ }^{144}$ As stated earlier, people saw the decline of the wango-o tradition in the camps as one of the main reasons for the loss of Acholi culture. During the time of my research, there were different attempts to revive the wango-o. Donors involved in 'post-conflict peace-building' had discovered wango-o as a means to foster peace, societal reconciliation and 'cultural revival' (for an account of recent attempts by NGOs to reinstall the wango-o tradition, see Cagney, 2011). Some communities, who had returned to their original villages from the camps, had restarted the practice (group interview Bungutera, 03.10.2010). However, the majority of the young people I encountered, both in town and in the villages, had not actually experienced the wango-o themselves and many did not believe that the practice could be revived. One of my interlocutors, a young man in 
The topic of traditional dances has not been a major focus in the literature dealing with 'cultural revival'145. This is somewhat surprising, because of the widespread popularity of traditional dances among all segments of the Acholi population and the extent of international and local attempts to set up and support so-called cultural groups, which perform these dances and teach them to youth. During my research, I spent a lot of time working with youth cultural groups, especially one group, the Gulu Theatre Artists (GUTA, cf. Chap. 2). I watched their practice sessions, accompanied them to traditional dance competitions, and discussed the meaning and relevance of traditional dances with members of the group. The following analysis is largely based on my own observations on contemporary practices and interpretations of traditional dance, and on interviews and personal conversations in which this topic was discussed.

According to my interlocutors, the Acholi have a very rich dance culture and are widely known for their repertoire of traditional dances. In one of my first visits to GUTA (cf. field notes 14.03.2010), one of their members introduced me to the most popular and well-known dances of the Acholi and their specific functions:

- Bwola, the royal dance, which was originally performed only for the rwot but is nowadays performed whenever an important person comes to visit.

- Ajere and Larakaraka, both courtship dances, which were originally organized, so that boys and girls from different clans could meet and get to know potential marriage partners.

- Dingi Dingi, a dance for young girls.

- Myel lyel, a funeral dance, which was originally practiced during funeral ceremonies, especially those of "big people", and is still sometimes performed today. (I was later explained that the funeral dance is performed to find out what killed the person who is being buried and to eliminate the source of evil, personal conversation cf. field notes, 26.06.2010).

- Otole, the war dance, which was practiced in the olden days to declare war on another tribe, but is rarely performed today (field notes 14.03.2010).

his early twenties, told me that it was mainly the Western NGOs who were calling on people to revive the wango-o, but that without the effort of these NGOs the wango-o tradition would eventually disappear. He cited a number of reasons why nowadays people were no longer interested in wango-o: there was electricity so people no longer needed to sit by the fire to have light; young people in town preferred watching TV and Western movies; and even in the villages people went to the disco halls or bars in the trading centers to "hang out" instead of sitting at the wango-o (personal conversation cf. field notes 30.03.2010).

145 However, there is a well-known and internationally celebrated documentary film "War Dance" (Nix \& Fine, 2007) about a group of children from Patongo IDP Camp who travel to Kampala for the national music and dance competition. 
Bwola, Larakaraka, Ajere and Dingi Dingi were among the dances, which were most frequently performed in competitions and festivals. Others included Nanga and Apiti, both dances for married women (field notes 26.06.2010; cf. INT Simon, 31.03.2010).

In the current discourses on Acholi culture, traditional dances have come to be regarded as one of the most important cultural practices of the Acholi. They are seen to represent the richness and vivacity of Acholi culture and are thus celebrated by all segments of Acholi society. In the context of 'post-conflict peace-building', the development community has also discovered traditional dance as an example of a positive and 'harmless' cultural practice, which can be easily supported in order to revive Acholi culture. In urban Gulu today, traditional dances are mainly performed for entertainment purposes - during music and art festivals, in competitions, but also during important political functions (e.g. election campaigns). Due to these public performances, traditional dance is one of the most visible and wide-known cultural practices.

Despite the high public visibility, many young people I talked to lamented that they only knew very little about the original functions of the dances and the way they were performed. Most had heard about the Bwola dance and the courtship dances, and many knew how to perform at least one or two of these. Some did not have any practical knowledge at all. My interlocutors sometimes complained to me that in former times all young people had known many different dances, because they were taught by elders or older youth in their communities, which was no longer the case today (personal conversations cf. field notes 14.03.2010; 20.06.2010; INT Ojok 31.03.2010; INT Elima, 09.04.2010; INT Denis, 16.04.2010; INT Martin, 21.04.2010; INT Laurence 28.04.2010). One of my elder interviewees, Okello, once vividly explained to me how dance training for the young was provided at the wango-o:

"After people have eaten, they are satisfied, people are now fit. Children would just get in groups like that, then they would practice traditional dance. The big men [elders] would teach them, they would go, showing them how to dance Bwola. Then people would just stand in a circle like this, they begin the song, the movement, the up movement, the down movement, the movement across, just inside like that [imitates the moves while speaking]. So children would just learn traditional dance, the ladies would be assembled and the [older] ladies would teach [the younger girls]. The men would teach the boys. But in case of certain dances which need ladies to dance together with the men, the ladies will come, knowing their steps, and the boys also will know their steps. So when the boys are dancing there in the outside circle, the ladies always have the inside circle, then they dance with the same drum, but the movement will be the same..." (INT Okello, 26.09.2010).

Nowadays, rather than being taught by older relatives as described by Okello above, most young people are introduced to traditional dancing in school. Dance and 
music classes are a compulsory part of the primary school curriculum and there are nation-wide competitions between students from different primary schools (cf. Cheney, 2007: Chap. 7; field notes 16.06.2010). Many of the dance and music teachers at school are specifically hired experts, who are also involved in traditional dancing outside of the school context - as trainers or chairpersons of cultural groups or as judges in dance competitions. Students thus learn about the existence of cultural groups from their teachers, and those who enjoy traditional dancing and wish to continue, often join one of these groups in order to intensify and practice their knowledge and skills (personal conversation, cf. field notes 20.03.2010). The majority of my interlocutors, who were members of a cultural group, had been introduced to traditional dancing through school. When I asked them why they had joined a cultural group, I often got responses like the two following:

"I started liking this traditional thing, because you know in primary [school] they conduct what is called music festival. In music festival in primary they do all these kinds of activities, there is creative dance, there is traditional dance, there is Western piece [choir] ${ }^{146}$ (...) I was one of the participants in the music festival, so we went for several competitions, (...) so when I joined S1 [first class of secondary school], I joined this [cultural] group. I joined this [specific] group, because the person who was aiding the music department at that school was the chairperson of this group" (INT Odong, 04.05.2010).

"At first I was in the music festival, I was doing music at school, so I had interest in music. So from there I started feeling interest in cultural things, I joined [this group], now I am 12 years old in this group. I joined when I was in P7 [last year of primary school]... in 1999" (INT Innocent, 04.05.2010).

It seems that in their current form, cultural groups had only been started in Northern Uganda in the late 1990s (cf. INT Innocent, 04.05.2010). During this time, international donors involved in societal peace-building had been eager to support youth activities, especially for 'vulnerable youths' (i.e. those who had been formerly abducted by the LRA, and those living in the camps). Due to donor's provision of funding (and attributable to their need to have local partner organizations), many local $\mathrm{CBOs}$ were founded, which started to carry out youth projects involving (among other things) sports activities, break-dance and traditional dance. These projects were seen both, as a means for healing youth from war traumas and as a means for 'normalizing' social relations. Traditional dance and music were further regarded as a means to support the revival of culture and thus became especially prominent.

146 Apart from "traditional" music and dance, students in primary school are also introduced to "Western" music, i.e. choir. In the nation-wide school competitions, traditional dance performance is only one of the disciplines. Others include choir, drama, instrumental piece (i.e. a performance with "traditional instruments"), and "original composition", i.e. the composition of an original song (cf. Cheney, 2007: Chap. 7). 
One of the most well-known organizations, which aimed to provide "life skills through health, formal education, play therapy and arts" to vulnerable children and youth in Gulu, was H.E.A.L.S (Health, Education, Arts, Literacy and Sports). H.E.A.L.S's provided school sponsorships, health education and literacy classes as well as a "Play Therapy Program", which offered traditional dance and music classes, sporting activities, and art classes (H.E.A.L.S., cf. http://www.facebook. $\mathrm{com} /$ healsuganda? $\mathrm{v}=$ info, accessed 24.07.2012). Despite its popularity and initial success, H.E.A.L.S was no longer operating, when I did my field research in Gulu. According to one of my interlocutors, who had attended many of their programs, H.E.A.L.S. had been closed down due to mismanagement (personal conversation cf. field notes 22.05.2010).

By the time of my field work, donor support for youth activities had started to fade. Some youths, who had formerly participated in donor-funded youth projects, reported that many had been closed down due to lack of funding. One interlocutor speculated that NGOs were pulling out of youth projects because many young people had returned to the villages. He believed that, because the returnees had restarted farming, the only programs donors were now concentrating on were agricultural projects (personal conversations cf. field notes 14.03.2010; 22.05.2010).

Of all the former donor-funded youth activities, traditional dancing proved to be the most sustainable. Cultural groups, which had been formerly supported by donors, continued and were often re-organized by young people themselves. Older youth, often young men in their late teens and early twenties, organized the practice sessions and trained the younger members of the group. They also arranged for the groups to participate in competitions and festivals or to perform at weddings, funerals or business functions. The latter were important income-generating activities, which were needed by the groups to compensate the cut in donor-funding. While many cultural groups still received smaller amounts of support by external donors (often, for instance, donors paid the school fees of members or financed specific programs such as the organization of the Miss Acholi Event), the money was not enough to cover the rent for office and training venues, for costumes and instruments, or to pay the fees to enter competitions (personal conversation cf. field notes 17.12.2010).

Members of the cultural groups, especially those in leading positions, often saw their role as preservers of Acholi tradition. My interlocutors sometimes stated that without cultural groups young people (especially those in town) would simply forget about Acholi traditions and cultural practices. They lamented that many of their peers only knew "the Western culture" and further claimed that the urban lifestyle was spoiling their generation. The following two quotations are exemplary:

"In fact, they don't know [young people today who are not in cultural groups no longer know their culture], because they lead this life like Westerners. They like picking the style from the Westerners... Like for my case and him, Odong [points to his friend], we like cultural groups. Other people, they pre- 
fer going for clubbing rather than [joining a] cultural group, they like [disco] music better than this cultural group. Yet cultural group, it has more value than going for clubs, for disco..." (INT Innocent, 04.05.2010).

"At least for us we are lucky, because we are just in a cultural group. We don't go in for other things like stealing, (...) all those things, taking drugs... But other people, who are idle, they are just outside there. They are so many (...) mostly youths, not old people, but mostly youths, you find them there, taking drugs, (...) all those kind of things (...) If you do your research a little, you find that people who are in groups, in cultural groups, their lifestyle is different from people who are outside there. Because they teach you morals, behavior, on how to conduct yourself, and the way you should behave to the whole community. So you find that people who are here, in cultural groups, you see the way they behave it is quite different, it is quite different to people who are outside" (INT Odong, 04.05.2010).

However, my interlocutors also recognized that the opportunities of preserving Acholi culture through cultural groups were limited. They acknowledged that many of the cultural practices they were trying to promote were very different from the way they had been practiced in former times. The meaning and context of traditional dances, for instance, had been fundamentally altered in response to various internal and external influences throughout the war years. Cagney (2011: 31) illustrates this 'problem' with reference to the Bwola dance:

"Another example of this dilemma, and the changing context of dance, is in the iconic Bwola dance. Not only are the costume pieces expensive, its performance has been made much more public and less exclusive than in the past. Dances were not meant for entertainment for a crowd of strangers. Most of them serve a functional purpose. (...) [T] he Bwola was only performed for royal events, not for outsiders. Now, the Bwola may be performed in national dance competitions, celebrations, or when heads of state visit from other countries."

In a similar vein, my interlocutors often pointed out that most of the traditional dances were nowadays performed for entertainment purposes only. As an example, they usually mentioned the courtship dances. They explained that in former times these had served as an important social setting, where young people could meet their future husbands and wives, while today young people met at school or in disco halls and no longer followed the original courtship procedures (INT Okello 26.09.2010; INT Simon, 31.03.2010; personal conversations cf. field notes 14.03.2010; 08.05.2010; 20.06.2010).

Another commonly mentioned example of a tradition in change was the funeral rite (see above) and its corresponding funeral dance Myel lyel. The Myel lyel originally had a spiritual purpose (i.e. to find out who or what had killed the deceased and to 
eliminate the source of evil), but was nowadays performed by dance groups, which were hired and paid for their performance. In the words of one of my interviewees:

"There are things that are difficult to revive. I think people just abandon them, things that... I have seen for example practices like funeral rites, yeah, that one, it is there, it is on, but it is modernized in a way. We used to have the drums and all this, now what I see happening is: [People say] 'we're going to have a funeral rite of the late bla bla [substitute for the name of the deceased person]', several of them. And then they make announcements and people gather and then maybe dance and so forth. The traditional way would be to bring on drums and people sing and dance for one night or two. What now happens is you hire a public dance team and you go and play disco. People still dance, and so I think even if the principle is still there, but the real practice has changed, it is different" (INT Rocki, 16.03.2010).

Apart from the desire to contribute to 'cultural revival', for most of my interlocutors traditional dance was also an opportunity to enter social realms that were normally not accessible for young people of a poorer background. Being a member of a cultural group provided them with the prospect of traveling to exclusive and/or distant places, and offered the chance to gain recognition and prestige. When I asked one of my interviewees whether Acholi traditions were still important for him he answered:

"Yes, yes, the reason why I say it is still important [is the following]: those days I don't used to know those big people like RDCs [Resident District Commissioner], other big people. But when they hire us for dances, that is the opportunity, we get to see them and talk to them, like RDC Walter Ochora [the RDC of Gulu at the time], or [Norbert] Mao, the chairman of Gulu District. In 2008, the German president Horst Köhler, he came to Gulu, we appeared in the newspaper with him, we went in Bouma Hotel [one of the most expensive hotels in Gulu], and we danced. He came and shook my hand and we talked (...) It [culture] is still important for me, cause I get the opportunity of seeing where I would not see if I was not in the [cultural] group, so I still like it and I still do it (...) If the other deal works out well, we are going up to Sweden for a show (...) These people like traditional dances (...) When I was in O-Level [first four years of secondary school] I was elected entertainment prefect, simply because of the traditional dances I do (...) When I get back to the school, in A-level [last two years of secondary school] there, they still wanted to elect me entertainment prefect, because I used to do things that make them happy" (INT Simon, 31.03.2010).

Apart from gaining new experiences and social acknowledgment, successful cultural groups also had the chance to make some extra money. Through performances at business functions, weddings or in tourist locations they could easily earn 150,000 UGX (approximately 50 Euro) or more. Even more profitable were the prize moneys 
Julia Vorhölter: Youth at the Crossroads

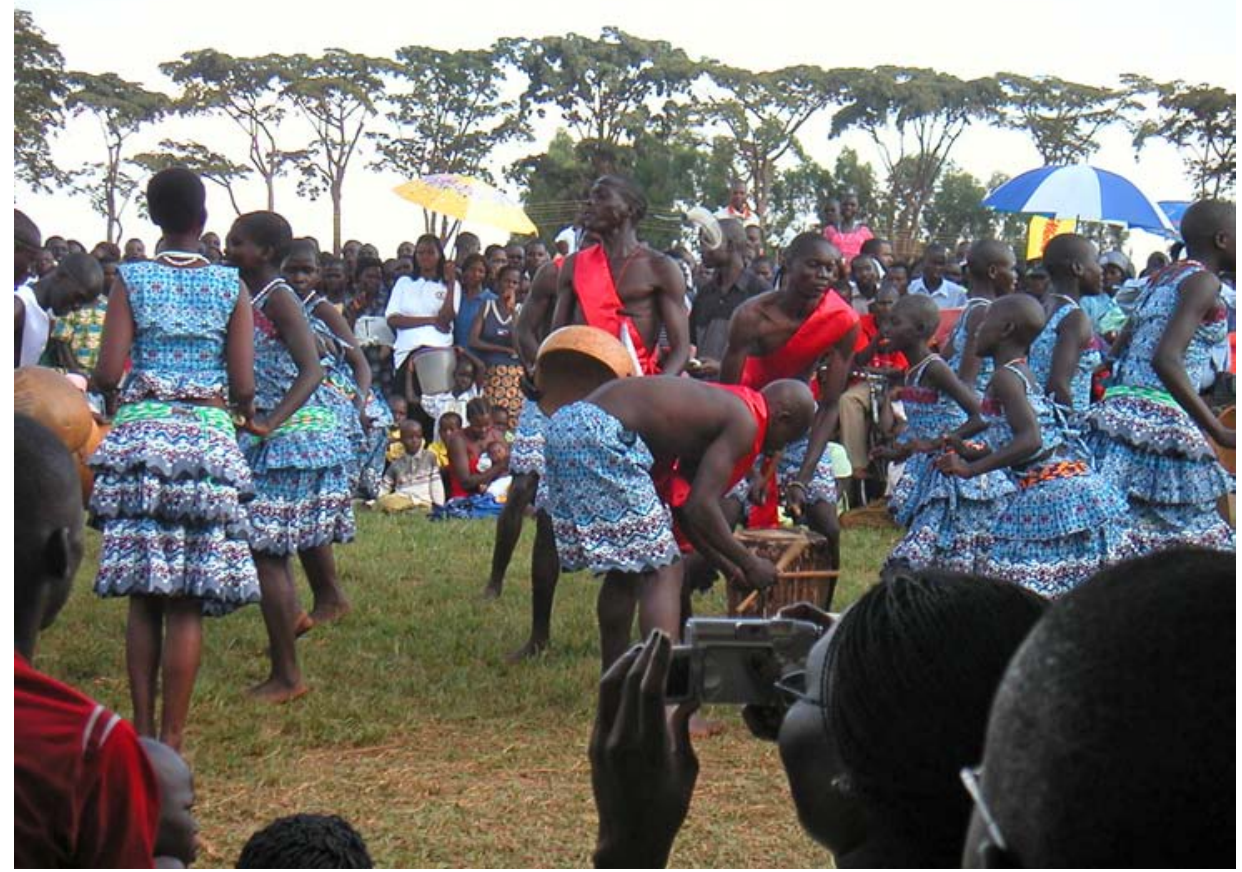

Illustration 1: Radio Rupiny Traditional Dance Competition at Kaunda Grounds, Gulu (photo by author)

offered in big dance competitions, for instance by Senator (a beer-brewing company) or Radio Rupiny (a local radio station). According to my interlocutors, the winner of these competitions could earn between one and six million Ugandan Shilling, i.e. up to 2,000 Euro (personal conversations cf. field notes 26.06.2010; 17.12.2010; 03.01.2011). I sometimes had the impression that the prospect of winning so much money paralleled or even superseded the primary motivation of the cultural groups of being cultural ambassadors. It was also a reason for the fierce competition between different cultural groups (cf. field notes 22.05.2010; 30.05 . $2010 ; 26.06 .2010 ; 28.11 .2010 ; 17.12 .2010 ; 03.01 .2010)$. The following is an extract from my field notes, which deals with this issue:

"We (Odong, Innocent, David and me) talk about the Senator competition: Odong tells me that some years ago GUTA was second at the National finals and received 1.5 million Shillings. He says the winner received six million and adds that the money is the main reason why everyone likes Senator so much. 'At least they pay you well unlike in other competitions.' The three guys tell me about a competition, which used to be held in Kampala every year and which was sponsored by the Italian government. One cultural group from each district 
used to perform there and the whole event took a week. All participating groups received free food, transport and accommodation. 'But', so the guys complain, 'there wasn't any money to win and it was therefore really a waste of efforts to participate in the event. Even the winners only got trophies'. I am surprised and say that staying in Kampala for free for a whole week is already quite a good deal, whereupon Odong replies that they actually 'perform to get money and not just for fun'..." (field notes 03.01.2010).

This extract shows that locally organized and seemingly 'pure' attempts to revive Acholi culture, such as those by the cultural groups, were also influenced by material interests, and irrespective of the enthusiasm and the genuine motivation of many Acholi involved in these groups, also served particular interests.

The preceding analyses have shown the ambiguity and creativity of contemporary attempts to revive 'traditional culture' in Gulu. While the loss of Acholi culture is generally perceived as a very serious matter with profound social, ethical and moral implications, not all attempts to revive the culture are unanimously celebrated by the Acholi people. Especially the large projects which were supported and sometimes initiated by the international donor community were regarded with scepticism as they seemed to mainly serve the interests of some key actors in Acholi society. Irrespective of their underlying motivation to revive Acholi culture, these projects were always also opportunities to make money, to gain status and respect and to influence current discourses and dynamics. Local attempts to revive Acholi culture, such as the formation of cultural groups and the pervasiveness of traditional dances, were extremely popular and regarded with less skepticism. But upon closer inspection, even these attempts, just like the revival of traditional authorities and traditional justice, were in many ways "inventions of tradition" (Hobsbawm, 1983) which served particular interests.

\subsection{Concluding Remarks: Contemporary Discourses on Acholi Culture}

In the preceding chapter, I have dissected older as well as contemporary notions of Acholi culture. In the first part, I cited accounts from earlier ethnographies written by social scientists and local ethnographers, which have contributed to shaping contemporary representations of Acholi culture. Thereafter, I discussed what Acholi people today mean when they speak of "traditional culture in those days" and analyzed how they perceive socio-cultural changes, which have occurred in the past decades and which they largely attribute to the war and the displacement situation in Acholiland. Lastly, I have given a brief overview of current attempts to revive and 're-invent' Acholi culture. Throughout the chapter, I have made extensive use of direct quotes in order to give the reader a more vivid insight into contemporary 
discourses on Acholi culture and to present some of the multiple voices involved in the production and reproduction of these discourses.

As discussed, the issue of reviving culture was widely debated among all segments of Acholi society. However, most of my interlocutors, both young and old, doubted that "traditional culture" could be completely revived because people had become accustomed to a new way of living during the war years. Some were concerned that especially the younger generation might not be interested in returning to a lifestyle as rural farmers because they felt more attracted to a "modern", "Western" and urban life. In the words of one of my interlocutors:

"So you find that although people have already gone back to their homes and their villages, people I don't think they are going to revive the culture. People are so much addicted. Even others they don't want to go back to the villages, they just want to remain in the camps, because in the camps you have so many things: the video halls, the bars, all those... So they want to stick to that kind of life and don't want to go back to the villages and again digging..." (INT Laurence, 28.04.2010).

The people in urban Gulu generally seemed to believe that those Acholi, who had returned to their villages, had a better chance of reviving old practices and conventions than the people living in town. But they always asserted that this would take time and that many of the changes caused by the camp interregnum were irreversible. When I asked Okello whether he thought that "traditional Acholi culture" could be revived, he said:

"Not really, because the ideology that the children and the parents got from this insurgency are sticking in their minds. They cannot really go back to this original lifestyle, they cannot. But because they will have something to do at home, it will be reduced, the careless life will be reduced. Because now people who have gone back to the village have got self-employment, they are employing themselves, you find boys are just cultivating land, they are planting cassava, sugar cane, like that. They get small small money and it goes in their pocket, so they are now self-independent. It is now much better than the time when people were in the camp" (INT Okello 26.09.2010).

When my interlocutors spoke about the situation in town, they usually assumed that there the attempts to revive or preserve Acholi cultural practices were more difficult to reconcile with the daily routines of the people. This might explain why initiatives to revive Acholi culture often concentrated on specific, extra-ordinary events. A vivid example of such an event is the Miss Acholi Contest which I described in the beginning of this chapter. The event revealed both the enormous importance that is attributed to Acholi culture as well as the creativity in the attempts to preserve and revive it. The fact that the Miss Acholi Contest was "not a conventional beauty contest", but a "competition about cultural knowledge", reflects the widespread feeling that it is no longer self-evident for the younger generation to "know their 
culture". On the contrary, the assumption underlying events like the Miss Acholi Contest was that young people need to be encouraged to re-learn the "traditions" of their forefathers and -mothers. One could thus argue that such events serve to advertize Acholi culture in order to render it more attractive to young people, and to demonstrate how Acholi cultural practices can be combined with a 'modern', urban lifestyle. Hence, in contrast to the hegemonic discourse, which proclaims that "traditional Acholi culture" as it was in "those days" has been lost and thus seems to imply a uniformity and unchangeability of Acholi culture, in practice, imaginations of Acholi culture are innovatively adapted to fit people's lived realities.

I will turn to this matter in more detail in the following two chapters, where I show that different social groups have different opinions on the question whether Acholi culture should be revived. I will discuss how socio-cultural change and 'cultural revival' are negotiated in urban Acholi society today - between the younger and the older generations, between men and women, and between richer and poorer segments of the population - and will focus on the conflicting imaginations of a future society and the social conflicts which erupt on this matter between different interest groups. 



\section{Between "Tradition" \& "Modernity" Cultural Styles \& Discourses on Socio-Cultural Change Among the War Generation in Urban Gulu}

In this chapter, I analyze how young people in Gulu position themselves in discourses on Acholi culture and how they evaluate the changes Acholi society is seen to be undergoing. I discuss the various strategies they adopt in dealing with a situation of cultural flux and uncertainty. The chapter intends to illustrate how youth in Gulu, particularly members of the war generation, strategically react and contribute to contemporary discourses on socio-cultural change in post-war Acholi society. I show that, on the one hand, members of the war generation experience sociocultural changes in a similar way, while on the other hand their interpretations of and reactions to change are also dependent on individual characteristics, situational context and, related, societal power constellations and dynamics. In support of my research hypothesis, I explicate that members of the war generation experience their current situation as being torn between conflicting notions of tradition and moder- 
Julia Vorhölter: Youth at the Crossroads

nity and that, as a result, many feel ambivalent about the way they imagine their future society and about the role they are to play in realizing this society.

\subsection{Youth Perspectives on Socio-Cultural Change}

In the previous chapter, I outlined the hegemonic discourse on Acholi culture which proclaims that "traditional Acholi culture" as it was in "those days" has been lost through war and displacement. I discussed the multiple voices and authorities involved in the construction of this discourse and already hinted at the fact that the understanding of Acholi culture and the role it is to play in contemporary and future Acholi society are heavily contested among different groups of actors within (and outside of) Acholi society. When looking at some of the literature about the postwar-situation in Northern Uganda, especially NGO-reports, one can easily get the impression that the 'retraditionalization project' is widely supported by all members of Acholi society. However, when engaging with the matter more thoroughly, it becomes evident that support for reviving Acholi culture (or certain aspects thereof) is strongly dependent on the background of the speaker (as regarding for instance gender, class, age) and the context, in which he or she is asked to comment on the matter. In this chapter, I focus on urban youth and specifically on members of the "war generation" with whom I worked in Gulu. I address the following question (and related sub-questions), which is central for my study:

$\rightarrow$ How do members of the war generation perceive changes in Acholi society and (how) do they position themselves as agents or 'victims' of these socio-cultural changes?

- How have their life experiences influenced their understanding of Acholi culture and values?

- How do they picture their individual futures and the future of Acholi society?

- How do they react to the expectations directed at them by older members of Acholi society?

I argue, as others (e.g. Branch, 2008: 16) have done, that although there is a general concern among all members of Acholi society about the perceived loss of their culture, the main proponents of 'cultural revival' and a return to the old life are adults and elders. Young people, as I have shown in the example of the cultural groups in the previous chapter, do take an active part in and support the discourse on cultural revival. However, due to the specific situation they have been confronted with in the past and the specific challenges and opportunities they face today and regarding their future, their position on the whole is somewhat different from that of the adult and elder population. 
On a theoretical level, one can apply Mannheim's concept of historical generations (1972: 288ff.), and argue that the young generation's "similarity of location" in time, space and the social whole offers them new perspectives and experiences which are different from those of former generations. Based on my emprirical insights and as stated in the introduction, I assume that the generation which grew up during the turbulent years of the war (especially those born between the mid-80s and early 1990s) has developed a distinctive generational consciousness, which has led its members to re-orient their practices, attitudes, feelings and to engage differently with accumulated social and cultural heritages when compared to former generation $s^{147}$. Within the historical generation of urban youth in Gulu, however, one can make out different responses to and interpretations of the ongoing sociocultural changes, which I will analyze more thoroughly throughout this chapter. Mannheim uses the term "generation units" to refer to those generational subgroups which share an "identity of responses" (Mannheim, 1972: 306), i.e. similar convictions how to respond to a particular historical situation. I will not apply the term, however, because the different perspectives on socio-cultural change I found among the young generation in Gulu did not map neatly onto distinct groups or units, but - as I will argue in the course of this chapter - were among other things also dependent on situational context.

In the debates on socio-cultural change which I discuss throughout this and the following chapter, one frequently finds references to "tradition" and "modernity". From a social science perspective, both are very problematic and contested terms, which have undergone many shifts in recent decades. Up until the 1980s, tradition was generally understood as an inherited legacy which establishes continuity with the past (cf. Otto \& Pedersen, 2005: 12). Following Weber, tradition was taken to imply the opposite of modernity and rationality, and was seen as characteristic of non-Western societies (Appiah, 1991: 343). This 'commonsense' meaning of tradition still exists today, mainly outside of anthropological circles. But many anthropologists and other social scientists have over the years attempted to refine and redefine this notion of tradition as it has proven empirically and theoretically inadequate (Handler \& Linnekin, 1984: 273; for a summary of these debates see Otto \& Pedersen, 2005, and Hermann, 2011: 3ff.).

Just like tradition, the concept of modernity has undergone several shifts in meaning and can refer to a plethora of things. On the one hand, modernity is used to refer to a historical epoch, characterized by scientific, technological and intellectual innovations, industrialization, insetting capitalism and the establishment of the modern nation state which started in Western Europe throughout the $15^{\text {th }}$ and $18^{\text {th }}$ century. On the other hand, modernity has increasingly come to be understood as a

${ }^{147}$ According to Mannheim (1972: 293f.), every new generation establishes "fresh contact" with the already existing social and cultural heritage but with a different attitude than former generations. Thus, every generation assimilates accumulated heritages differently and selects different cultural elements to be kept and others to be forgotten. 
concept, which contains specific institutions, practices and ways of thinking about the world including democracy, a capitalist market economy, science-based technologies and 'rational discourse' (Wittrock, 2000). In the 1990s, social scientists started to criticize such Western-centered conceptualizations of modernity and a debate emerged on the possibility of alternative, multiple, subjectively and culturally defined modernities (e.g. Knauft, 2002, Appadurai, 1996; Eisenstadt, 2000, Wittrock, 2000). These debates were of particular relevance to anthropologists working in non-Western parts of the world where they were confronted with local versions and discourses of modernity.

Among Africanist scholars, a new focus has emerged in the study of tradition and modernity since the 1990s, which concentrates on emic discourses within Africa (cf. for instance Comaroff \& Comaroff, 1993; Ferguson, 1999; Kratz, 1993; Gable, 2000; Geissler \& Prince, 2010). Modernity and tradition are seen to have become "highly problematic terms, meaningful only at a very high level of abstraction, but of little use as concepts guiding empirical research and critical enquiry" (Probst et al., 2002: 10), and are thus understood as being "contingent" (ibid.: 10f.). Recent studies, including my own research, reveal that in emic discourses a very normative and ambivalent meaning has been attached to modernity and tradition (cf. Ciaffa, 2008: 122f.). On the one hand, modernity is seen as a blessing, a sign of progress and an ideal to be pursued. On the other hand, one can find strong support for attempts to 'retraditionalize' African societies and proponents of these attempts often regard modernity as an abomination, which has destroyed local traditions and created rather than solved the problems people face today (Geschiere et al., 2008b: 1). The ambivalence inherent in the two concepts and the diverse ways they are applied and negotiated in different African contexts and among different actors lie at the heart of the current debates in anthropology (and beyond). In the following two chapters, I will relate to these debates, when I discuss notions of tradition and modernity among my interlocutors in Gulu. I will show how the two terms have come to be central reference points in discourses on Acholi culture and the future of Acholi society. As with other 'problematic' concepts I discuss throughout this book, like culture (cf. Chap. 4), I concentrate on the emic conceptualizations of tradition and modernity among my interlocutors. Thereby, I loosely draw on Hermann's (2011) concept of tradition (and modernity ${ }^{148}$ ) as "context-bound articulations" which she delineates as follows:

"The meanings ascribed to cultural traditions constantly shift in the course of interactions between people and their ideas, actions and objects. They are always articulated from specific perspectives that social actors have staked out within historically developed interconnectivities and multifaceted power relations. Being formed and expressed in relation to particular circumstanc-

${ }^{148}$ Hermann only applies the concept in the context of debates on tradition, but I argue that notions of modernity can similarly be understood as "context-bound articulations". 
es, they can be said to articulate the specific contexts in which interactions take place” (Hermann, 2011: 1).

Based on this idea, I analyze how young people in Gulu attribute certain meanings to concepts like tradition and modernity, which they use to articulate their past, present and future imaginations of Acholi society.

I introduce this chapter with a further extract from my field notes which describes my first visit to Herm's Club, a night club in Gulu, which at the time of my research was extremely popular among youths. I selected the extract to give a very vivid insight into (one aspect of) contemporary youth culture in Gulu, which contrasts starkly with the representations of 'traditional' Acholi lifestyle and practices depicted in the former chapter, in order to give the reader an impression of the broad spectrum of youth cultural practices in Gulu. Following and complementing this particularistic ethnographic introduction, I characterize the generation of urban young people who were born and raised during the war years and who live in Gulu Municipality today (cf. also introduction). I also point out important differentiating factors between members of this generation.

In the subsequent part of the chapter, I first discuss youth practices and behaviors with regard to Ferguson's (1999) concept of “cultural styles". Thereafter, I focus on discourses on culture and socio-cultural change among the young generation. I delineate four 'prototypical' positions young people adopt regarding this subject: a desire to retraditionalize Acholi society, a desire to modernize Acholi society, ambivalence or creativity.

The data underlying the analyses in the chapter are based on participant observation, personal conversations, interviews as well as a questionnaire ${ }^{149}$. The combination of these different research methods, especially the combination of interviewing and observing, revealed to me how youth in Gulu strategically conjured different facets of identity depending on the setting they were in and the power constellations involved. Throughout this and the following chapter, I discuss the complexities of analyzing and understanding youth practices and discourses against the backdrop of shifting societal expectations, different power influences as well as local and global discourses.

${ }^{149}$ I distributed the questionnaire to approximately 100 youth in Gulu Municipality (cf. Chap. 2). 


\subsection{Hip Hop Contest at Herm's Club - Extracts from my Field Notes}

April 1 ${ }^{\text {st }}$, 2010. 6.30 pm. I am waiting in front of "Da Pub", a tavern in the center of Gulu Town, to meet Lisa, a MA student from Marburg who wants to talk to me about her research in Gulu150. While I am waiting, I bump into Simon, who is coming home from a traditional dance practice at his school and we start talking. When Lisa arrives, I introduce her to Simon and he joins us for some drinks. After we have chatted for a while, Simon becomes very absorbed into watching "La Tormenta", a Latin American soap on the TV playing behind us, and Lisa and I exchange some thoughts about our respective researches.

It is Thursday night and I remember that Akello had asked me to meet her at Herm's Club, a local night club, where she will be performing in a hip hop competition. I have never been to the club before, but Simon says he knows it very well. So I ask Lisa and Simon whether they would be interested in joining me and watching Akello's performance. Around 10pm we leave Da Pub and walk to Herm's Club through the dark streets of Gulu. Simon leads the way and tells us that he also performs in the hip hop contests sometimes. I am really surprised that so many young people know about these contests, and I think to myself that I cannot believe that Simon, who always seems rather quiet and does not really seem to have quite the right 'hip hop style', would actually perform on stage in front of a crowd.

We pay the entrance fee of 1,000 UGX (approximately 0.35 Euro $^{151}$ ) and enter the club. Downstairs, there are two bars, one at the back and one at the side. The stage is at the far side of the room. On the dance floor, in front of the stage, several lines of plastic chairs have been set up and Lisa and I sit down on two of them (Simon has briefly gone home to get changed). The first thing we both notice is that there are mainly guys around us, and that we are the only two munu (white people). The club is still fairly empty and although it is already $11 \mathrm{pm}$ the competition has not yet started. Akello, who had told me to be there by $9 \mathrm{pm}$, is not there. A Premiere League football game is playing on one of the TVs and several young guys seem to be watching it. On the side of the club, near the bar, a group of five or six women in their 20 s is sitting on high chairs around a table. They are all wearing extremely tight and short pants and tops and a lot of make-up. I have to think that most of my Acholi interlocutors would probably identify them as "prostitutes" straight away, and even to me they look very different from the average Acholi women I have seen in public. The women are joined by some men, some of whom seem quite a bit older, maybe in their late 40s. The table is full of empty bottles of alcohol.

${ }^{150}$ In the context of my work at IPSS, I occasionally met some of the international students and researchers, who came to IPSS to collect information on the war and the current situation in Gulu (cf. Chap. 2).

151 There is also a "VIP area" upstairs, which would cost 5,000 UGX (for information on the average income in Gulu cf. Chap. 4 and figure 3 in the appendix). 
The music is playing so loud that one can hardly talk, so Lisa and I just observe our surroundings. Occasionally, guys come up to us to talk or just sit next to us. I know one or two of them from the hip hop group. Slowly, more people start coming in and after some time Simon is also back. He is wearing a pink hoodie-jacket and a pink hip hop cap, which makes him look even more out of place than before. He says he wants to register for the contest, but then finds out that it is the monthly final today and only those who previously qualified will be allowed to perform. Simon seems to know quite a few people in the club and talks to some of them.

At $11.30 \mathrm{pm}$, two MCs enter the stage to announce that the contest will be starting soon. Most of the plastic chairs are taken by now, but Akello is still nowhere to be seen. The audience is made up largely of young men, probably in their teens and early twenties. Simon says he knows many of them from school. I am surprised, because I somehow imagined the hip hop scene in Gulu to be quite marginal and that most of these kids would be out-of-school youths, who have nothing better to do on a Thursday night than hang around in places like this. More and more, I get the impression that hip hop is a vital part of urban (male) youth culture in Gulu and I wonder when this trend started.

Finally, the show begins. The first part consists of playback performances for which anyone could sign up. The second part will be the final of the so-called "lifeline" competition in which the participants perform their self-composed raps on stage. I learn that the preliminaries for the lifeline contest take place every Thursday and that the best two competitors qualify for the final which is held on the last Thursday of each month.

The playback competition starts. The two MCs call out the names of the people who have registered and give them a microphone. Each contestant gets to perform only one song. No girl has signed up ${ }^{152}$. Most of the guys on stage have chosen US-American rap songs and look like they are trying hard to imitate the 'gangsta style', well-known from US-American rap videos. Even the stage names some of the performers have chosen are copied from US-American rap artists like Nas, 2Pac or 50 Cent. They are wearing baggy pants, caps, wide shirts, and skater shoes. From the look of their clothes one can infer whether they are from a poorer or richer background - at least I think so, because some of the clothes seem very new and 'stylish', while others have designed their outfit from torn rags.

To me, the atmosphere on stage and in the club seems 'ultra-masculine'. Some of the gestures by the performers are extremely sexist and, judging from a woman's perspective, actually quite offensive. Nearly all the performers grab their crotch and/or imitate obvious sexual movements. One guy, who seems highly intoxicated, is especially extreme. His huge baggy pants has a big hole around his crotch and at one point of his performance he flips out his penis, while he is scratching himself and making unmistakable sexual movements. I have to laugh to myself when, in this context of aggressive masculinity, I suddenly notice that one of the MCs is wearing a t-shirt, sponsored by UNIFEM, which

152 During some of my later visits to Herm's Club I do occasionally witness performances by girls, but they are comparatively very rare 
has the slogan "Fathers should accompany their wives to antenatal care" written in capital letters across the back.

There are some few performers who do not engage in this chauvinist behavior and rather seem to expose their 'soft and romantic side'. They have chosen R\&B or dancehall songs and their performances are more reminiscent of soft rock videos than of gangsta rap, which seems a little strange in this context. Most of the performers seem intoxicated (by alcohol and maybe other substances? ${ }^{153}$ ), which negatively affects their performances. One guy nearly falls of the stage and is not allowed to perform any further. Towards the end of most songs people from the audience walk up to the stage to put coins or small notes into the pockets of the contestants as a sign of appreciation.

While the contest on the stage is continuing, I observe some 'interesting' sideincidences: one very drunk guy is getting kicked out of the club after screaming around and trying to pick a fight; two young couples are more or less falling over each other, exposing far too much skin and intimacy than would generally be considered appropriate for a public location in Uganda. All in all, the whole situation in the club to me seems very bizarre and so different to anything I have seen and learned so far about Acholi culture. I wonder whether this is what older people mean when they say that Acholi values have been lost among the young generation.

After what seems like an endless amount of playback performers, the first part of the show is over. But before the lifeline contest starts, there are some more acts for entertaining the crowd. At first, three women perform a dance act on stage. I guess they are in their early 20s. They are wearing very short hot pants and very short tops, combined with what looks like football socks pulled up to their knees - again very unlike the conventional dress codes for Acholi women. Similar to their male precedents, their dance is highly sexualized, but in this context it does not seem emancipatory but rather very degrading to the girls, who do not look as if they feel very comfortable with their performance. Many guys go up on the stage and put money into the girls' pockets. Some actually touch the girls in very inappropriate ways and one guy even licks the girl's legs and pants. While some young guys in the crowd cheer and encourage the guy to push things further, Simon and many others seem to find this sort of behavior very disgusting and Lisa, who is sitting next to me, just looks at me - in disbelief...

After the girls have left the stage, the MCs announce a comedy act. Two young guys, who are dressed in very strange costumes (both are wearing stockings with G-Strings and very tight shirts, one of them has a pillow under his shirt to make him look pregnant) and have white paint in their faces, enter the stage. Basically their whole performance is centered on imitating a sexual act on stage, in various positions. I am not quite sure what to make of the performance and it seems to me that many people in the audience feel likewise.

After the guys have left the stage, it is finally time for the lifeline competition we have been waiting for. It is nearly $1 \mathrm{am}$. The MCs call the eight finalists onto the stage. Only

153 According to one of my interviewee, alcohol, marihuana and khat were the most commonly consumed drugs among urban youth (INT Joseph, 14.12.2010). 
now do I notice Akello who must have arrived in the meantime. She is the only woman in the contest. The performances start. Each contestant gets some background beats and has to fit his/her self-composed raps to match the beats. Most of the raps are in English and again strongly remind me of US-American rap songs. Only Akello and one other guy rap in Acholi. Akello is the sixth performer. She seems very nervous and when she walks past me on her way to the stage she does not look at me. When the beat starts, she performs a very hard rap. I have never actually heard her rap like this and am surprised how good she is. The audience cheers and many walk up to the stage and give her money. I think many people are actually impressed by her courage and the quality of her performance.

After all finalists have performed, there is one more entertainment act: a break-dance performance by four young men, which, to my surprise, has no sexual implications. Then it is time for the jury, made up of three young men in their twenties, to select the respective winners of the playback and the lifeline contest. The judgment process reminds me of a TV casting show. First, the competitors of the playback contest are judged. One by one, they are called to the centre of the stage and receive a short comment by the jury. Some comments are actually quite harsh. The best three performers are told to stand aside, while all the others have to leave the stage. Finally, the third, second and first are called out and they each receive a small prize.

The same process applies to the lifeline competition. I watch Akello lingering around on stage, waiting for her judgment. She does not look very confident. With great interest, I listen to the comments of the judges, who often say things like "you should try to be more authentic, don't imitate American gangsta rap, try to rap in Acholi..." I wonder what "being authentic" means to this young generation of Acholi? Maybe being gangsta rappers is authentic to them? Akello gets a long and quite controversial feedback from the judges. One criticizes her performance, while the other two say that they really liked it and that it was great that she rapped in Acholi. In the end, she comes second and receives an umbrella as a prize ${ }^{154}$. Akello seems relieved when she leaves the stage and is no longer the centre of attention. She greets me briefly and then returns to her seat in the back.

It is around 2am and Lisa and I are ready to leave. Outside, I meet some people I know from the hip hop project and I chat with them for a while. Akello is also there, but as usual, seems very shy around all the guys. While we are standing outside, a small fight erupts between some drunken guys, but can be resolved fairly quickly. We decide that Simon will accompany Lisa home on a boda, while I go with Akello. I am surprised to learn that she came all by herself. We get a boda together and ride back to Pece [subdivision of Gulu, where both Akello and I were living at the time]. On the boda, for the first time, she seems more at ease. We talk briefly and then say goodbye (field notes 01.04.2010).

154 Throughout my research, I learn that the prizes given out at hip hop contests vary quite substantially and range from large sums of money (apparently up to 100,000 UGX) to smaller amounts of money and/or material prizes like umbrellas, flasks or bicycles. Often, however, the promised awards are much bigger than what the winners receive in the end. 
At the time of these happenings, I had been in Gulu for less than a month. During this time, I had started to gain some first insights into social practices, norms and rules in Acholi society by talking to various people, old and young. I had met and interacted with different groups of young people, at the Gulu Youth Centre, the hip hop project and the cultural group at Luo Talent Centre. I had been to a "show" at a night club before, in which local artists had performed their songs on stage (while the $\mathrm{CD}$ they had recorded was playing in the background), but which had been attended by a much broader audience including youth, adults, elderly people and even some families with young children. I am no longer sure, what I expected before I went to Herm's Club, but it was certainly very different from what I encountered there. I remember being amused and shocked at the same time.

In my former encounters with youth, most of them had been very disciplined, rule-abiding and rather quiet. I had frequently been told that moral integrity was of highest value in Acholi society. Excessive drinking, inappropriate dressing and exposure of intimacy and sexual gestures in public had always been described to me - by both younger and older interlocutors - as something "Western" which was considered disgraceful in Acholi society. I had heard different people complaining that a "moral degeneration" had set in and that young people were no longer respecting Acholi norms and customs, but I had rarely encountered any evidence of this "moral degeneration" in public. Thus, I was quite surprised by the events at Herm's Club, where 'ordinary' school-aged youths transcended all social norms and rules and excessively engaged in what was locally referred to as "immoral Western cultural practices".

I will discuss in the next chapter how the binary opposition Western vs. Acholi is often used in local discourses to comment on contemporary Ugandan society. At this point, however, it is important to note that the young people in the club did not simply imitate Western, especially US-American, popular culture they knew from music and films. Instead, I had the impression that the scene at the club was an example of a truly "transcultural" phenomenon (cf. Welsch, 1999), which cannot be grasped analytically without considering its origins in both, local and global youth cultural practices and their respective frames of reference (cf. Loimeier et al., 2005b: 17ff.), including Latin American soap operas, English Premier League football, USAmerican rap music and UNIFEM slogans as well as Acholi norms and rules against which the young people seemed to rebel.

For the purpose of this chapter, the scene at Herm's Club serves to introduce one example of contemporary youth culture in Gulu which is very different to the phenomenon of youth cultural groups portrayed in the former chapter. At first sight, the ways the young people spoke and acted in the club seem diametrically opposed to the way young people positioned themselves in the context of cultural groups and traditional dance. While the former openly rejected established Acholi social conventions, the latter were explicitly critical of the type of disrespectful and 'nontraditional' behavior the young people exposed in the club. Interestingly, however, there are quite a number of young people who participate in both, cultural groups 


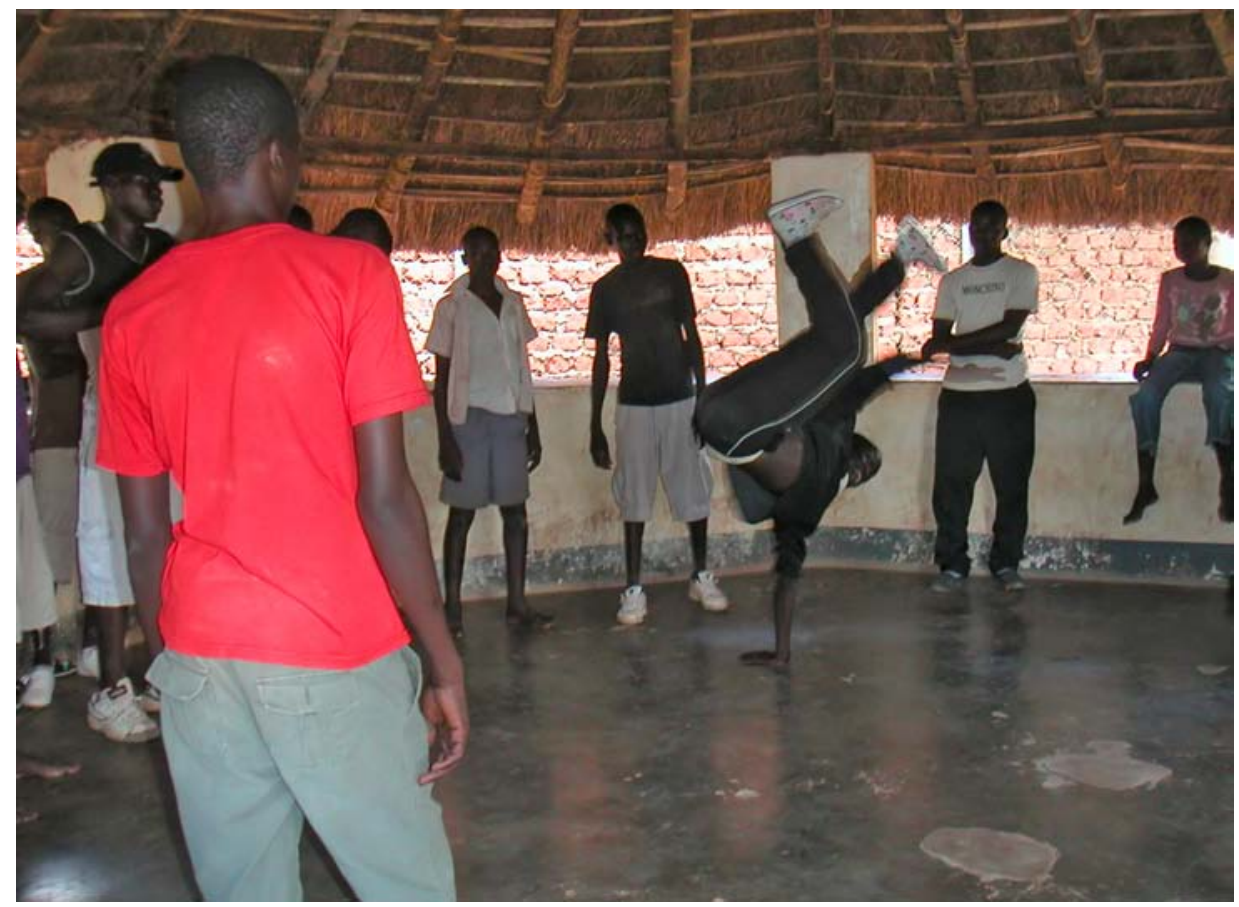

Illustration 2: Breakdance Performance at Gulu Youth Centre (photo by author)

and hip hop events like the one described above, and seem to switch between 'traditionalist' and 'modernist' "cultural styles" (Ferguson, 1999, see discussion below). On the one hand, the ability to combine the membership in different cultural scenes is heavily dependent on the individual traits of a young person (regarding especially gender, class and social upbringing). On the other hand, the different, at times overlapping cultural scenes in Gulu and the various cultural elements and practices they reflect can only be understood against the backdrop of the particular time and place of their setting, and the generational characteristics of their main protagonists. In order to give the reader a more complete picture, I will briefly portray the generation of urban youth, which I focus on in this chapter, and point out similarities and differences among its members.

\subsection{Characteristics of the War Generation}

In the following section, I analyze the life conditions of young people currently living in Gulu and focus especially on the generation that grew up during the war years (i.e. roughly those born between the mid-80s and early 1990s) and which I will subsequently refer to as the "war generation". I identify important similarities 
between its members, which underpin my decision to speak of a "historical generation", but also point out important differences between members of this generation which are relevant to understanding their different positionings in discourses on socio-cultural change.

\subsubsection{Similarities of the War Generation}

Due to their "similarity of location" (Mannheim, 1972: 290) in time and space, members of the war generation share a number of experiences and face a number of similar challenges when compared to other, older and younger, generations. Above all, their lives have been characterized by a particular form of uncertainty and ambivalence. During their childhood and early youth, they experienced the insecurity and confusion associated with growing up in a war zone as well as the marginalization of Northern Uganda and the nation-wide stigmatization of the Acholi. In the current phase of their youth, they are confronted with the challenges and chances of living in the post-war setting of Gulu Municipality which has given rise to new hopes and aspirations but has also created new asymmetries and exclusions for members of the war generation. I will briefly elaborate each of these points.

\section{Insecurity and Confusion Associated with Growing up in a War Zone}

Most of the young people I encountered during my research had spent a large part of their lives in Gulu Municipality. Some had been born in Gulu, while others had been born in their ancestral villages and moved to Gulu at a young age due to the war. Some, especially those with a higher education and from economically bettersituated families, had spent part of their schooling in other parts of Uganda. But generally speaking, the majority of my interlocutors had experienced the war years and the rapid changes, which occurred in Acholi society during this time, in urban Gulu ${ }^{155}$. They often described to me how Gulu had changed from being a small, provisional town to becoming the center of international relief operations with all its required amenities (e.g. INT Laurence, 28.04.2010). Living in Gulu during the war had many advantages when compared to its alternative, i.e. living in one of the IDP camps. Town residents enjoyed greater freedom and safer living conditions. However, town life also had its detriments and many families struggled with the high costs of living, unemployment and sometimes hunger since no food aid was given out (cf. Branch, 2008: 5ff.).

Although LRA attacks were rare in Gulu and the security situation much better than in most of the surrounding rural areas, many of my interlocutors reported that they constantly felt threatened and were always aware that they were living in the middle of a war zone. They sometimes narrated how there had been curfews

15546.8 percent of the respondents to my questionnaire had been born in Gulu Municipality and 63.8 percent had spent the largest part of their lives in Gulu Municipality. 
at night and roadblocks along the Kampala highway, how night commuters had walked into town every night to sleep in relative safety, and how fellow students had been abducted by the LRA. They also told me how the LRA had once attacked a night club and killed seven youths, how they had heard gun shots at night, how they had been harassed by UPDF soldiers and about the general situation of insecurity, confusion and turmoil which characterized life in Gulu during those years (personal conversations, e.g. field notes 14.03.2010; 20.03.2010; 27.03.2010; 14.04.2010; 28.10.2010; INT Akello, 26.11.2010).

My interlocutors furthermore reported how established social practices, norms and rules had been suspended during the war time. For the majority of families who had fled to Gulu, life in town meant a total break with their former routines. As parents struggled to set up a new life, children were sometimes left to themselves. Others had lost one or both parents or had been sent to town to stay with relatives. Unguided by parental and community authorities, many young people found their own ways to adapt to urban life. Over time, they established new social practices and rules, which sometimes conflicted with the demands and expectations of parents and community elders. Conflicts within and outside of the family setting erupted more frequently due to the general frustration, despair and dissatisfaction of having to give up former living standards and established routines (e.g. INT Okello, 26.09.2010; group interview Kapedopong, 28.06.2010; personal conversation, field notes 30.03.2010).

One source of frustration and uncertainty was the social and political marginalization of Northern Uganda and the nation-wide stigmatization of the Acholi, which affected the young people in a very particular way.

\section{Marginalization of Northern Uganda and Stigmatization of Acholi}

Most of my interlocutors were aware of the war-related and politically-fabricated economic and political marginalization Northern Uganda had suffered during the war years (cf. Shaw \& Mbabazi, 2008). For the young generation, marginalization became especially evident in the education sector. Due to insecurity, many schools had been closed or displaced from the rural areas to Gulu town. The quality of education suffered greatly due to lack of (government) funding, high fluctuation of students and teachers, and other war-related problems (cf. Shaw \& Mbabazi, 2008: 225). The Gulu District Education Officer (DEO), Vincent Ochieng, described the situation of education during the war years as follows:

"During the war, our education system was just run on emergency, it was not really proper education going on. And we are getting the results now by the poor results we are having in our performances. At all national level examination you can see the results now. These are students that started education during war time" (INT Vincent Ochieng, 26.03.2010). 
To this day, most schools in Northern Uganda are of inferior standard, so that parents who can afford to do so send their children to attend schools in other parts of Uganda. The DEO reported that out of all the thousands of primary school students, who sat for their Primary Leaving Examination in 2009, only a total of 242 students (!) had passed and thus qualified to enter secondary school ${ }^{156}$.

For Acholi students, who attended school outside of Northern Uganda, ethnic stigmatization was a frequent problem during the war years (and still occasionally happens today). Some of my interlocutors reported how they had been provoked and called "Kony" by fellow pupils and even teachers (personal conversations, e.g. field notes 09.04.2010). Negative stereotypes about the Acholi as a 'war tribe' prevail in many parts of Uganda (cf. Chap. 3). As a consequence, some Acholi try to repudiate their ethnicity when they are not at home, for instance by refusing to speak Acholi. As the DEO explained to me:

"Because of the war, our children even fear speaking their language, because the name that you come from here is so negative: that you are a warrior, you are backward, you are primitive and all that. And so many people don't want to admit and are ashamed that they are from the North and this waraffected area, they rather speak other languages (...) So there is quite a lot to change that image of the North that has been created by the war and that now makes our children even fear belonging here." (INT Vincent Ochieng, 26.03.2010).

There were others, who felt more self-conscious about their Acholi ethnicity and who actively tried to change the negative stereotypes of the Acholi or lobbied for more Acholi visibility and influence in Uganda ${ }^{157}$. In any case, the sensibility and

156 The DEO (INT 26.03.2010) gave me some rough figures for the schooling situation in Gulu at the time of my research. In the primary school sector, there were 113 government-headed schools with 61,298 students enrolled in the rural areas, and 32 government-headed schools with 41,000 enrolled students in Gulu Municipality. In addition, there were a number of private schools (three in the rural areas with less than 1,000 pupils, and 25 in Gulu Municipality with about 10,000 students). In the secondary school sector, there were 15 government-headed schools (with approx. 10,000 students) and 25 private schools (with approx. 5,000-6,000 students). Of all the primary school students who sat for their Primary Leaving Examination in 2009 only 23 pupils had passed in the rural areas and 219 students in Gulu Municipality!

157 The following is a telling example from my field notes (06.01.2010): I once witnessed a debate between four university students who were having a big argument about language in Uganda. Three of them argued, that if there was to be a national language besides English it should be Luganda because most people even outside the Luganda region had some understanding of it and it would be easier for those people to adapt to Luganda than everyone adapting to Luo. Opio, a friend of mine, was the only one who heavily opposed this idea. He said that people who argued like that were not proud of being Acholi and that he had even intentionally refused to learn Luganda when he went to school in Kampala. The others replied that they were also proud of being Acholi but that they were just thinking practically and that there was no chance of Luo ever becoming a national language. 
explosiveness of the matter led to a heightened awareness of their Acholi ethnicity among the war generation and the marginalization connected with it, a phenomenon that Meyer \& Geschiere (1999: 2), referring to the "hardening of cultural contrasts" in the context of globalization, have labeled "cultural closure".

\section{Post-war Setting of Gulu Municipality}

In post-war Gulu Municipality today, the young generation is faced by specific chances and challenges of living in a place which is recovering from the traumas of war. On the one hand, Gulu is a rapidly growing economic center. It has promising business opportunities due to its reestablished and newly emerging national and international trade connections, for instance through the return of some prosperous members of the Acholi diaspora, who spent the war years in the UK and the USA and are now setting up businesses in Gulu (cf. Wesch, 2011), or through the trade opportunities arising from Southern Sudan's newly gained independence. Businesses, banks and hotels are proliferating everywhere and the state has improved its service provision (at least in some domains, for instance regarding road conditions and electricity). Furthermore, since 2003, Gulu has its own public university. In search of business and higher education opportunities, people from all over Uganda are now coming to Gulu, and despite the withdrawal of many aid organization, there is still a relatively big international NGO scene.

On the other hand, few of the young people I met could profit from Gulu's economic expansion. Most of them were struggling to pay their school fees even at the cheaper and generally lower-ranked public schools or had given up trying, were unemployed or working in poorly paid jobs, and were having difficulties in meeting even their basic needs. Some youths, whose families had resettled in the village and had restarted cultivating their land, earned a small income by helping on the fields (mainly during the school holidays) and selling some of the harvest. Most, however, could not imagine a future life as farmers, and instead dreamed of finishing school, attending university and finding good employment in town. For most it remained simply that - a distant dream. Even the luckier ones, who had attained a university degree, rarely had secure jobs. Thus, while Gulu youth grew up in an economically booming and increasingly globalized setting, most of them were in fact only "licking at the shop window" (Mbembe quoted in Meyer \& Geschiere, 1999: 5).

Furthermore, HIV/AIDS constituted a big concern for young people. Resulting from the effects of war and camp life, but also from Gulu's new role as trade centre, the HIV/AIDS prevalence in Gulu District was significantly higher (approximately $16 \%$ ) than in the rest of the country (approximately 6-7\%). According to figures given in the New Vision (Ocuwun, 2010: 7) and the Daily Monitor (Lirri, 2010: 7), the HIV/AIDS prevalence in Gulu Municipality at the time was as high as $22.1 \%$ percent. In my questionnaire, 31.25 percent of the respondents named HIV/AIDS and other sexually transmitted diseases as the biggest problems for youth today, fol- 
lowed by unemployment $(26.89 \%)$, educational problems (high school fees, low quality etc., $12.5 \%$ ) as well as poverty and substance abuse (both $6.25 \%$ ).

Therefore, in many ways, young people remained untouched by Gulu's economic boom. The youth cultural scene, however, was heavily influenced by the rapid changes. In the growing number of internet cafes, in movie halls as well as in bars and eating places where TV programs and movies were playing 24/7, and through the personal exchanges with foreigners, young people were exposed to new forms of media and consumer culture on a day to day basis ${ }^{158}$. As the introductory extract from my field notes revealed, Gulu youth culture was therefore becoming an increasingly hybrid phenomenon. This was particularly reflected in the expanding music and club scene, in young people's dressing styles and their consumer behavior more generally ${ }^{159}$. Most of the young people in Gulu had a mobile phone, and many had joined online social networks such as Facebook or used the internet to watch and download music clips, films and the latest gossip on pop idols and other celebrities.

Despite these influences and changes in popular culture, Acholi youth still generally perceived themselves to be in what (Hannerz, 1996: 70ff.) has called the "periphery" of "cultural flows" - both nationally and internationally. When I asked one of my interviewees to state his perception of young people in Uganda today, he said:

“(...) I think the government is also doing very little to help the youth. (...) I think the youth are still being fed that ancient knowledge, it is ancient. (...) You cannot bring the solutions to the problems of the $20^{\text {th }}$ century to solve the problems of the $21^{\text {st }}$. No, it can't work like that! I think they should just wake up by themselves, and know that things have changed."

When I asked him to comment more specifically on youth in Northern Uganda, he added:

"Well, these guys here are not so much different from the East, from the West, but with Kampala - they are a little bit different, because those guys down there can get inspired (...) there are so many influential people whom they see around them, so they work hard. They are not like here, there is no one who inspires these guys so much. They talk about Lumix [a successful Acholi hip hopper], but Lumix does not even live here, Lumix is in Kampala,

158 On the crucial role of the "mobility of meanings" through media and human beings see Hannerz (1996: 19ff.).

159 When asked to name the biggest changes between their generation and their parents' or grandparents' generation, the second most common answer given by 14.74 percent of the respondents related to 'style', i.e. styles of dressing, dancing, walking etc. (The most common answer mentioned by 23.15 percent of the respondents was education). "Westernization" (8.42\%) and "mass media influence" (6.32\%) were also common responses. Furthermore, when asked to evaluate the statement "young people today are too westernized", 76.35 percent either agreed or strongly agreed. 
somebody very far cannot inspire. (...) So you get inspired when you are kind of close with the people who are inspiring you, but these guys, here it is still a little bit behind, it is still backward, the inspiration is still low here" (INT Joseph, 14.12.2010).

The quotation reveals the importance attributed to living in the 'center'. The respondent states that only there young people can find meaningful sources of inspiration whereby those in the periphery only admire their distant idols but do not have or believe in the chance of ever becoming part of their scene.

Hannerz (1996: 70) has argued that it is "particularly the asymmetries of the market and the state frames that create relatively unambiguous centre-periphery relationships" and this seems to be realized also by the young people in Northern Uganda, who in many ways feel excluded from the 'processes of modernization' surrounding them. In this sense, Ferguson (2006: 20) has argued very aptly that (young) people's "yearnings for cultural convergence with an imagined global standard (...) mark[s] not simply mental colonization or capitulation to cultural imperialism, but an aspiration to overcome categorical subordination." As the introductory scene from my field notes revealed, youth in Gulu frequently sought inspiration from the '(pop)cultural centers' of the world - not only because they were lacking local idols, as the interviewee above maintained, but also to demonstrate that they wanted to take part in and be recognized as a part of the global youth cultural scene.

\section{The War Generation in Local Discourses}

The brief summary in this section has outlined only some of the unique experiences of the war generation, which clearly differentiate it from both older and younger generations. Members of the war generation experienced their childhood and youth as a situation of profound uncertainty in which many formerly established social norms and practices were in flux. Thus, one can argue that the young generation's break with the past was more rapid and more radical than generational changes which happen in all societies under more conventional circumstances. As a consequence, a deep-seated rupture seems to have occurred between the younger and the older generation which was reflected, for instance, in the way elder Acholi spoke about the young. They frequently accused Acholi youth of being materialistic, undisciplined, disrespectful, westernized and other similar vices, and related this to the turbulent circumstances in which they grew up (see e.g. group interviews Pabbo, 23.10.2010; Kapedopong, 28.06.2010). Sometimes, elderly interlocutors expressed their hope that the new generation, which was born in the post-war phase, would again learn some of the Acholi virtues of the past. In the words of one male elder: "For the very young people - those who are under ten [years of age] now - things will change. But for those who are now in their teens the old values will not come back" (group interview Pabbo, 23.10.2010, translated from the Acholi original by John Omara). 
Statements like these seem to confirm what the above outlined factors would suggest: namely, that not only from an etic perspective it is legitimate to distinguish the war generation from other, older (pre-war) and younger (post-war), generations of Acholi, but that this distinction can also be found in emic conceptionalizations of Acholi society.

\subsubsection{Differences within the War Generation}

Despite the above outlined similarities of the war generation, one can make out significant divergences between its members, most importantly regarding their class and educational background, family situation and gender. I will briefly comment on each of these factors ${ }^{160}$.

\section{Class and Educational Background}

'Class' constituted one of the most fundamental differentiating factors among the war generation. In Gulu (as probably elsewhere), class correlated highly with the economic situation and the educational level of a person. Young people from wealthier families (henceforth 'elite youth') had usually attended better schools, often outside Northern Uganda, and had often studied or were in the process of studying up to university level. Due to their comparatively superior education and because their families were involved in local elite networks, they usually had better chances of attaining a good job, although I also knew many who were unemployed nevertheless. However, unlike for youth from poorer families, unemployment did not entail a situation of existential uncertainty for elite youth. They were less compelled to work in underpaid jobs, rarely engaged in farming activities, ate and slept at home and spent their days hanging out in internet cafes and bars, waiting for a job offer that suited them.

Elite youth usually owned up-to-date media technology (smartphones, laptops, TVs and DVD players), wore new clothes, traveled more frequently, and often went out to clubs, restaurants or shows. In addition to their material advantages, elite youth also had many social benefits. They were invited to 'high society' social events (e.g. weddings, graduation ceremonies, political events), where they could intermingle with the local business and political elites. For boys and young men, a further very important social advantage when compared with non-elite youth, concerned their prospect to get married (once they had found a suitable girlfriend) due to their families' ability to pay the exorbitant brideprices currently demanded in Acholiland

${ }^{160}$ Of course, one could make out several other factors which distinguish members of the war generation from one another. But I will comment only on the three above because I regard them as the most fundamental, and also because I did not gain sufficient data on other potentially relevant differences like, for example, religion. 
(personal observations and conversations, e.g. field notes 09.03.2010; 18.04.2010; 02.09.2010; 30.12.2010).

The majority of youth I encountered in Gulu (henceforth 'ordinary youth'), however, came from poorer backgrounds. They generally had a much lower level of education, had usually attended government-schools, which, on average, were of lower quality than the private schools, and had often had to interrupt their schooling because of failure to pay the school fees. Many had dropped out of school in the first years of secondary school and were now looking for a sponsor who would pay for them to go back ${ }^{161}$. Some were working in underpaid and often temporary jobs, others took on volunteering positions (often in youth projects sponsored by international donors) in hope of getting permanently employed, while again others could not find employment at all and spent their days hanging around with fellow youth.

Many ordinary youth struggled to provide for their daily needs and wants. For some, especially those who had no relatives in town or were not supported by them, even food and shelter were not always secure. Nevertheless, ordinary youth often found innovative ways to participate in popular consumer culture: They bought cheap second hand clothes (often exported from Western countries ${ }^{162}$ ) on the local market and exchanged them among each other. They traded old phones which could be bought and sold in Gulu for little money. And they went to movie halls to watch films, where the entrance fee was only 100-200 UGX (less than 0.1 Euro) per film (personal conversations and observations, e.g. field notes 17.05.2010; 21.05.2010; 10.08.2010). Generally speaking, the social networks and locations frequented by ordinary youth were different from those of elite youths. They lived in different neighborhoods, met in open spaces and not in bars and cafes, and attended social events that were free of charge. Although 'youth scenes' occasionally overlapped, especially among the younger ones, public spaces in Gulu were clearly demarcated by class. In local discourses, for instance, I often encountered expressions like "that place is for big people", meaning people with money (personal conversations, e.g. field notes 30.12.2010; 31.12.2010).

In summary, present and future opportunities for ordinary youth in terms of job perspectives, livelihood security and marriage prospects were more limited than for elite youth. These differences in life chances were felt more intensely the older people grew. While interactions between youth from different class backgrounds were not unusual when they were still in their teens, their lives usually took very different paths once they reached their early 20 s and subsequently interactions became less frequent.

${ }^{161}$ Of the 94 youths, who filled out my questionnaire, 28 (30.11 percent) were (temporarily or finally) out of school; only five of them were currently working.

${ }^{162}$ For an in-depth discussion of second-hand clothing consumption in Africa, specifically Zambia, cf. Hansen $(1999,2002)$. 
Julia Vorhölter: Youth at the Crossroads

\section{Family Situation}

A second distinguishing factor concerned the family situation of youth in Gulu. While some had very stable family backgrounds, i.e. they lived with both parents, had a large family network which usually extended to the rural areas and were on good terms with their relatives, many families had been broken by the war, diseases and conflicts, or were spread throughout Northern Uganda and beyond. Many of my interlocutors had lost one or both parents and were staying in town with a sibling or a more distant relative. Some families had returned to their original villages and had left their school-aged children in town - either in boarding school or with relatives. Some youth were also staying by themselves. ${ }^{163}$

Judging by the accounts of my interlocutors, family conflicts seemed to be common and usually occurred along generational lines or between husband and wife/ wives. Polygamous families seemed to be particularly conflict-ridden, especially where material resources were limited. I heard several stories of co-wives who fought each other not only verbally but also physically (personal conversations, e.g. field notes $04.09 .2010 ; 17.12 .2010 ; 02.01 .2010$ ). Children and youth often suffered the most from these conflicts. Some avoided spending time at home or tried to find alternative places to stay. Some were torn between their parents and often worried about the fighting at home. One young woman expressed this problem very clearly during a group interview when she said:

"The level of understanding between the parents is very low, there are many conflicts between the parents, in many cases the homes are conflict zones. So young people look at that and they identify with one of the parents, mostly on the mum's side, because there are many situations where especially men - where men always go out to drink and they come home very late and beat their wives. In such situations the children will not respect the father. Another thing is love - fathers don't show love to their children... For the young ones, sometimes there are situations where you want your father to say 'I love you so much', but he doesn't... Then they look at what their neighbors do, maybe the father of the neighbors is really a friend to the children. When he comes home he shows a lot of love and brings many things for them, he comes and carries [the child]... So as long as that love is also reflected in the family, there are not so many conflicts. It is like an institution: when there are many conflicts at work, then the work outcome will also be very negative..." (group interview Pabbo, 23.10.2010, translated from the Acholi original by John Omara).

163 Out of the 94 youths who participated in the questionnaire, only 24 were staying with both parents. 30 were staying with a single parent and 13 with a sibling. The rest were staying with more distant relatives, with friends or alone. 
The quote well-summarizes the different emotional contexts in which youth from stable and youth from unstable family backgrounds grew up. Particularly interesting is the way the respondent compares the family with an institution which cannot function properly if its members are in conflict with each other. In many ways this is quite an accurate comparison. During my fieldwork, I often noticed that youth from stable family backgrounds had better support networks (even if their families were relatively poor) and felt more embedded in the society as a whole, while youth with unstable family backgrounds tended to live more precarious lives, moved around more often, engaged in risky behavior more frequently because they lacked parental control and had no one to support and speak up for them (personal observations, e.g. field notes 13.08.2010; 13.12.2010).

\section{Gender ${ }^{164}$}

Gender is one of the most important distinguishing factors when discussing youth and youth culture in contemporary Gulu. As the introductory-extract from my field notes has clearly shown, youth culture and youth spaces in Gulu were highly gendered. For instance, while the club and hip hop scene was very male-dominated, cultural groups usually had more female participants.

As has already been discussed in the previous chapter, contemporary gender relations were perceived by many Acholi as largely different from those in former times. In many ways, roles and opportunities between men and women were perceived as being more similar and less complementary. This was partly attributed to the disruptions in Acholi society caused by the war. The younger generation, especially, seemed to have a different understanding of gender relations, roles and images than their parents and grandparents. Urban youth, for example, had very different ideals and future plans regarding marriage and family life than members of older generations. Most of the respondents to the questionnaire stated that they wanted fewer children than was common in former generations and the great majority ( 93 percent) said that they could not imagine living in a polygamous marriage. This could be due to their different life experiences during the war years, but also due to several national and international influences, such as media campaigns on gender equality or national initiatives under the Museveni regime to promote women's and girl's rights, especially in the education sector (cf. Vorhölter, 2010b).

But although opportunities for boys and girls were generally perceived as more equal than in former times, gender remained an important differentiating factor between male and female youth. I was told (and could observe) that at home, and to a lesser extent at school, children were still socialized and trained according to the long-established gendered patterns of behavior and division of labor common in Acholi society. This meant that within the family context, but also in society more generally, girls were still more restrained and controlled than boys: they had more

${ }^{164}$ I will focus more closely on gender issues in the next chapter. 
chores in the household and were more protected and confined to the family home, while boys generally enjoyed greater freedom, for example to hang out with friends or to go out at night. Therefore, in most places where youths hung out in town such as bars, night clubs, movie halls or sports clubs, one could find a much higher number of male youth although, as the example of Akello shows, girls did find ways to escape the confines of their home ${ }^{165}$.

Among the urban youth I worked with, it was interesting to observe that ideals of how women and men should be were very ambivalent. In some ways, it seemed that gender images and ideologies ${ }^{166}$ were changing while in others they remained highly conservative. My interlocutors conveyed to me that generally "traditional" attributes for girls and women were (still) more valued in Acholi society than "modern" attributes. Girls, who wore short skirts, drank alcohol or went to night clubs, for instance, were often later accused, even by their peers, of being prostitutes, and my male interlocutors sometimes remarked that they would never choose a girl who behaved "like that" as a girlfriend (e.g. INT Henry \& Bangi, 27.04.2010). Furthermore, if a girl's family found out about such 'indecent behavior', the girl could be thrown out of home or sent to a relative in the village, as I was often told. Even female university students, who were usually in their mid-20s and came from comparatively 'modern' families, often had to cope with being accused of neglecting their child-bearing and marriage responsibilities by focusing too much on their education and the "modern lifestyle" associated with university life (personal conversations e.g. field notes 13.08.2010; 04.09.2010; 10.09.2010; 02.10.2010). Thus, overall it seemed that girls were more confined in choosing their lifestyle and that deviations from social norms were more seriously sanctioned than for boys. I will further take up this point in the next chapter.

\section{Inner-generational Differences and Cultural Style}

As has been discussed above, members of the war generation can be separated along the lines of gender, class, educational background and their family situations. Therefore, a broad range of different experiences can be found within the war generation despite its "similarity of location" as a whole. When discussing young people's behaviors and cultural styles and their perceptions and evaluations of socio-cultural change in Gulu, as I will do in the following section, it is important to keep these differences in mind because they can help to understand an individual's reasoning for how he or she acts and argues in the face of the perceived rapid socio-cultural changes. It would be misleading, however, to assume that one can make generalized claims about which discourse or style a particular 'generational subgroup' supports:

165 I still remember being very surprised when Akello once told me how she used to escape from her parents place (approx. $4 \mathrm{~km}$ out of town) at night and walk alone to a club in Gulu (INT Akello, 26.11.2010).

166 The term "gender images" refers to the way women and men are seen, characterized and described, whereas "gender ideologies" refers to the way they should ideally be. 
elite youth are not necessarily more 'modern' than ordinary youth, girls not necessarily more 'traditional' than boys. Ferguson (1999: 92) has formulated this idea very well with regard to his concept of "cultural styles" which I introduce below. He writes:

"It is important to note, too, that this duality of cultural style [Ferguson differentiates between cosmopolitan and localist "styles", see below] did not map neatly onto expected differences of other sorts - such as education, occupation, social status, length of residence in town, and so on. So-called modern economic occupations and institutional attachments by no means excluded localist style, and cosmopolitan style was no straightforward index of social status or education. At the very highest levels, those with professional employment and education did normally exhibit a cosmopolitan style. But so, in a different way, did many prostitutes and street criminals (...). Indeed, both cosmopolitanism and localism had their high and low forms, their respectable and disrespectable versions."

\subsection{Youth Practices \& Cultural Styles}

Ferguson (1999) uses the term cultural style "to refer to practices that signify differences between social categories. Cultural styles in this usage do not pick out total modes of behavior but rather poles of social signification, cross-cutting and crosscut by other such poles" (ibid.: 95). Ferguson emphasizes that cultural style is "first of all a performative competence" (ibid.: 96), does not necessarily reflect "questions of identities or commonalities" and thus "means moving away from the quest to locate underlying 'real' identities and orientation” (ibid.: 97). Nevertheless, Ferguson argues that "cultural style tends to stick with a person" because "a style requires not simply a situational motive but an internalized capacity that can only be acquired over time" (ibid.: 96).

I found Ferguson's concept of cultural styles very suitable to my research context in Gulu, where people I encountered often differentiated between "modern" and "traditional" style (although they rarely used the actual word "style"). In many ways these categories were quite similar to what Ferguson, who studied adult miners on the Zambian Copperbelt, has called "cosmopolitanism" and "localism". In his chapter Rural Connections, Urban Styles (1999: 82-122), Ferguson defines these two distinct "cultural styles" he encountered among his Zambian interlocutors as follows:

"Among the copper miners with whom I worked in Kitwe, it was impossible not to distinguish two contrasting cultural modes, which I will call 'localist' and 'cosmopolitan' (...). The extremes of these two contrasting modes were immediately visible and obvious. On the one hand were the cosmopolitan workers, relaxing in bars and clubs, drinking bottled beer or liquor, listening 
to Western or 'international' music, speaking English and mixing languages with ease, dressing smartly (and even ostentatiously), and adopting an air of easy familiarity with whites like me. On the other hand were the localists, drinking in private homes or taverns, preferring 'African' or home-brewed beer, speaking the local languages of their home region, dressing in drabs or even ragged clothes, listening to 'local' music, and presenting to a white foreigner like me an impression of intimidation and sometimes even servility" (Ferguson, 1999: 91f.).

In a similar fashion, those Acholi in Gulu who were labeled and perceived themselves as "modern" often talked derogatively of Acholi culture, claimed that Uganda as a whole was still "backward" and needed to be "modernized", tried to avoid going to "the village", spoke English even in contexts where everyone present knew Acholi, and tried to copy fashions and technologies and imitate behavioral traits they regarded as Western (and thus modern) and which they usually 'knew' from films. Acholi who were labeled and perceived themselves as "traditional", on the other hand, were often nostalgic about Acholi culture and 'the good old days', had stronger ties to the village, spoke Acholi even in contexts were non-Acholi were present, and talked derogatively of those Acholi who were trying "too hard" to copy the West. At the extreme ends, some of the young people I met framed their styles in very exclusive terms as either 'fully modern' or 'fully traditional', but these were by far the minority. Most young people rather seemed to be floating between these two styles, which may be explained not only by their age and life situation - youth generally being a time of uncertainty and change - but also due to rapidly changing living circumstances they had experienced during the time they grew up.

This floating between styles seems to relativize Ferguson's argument that "situational switching of style is possible only to a limited degree" (1999: 95f.), because people have to invest in their style in order to acquire an "internalized capacity" to be able to perform it convincingly. During my research, I found that unlike the adult miners Ferguson studied on the Copperbelt, most of whom had long established themselves as either "cosmopolitans" or "localists", many of the young people I worked with in Gulu were still in the process of finding their style and thus were still more flexible in combining different stylistic practices or switching between styles depending on the situation. Furthermore, I found that various stylistic practices, like doing hip hop or traditional dance, not necessarily correlated with a coherent style or neatly mapped "onto an underlying cultural orientation" (Ferguson, 1999: 97). Some of the young people who I observed in the scene at Herm's Club described above, for instance, were also members of youth cultural groups.

As I observed the behavior of my interlocutors in different settings and got a more complete picture of their lives, I often had the impression that they strategically conjured different styles depending on the setting they were in. This was especially evident when comparing how youth presented themselves among fellow youth in town as opposed to their behavior at home or when visiting relatives in 
the village. One young man described to me very bluntly how he switched between different styles according to context:

"There is a saying that says 'when you are in Rome, behave like Romans'. So maybe when you go to the village, you portray those kinds of characters there. But when you come back to town, you drop the village stuff in the village, and you cope up with lifestyle in town" (INT Martin, 21.04.2010).

The interviewee acknowledges the different social expectations which are at work in the different settings - village and town. Although he considers himself a town person and regards the lifestyle in the village as "backward", he nevertheless adapts to village life, because he fears that people and especially his family members would not accept him otherwise. In the village, elders are seen to have more influence and power than in town to define social conventions and to sanction those who deviate from them. Thus, the interviewee's willingness to adapt his behavior to the village setting is also a reaction to local power relations which not only define behavioral guidelines, but also the rules of the discourse, i.e. who is allowed to say what in which situation.

I will turn to discourses on Acholi culture and socio-cultural change in the next section. As the example above shows it is not always easy to differentiate between discourse and social practice ${ }^{167}$, as discourses influence and recontextualize social practice and vice versa (cf. van Leeuwen, 2008; Fairclough, 2001: 14ff.). Thus, one cannot clearly make out whether the interviewee changes his style and behavior in the village because he is subjected to discourses which emphasizes that village and town are contrasting social spaces with different norms and forms of behavior (see below), or because his practical experience has taught him to imitate the village "habitus" (cf. Bourdieu, 1976).

Fergusons's concept of style, which I have used in this section to discuss youth practices and behaviors, is able to accommodate the influences of discourses on social practices. Although Ferguson clearly uses cultural style to refer to social practices, he also draws on the work of Judith Butler (who bases her theory on the work of Foucault) to stress that differences in style are continually (and discursively) produced in the context of power relations (Ferguson, 1999: 94). As I demonstrate in the course of this chapter, both actions and ways of speaking are heavily affected by the situational context in which they occur, that is both by other social actors and supra-individual discourses.

${ }^{167}$ The relationship between discourse and social practice has long constituted a major field of debate in anthropology (cf. van Leeuwen, 2008: 4f.). 


\subsection{Discourses on Socio-Cultural Change among the War Generation - Four Positions}

As the previous chapter has demonstrated, there was an all-encompassing and ongoing discourse on socio-cultural change and the future prospects of "traditional culture", in which all members of Acholi society engaged. In this chapter, I focus specifically on the perspectives of the war generation because, as I argued above, their exposure to different experiences during their childhood and youth, i.e. their "similarity of location", suggests that their engagement with Acholi culture and their perceptions of socio-cultural change might differ from those of other generations. As discussed before, however, this does not mean that all members of the war generation have a shared perspective. On the contrary, one can identify different positions or 'sub-discourses', which I analyze in the course of this section.

Before I turn to the different positions, however, I will briefly point out some common elements which underlie the discourse on socio-cultural change as a whole. Following Foucault (1981a [1969]; 1981b [1970]; 1994 [1971]; 2005 [1968]) and the interpretations of his works by different authors (Hall, 2001: 73f.; Dracklé, 1996b: 37f.; Mills, 2007: 51ff.; Ruffing, 2008: 105), I understand discourse as a highly regulated arrangement of statements or opinions which is internally structured and follows certain rules of formation. As I already stated in the introduction, the aim of discourse analysis, then, is to analyze what is said, how, and by whom, and under which effects of power (Dracklé, 1996b: 28; Foucault, 2005 [1968]).

In the previous chapters, I have already outlined the social and historical context in which the discourse on socio-cultural change in Acholiland was taking place and the "episteme" (cf. Foucault, 1995 [1966]: 213f.; 260ff.; Mills, 2007: 60ff.; Hall, 2001: 73), i.e. the state of knowledge and the way the reflections about socio-cultural change were structured. In the following, I will now identify certain statements, continually repeated terms and symbols which characterized the discourse and its different sub-discourses. Furthermore, I will allude to socially established, but often implicit rules among Acholi speakers. These rules guide who can say what at which point in time and thus also provoke that people (have to) switch between discourses depending on the situation they are in and the power constellations surrounding them.

Underlying the discourse on socio-cultural change as a whole seemed to be a general consensus that social relations and Acholi culture had substantially changed in the past two decades - although the exact date of when these processes began, the explanations what caused the changes and the normative assessment of these changes differed ${ }^{168}$. Furthermore, the overall discourse was characterized by clear

${ }^{168}$ In my questionnaire, 99 percent of the respondents answered "yes" when being asked whether they thought Acholi culture was changing. Interestingly, only 19 percent attributed this change to the war, while 39 percent argued that education was the most important reason for explain- 
temporal and spatial reference points, typified by a certain number of continually repeated terms. With regard to time, speakers differentiated between "those days", referring to the pre-war past, and "nowadays", i.e. the present time. With regard to space, speakers commonly applied a scale, ranging from "deep deep village", "village", "town" (i.e. Gulu) to "the West". Most of my younger interlocutors had not experienced the pre-war period. Neither had they spent longer periods of time in the ("deep, deep") villages, nor been to a Western country, so their knowledge about these times and places was largely based on common narratives, information given by people who had lived then or had been there and images presented in the media. Rather than just being temporal and spatial categories, these categories were also symbolic or social categories, which implied a ranking and a valuation by the speaker and which correlated in some ways with a distinction between 'traditional' and 'modern' cultural styles. "Those days" and "deep deep village”, for instance signified 'pure tradition', while "the West" stood for 'high modernity'. Depending on the speaker these attributes could be either positively or negatively connoted (I will discuss this aspect in more detail in the next chapter). Ferguson (2006: 6) has captured the idea of overlapping spatial and social categories very well, when he writes: "The world', in my usage, refers to a more encompassing categorical system within which countries and geographical regions have their 'places', with a 'place' understood as both a location in space and a rank in a system of social categories (...).”

Within the general discourse on socio-cultural change, I identified several subdiscourses among the war generation, which reflect opposing normative evaluations (positive/negative/ambivalent) of socio-cultural change and, related, diverse imaginations of a future Acholi society. Interestingly, when looking from a theoreticallyinformed, anthropological perspective, the different contentual positions found in these respective sub-discourses seem to correlate with different conceptualizations of culture and agency. Culture is variously understood either as monolithic and static, or as fluid and in motion. Speakers' perceptions of their ability to shape future developments ("agency") range from feelings of apathy and victimhood to senses of optimism and creativity.

My understanding of agency in this section is based on Ortner's (1997, 2001, 2006) concept of "agency of intentions", which designates the ability to imagine, plan and exert one's own projects by drawing on personal and cultural resources (cf. introduction). The creative element inherent in the agency of intentions is arguably similar to what Appadurai (2004) has called "the capacity to aspire", i.e. "a navigational capacity which is nurtured by the possibility of real-world conjectures and refutations" (Appadurai, 2004: 69). I use this concept of agency to assess youth's future aspirations. Do they have visions for the future or "projects" at all? If yes, where do ideas and inspirations for these projects come from? How do they perceive their chances to influence societal developments? I take the way young people reflected

ing "cultural change". A further 31 percent believed that the media had the greatest influence on "cultural change". 
on their future and the ways they practically tried to realize their goals as an indicator of the way they perceived their own agency capacity in relation to societal structures, i.e. whether they felt they had to adapt to established structures or whether they believed that they could challenge and change them.

In the following, I elaborate the above-mentioned points by discerning four sub-discourses which I encountered among my young interlocutors in Gulu: the Retraditionalization Discourse, the Modernization Discourse, the Ambivalent Discourse, and the Creative Discourse. I developed this typology by following the four steps of "typification" outlined by Kelle \& Kluge (2010: 91ff.). First, I worked out relevant dimensions of comparison in the course of coding my data (cf. Kelle \& Kluge, 2010: 94f.). As stated in chapter 2, I already started analyzing some of my data during my fieldwork in order to make out recurring themes and identify contradictions or aspects I had not completely grasped. This enabled me to focus my observations and complement my interview guide with important questions I had not previously considered. After I returned from my fieldwork, I started to analyze my data systematically. This entailed reading through and coding all the interview transcriptions and observation protocols in order to identify central themes and potential analytic categories ("inductive coding"; Bernard, 2006: 493.). Afterwards, I clustered the different statements on socio-cultural change and discerned contexts of meaning ("Sinnzusammenhänge") within the different categories of statements. In this way, I identified four different types of discourses on socio-cultural change among my interlocutors which I characterize in more detail below.

I first give a general overview of the respective discourses, their main line of argumentation and their respective conceptualizations of culture, and analyze selected statements by my interlocutors which are representative for the respective discourse as a whole. I present some background information on each of the 'speakers' in order to clarify the subject position they are speaking from. I explore how they think about the future (both their individual future and the future of Acholi society) and analyze, with reference to the theoretical concept of agency, how they perceive their role and see their opportunities in shaping this future. By doing so, however, I do not imply that speaker-discourse positions are fixed. Although certain individuals are more 'affine' to one discourse than to others, speakers do switch between discourses depending on the context and its interrelated power constellations which define the rules of the discourse, i.e. who is allowed to speak about what in which setting.

In interviews I conducted with mixed groups of elders and youth, for example, the latter rarely contradicted the opinions of the former and usually claimed to support retraditionalization because the discourse prescribed a 'principle of seniority' as well as a certain way of speaking about socio-cultural change when elders were present. In a different context, for instance in personal conversations with me, the same young people, who had formerly claimed to support retraditionalization, would suddenly revoke their opinion and claim to support modernization and Westernization. 
In a similar vein, gender-specific restrictions which were defined by the order of the discourse (cf. Hermann, 1995: 290ff.) had an important impact on what, when and how men and women spoke about socio-cultural change. Generally, and irrespective of the subject discussed, young women were very shy to express their opinions in public, especially when men were present ${ }^{169}$. In the group interviews, but also in individual interviews, my young female interlocutors usually kept very quiet and answered my questions very briefly with only a few words ${ }^{170}$. It seemed to me that they felt they had nothing to say which could possibly be of interest or relevance to my research, and that they did not want to risk criticizing or relativizing anything other people had said in front of the voice recorder (cf. Bernard, 2006: 222 on this type of "nonverbal respondents"). Furthermore, it seemed to me that in public contexts deep-seated ideologies regarding gender and 'tradition' were still at work which reinforced the notion that men should be the ones to speak in public while women, especially younger ones, should keep quiet. Women were commonly depicted as gossipers and thus discredited as serious speakers.

In more informal and private settings, however, I often found girls and young women to be very outspoken and explicitly political. In many conversations, I witnessed how they heavily criticized their situation as young women in the family and the society at large and discussed situations in which they had surreptitiously deviated from "traditional" social norms. To me, the different roles (young) women assumed was most obvious when I visited my female friends in their family homes. While in most other contexts, we interacted and conversed very freely with one another, in the home setting they usually left me to speak with their fathers or elder brothers and kept very quiet. During meals, I was invited to join the men at the table, while the women sat on the floor or in a separate room (cf. field notes e.g. 17.04.2010; 20.07.2010; 20./21.12.2010). Even though these young women criticized gender-unequal social structures and discourses, and in many situations actively transgressed them, they nevertheless accepted and reproduced them in the family setting.

In this sense, subject positions or "identities" are always to a certain degree incoherent and even contradictory, or, as Stuart Hall (1996a: 4) puts it, "never singular but multiply constructed across different, often intersecting and antagonistic, discourses, practices and positions". Furthermore, what people say not always neatly correlates with what they do in practice, so that the cultural style a person performs may not necessarily conform to the opinion he or she claims to have on this particular subject matter.

A further good example hereof was a public debate that I witnessed at Gulu University (cf. field notes 24.11.2010). During this event, students from the debate

${ }^{169}$ Even at university level, women who spoke in public debates were by far the minority (personal observations, cf. field notes $10.03 .2010 ; 24.11 .2010$ ). For this reason, youth discussions, for instance at Gulu Youth Centre, were usually organized in single sex groups.

170 This is also reflected in my data which has a male bias, especially in the interviews with youth (cf. Chap. 2). 
club and the audience discussed the motion "This House resolves that Culture is being lost among the Youth" ${ }^{171}$. Most of the speakers supported the motion and criticized that Acholi youth were too much drawn to "the Western culture" and thus contributed to the erosion of Acholi traditions. They praised the morals and values of Acholi culture and contrasted these with the decadence and immorality inherent in Western modernity. However, during the debate, the speakers were constantly mocking each other or even themselves for being exactly those "westernized Acholi youth" they were complaining about in their speeches. In the words of one speaker:

"I think it is high time we put ourselves to say that African culture is completely being lost. We cannot discuss a motion which reads 'African tradition is being lost' and we are discussing in English. You are Acholi! [A lot of supportive noise from the audience.] You are being forced to discuss in English (...), so it is completely true that even you - your culture is being lost! Look at the way you are dressed - that is not African dress [laughter because he himself is wearing a track suit] (...) The dress code - it has eroded in me, this is not our African culture, so it is completely eroded..." (Audio record - Debate, 24.11.2010).

The situation exemplifies that the speakers in the debate all knew the implicit rules of the contemporary discourse on socio-cultural change which prescribed that all Acholi should be concerned about the "loss of their culture". Furthermore, there seemed to be an implicit rule in student debate culture that critical and politically well-informed students should adopt anti-imperialist, anti-Western and in particular anti-US-American positions ${ }^{172}$. Very few of the participating students, however, practiced what they claimed to support, i.e. the rejection of a "Western" lifestyle, but instead conversed in English, wore "Western" fashion and consumed "Western" media products. Although in the particular context of the debate, nearly all the speakers claimed to support "traditional culture" and lamented its decline, they at the same time recognized the contradictions between their statements and their very 'non-traditional' behavior in most other contexts.

Generally, the positions of young people on the subject of socio-cultural change were more nuanced than this example suggests. Their imaginations of themselves and of an ideal Acholi society seemed to move along a continuum between 'highly modern' and 'conservative-traditional'. I will now outline four positions, which are located along this continuum.

${ }^{171}$ Debating is very popular in Uganda and is carried out in schools and universities. Although the positions taken by the teams in the debate and the statements given by the speakers do not necessarily correspond to their personal opinions on the matter discussed and are often exaggerated, the statements nevertheless reflect popular discourses and common opinions.

${ }^{172}$ I witnessed several examples of anti-imperialist and anti-US-American statements and discussions - in seminars, public debates and student conversations (cf. e.g. field notes 06.03.2010; 10.03.2010). 


\subsubsection{The Retraditionalization Discourse: Idealization of Tradition \& the Past}

Although the retraditionalization discourse was mainly promoted by conservative elders (both men and women), it was not uncommon among members of the war generation ${ }^{173}$. The basic underlying sentiment of the retraditionalization discourse was a strong idealization of an imagined past and a fear of future developments in Acholi society. According to Hall (1996b: 630), attempts by retraditionalists "to reconstruct purified identities, to restore coherence, 'closure', and Tradition (sic)" is one typical reaction to the (real and perceived) increased hybridity and diversity in the era of globalization.

Supporters of retraditionalization often maintained that everything had been better when Acholi culture was still 'intact', guided by clear moral principles, and when men and women, elders and youth still had their clearly defined roles in society. Nowadays, they argued, Acholi culture had been lost and many feared that it could not be revived and reinstalled ${ }^{174}$.

Underlying the retraditionalization discourse was a very static understanding of culture which was somehow similar to outdated "anthropological culture concepts" (cf. Hannerz, 1996: 30ff.). Culture was regarded as a bounded, coherent, continuous and unchangeable whole that was shared among a homogeneous group of people. Tradition and modernity, in this discourse, appeared to be irreconcilable binary oppositions. Youth who supported retraditionalization often blamed their fellow youths for becoming too "modern and westernized", for no longer respecting Acholi traditions and values, and thus for destabilizing Acholi society. In many ways their arguments sounded similar to the expressions commonly heard among Acholi elders, as the following example of a quote by a young man (24) ${ }^{175}$ reveals. When I asked him about the biggest challenges for his generation and how these differed from those of former generations, he replied:

"This generation, I can see many young people floating. They are not going to school, [even] when they find good things they just turn their life to the worst, they don't see that they should reach some point. Mostly they turn out drinking, even you find some who come from a very good family, you find them floating on the street drinking (...). For theirs [parent's and grandparent's generation] it was good, it was better, in those times. Our parents always listened a lot to our grandparents, and when they [the grandparents] are teaching a lesson you find them sitting together... Storytelling could also be there, there are a lot of things those grandparents were doing to our parents,

${ }^{173}$ For instance, 38.72 percent of the respondents to my questionnaire either disagreed (26.89\%) or strongly disagreed $(16.13 \%)$ with the statement "Life is better for young people today than it was in the past".

17438.30 percent of the questionnaire respondents believed that Acholi culture would eventually get lost completely.

175 The ages indicated in brackets refer to the age of my interlocutors at the time of my research. 
so that generation was good. Nowadays you see AIDS is real, there is a lot of AIDS everywhere, so it has spoiled a lot. In those days AIDS was not there, because in Uganda I remember when it started in 86, in that year I was born. So theirs [their generation] was good..." (INT Denis, 16.04.2010).

The quote expresses very well the young man's yearning for the past, which he imagines to have been a time of family solidarity and stability. Like other young people, who participated in the retraditionalization discourse, the interviewee felt overwhelmed by the rapid changes Acholi society was undergoing. This also becomes evident through his description of his generation as "floating". Throughout the interview and in personal conversations afterwards, I learned that, although he came from an economically stable family, he had faced many struggles throughout his life. When, as an introductory question to the interview, I asked him very unspecifically to tell me a little bit about himself, these were the first sentences he said:

"I come from a place called Amuru District. That is where my village is. According to me, this war has affected young people's minds a lot, and it has not been easy for young people, especially because many people lost their parents in this war. Me, I have not been there [in the village, due to the war], the only times I go [went] there was maybe during our holiday times, we go [went] to our village there and we find [found] there is sort of war. It's not been easy to stay there, so all of our relatives are living here in Gulu. (...) For me, there are difficult things: my father was working in Lacor hospital, he was a doctor there, and during Ebola outbreak here in $2000 \mathrm{I}$ lost my dad, he went away through the Ebola virus. So from there we came from Lacor hospital to town where I am living now..." (INT Denis, 16.04.2010).

He went on to recall how after his father's death he stayed with relatives in town and struggled through school. He never finished his A-level and instead started different job-trainings and courses, not all of which he completed. At the time of my research, he was working in a badly paid job at a local internet café. He was very frustrated with the job and his future perspectives. Although he sometimes talked of his dreams - to become a successful musician, to have a secure job and a family - he did not really seem to believe that they would ever come true and subsequently he did not seem to actively pursue them. At some point, he quit his job in town and I never saw him again. I later received an email from him saying that he had quit his job because he was not being paid properly. He further reported that he had been suffering from Malaria, that he was having a "financial crisis" and that his future plans had all failed because the people he relied on had disappointed him (email communication 30.05.2010).

Denis' visions for the future of Acholi society seemed equally bleak. When he talked about urban youth he repeatedly mentioned alcoholism, suicide and prostitution as major problems which incapacitated many members of his generation. $\mathrm{He}$ 
lamented how young urbanites were losing all the "beautiful things" of the past. One time, he told me that if he was to find a future wife it would have to be in the village, because girls in town were all "spoiled".

Denis' way of speaking about the past and the village typically represents the retraditionalization discourse. Like him, many of those who were in favor of retraditionalization had experienced difficult times throughout their youth in town and currently felt stuck in life. Frustrated, with no educational or job perspectives and no prospects of getting married and starting a family they perceived their situation as hopeless and feared for their future. They were skeptical of the promises of modernization, which had remained largely unfulfilled for them, as their daily realities contrasted starkly with images of a 'modern life' presented in the media - of wealth, prosperity, consumer culture and individual freedom (cf. Ferguson 2006: Chap. 7). They did not believe they could change their situation for the better and thus had a very limited sense of their own agency - in the words of Durham (2008: 153ff.) they could be considered "apathetic youth" ${ }^{176}$. Instead of talking about their future plans and "projects" (Ortner, 1997, 2001, 2006), they idealized the past and claimed to see the only solution to contemporary problems in going back to an imagined "traditional culture". In this sense, they lacked a "capacity to aspire" (Appadurai, 2004).

However, despite their rhetoric, in practice not all youth who claimed to have given up on their future were lethargic or apathetic. Neither were all of those who claimed to support retraditionalization 'traditionalists'. Denis, for instance, was part of the hip hop project and worked in an internet café, which for many Acholi signified quite a "modern" cultural style.

Thus, although their opinions on tradition and socio-cultural change were by no means arbitrary, what youth said and how they acted in practice not always neatly corresponded. Youth were more prone to 'adopt' the retraditionalization discourse in some situations, for instance, when they were specifically asked to reflect on their lives and their future prospects or when they were looking for support from older people (or from "Westerners" whom they believed to be nostalgic about "traditional African culture") or in specific settings, for instance in the family home or in the village. In these sociopolitical contexts, specific power relations and ideologies (cf. Fairclough, 2001: 2) were at work, which were favorable to the retraditionalization discourse and excluded or impeded other ways of speaking about past and future. In other situations and settings, however, the same young people, who had claimed to support retraditionalization, would deny their affiliation with tradition and pretend to be "modern" or adopt the modernization discourse.

${ }^{176}$ Deborah Durham or, more accurately, her 'elite' youth interlocutors in Botswana, have coined the term "apathetic youth", describing those youth, usually from underprivileged backgrounds, who were politically uninterested and did not take their future in their own hands. 


\subsubsection{The Modernization Discourse: Idealization of Life in the West}

On the surface, the modernization discourse represented the complete opposite of the retraditionalization discourse. It was commonly supported among members of the war generation, but also among some members of the adult generation. Members of the elder generation rarely participated in the modernization discourse. The basic argument of the modernization discourse was that life today should be "modern", "civilized" and "developed" and that African nations needed to "catch up" with the Western industrialized countries. Proponents of this discourse argued that "traditional Acholi culture" could not accommodate the changes which were necessary to become "modernized" and that "Western" ideas were replacing it. Just like in the retraditionalization discourse, tradition and modernity were perceived as irreconcilable binary oppositions and culture was understood as something static, bounded and coherent, which 'belonged' to a specific group of people. In this sense, the following statement by one of my interviewees, a 26-year old young man, is typical for the modernization discourse. When asked to comment on the biggest differences between the young generation and the parent's or grandparent's generation, he responded:

"If I can compare our generation, the now and the then generation, I can see there is some change we are getting, when I (compare it) to old stone age there... At least you can see some modern roads here, some machinery, you know those kind of things. In those days you couldn't see these things, they were backward, they didn't even know what education is. Right now an African child can do something cool, at least we are getting well versed with the world, in some few generations to come we are at the same level with those white people. Though some of us, we have coped up, but there are some people still living in those mountain areas, still having those kinds of mentalities. (...) What I can say in Africa, more especially in cities, town and centers, the Westerners, they are taking over, they are bringing their culture. (...) The culture of Africa, the way I am seeing it - I can't force something it is going to get lost. For sure, it is going to get lost. (...) People are comparing the culture, the Western culture and the local culture, and when you are still doing local things... Nowadays they say the world is just growing, and for you are still backward, nobody wants to be called local, so people move away from their culture. And even when you know how to do something in this culture, you don't do it, you just run away to the Western life, so that is it..." (INT Martin, 21.04.2010).

The quotation reveals the ambiguity of change and the feeling of being 'seduced' to give up one's own culture in order to participate in 'modernity'. Interestingly, the respondent does not blame the West for enforcing its culture. Rather, he describes the decision to move away from the "local culture" as a conscious and strategic choice. The way Martin attributes a deeper meaning to this development, which 
occurs within a well-established (global) system of power, can be regarded as an expression of agency (of intentions) in Ortner's sense. He seems to have internalized the widespread narrative of Africa as a place that is "backward" - economically, culturally and socially. He does not believe that "the culture of Africa" can coexist with elements of a "modern", "Western" society, but rather that all spheres of life need to be modernized and westernized in order to catch up and "grow" with the rest of the world. But, importantly, he sees himself and (some) members of his generation as drivers and 'agents' of this (necessary) change which is implied in the statement "some of us, we have coped up".

A further quotation from another interviewee (20) also reflects this idea. The young man points out further benefits of modernization and Westernization: independence, individual freedom, civic rights, and the possibility of overcoming patriarchal and gerontocratic structures. According to him, there are three categories of youth with very different views on culture:

"First, the children of the rich, those ones, they are so westernized and that is so fine - for me I don't see a problem there. Then, the middle ones, the ghetto dwellers, those who live in the ghetto [urban neighborhoods, slums]: those ones have both the local culture and the Western culture, and yeah they are transforming and that is good. Then there is the other - the ones in the remote areas, the young people who are in the village. For them, they still have the culture thing in them, you can see them, the ladies are getting circumcised and they are not complaining; there are so many things happening to them, they are getting married young and they are not complaining. It is because their mind is still narrow, their thinking is still narrow, they are still focused on that thing... like 'I want to be like my grandfather, he had 12 wives" (INT Joseph, 14.12.2010).

The respondent seems to embrace "Westernization" among Ugandan youth. For him, "local culture" is strongly related to the idea of being controlled, restricted and not being able to make independent decisions. He refers to young girls in the villages who are being circumcised or married off at a young age, probably partly against their will. He also refers to ideas which for him seem outdated, e.g. that a man has twelve wives, which was common in the past. He talks about young people living in rural areas in a very essentialist and also derogatory manner, which becomes obvious by his choice of expressions, especially the repeated use of the term "(culture) thing".

Both of the respondents quoted above faced similar struggles like Denis, the interviewee quoted in the section on the retraditionalization discourse. Martin had lost his dad, who had been shot in the war, and was currently staying with his uncle. Joseph had grown up without his parents in the custody of his grandmother and was currently struggling to cope with life alone in Gulu. Although Martin and Joseph were originally from economically stable families and had attended part of their schooling in Kampala, both were currently in a situation of economic uncertainty 
and were not very optimistic about their future perspectives. However, unlike Denis they did not idealize the past, but in fact blamed the past for the current state of Ugandan affairs. They also had more faith in their own agency. Although, when I spoke to them, they often expressed discouragement and despair at their current situation, they nonetheless always seemed driven by their dreams, i.e. to participate in what they understood as Western modernity. Martin dreamed of becoming a hip hop star. He was well-informed about the international hip hop scene and was one of the most active members of the hip hop group. He really believed the project would promote him as a hip hopper and was deeply disappointed and angry, when he realized that the hip hop project would not live up to its promises. Joseph described himself as a poet and I often discussed his poetry with him. He loved reading and writing, had read many internationally well-known novels and books, and dreamed of winning the Nobel Prize or a Pulitzer Prize one day. He tried to publish his poetry online and was very focused on his career as a writer despite the economic struggles he was facing. Even after I left Gulu, he sometimes sent me emails with his latest poetry.

When I asked the two interviewees how they imagined their future society to be both, Martin and Joseph, talked about the political situation in Uganda. They were both very critical of the current government and doubtful that its policies would bring about major improvements for their generation. Both stated that Ugandan politics needed substantial reforming in order to initiate a development process from which the whole country would profit. Thus, although they were skeptical regarding Uganda's future perspective, their analysis of the situation was very different from that of the retraditionalization discourse. Instead of imaging a 'local solution' to contemporary problems and a return to 'traditional life', they referred to the national and even global level and saw the key to a successful future of their society in political reforms and development initiatives.

In conclusion, one can state that in some ways the analysis of the current state of Acholi culture found within the modernization discourse is similar to the discourse on retraditionalization. Both discourses claim that Acholi traditions are getting lost because they are not reconcilable with "modern life". But the conclusions drawn from this argumentation greatly differ. While the retraditionalization discourse attributes the current, negative state of affairs (poverty, high unemployment, limited access to quality education etc.) to the loss of Acholi culture, the modernization discourse in fact blames the current problems on the continuing interference of "local culture" with modern life ${ }^{177}$. It sees the solutions to contemporary (individual and

177 Similar ways of reasoning, i.e. blaming the break with traditions for contemporary crisis, have been studied by anthropologists in other African contexts. Geissler and Prince (2010), for instance, have ethnographically researched how a Luo community (JoUhero) in Western Kenya tries to cope with severe crisis sparked by poverty, unemployment and the AIDS epidemic. Conflict lines in Uhero were particularly pronounced between "Luo traditionalists" and "Saved Christians". In order to cope with the crisis, "Luo traditionalists" had started to codify rules and traditions of the past, which should guide young people to reorient their lives and revive the stability 
national) problems not in "tradition" and a return to the past, but in copying "the West". Thus, instead of a glorification of the past, we find an idealization of life in the West and a deep-seated belief that the adoption of "Western" models can help Uganda to become "modern" and "progressive".

When analyzing the perceptions of agency among the young people who promoted the modernization discourse, we find that they are double-edged. On the one hand, they saw themselves as the drivers of change, who had a vision for the future. On an individual level, they not only imagined, but tried to plan and exert their "projects" and had an "active projection of the self toward some desired end" (Ortner, 1997: 146). Unlike the "apathetic youth" typically associated with the retraditionalization discourse, they had faith in the promises of modernization theory (cf. Ferguson 2006: Chap. 6, 7), namely that one day Uganda would reach the same level of development as the countries in the West. On the societal level, however, they did not believe that they could freely design the type and tempo of change they were pushing for. Rather, they felt that in order to overcome "backwardness" and the narrow confines of "traditional" society they needed to imitate the "Western" model and follow a predefined development path. Furthermore, many believed that substantial political reforms were needed in order to "modernize" and democratize Ugandan society, but few believed that in the current situation of Ugandan politics, they could contribute to instigating these necessary political changes.

Again, as stated above, speaker-discourse positions were by no means fixed and promoters of the modernization discourse sometimes switched to other discourse positions. Generally speaking, the modernization discourse was most commonly adopted in discussions about economic development and political liberalization. While many younger and older Acholi agreed that they would like to have the economic benefits and the political power associated with Western modernity (a common view among my interlocutors was that people in the West are rich and live 'easy lives' due to their technical and economic advancement and political superiority), they were more critical of adopting the 'Western model' in social terms. Thus, whenever the conversation turned to the subject of values and social relations, even stern supporters of modernization usually acknowledged that Western society was too materialistic, individualistic and "immoral" when compared with "traditional Acholi culture". (I will further elaborate on this point in chapter 6). Generally, many Acholi had a very ambivalent attitude towards socio-cultural change and thus commonly adopted the ambivalent discourse.

and prosperity associated with the past, while "Saved Christians" rejected Luo traditions and in fact saw "traditional cultural practices" as the reason for the contemporary crisis. Similar to my analysis, Geissler and Prince show how social rules and imaginations of the 'right society' were heavily contested, even within the two 'factions', and how interpretations of what is "modern" or "traditional", right or wrong varied according to speaker, context and situation (cf. Geissler \& Prince, 2010: 79; 142ff.; Prince, 2009: 75ff.). 


\subsubsection{The Ambivalent Discourse: Uncertainty in the Face of Change}

The ambivalent discourse combined the two discourses outlined above and reflected the most widespread position among members of the war generation in Gulu. Proponents of this discourse were unclear on whether "modern" life in town today was better or worse than "traditional" village-life in the past. While they appreciated many aspects of contemporary urban life and could not imagine going back to a rural lifestyle of former times, many still valued Acholi culture and expressed sadness that they had not practiced and learned more about Acholi traditions and cultural practices during their childhood. The ambivalent discourse, like the former two, relied on a number of binary opposition (tradition - modernity, past - future, urban - rural), but it supported a more dynamic view of culture than the two previous ones. It acknowledged that certain elements of culture could change over time, that culture could be incoherent and that there could be different cultural styles within one ethnic group. According to this understanding, certain elements of culture could get lost, but not Acholi culture as a whole. Therefore, while most believed that life in the past had been good and that "traditional Acholi culture" was something to be proud of and that should be preserved, they also acknowledged that times had changed and it was not possible to revive the past as it had been which in some ways was good and in some ways was bad. The following quotation by a young man named Odong (19) typically reflects this position. When comparing his generation to former generations he stated:

"This modernity and this technology has changed everything, most of the things. (...) The biggest difference nowadays is respect and morals. Those days, our parents, old people those days, they were so respectful, they were uprightly brought up, they were so disciplined, but nowadays (...). These children, they are used to these video things, they are used to what they see from screens, they will start imitating, and when you tell them you don't know anything, your life... Just look at life those days where you used to live, this and your generation and modernity (...) so that is the biggest challenge, that is the biggest difference which I see between the people of those days our parents - and the people nowadays of this generation."

When I asked him whether he thought that "modernity" - as he called it - had brought only negative things, he replied:

"You see, everything has a bad part and a good part. But the way I see it, the bad part of it [modernity] is bigger, (...) there is so much indiscipline and no respect. You know in Africa those days, I mean in our culture, in Acholi culture, ladies were not allowed to put on miniskirts. If you put on something like that, oh - they will cane, they will chase you from home, they will call you prostitute, that you are trying to ruin and disgrace the name of the family, so those things were not allowed. (...) The worst thing was trousers, 
when ladies put on trousers they will say you are competing with your father, they will chase you and no one will marry you because they will say you are a prostitute, so you are useless. [Laughs]. But nowadays everyone puts on trousers. (...) Anyway, modernity and civilization have brought also good things, because it [modernity] has opened our eyes to the world. Like I told you, it has brought so many things we used not to know, but somehow somewhere it has also ruined our future and our culture, it has ruined our behavior... and our lifestyle - it has affected our lifestyle badly" (INT Odong, 04.05.2010).

The quotation well captures the ambivalence and uncertainty regarding the contemporary role of tradition I encountered among many youth. They had heard about formerly established norms and rules in Acholi society, for instance regarding gendered forms of behavior or certain rituals which used to be performed. On the one hand, they seemed proud of such traditions and regarded them as desirable and well-suited to establish social order. On the other hand, they also found many 'traditional practices' strange and outdated and very much in conflict with their 'modern' values.

Odong had grown up and gone to school in town. Throughout his youth he had participated in diverse youth activities ranging from break-dance and football to traditional dance. He was a stern supporter of English Premier League Football and a very active member of a cultural group. Although he dreamt of attending Gulu University, he had been compelled to start a course at a teacher's college because he could not afford the university fees. When he spoke about his future, he always seemed torn between his dream of a "modern life" - with a house, a car and other luxury objects - and a more realistic vision of a life as a teacher, who might be sent to teach in a rural area, who would have to struggle to provide for a family, but whose lifestyle would be closer to the 'original life' of the Acholi people. He, like many other young people, felt that it was not so much his own choice how his personal future and the collective future of the Acholi people developed, but that it was determined by external circumstances. Thus, he accepted the changes Acholi society was undergoing without trying to actively influence them. In this sense, his perception of his agency was quite limited, but other than the "apathetic youth" who supported the retraditionalization discourse he did not resign but simply adapted to the changes.

Unlike the former two discourses, which were adopted in situations in which the speakers had a clear opinion on whether Acholi society should be retraditionalized or modernized with regard to the matter discussed, the ambivalent discourse was adopted in situations in which the speakers were truly torn between the advantages and detriments of either, retraditionalization or modernization. To me, this became especially evident in conversations I had with youth about gender norms. Both, my male and female interlocutors, regularly stressed that women and girls should show "culturally appropriate behavior", which implied conforming to established Acholi gender norms. But whenever I asked the young men to describe how their future wives should be, they also mentioned that she should be "modern", attractive, 
educated, able to take decisions on her own and also share financial responsibilities in the family. This ambivalence concerning female gender norms, which I found among many of my interlocutors and which I will discuss in more detail in the next chapter, is clearly revealed in the following quotation by a male interviewee (20), whom I asked to describe his ideal future wife:

"Sure, I need to have a wife who is educated. But not quite - because sometimes when my wife is so much educated, and she works in the same situation like me, there is a tension in the family. Because, you know, men are different, women are different, and women when they are educated they start to see things in a different way. It is not worthy in Africa. So in Africa there is what we call... a man is the head of the family and he should decide. (...) But what I need in a woman: she should be someone caring, loving, and she should understand our culture, not to deviate from things when she gets exposed to your [Western] life (...) She should do things according to the tradition. I know other traditions nowadays they cannot work anymore. But what I mean is just to fulfill the role like a woman..."

When I asked him to explain which "traditions" exactly he was referring to, he went on to say:

"Those days, there were a lot of... Let me say - when it comes to family, mostly women were taken as properties and they were not having that freedom of speech. So that is what I don't want to have. Those are the customs and traditions, which don't work nowadays. She should feel free and express herself. It is better when you have a good woman, who can continue when you get stuck. It is not like I should put myself to be the principle. That is not good in a family" (INT Elima, 09.04.2010).

In this sense, the ambivalent discourse implied not just a switching between retraditionalization in one situation, and modernization in another, but pertained to situations, in which the young people I encountered were really undecided about one specific matter (for instance marriage) with regard to which they felt that they could not really combine "traditional" and "modern" elements or decide which of both was more desirable. This ambivalence and indecisiveness posed a major difference to the position represented in the creative discourse.

\subsubsection{The Creative Discourse: "Translating"178 Acholi Culture}

The attitude underlying the creative discourse is best captured by a statement from one of my interviewees. When I asked him whether he could imagine a future life in the rural areas, he answered: "If I go back to the village, I will go with a new style..."

${ }^{178}$ Hall (1996b: 628f.), following Robbins and Homi Bhabha, uses the term "translation" to describe those positions which "accept that identity is subject to the play of history, politics, representa- 
(INT Elima, 09.04.2010). Like him, supporters of the creative discourse believed that Acholi culture was currently undergoing many changes, but that this was a natural and desirable process. Rather than blaming certain groups within Acholi society of contributing to the erosion of "traditional culture", they encouraged every Acholi to contribute to transforming and actively shaping Acholi culture.

The creative discourse did not primarily assume a binary opposition between tradition and modernity, local and global, Africa and the West, and did not see globalization processes as a new, homogenizing threat to 'local cultures'. Instead, it argued that globalization and, related to it, socio-cultural change and exchange were interconnected and historical processes which offered new chances and brought about new challenges. Thus, rather than being in favor of retraditionalization or modernization, or being torn between the two, proponents of the creative discourse contended that different facets of identity could coexist and be combined. This argumentation underlying the creative discourse is somewhat reminiscent of contemporary approaches in anthropological and Africanist theory (cf. Loimeier et al., 2005a; Hall, 1996b). Hall, for instance, argues that

"[e]verywhere, cultural identities are emerging which are not fixed, but poised, in transition, between different positions; which draw on different cultural traditions at the same time; and which are the product of those complicated cross-overs and cultural mixes which are increasingly common in a globalized world" (1996b: 629, emphasis in original).

In a similar vein, the conception of culture underlying the creative discourse came close to recent anthropological convictions, namely that there is a need "to exchange a static, homogenizing concept of culture in favor of more open, fluid notions which are able to contain the making and unmaking of localities and the shifting of boundaries which these processes entail" (Meyer \& Geschiere, 1999: 3). Proponents of the creative discourse saw culture on a continuum between tradition and modernity, as being dynamic rather than static. Accordingly, changes in Acholi culture were acknowledged, but they were not interpreted as a sign of cultural loss but rather as necessary adaption to changed living circumstances and as a result of cultural transitions and transformations. The following quotation by Laurence (20) is a typical example. When I asked him why he thought Acholi culture was changing, he replied:

"When you are stuck to your tradition or when you are stuck to one thing, sometimes you don't achieve much. Though I believe culture is wealth, that is true, but sometimes culture when you stick to it, it will not bring you the world. Sometimes you go and also try to copy up some other people's culture, then you come back to yours. That is when you can lift up your culture and go ahead, when you know all or maybe both cultures (...). You have to 
change, in order also to cope up with others - as the world grows you grow together with the world. Because if you are to remain behind, you remain for good. That is why you see there are certain countries that are still backward. Uganda is among them, but I see they are now trying to improve... There is much improvement because of the culture changing... even the system of education has changed, that is why we are also able to speak English, we are able to communicate to other people... you have to change your culture at times, and you know, adjust to other cultures also..." (INT Laurence, 28.04.2010).

The quotation is evocative of the idea formulated by Stuart Hall (see quotation above), namely that in the era of globalization, "as the world grows together", people can draw on different cultural elements in order to cope with the complicated challenges of contemporary life. The interviewee stresses that people of different cultural backgrounds should learn from one another and integrate the new insights they gain into their existing 'cultural repertoire' - without interpreting the ensuing changes of "their culture" as a sign of loss. Stagnation, the belief in cultural purity and the desperate latching onto one's own traditions are interpreted as hindrances to a country's or a people's development. The respondent gives the pertinent example of language and communication. The latter can work only if people are willing to engage with one another, to learn new languages, and to adapt their own languages or dialects in order to facilitate mutual understanding.

Laurence came from an economically stable family background. His mother had died when he was still young and he had grown up with his grandmother in the village and later with his father in town. Currently, he was staying in Gulu with his father and his new wife. He told me that he had always been a successful student and that his father was planning to send him to a good school in Kampala for his A-level, or even abroad. Laurence was a dedicated member of the hip hop group, who felt inspired by US-American rappers such as Ice Cube, Dr. Dre and Snoop Doggy Dog and even female rappers like Lil' Kim. But he also loved Acholi music, Ugandan dancehall and Congolese Lingala. He had many different plans for his future: he told me that his father was planning to open a big farm in the village and he would probably be involved in the management of the farm, but that he could also imagine becoming a musician because he really loved music. In the interview, he repeatedly emphasized that he was very proud of being an Acholi, and that he came from the Pakwa clan and that his great grandfather had been an important clan leader ("king"). In his words:

"It is always good to be proud of who you are, always be just proud. I am an African, I am black, I am proud of being an African and black, like you are a white lady, and you must be proud of your color, and you must be proud of your tribe you come from. I am proud of my tribe, I am proud of who I am, my culture all supports me, so being an Acholi is not something bad (...) 
I am someone from the Pakwa clan. You know this Doloby? Doloby was a king, and I am glad to say that I am also a prince because he was my great grandfather..." (INT Laurence, 28.04.2010).

In some ways, Laurence was a typical representative of the creative discourse. $\mathrm{He}$ had a good level of education, his family was planning to set up a large-scale farming business in the rural areas and he was generally very optimistic about his future. He usually performed a modern cultural style, which, from an emic perspective, made him appear quite "westernized". But unlike the proponents of the modernization discourse he often proudly emphasized his Acholi identity and, unlike the representatives of the ambivalent discourse, he did not perceive his Acholi identity to contradict his 'modern style'.

Alfred (in his early 20s), another one of my interlocutors who I met occasionally in the context of my work at Gulu University, was another typical representative of the creative discourse. After his A-level he had completed a nine-month diploma in law and was now studying public administration at Gulu University. Alfred was a very active student. He was part of the student guild, member of the debate club, had played football for the Gulu football club, and was involved in several political activities which aimed to strengthen the political voice of youth. In 2008, he had been part of a delegation of Ugandan youth who travelled to Nairobi and met youth from other African countries to discuss and revise the African Youth Charter. I always imagined him to be one of Northern Uganda's future politicians or a successful business man in Kampala. But, to my big surprise, when I once asked him about his career plans he told me that he was planning to return to his village in Koch Goma, a rural area in Nwoya District ${ }^{179}$, although he also had a small business project in Kampala. He added that he was really a farmer and that his family land was there. Enthusiastically, he started to recount stories of his hunting adventures during his youth and about his old grandfather who had taught him many things about rural life (field notes 24.11.2012). Unlike many other Acholi I met, he did not seem to see a contradiction between his current lifestyle in town and his 'real identity' as an Acholi farmer. I gained the impression that he had found a way to combine two allegedly very different lifestyles - urban and rural - which many Acholi perceived as irreconcilable.

Like Laurence and Alfred, most proponents of the creative discourse had economically stable backgrounds and thus had to worry less about their future than youths from more precarious backgrounds. Due to their relative economic security and, related, their higher social and spacial mobility, they could actually choose how and where they wanted their future to be and, even if they decided on a rural life as farmers, for them this usually did not mean a complete break with their urban lives. However, I also met youths from more precarious backgrounds, like Simon, who

${ }^{179}$ Nwoya District, formerly part of Amuru District, is part of the Acholi sub-region and is located southwest of Gulu Municipality (see appendix, figure 1). 
Julia Vorhölter: Youth at the Crossroads

quite successfully managed to combine urban and rural, 'modern' and 'traditional' lifestyles and perceived their extensive 'cultural repertoire' primarily as a resource and not as a source of conflict.

In terms of agency, 'creative youth' saw themselves as self-conscious agents of change, not only regarding their individual lives but with regard to the future of Acholi society as a whole. They envisioned a society in which people could freely choose their style of living and in which elements from different cultures, including Acholi "traditional culture" could coexist or even be combined. While acknowledging socio-cultural change as a naturally occurring phenomenon, they also perceived it as a process which could be actively shaped by social actors by intentionally choosing elements of culture which should be preserved and others which should be transformed.

This question of selecting suitable and unsuitable cultural elements often came up in conversations with my interlocutors and I also took it up in my questionnaire. Most of my respondents were very resolute about which Acholi cultural practices should be abandoned and which should be preserved. Regarding the former, i.e. abandonment, the most common answers were usually witchcraft/belief in witchcraft $(16.67 \% \text { of the questionnaire respondents })^{180}$, certain ritual practices like the twin ritual or the last funeral rite $(14.1 \%)$ and wife inheritance $(11.54 \%)$. With regard to the latter, preservation, the most common answer, by far, was traditional dance $(51.61 \%)$, followed by appropriate dressing styles (probably implying no miniskirts, baggy pants etc., $9.68 \%$ ), "traditional food" and "traditional marriage" (both $8.6 \%$ ). Overall, nearly half of the respondents to the questionnaire (47.68\%) disagreed or strongly disagreed that Acholi culture did not fit modern times and more than half $(52.12 \%)$ disagreed or strongly disagreed that young people should not stick to traditions of the past.

Thus, when asked to specifically reflect on the nature of socio-cultural change, many young people were able to differentiate between and select cultural elements which could easily be integrated into their "modern", urban life and others which could or should not. However, as with all other discourses, the way young people spoke about 'cultural mixing' was heavily influenced by situational factors and power constellations. Furthermore, the ability for young people to mix cultural styles and participate in different cultural scenes was dependent, at least to some degree, on their material resources. As Hannerz (1996: 73f.) has pointed out, although people are free to choose and can adopt various discourses, they are influenced not only by the state and the market, but also by their capacities as cultural consumers.

180 The percentages given in brackets all refer to the respondents of the questionnaire. 


\subsection{Concluding Remarks: The Positioning of Youth in Post-War Acholi Society}

This chapter has shown how members of the war generation positioned themselves in ongoing discourses on socio-cultural change. Four sub-discourses were identified in which different perceptions and future implications of change were subsumed: the retraditionalization discourse, the modernization discourse, the ambivalent discourse and the creative discourse. Underlying each discourse were different conceptualizations of culture and agency and different evaluations of the effects and, related, the desirability of change. In addition to analyzing the way young people spoke about change, the chapter also looked at social practices and the ways young people acted in the face of socio-cultural change with reference to Ferguson's concept of cultural styles.

The analysis revealed that individual members of the war generation engaged very differently with the subject of socio-cultural change. Some tended to dream of a return to the imagined stability of the past and felt inclined to revive "traditional cultural practices", for instance traditional dance. Others were more prone to believe that they could overcome the conservativeness they saw as inherent in "Acholi traditions" by orienting their styles and behavior towards what they labeled "Western modernity". As has been argued repeatedly, these different positionalities depended on individual characteristics (age, gender, social status, life experience), situational context and societal discourses. Few of the young people I met exclusively adopted only one cultural style or supported only one of the four sub-discourses. Rather, they switched between discourses and styles depending on the people they were interacting with and the power relations involved and thereby exposed different facets of their identity as Acholi youth.

Despite the individual reactions to and interpretations of socio-cultural change, one can also make out a distinctive war-generational perspective on socio-cultural change, brought about by the specific experiences of this generation and reinforced by societal discourses on the war generation. This perspective was characterized, above all, by ambivalence and uncertainty. The young people I worked with in Gulu Municipality grew up in very turbulent circumstances and currently found themselves in a situation in which collective norms, rules and conceptions of life seemed to be in flux. Many of them could not or did not want to fulfill the roles and expectations - in terms of lifestyle, occupation, marriage and family structures - which would have been required of them in 'traditional' Acholi society and which were still envisioned by some of their parents and community elders. Similar to many young people in other societies, they rebelled against the older generation and defined new ideals, which were more in line with their individual biographies and their hopes for the post-war future. At the same time, however, all members of the war generation were confronted with the societal discourse on retraditionalization which strongly idealized the past and which blamed the loss of Acholi culture not only on the war, 
but also on the young generation of Acholi. This highly emotive discourse appealed to the young generation to participate in the revival and maintenance of Acholi traditions and by doing so to restore social stability and the reputation of the Acholi as a people. Some young people managed to integrate the latter exigency into their future plans, but most were caught in between the highly moralized societal expectations and their individual dreams and "expectations of modernity" (cf. Ferguson, 1999).

Thus, when looking from a macro perspective, societal conflict lines between different generations became obvious regarding the ways to deal with socio-cultural change. These were further manifested by local power struggles between the young and the old, but also by global discourses which categorized certain lifestyles as more desirable than others. These influences as well as the life experiences of the members of the war generation thoroughly affected their understanding of Acholi culture and values and their perceptions of changes in Acholi society. To conclude, one can retain that while there is a distinctive generational perspective on sociocultural change, there are also different sub-discourses and styles to be found within this generation. I will take up this point in the next chapter where I look at the ways Acholi and Ugandans, in different contexts, use references to the West to position themselves in discourses on socio-cultural change. 


\section{Westernization versus Neocolonialism Representations of "Africa" \& "The West" in Debates on Aid, Capitalism \& Sexuality}

In this chapter, I dissect perceptions of 'Western-influenced' socio-cultural change in Acholiland and Uganda at large ${ }^{181}$. I aim to understand why the West is such a frequent point of reference and comparison in contemporary discourses on sociocultural change and why and in which contexts local actors respectively establish positive or negative associations with it. I differentiate between discourses on Westernization and discourses on neocolonialism. Both are analyzed as forms of social critique - one internally and the other externally oriented. The largely elitist discourse on neocolonialism is explicitly critical of the West and its interventions in Uganda. But it is not representative of the more ambiguous perceptions of West-

${ }^{181}$ Parts of this chapter have been published as a research article in the Journal of Modern African Studies (Vorhölter, 2012). 
ernization I encountered more frequently among my interlocturors who use references to the West to comment on contemporary Ugandan society. My argument in this chapter is that the binary oppositions modern vs. traditional and Acholi vs. Western culture are used as benchmarks to interpret, criticize and imagine post-war Acholi society. Furthermore, I reveal the highly sexualized dimension of discourses on socio-cultural change in Acholiland and Uganda generally and analyze the way these discourses are closely interwoven with power dynamics at the local, national and international level.

\subsection{Dissecting Acholi \& Ugandan Notions of "The West"}

As the two previous chapters revealed, "the West" constitutes an important spatial and symbolic reference point in discourses about socio-cultural change, which was commonly understood to denote the complete opposite of local, "traditional", village-based Acholi culture and which, depending on the context and the speaker, could be both positively and negatively connoted. As I already mentioned in chapter 4, "Westernization" was generally regarded as a major source of the ongoing changes in Acholiland, and its implication and desirability were strongly debated. Furthermore, in chapter 5, I analyzed how for some Acholi and/or in some contexts, "traditional culture" was seen as the ideal to be strived for in post-war society, while for others and/or in other contexts "the West" was taken as a point of orientation and inspiration.

In this chapter, I analyze the representations and perceptions of Westernization and the West in Acholi and Ugandan ${ }^{182}$ discourses more thoroughly. I aim to understand what Ugandans mean when they speak of "the West", and in which contexts and why they use it as a point of reference and comparison. In Ugandan discourses, as I will show throughout this chapter, the attribute "Western" is used in two, not clearly separable senses. It is used to refer to the actual interventions and political practices of Western, i.e. generally North-American and European, states and institutions (for instance in the context of development operations, structural adjustment and aid conditionality). And, it is used as a label to characterize specific cultural traits and practices. In the first sense, then, the West is seen and addressed as a political actor, in the second sense it is understood as a cultural complex. In both senses, the attribute "Western" can have positive or negative connotations.

Based on the analysis of my data from Northern Uganda and of statements in the Ugandan press, I claim that one can differentiate between two different types of discourses: on the one hand, discourses which mainly reflect negative perceptions of 'Western-influenced' change, focus mainly on the West as a political actor

${ }^{182}$ In addition to my field notes and interviews, I also analyze Ugandan media discourses in which references to the West are very common and reflect the pervasiveness of such references not only in Acholi discourses but in Uganda generally. 
and are used to blame the West for interference in Ugandan internal affairs. With reference to debates in postcolonial theory, I have labeled these "neocolonialism discourses". And on the other hand, discourses which echo more ambiguous views of Western influences, both political and cultural, and are concerned with Ugandan society itself. Following emic conceptualizations among my interlocutors, I refer to these as "Westernization discourses". I argue that both discourses are forms of social critique: one is more externally, the other more internally oriented, but they are not mutually exclusive and they sometimes overlap. Both discourses are strategic and follow different lines of argumentation (cf. Foucault, 1990: 36ff.). They serve certain purposes, reflect different positions within Acholi (and more broadly Ugandan society), and are thus employed by different actors in different contexts and for different reasons.

I argue that the discourse on neocolonialism is highly politicized and addresses, sometimes in a populist manner, historically grown, global power inequalities, Western aid politics and the processes of foreign-induced neoliberal change. To some extent, this is an elite discourse which is propagated by Ugandan leaders and intellectuals, and primarily targets Western politicians and development actors. Its main aim is to criticize the West and its continuing dominance in the world system, and to emphasize the sovereignty and autonomy of the Ugandan state despite its continuing aid dependence. A prominent example of a neocolonialism discourse is the current debate on the so-called "anti-homosexuality bill" in Uganda. I will briefly discuss this example in a later part of this chapter.

The discourse on Westernization, on the other hand, is more internally-oriented and comments on contemporary Ugandan society. It is less focused on the political processes of Western interventions, but is rather concerned with the cultural contents and manifestations of values, norms and concepts, which are labled "Western", and the consequences of establishing them in Ugandan society. In Northern Ugan$\mathrm{da}$, particularly, the discourse is characterized by a common distinction between notions of traditional society on the one hand, and notions of Western modernity on the other (cf. Chap. 5). In using these benchmarks, Acholi contest dynamics within what they perceive as their rapidly changing society. The token "Western" is deployed, sometimes arbitrarily, as a crucial signifier which can have both positive and negative connotations. Among the 'ordinary' population, especially, to which most of my interlocutors in Gulu belonged (cf. Chap. 2 and Chap. 5), I found this discourse to be much more prevalent than the discourse on neocolonialism.

This more ambiguous discourse on 'Western-influenced' change is often deemphasized in the literature which deals with the ways in which Western-induced neoliberal reforms and discourses have affected norms and practices in Uganda (e.g. Cheney, 2007; Tamale, 2009; Wiegratz, 2010). It is also overlooked in some of the literature on post-colonial theory. This literature predominantly reflects the critical discourse on the role of the West, which undeniably is very present. But it places less emphasis on the ambivalence and complexity of local discourses on Westernization (Slemon, 1995: 45) and often represents an elite discourse which has lost its rele- 
vance for many 'ordinary' Africans (Magubane, 2003; Quayson \& Goldberg, 2002; Ashcroft et al., 1998: 188ff.; Zeleza, 2003: 2ff.; Loomba et al., 2005: 3). For example, one finds the frequently expressed claim that colonialism, and more recently human rights discourses, the aid industry and the global media have created global hegemonic norms which have been enforced on African and other 'non-Western societies' (e.g. Esteva \& Prakash, 1998; Rahnema \& Bawtree, 1997). Particularly in the field of gender, kinship and sexuality several debates, often in the context of aid interventions, have been fought over whether the vigorous promotion of concepts like gender equality, the fight for LGBTI (LesbianGayBisexualTransIntersex) rights, or the banning of practices such as female genital excision, to name just a few, represent forms of imperialism or neo-colonialism (Mohanty, 1988; Njambi, 2004; Bennett, 2010) and whether gender and feminism are not by themselves already "Western" or "colonized" concepts (Oyewumi, 1997, 2002, 2005).

These debates have often and too easily been framed in binary oppositions. A common claim, in public discourses as well as in some of the academic literature, is that there are two clear-cut and irreconcilable positions: on the one side, Western politicians, activists and aid practitioners, who claim the universality of human rights and the necessity to enforce them if non-Western states are unable or unwilling to implement them; on the other hand, critical scholars and African politicians, who argue that human rights are just another excuse for Western state and development actors to interfere with the sovereignty of African states, and are thus a continuation of colonial politics. The perceptions and interpretations of the 'target populations' who, depending on the discourse, are to suffer or benefit from the imposition of 'Western' norms and rights discourses, have often been ignored in these debates. Wiegratz (2010: 123), for example, argues that the neoliberal restructuring of the Ugandan economy and society under the Museveni regime has led to "a spread of destructive norms and practices", and is "mainly driven by the interests, norms, practices and projects of sections of the domestic power elite, as well as foreign donors, organizations, corporations and special interest groups" (ibid.: 133). This is a very important aspect, but it does not capture completely the complex processes of compliance and resistance within Ugandan society, particularly among the 'ordinary' population.

My aim in this chapter is to demonstrate that the Acholi population, which was highly exposed to the Western aid regime during and after the war, is by no means a passive recipient of 'foreign imports', but actively and very critically engages with what they label "Western" values, norms and practices. Local actors negotiate whether these are desirable or not. They do not generally portray themselves as 'victims' of the West, but base their arguments on their position within Acholi society, depending among other things on generation, social class and gender. By looking at different local discourses on neocolonialism and Westernization, I show how the blurred, multiple and contradictory ways in which Western-connoted concepts and ideas are rejected and embraced, enforced and enacted on the ground. 
In the upcoming extract from my field notes, emic conceptualization of differences between Western and Acholi gender norms and images become obvious. I then turn to analyze how Western influences on Acholi society are framed and evaluated in contemporary discourses on socio-cultural change. In the first part of the analysis, I examine general discourses on Westernization, related to aid dependency, NGO intervention and generational change, all of which are much-debated topics in contemporary (Northern) Uganda. In the second part of the analysis, I place special emphasis on representations of the West in contemporary debates on gender, kinship and sexuality in which binary oppositions between local and global, modern and traditional and African and Western are particularly widespread and contested. Finally, I give an example of a neocolonialism discourse - the current national debate on homosexuality - and show that the motives, arguments and strategies behind it are very different from the discourses on Westernization. I relate the example of the "anti-homosexuality bill" to other recent sexuality-related legal measures proposed by the Ugandan state in order to control and discipline its population and argue, following Foucault, that discourses on sexuality can provide important insight to power dynamics at the local, national and international level.

\subsection{Simon's Story - Extracts from my Field Notes}

August $10^{\text {th }}, 2010$. Simon and I sit at Franklin's Inn, drinking soda, and catching up on what we have been doing lately. I ask him how his hip hop projects are coming along and Simon tells me that he has just finished shooting the video for his new song. $\mathrm{He}$ starts telling me about Peter, a young German, who helped him to produce the video clip. Soon, he digresses from talking about the video production. Instead, and rather excitedly, he starts to tell me of Peter's relationship with an Acholi girl. The following is my summary of Simon's story.

Peter came to Gulu to visit Julian, the German coordinator of the hip hop project for a few weeks. He was a good friend of Julian and stayed with Julian and his German girlfriend $\mathrm{Anke}^{183}$ in their flat in Gulu. Due to the work on the music video, Simon spent a lot of time with the three of them.

One day, Simon took Julian, Anke and Peter to a photo shop in Gulu to take some "snaps"184. A young girl, Ajok ${ }^{185}$, who Simon knew from previous visits, was working at

${ }^{183}$ All the names of the people mentioned in Simon's story have been changed.

184 "Taking snaps" is very popular among youth in Gulu. It involves going into a photo shop with a friend, often a girl- or boyfriend or a 'muno friend', and posing in front of fake photo-poster backgrounds, for instance a beach, a palace, a park etc. Six snaps in the size of passport photos cost around 1.500 UGX (approx. 0.5 Euro).

185 When Simon told the story, he just referred to her as "the girl", but for readability purposes I have decided to give her a name, Ajok, which is a common Acholi name and usually given to girls "with a mark on the body that is believed to be of supernatural origin", i.e. to girls who are somehow feared for their possible supernatural connections (Adong \& Lakareber, 2009: 180). 
the front desk. She started to flirt heavily with Peter from the moment they entered the shop. (Simon explains to me that he felt very embarrassed by the girl's behavior because she was "making very clear signs to Peter"). Even Julian, who had been living in Gulu for several months, asked Simon whether that was the way "Acholi girls normally behaved" - apparently he had never seen anything like it - and Simon told him that this was "definitely not the way Acholi girls should behave" and that it was "more like the way prostitutes acted". Peter, however, did not seem to notice or to care about the girl's "inappropriate" behavior and after this first encounter he and Ajok started to meet on a regular basis.

One night, when Simon went to perform his new hip hop song at Herm's Club, Julian, Anke, Peter and Ajok came along. Simon recounts the evening and the many interesting details he observed. He tells me that "the whole time Ajok was trying to do with Peter what Julian and Anke were doing. When Julian and Anke stood arm in arm, she also put her arms around Peter, and when Julian and Anke were dancing very closely, grinding their bodies ${ }^{186}$, she would also dance the same way with Peter." According to Simon, this made the other Acholi guests in the club look at them funnily and when I ask him why, he explains: "The way Western people behave should not be the same way for Acholi people. When Westerners kiss and hug in the streets, when they dance funnily (and dirtily), people here laugh at them, but they tolerate it, because it is the way Westerners behave. But when Acholi people, especially Acholi girls, behave in that way, people find it very embarrassing and think the girl might be a prostitute".

Simon continues his narration of the evening with a critical undertone. He reports, somewhat disapprovingly, how he observed that Julian, Anke and Peter were drinking and even smoking the whole night. [A common cliché about Westerners is that they drink, smoke and behave immorally in public. Most Acholi have become accustomed to this behavior and while it is seen as tolerable for Westerners, at least in the official discourse, it is regarded disgraceful if Acholi people, especially women, do the same].

Later in the night, Simon walked home with Julian and Anke (Ajok and Peter had already left earlier). On the way, Julian pulled him aside and said he wanted to talk to him. He told Simon that he really did not like the way this Acholi girl was behaving, always being around Peter. She had even slept at their place for two nights, and this night would be the third night. Simon explained to me that Julian and Anke never invited anyone [probably implying anyone Acholi] to their place and therefore must have been very annoyed by Ajok's nightly visits. Simon tells me that he apologized to Julian and tried to explain to him that "this girl was really like a prostitute" and that "the way she was behaving was not what people would expect from an Acholi girl".

${ }^{186}$ According to Wikipedia, "[g]rinding, (...) is a type of close partner dance where two or more dancers rub or bump their bodies against each other, especially a male dancer rubbing his crotch against a female dancer's buttocks, in imitation of rear-entry or 'doggie-style' intercourse. Grinding gained its initial popularity in night clubs, and eventually moved on to high school and middle school dances especially in the US and Canada where there have been cases of administrators attempting to ban it due to its explicit nature" (http://en.wikipedia.org/wiki/ Grinding_\%28dance\%29, accessed 21.09.2012). 
I interrupt Simon and ask him if he generally thinks that girls who go to night clubs are prostitutes, a claim I had often encountered among other of my Acholi interlocutors. He answers that many of the girls in the clubs are actually prostitutes, but not all. According to his 'analysis', there are some student girls (I think he refers mainly to university students) who just go there to have fun and dance. But there are also many girls who are working in unskilled jobs and who go to clubs to find a future husband because they think the guys there may have some money.

Simon continues with his story about Ajok. He tells me that even now that Peter has gone back to Germany she is still obsessed with him, telling everyone that she wants to marry Peter and that she had always wanted to marry a white guy. Simon just contemptuously comments that "she is aiming too high" (probably implying that a white man is of a higher economic and social class than Ajok and that Ajok should rather find a husband within her own 'class').

After we have finished our drinks, Simon says we should go and take a "snap" at the photo shop which is nearby, so that I can have a look at Ajok. We cross the road and enter the photo studio. Ajok is not there. Instead, a photographer welcomes us who seems very eager to see a white customer and tries to impress me by talking non-stop with a fake American accent, thereby completely ignoring Simon. We move to the back of the studio into a room with different wall papers. The motives include a beach setting, a palace, and a park. Before our pictures can be taken, Simon applies some white powder to his face and explains to me that he has seen people in the movies do it. Finally, we pose in front of the photo wall portraying a palm tree and a beach. The photographer keeps blabbing and when I turn to Simon to signal him that I want to leave, the photographer tells me that "this guy" (pointing to Simon) was his good friend and regular customer (later it turns out that he does not even know Simon's name). When Simon goes to pay for the snaps, the photographer looks to me and apologizes that the photos will only be ready tomorrow because, unfortunately, they do not have digital cameras yet like "in the first world".

We leave and I ask Simon what he thought about the guy's behavior. He shrugs his shoulders and tells me that the guy acted similarly around Peter and that it was even a matter of conflict between Ajok and the photographer who were competing for the attention of the white guy (field notes 10.08.2010).

Simon's story raises several interesting points. For one, it reveals how closely the behavior of "Westerners" and their interactions with Acholi are observed by the people living in Gulu (cf. Chap. 2) and how, based on these observations, moral judgments are pronounced. Hereby, the behavior of "Westerners" is judged very differently from the behavior of Acholi people and the behavior of women is judged very differently from the behavior of men. Simon's interpretation of Ajok's behavior as un-Acholi and disgraceful is especially interesting when contrasting it with the events at Herm's club I described in the former chapter. While sexist behavior of Acholi men, including interactions with women which were on the verge of sexual harassment, were tacitly tolerated and in some instances even encouraged, 'aggres- 
sive courting' of Acholi women, like in the case of Ajok, seemed to be generally regarded as unacceptable, especially when it was directed towards a white man. In this regard, it is interesting to note that not only Simon, but also Julian used the discourse to express his disapproval of Ajok's behavior as 'un-Acholi' and inappropriate.

The image of whites in connection with debates on gender and sexuality is a second aspect which Simon's story reveals and which I will discuss throughout this chapter. Many young Acholi I spoke to, both men and women, told me that they dreamed of having a white girl- or boyfriend. When I asked them why, they usually mentioned one or more of the following reasons: whites are "financially stable", they are more interesting and 'exotic', having a relationship with a white person enables the migration to a Western country, and having a relationship with a white person raises one's status in Acholi society (personal conversations and observations, cf. field notes e.g. 02.09.2009; 12.08.2010; 02.11.2010; 31.12.2010; for similar debates among Madagascan youth, see Cole, 2011). The desirability of white people as marriage or sexual partners was also reflected in dating adverts published in Ugandan newspapers where one could frequently find statements like "Man wants a white lady for love"; "African lady, 21, wants a white man, 25-35, from UK, USA, Canada and Australia for marriage" or "Chris, 28, is looking for a financially stable white lady, 19-30, for a serious relationship" (all published in Saturday Vision, August 21 $1^{\text {st }}$,2010: 29). In the dating ad from which all these quotes are taken, 22 out of 92 advertisers were specifically looking for a white partner ${ }^{187}$.

However, representations of Western/white people in the Ugandan media are not all as admiring as these advertisements would suggest. With regard to gender and sexual issues one can often also find ridiculing remarks about white people's perspectives and behaviors as the following two example show. In an article about how women can "lose that belly after giving birth", for instance, readers are advised to eat their last meal three hours before they go to bed and assured that "[ $t]$ his is not all about acting like the whites" (Omurungi, 2010). Implied in this statement is a common conviction that white people make too much fuss about their appearance and (can afford to) consider it more important than many other, more mundane aspects of life which Ugandans have to struggle with. In another article entitled "G-spot is a myth?" a young Ugandan women is quoted saying: "We see it [the G-spot] in the western magazines we read and see it being discussed in movies so that we definitely know about it". "However", the article continues, "most of them [the young women] don't fuss about it like their western counterparts" (Kalumba, 2010b). A Ugandan man in the same article is quoted as saying "This thing about women having a spot that I hear stimulates them so much called [G-spot] (sic) is a concoction from the west by the bazungu [whites]." These quotes again suggest that white people try too hard to be sophisticated and overly concerned about everything, including very ordinary and 'natural' matters like sex.

\footnotetext{
${ }^{187}$ For similar observations in other African contexts see Honwana, 2012: 96.
} 
Some articles also make fun of Ugandan's 'obsession' with white people. One article I found in the Saturday Monitor, for instance, discussed the question why black women hated white women and "went livid, bananas, and all those things upset when they saw a black man with a white woman". The columnists argued that one of the reasons might be that "while a white women has the mostly straight and soft hair, the black women has to endure hours of hours of work to her head, make sure she looks beautiful and also, hold down a proper job just so that she can leave her house and have to compete for the love, attention and affection of a black man..." (Matanda, 2010). This statement again reflects that white people are generally seen as privileged and that they are at the same time admired, envied and despised for their privileged status.

The three articles mentioned here are just random examples ${ }^{188}$ of the way gender and sexual issues in the Ugandan media are often discussed with reference to the West. The ambivalent representations of white people one can infer from these articles are also reflected in Simon's story. On the one hand, whites are admired and highly respected. This becomes evident in Ajok's behavior towards Peter, but also in the photographer's behavior towards me (trying to imitate an American accent, making reference to "first world" technology...). On the other hand, the comportment of white people is also judged critically and even contemptuously, for instance with regard to alcohol and tobacco consumption.

In the following chapter, I will analyze in more detail how Western/white people and the West are represented in local and national discourses, and how valuations of the perceived "Westernization" of Ugandan society vary depending on the context, speaker and subject of debate. First, I will look at discourses on Westernization in the context of aid dependency, NGO intervention and generational change.

\subsection{Discourses on Westernization in the Context of Aid, Modernization \& Generational Change}

Over recent decades, Uganda has experienced wide-ranging changes in the political, economic, cultural and social spheres. Since President Museveni came to power in 1986, these changes have been heavily influenced by Western state and development actors. The Museveni government has willingly succumbed to foreign policy interventions and accepted structural adjustment measures in order to receive large amounts of international development aid (Ndikumana \& Nannyonjo, 2007). Throughout the 1990s and 2000s, Uganda's relationship with its Western donors remained quite favorable as the Museveni government continued to take up prominent development trends and discourses, e.g. on liberal economic reforms,

${ }^{188}$ Throughout my research stay I read and collected numerous newspaper articles on gender issues and particularly gender issues which were discussed with references to "Westerners". 
education, women's and children's rights (cf. Cheney, 2007; Vorhölter, 2010b). Until today, development partners finance a large percentage (at least 25 percent) of the Ugandan national budget (Tabaire \& Okao, 2010: 6; Branch, 2012: 85). Furthermore, the high presence of Western aid workers - in all parts of the country and in Northern Uganda in particular - and the expansion of the mass media have influenced the dreams and expectations of Ugandans and led to a change in consumer trends and popular culture (cf. Chap. 5). Whereas the Ugandan elites profited from these developments, poverty remained widespread, especially in rural areas and in the North (Ndikumana \& Nannyonjo, 2007: 21f.; Shaw \& Mbabazi, 2008), and levels of social inequality rose.

The wide-ranging processes of socio-cultural change have created feelings of uncertainty and ambivalence among large sections of the population, not only in Northern Uganda (as discussed in the previous chapters) but in all parts of the country (cf. for instance Karlström, 2004, on Buganda; Whyte \& Whyte, 2004, on Eastern Uganda; Wiegratz, 2010, on Uganda generally) ${ }^{189}$. There are frequent discussions whether the rate of change is too fast and whether it is actually for the better or the worse. Elderly people, in particular, fear that their "traditional culture" is "getting lost" and that the young generation is being confused and destabilized by the lures of "Western modernity" (cf. Chap. 4).

However, not all values and products which are perceived as Western are also perceived as negative. On the contrary, some are very much desired. Neither can the debates about positive and negative impacts of Western-induced change be framed purely in generational terms. Socio-cultural change is a very complex phenomenon, and positions regarding its desirability and extent depend on a number of factors: age, gender, educational background, class, setting (urban or rural), as well as changing circumstances and situations (cf. Chap. 5).

As the previous chapter has shown, many of my younger respondents in Gulu expressed a desire and a need for change. They felt unsatisfied with their current situation, and many believed that the adoption of "Western" models could help Uganda to become "modern" and "progressive". Despite some improvements since the end of the war, the majority of the population still suffered from poverty, high unemployment rates and limited access to quality education (Branch, 2008; Whyte et al., 2012; Spitzer \& Twikirize, 2013; Webster, 2013). Daily realities contrasted starkly with images of a modern, Western life presented in the media - of wealth, prosperity, consumer culture and individual freedom - which young people hoped to achieve.

However, despite the hopes of economic development and a liberalization of society which Acholi youth, in particular, connected with the idea of Westernization, they also had doubts and fears of its potentially destructive effects (cf. Chap. 5). It

189 This is also reflected, for instance, in advice or counseling sections on issues such as relationships, health, lifestyle etc. in the Ugandan daily newspapers Daily Monitor and New Vision, where readers discuss issues and problems of concern to them. 
often seemed to me that my interlocutors wanted to have the economic benefits they associated with Western modernity. A common view was that people in the West are rich and live 'easy lives' due to their technical and economic advancement (cf. Ciaffa, 2008: 122 for a description of a similar perspective in "African philosophy"). However, most were very critical of adopting the 'Western model' in social terms. Many people I talked to and interacted with in Gulu seemed to believe that Western society was materialistic, individualistic and "immoral" - characteristics which are somehow linked to Western capitalism and economic success, although this was not always explicitly reflected by my interlocutors. One of my friends and regular interlocutors, Fred, for instance, often complained to me about the "Westerners" in Gulu who he saw as somehow representative for Western people as a whole. He used to tease me by claiming that "Western people", especially those from the aid community, all kept to themselves, only interacted with Ugandans when they needed them for their work or research, lived an excessive lifestyle, were arrogant and egoistic and so on. But he also remarked that many "westernized Ugandans", primarily those from the upper class and many youths, had started to adopt similar attitudes (cf. e.g. field notes 14.03.2010; 27.03.2010; 04.04.2010; 18.06.2010).

Especially elderly people often expressed a feeling of despair at the socio-cultural changes which, according to them, were happening as a consequence of adopting "Western culture", and many saw the only solution to contemporary problems in going back to their often idealized "traditional culture" (cf. Chap. 4). The ongoing debates that I witnessed in Gulu between youth and elders about the extent to which Acholi society had become "westernized and modernized" reflect generational conflicts about societal ideals and future expectations, including a fear by elders to lose the control they originally had in society, which was based on principles of seniority. The following quotations were typical expressions I encountered when talking to elderly people:

"Youths today are very lazy, idle and disorderly. They are confused, they don't know what to do, they don't know what is the right way anymore, they are so full of confusion. Maybe that is also because they don't know how to combine human rights with their culture. Today, many children don't listen to parents anymore; when they are given some advice, they say 'I have my own rights, leave me alone'. That is making youths to be so unstable today because they don't have proper guidance" (male elder, group interview Kapedopong 28.06.2010, translated from the Acholi original by Kenneth Oyet Odong).

"Respect is the biggest problem. The young people today are following the Western culture, whereby boys are wearing earrings and pulling their pants down. When the elders talk to them, they say 'ah, for you, you are local'” (male elder, group interview Paicho, 17.10.2010, translated from the Acholi original by John Omara). 
The derogatory use of the word "local", referred to in the second quote, reflects an internalized view of a widespread hierarchization between global (equals modern) and local (equals traditional). Describing an elder as "local" could imply that he does not have formal education, cannot speak English, or does not know about recent consumer trends and developments. These aspects were frequently discussed in the interviews I conducted with mixed groups of elders and youth. However, as also discussed in the previous chapter, not only elders but also young people sometimes idealized the past and were desperate for more structure and elderly guidance in their lives.

Interestingly, while both groups - those who embraced 'Western modernity' and those who rejected it - felt somewhat determined by and experienced confusion as a result of the recent processes of socio-cultural change, most of the people I interacted with did not explicitly blame the West for enforcing its concepts, norms and ways of life. Although this "neocolonialism discourse" was also present in Northern Uganda (I sometimes encountered it among university students and among local political and/or economically powerful 'elites', cf. Chap. 5), it rarely came up in my daily conversations about socio-cultural change.

Due to my own critical standpoint on the Western aid regime and due to the post-colonial discourses I knew from the literature, I had expected people to be explicitly critical of these interventions. What I found, however, was that most of my interlocutors actually appreciated the humanitarian intervention in Northern Uganda. In interviews, I often asked my respondents to evaluate the work of foreign aid organizations in Northern Uganda and typically received answers like the following:

"Quite a number of them did very credible work. Actually, minus [without] their intervention, there would be a big problem here, a catastrophe in the North" (INT Vincent Ochieng, 26.03.2010).

"They [the NGOs] have done their best, always, and they are still doing their best. There was a need for them to come! (...) We also see that, there are organizations that will still exist, because there is a need (...) I know that the long term goal is to have them [the people] sustain themselves, but I know there is a time for everything. So I know, eventually projects will be phased out, but when they are phased out people should be left standing on their feet, not in limbo, pull-out just like that" (INT Faith, 18.03.2010).

"I should say, many positive things came from the interventions that humanitarian aid workers came with: human rights trainings, GBV trainings, all of this health and hygiene, water and sanitation. I can tell you that back then, in those villages 20 years ago, there existed no pit latrines, people just simply squatted somewhere and depended on nature to clean up the environment. But today you go back and you'll find there is a pit latrine for each 
home. They are conscious about their health. (...) I think that demonstrates that people have learned things" (INT Rocki, 16.03.2010).

Like these interviewees, most of my interlocutors stressed that the aid intervention had been necessary to support the people in Northern Uganda during the war and that aid was still needed today because people were still recovering from the war and adapting to the post-war situation. Of course, debates on aid dependency, the non-sustainability of development projects, and the unequal distribution of 'development benefits' were also widespread and my interlocutors often complained about the marginalized position of Uganda and the privileged position of the West ${ }^{190}$. All in all, however, and to my own surprise, the dominant discourse was not very critical towards the West. There could be different reasons for this: for one, the interviewer effect', i.e. me being a "Westerner". This, however, should have abated after some months of regular interactions, at least to some extent. A second reason could be that because of the war, the subsequent high levels of poverty, and the inability or unwillingness of the Ugandan government to help, most people in Northern Uganda felt dependent on interventions by the West. Most importantly, however, I argue that in the current post-war phase the dominant discourse revolved around 'rebuilding' Acholi society and was thus internally-oriented. Obviously, Western actors were a part of this 'rebuilding process', therefore debates about the introduction of "Western" values, norms, consumer goods etc. often came up. But rather than criticizing the West, my interlocutors blamed fellow Ugandans for trying too hard to imitate the "Western" lifestyle and values which they considered not or not yet suitable for Acholi society.

When discussing the impact of humanitarian NGOs in Gulu, for example, my interlocutors often emphasized that the NGOs brought new concepts (like human

190 The following quotation by one of my interviewees reflects these sentiments: "Too many organization and too many donors is not actually a good thing for the people in Gulu. What I think (...) and what I envision is to help people to have a sustainable program. Other than being behind them like a backbone all the time - so that if you pull out, the wall will collapse - the people who are here should actually be working on sustainable program that will make them develop their ability to reject funds. These organizations, I just have to mention it, most of them are money-minded, they are creating employment for the few who have studied. Corruption is another aspect, instead of targeting the very beneficiaries, when the money comes they have to think of themselves first (...). I feel there is too much being funded in Gulu, they need to reduce it and focus on sustainability, make a program that will make people learn that I have to work for something and get it, other than receiving it every time. (...) People want to eat and receive it [the food], but they don't want to do the work. What I want to say, people don't like work, they don't want to work, but they want to be ok. A lot [of humanitarian work] has been done in Gulu and that is the thing that is misleading them. It can be reduced. If people will be told they have to work hard for this, there will be a lot of transformation" (INT Ojara, 17.03.2010). In this quotation, the respondent criticizes the aid organizations for creating dependency, being "moneyminded" and corrupt, but at the same time he also blames the people in Gulu, who "do not want to work" and do not take matters into their own hands. 
rights) which in principle were very good. But then they went on to say, that because local people did not know how to use them properly, these new concepts were causing more harm than good, which is also expressed in one of the quotations above ("Maybe that is also because they don't know how to combine human rights with their culture"). Westernization does therefore not necessarily mean a process which is initiated from the outside, as the term might suggest, but rather something which is actively enacted by Ugandans. This is also evident in the following quotation:

"There are some people that are too modern, they are too westernized. You know, we here just try to imitate the Western culture, but we could not really do it .... We call it half-baked: sometimes you pretend to be Western, but it will not fit you well” (INT Henry, 27.04.2010).

Statements like these, which I commonly encountered, suggest that the discourse on Westernization is not about blaming former colonial powers and other Western states for the current processes of change. Rather, it is a discourse directed at the Acholi/Ugandan population, and represents a debate about which norms, values and practices should prevail and whether it is desirable to imitate a "Western" lifestyle. In using the term "Western" as a kind of benchmark, in both, a positive and negative sense, Acholi people are trying to come to terms with their own society. My interlocutors in Gulu seemed to have a stereotypical imagination of Western society, which was used as an external reference point. In discussing the desirability and undesirability of imitating this stereotypical Western society, they were negotiating what they considered desirable for their own society. In this sense, debates about the Westernization of society represent a form of internal social critique. Images of an ideal society are debated by comparing (an imagined) Acholi society to an imagined other.

Some people also strategically used the label "Western" to 'brand' certain norms and practices as foreign and therefore unacceptable, which they felt interfered with their personal affairs. They claimed to reject these 'foreign norms' on the basis that they were "Western" and legitimated their own behavior by claiming it was a "cultural practice". I sometimes encountered this line of arguing in discussions on gender roles and norms and the way they were currently changing. The following is a quotation from an interview with an Acholi man in his early 30s, who was working for an American organization as a "Capacity Building Manager" on issues related to Gender Based Violence (GBV). I asked him whether in his work he sometimes encountered people who blamed Western organizations for enforcing rights discourses and interfering with their lives, and he replied:

"GBV is a sensitive issue, not only here, I think in Germany, everywhere it is a sensitive issue, sensitive in a sense that people want to get the excuse to do the wrong things. It is also because of the power dynamics, people want to demonstrate their power and use it in some way or other. So when we question it - 'why do you act like this?' - then someone says: 'culturally this 
woman is supposed to be doing this.... You know, so they demonstrate that they still have to be in charge. (...) There are many who say it [gender equality] is a Western thing, but again you can ask: 'How many Western things are you using - from your dressing, to the phone, to your car, to English, everything'. I do not anymore know the boundaries between East and West, it just doesn't exist, it is a global village, and this problem affects everyone. (...) The fact is that bad is bad, rape is rape, if Western or not Western: rape is rape, and so there is no Western-Eastern attribution to it. For me, it is a phenomenal problem that has to be dealt with" (INT Rocki, 16.03.2010).

The quotation reveals that at the centre of the debates about Westernization are power differences and conflicts within Acholi society: between men and women, young and old, rich and poor, urban and rural populations, who all have very different imaginations of the ideal society. The critical question then is not how far Western actors are enforcing certain concepts on Acholi/Ugandan society, although this remains an important issue, but how Acholi and other Ugandans are trying to negotiate critical issues such as norms, values and practical developments which affect their everyday lives. Although many of these are shaped and influenced by trends and actors from the West, the discourse is less about processes of intervention as such, but about the contents of 'Western models' and the consequences of adopting them.

Furthermore, local discourses and negotiation processes on social norms can be regarded as expressions of agency, which reflect local appropriations of concepts that are labeled "Western". Whether a "Western" concept is adopted and becomes a social norm is not, as is often suggested, something which can be steered from the outside, but rather something which reflects positionalities and power differences within Ugandan society, based on age, gender or class. But although older, wealthier, urban-based men probably have more impact than for instance young, poorer, rural-based girls in imposing new policies and related norms and practices, power relations are neither fixed nor all-encompassing, and agency can be exercised even by the least powerful (cf. Ortner, 1997) ${ }^{191}$. A good example are debates about children's rights, also referred to in one of the quotations above. Elders and parents repeatedly complained to me that children were nowadays always talking about their rights, particularly their rights to education and leisure time. They complained that children rebelled if parents could not pay their school fees or when they were asked to work on the fields or in the household (cf. e.g. INT Okello, 26.09.2010). In contrast, children and youth I spoke to questioned former, more authoritarian educational methods and some scorned their parents for being "backward" due to

${ }^{191}$ As outlined in the introduction, Ortner's concept of agency is concerned with the mediation between conscious intentions and actions of the individual and the structures he/she is embedded in and which influence the individual's actions and intentions (Ortner, 2001: 77). Ortner argues that agency is a form of power which can be used by the powerful, but also by the seemingly powerless in order to keep up the status quo or to invoke changes. 
their lack of knowledge of "modern" rights discourses (personal conversation cf. field notes 09.03./13.03.2010). These debates reveal that children, who are generally seen as the least powerful members of society, actively use the discourses on children's rights to challenge established hierarchies and ideologies. Thus, although elites might have some influence in introducing certain measures such as neoliberal reforms, their influence is not as all-encompassing as authors like Wiegratz (2010, see above) suggest.

Here, it is helpful to employ a Foucauldian notion of power (cf. Chap. 1). Power produces social realities, but it is not 'possessed' only by dominant elites. Rather, it consists of a multiplicity of force relations and points of resistance, which together constitute an overall strategy or system of power, often with unintentional outcomes (Foucault, 1990: 93ff.). Different studies (e.g. Adogame et al., 2008a; Appadurai, 1996; Ferguson, 1990; Loimeier et al., 2005a; Rottenburg, 2002) have shown that the outcomes of development interventions, globalization, modernization and Westernization processes are often unintentional, and neither homogenizing nor teleological (Adogame et al., 2008b: 4). On the contrary, through the encounter with the "new" - through both, active appropriation and passive alienation - boundaries can be redrawn and identities recreated (ibid.: 13). Thus, foreign influences as well as changing norms and practices are negotiated at all levels of society, and although policies adopted and promoted by elites have far-reaching consequences for the rest of Acholi and Ugandan society, as the example of neoliberal reforms shows, their influence is not all-encompassing.

The next section emphasizes some of these points by analyzing common narratives about Westernization in Acholi discourses on gender, kinship and sexuality. Here, social norms and practices are particularly contested. I discuss common points of debate among my interlocutors in Gulu, and show how the perceived Westernization of gender, kinship and sexual relations manifests itself in a struggle between the older and younger generations, as well as between men and women.

\subsection{Discourses on Westernization in Relation to Gender, Kinship \& Sexual Relations}

In this section, I analyze Westernization discourses on matters related to gender, kinship and sexuality. The introductory extract from my field notes and the quotations from newspaper articles already hinted at the fact that references to "Westerners" and "the West" frequently come up in these discourses and constitute a significant point of comparison. Current popular discourses on gender, kinship and sexuality in Uganda and the reasons why the West figures so prominently in these discourses must be seen against the backdrop of historical developments and long-ranging popular and scholarly debates, which have discursively established the idea a) that there are significant differences between 'African' and 'Western' gen- 
der, kinship and sexual relations and b) that 'African' gender and kinship system have undergone drastic changes since colonial times, which have been significantly influenced by the West (cf. introduction). In order to contextualize contemporary Acholi/Ugandan discourses, I will briefly point out how the West is seen to have influenced gender, kinship and sexual relations and discourses in the colonial and postcolonial period in Uganda.

As already pointed out in chapter 4, Christian missionaries and the British colonial administrators are believed to have influenced gender relations and gender discourses among the Acholi and in Uganda more generally - through the introduction of Christianity and the moral discourses related to it, through the establishment of Western schools, through taxation and subsequent changes in the labour organization, and by challenging established hierarchies and forms of organization within communities (Schäfer, 2008: 332; Girling, 1960: 174-195; Dolan, 2002: 63f. and El-Bushra \& Sahl, 2005: 14ff.).

In the postcolonial period, specifically since Museveni came to power in 1986, Uganda has received exceptionally high levels of multilateral and bilateral development aid and, subjected to aid conditionality, was among the countries worldwide which most readily accepted structural adjustment programs and also took on Western rights discourses, especially regarding women's and children's rights (cf. Cheney, 2007: 42ff.) ${ }^{192}$. Since the late 1980s, international, mainly Western NGOs and the Ugandan government have started campaigns and programs to promote women's rights and gender equality which are seen to have 'reshaped' gender relations in Uganda (Wyrod, 2008). Furthermore, due to the high chance of gaining access to international funding, several Ugandan NGOs were founded, which claimed to support women's rights and raise awareness of gender issues (Tripp, 2000: 117ff.), but which remained "in many ways beholden (...) to donors" (Tamale, 2009: 67).

Throughout the 1980s and 90s and up until today, Uganda has been hit, both by armed conflict ${ }^{193}$ and the HIV/AIDS pandemic, which not only affected gender and family relations, but again provoked large-scale interventions by Western humanitarian and development actors along with their crisis-related gender discourses (see for instance the "Development - Gender" publications by BRIDGE ${ }^{194}$ : Marcus, 1993 \& El Jack, 2003).

${ }^{192}$ The supposed interlinkages between gender issues and economic growth, presumed by Western development institutions, become apparent in the following quotation from a World Bank report, which states that "Uganda is a leader in Sub-Saharan Africa in recognizing linkages between economic growth and gender issues. These linkages are critical for achieving a variety of development goals" (Ellis et al., 2006: 1).

193 Two recent studies, Dolan (2002) and El-Bushra \& Sahl (2005), document the impact of the armed conflict in Northern Uganda on Acholi gender relations. For a general overview of the linkages between gender, conflict and development see the influential volumes by Afshar \& Eade (2004) and Manzurana et al. (2005).

${ }^{194}$ According to the information provided in the two reports cited above "BRIDGE was set up in 1992 as a specialized gender and development research and information service within the Institute of Development Studies (IDS), UK. BRIDGE supports gender mainstreaming efforts of 
Recently, as has been repeatedly pointed out throughout this book, Ugandan youth, in particular, have become increasingly exposed to Western media and attentively watch (and sometimes copy) the attitudes and behaviors transmitted in films, TV shows and magazines (see e.g. Parikh, 2005).

In summary, one can state that for a long time gender discourses and debates in Uganda have been accompanied and influenced by Western discourses and the dichotomies they have created between Africa and the West. As the following analysis shows, this is reflected in the way Ugandan people talk about gender issues and in their frequent references to the West - as a major source of authority (for instance regarding topics such as gender equality) and as a point of comparison against which Acholi, Ugandan and African ${ }^{195}$ gender ideologies are discussed.

\subsection{1. 'Western Models' as Threats?}

As already discussed above, Ugandan people's deliberations on 'Western models' are complex and contested. This is particularly noticeable in the field of gender, kinship and sexuality. When discussing these issues with my interlocutors in Gulu, they often claimed that gender roles and norms, dating and marriage customs and sexual practices had been "westernized". They related this to a variety of causes, most prominently media influences, the promotion of women rights, and also the insurgency (cf. Chap. 4). Again, it was evident that references to Western influences were used to convey both positive and negative implications of these changes, the interpretation of which depended on the positionality of the speaker, as I will show below.

The positive aspects mentioned usually included: 1) more equality between the sexes and more chances for women (e.g. access to education and jobs and therefore greater economic and financial independence); 2) the decline of 'harmful cultural practices' (such as wife inheritance, which was most commonly mentioned, but also the reduction of polygyny, early or forced marriages); and 3) more personal freedom in relationships (e.g. to choose a partner, have more sexual liberties, and pursue the ideal of romantic love, cf. Cole \& Thomas, 2009).

The positive aspects of changing gender roles are mentioned in the following interview extract (INT Ojara, 17.03.2010):

Ojara: "Culturally it [gender differences regarding jobs] used to exist, but we are trying to change that. For example in the fabrication section with all those difficult technical aspects, (...) traditionally those jobs were for men. But now, when they come [for career guidance],

policy-makers and practitioners by bridging the gaps between theory, policy and practice with accessible and diverse gender information."

195 Interestingly, I found that in these debates similarities between Africans are often emphasized, and related to an "African identity" in addition to ethnic and national identities. "African" as opposed to "Western" values are thus conceived in extremely essentialist terms. 
a lady might choose to go for tailoring. Then we counsel them, we say: 'How many tailors do we need in Uganda? What will be the benefit? You are like a man, you are an ordinary human being, you can do what a man does'. So after talking to them, we saw a lot of the women diverting to other sections like building, welding and fabrication. At the moment there are about three welding workshops being run by ladies."

J.V.: "Is there opposition by the community?"

Ojara: "No, they have not been opposing that. They used to think that it is not good, but poverty is streamlining people. When you don't allow a girl to do that, you deny a lot of opportunity. A situation might come that you don't have a boy, you may have only ladies, so if you don't allow them to do those jobs you will remain in a desperate situation. (...) That's why there are ladies going for driving, going for engineering... So equality and the gender thing is already being practiced to the maximum. (...) I believe they [the community] have understood the value of gender equality."

In this extract, we find that gender equality is connected to the idea of economic development and, implicitly, the idea of being somehow progressive. The idea of modernity is linked to fulfilling ideals which have been promoted by the West. Although in this quotation the West is not explicitly mentioned, gender equality is generally understood and frequently referred to as a "Western" concept. An Acholi elder once mentioned to me in an interview that the notion of "gender balance" had existed and was practiced in pre-colonial Acholi society, but that gender equality as a political concept was recently introduced and is nowadays commonly referred to as a "Western" idea (INT Okello, 26.09.2010). In the above quotation, as in the other examples cited above, the West is not explicitly blamed for enforcing its concepts. Rather, economic arguments, i.e. gender equality is good for economic security and advancement and necessary in the context of post-war reconstruction in Gulu, seem to have convinced the Acholi population of the need to change according to "Western" principles. The respondent states that "poverty is streamlining people", implying that changes in gender roles have become a necessity, but were originally not desired ("they used to think that it is not good"). This implies skepticism towards changes in gender norms and relations, which, however, have become reluctantly accepted due to the economic crisis.

Generally, more often than being completely accepted and supported, developments related to women's emancipation and changes in gender roles were viewed quite ambiguously among my interlocutors. The following example is an extract from an interview with a Ugandan woman who was working in a project aimed at reducing sexual and gender-based violence (SGBV) in the Acholi sub-region. The 
project was supported by the Acholi cultural institution Ker Kwaro Acholi and focused on the need "to modify or update some of the cultural practices that do not promote women's human rights in Acholi land (sic)" (Ker Kwaro Acholi, 2010a: 2). In the interview, she explained the ambiguous effects of changing gender relations in Northern Uganda, which she attributed to "the conflict and Western culture":

"In this generation now, there is gender equality, women can make their own decisions, things have generally changed. Formerly, there were culturalbased-practices which were discriminating against girls and which are slowly changing today. But not all cultural-based-practices were bad; some were also good which have been destroyed. ... There are definitely both - good and bad things [being imported from the West]. On the positive side: women's empowerment, valuing of women, equal rights for the girl child, and education. On the negative side: violence - in the movies, also the vulgar language which is taken up by some people (and it is worse if it is taken up by women); defilement; and also emancipation because it has gone out of proportion and has led to a loss of respect, especially in marriages, and thus also causes violence. The changes have come too fast and people couldn't adapt properly" (INT SK, 23.03.2010).

The ambiguity expressed in this quotation is notable: changes in gender norms are not necessarily negative, but have "come too fast" and have "gone out of proportion". The respondent stresses that not all "cultural-based practices were bad", as might be inferred from Western discourses on gender equality, but they were "destroyed". She does not say why or how. Overall, the most common negative aspects of 'new' concepts such as gender equality and women's rights mentioned during my research were increased conflict and violence between men and women, a rise in 'immoral' or inappropriate behavior, a decline in social courtesy, and resultant instability in the community and society as a whole (cf. Chap. 4). I analyze these factors in more detail below.

My data reveal that debates about gender, kinship and sexuality are more emotive and fought along more essentialist lines than other discourses on Westernization and socio-cultural change. One explanation may be that these are crucial factors in social reproduction and, in the long run, societal survival. According to my findings, most of the concerns voiced in Ugandan discourses about changes in gender, kinship and sexuality matters can be related to three fundamental threats which are, implicitly or explicitly, feared by the speakers: 1) a threat to the family and kinship system; 2) a threat to the moral integrity of society; and 3) a threat to established gender orders. All three are closely interrelated and by no means specific to the Ugandan case, but have been analyzed with regard to other societies in the "late age of modernity" (cf. Giddens, 1991). In discussions about these threatening aspects of Westernization and modernity, my interlocutors often contrasted "traditional" Acholi/Ugandan/African society with an imagined "modern" and "Western" other. By looking at three typical narratives, I show how these binary oppositions are used 


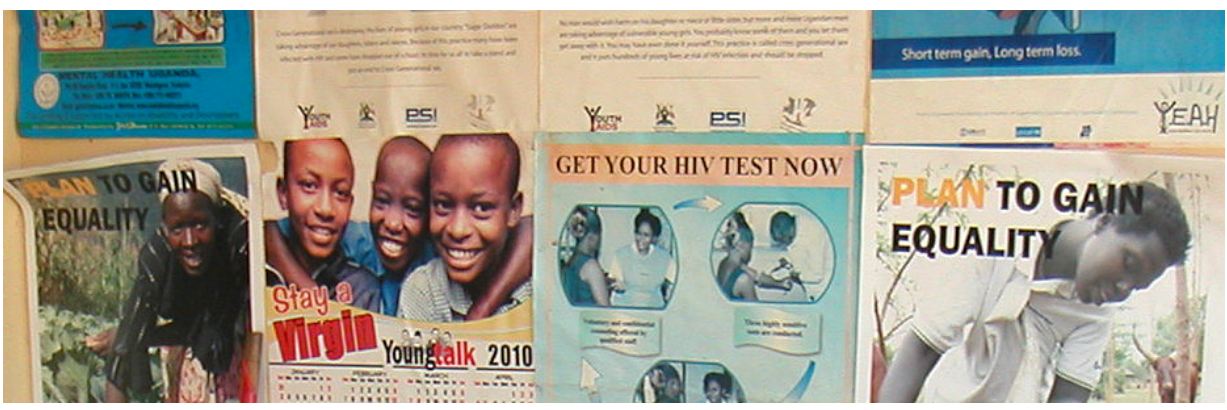

Illustration 3: Posters at the registration desk, Gulu Youth Centre (photo by author)

to negotiate generational and gender-based conflicts in Acholi society. I thus illustrate my argument that discourses on Westernization, rather than providing an externally-oriented criticism of the West, are internally-oriented and reflect different evaluations and interpretations of socio-cultural change in which the West figures as a benchmark.

\section{Narrative 1: Westernization as Threat to the African Family and Kinship Model}

Changing family and kinship relations were a common topic among my interlocutors, and were often discussed by using the above-noted binary oppositions. According to a widespread narrative (cf. Chap. 4), in "traditional African society", marriage served to create bonds between different clans or lineages, and was not primarily seen as a relationship between two individuals. Nuclear families were incorporated, supported and controlled by a huge network of relatives. Extended families usually co-resided and/or collaborated to guarantee subsistence. Relationships between proximate generations were reciprocal, i.e. children took care of their parents in old age. Descent was clearly regulated by patrilineality. Most importantly, African society was seen to be based on solidarity and communality, as was repeatedly and emphatically conveyed to me (e.g. field notes 17.03./28.04./05.05.2010).

In contrast, "Western society" was described as being individualistic, materialistic and unappreciative of communal values. My interlocutors claimed that these characteristics, which they saw as jeopardizing and undermining the stability of the "traditional" system of social relations, were now finding their way into Ugandan society through the "modern and westernized" young people. The latter were accused of finding their marriage/sexual partners without consulting their parents and kin, moving away from the villages and trying to distance themselves from the large kinship network and the obligations that come attached to it. As a consequence of individualization and selfishness, "these young people" were no longer committed to their marriages and families, and just left to do their own thing as soon as problems came up. Therefore, divorces, which had formerly been very rare, were increasing and early, extra-marital and/or multiple relationships were becoming more common 
(e.g. field notes 04.09./10.09./02.12.2010). In an article entitled "Why marriages break up", the author argues in a similar fashion to my interlocutors:

"[M]any young couples are facing (...) predicament. Either their marriages are slowly rotting such that they are literally living separate lives, or the divorce papers are already signed. But why are young marriages faltering? (...) Moral decadence is part of the trouble. A man is being driven in one of those Benzes to his wedding and yet he is busy texting his many exes as to when they will meet when the honey moon is out of the way! A young married woman wanting to climb that corporate ladder will with no qualms lift her skirt to whoever matters in her quest to get that job. We are that immoral! The moral values in our society went bust a long time ago. Money is the other reason. (...) Personally I think the lack of sacrifice in many couples is the culprit for many of the break-ups. (...) Our parents' marriages faced some serious hardships, right from their design, where women had zero rights to the structure that clearly had men as the sole bread winners. But despite the complications, which at the time required the intervention of the local church at the village to get the marriage on track, the marriage somehow survived. It could have been abusive and ugly but to this day after 50 years of such marriage, they are still together..." (Kalumba, 2010a).

Like the author, many of my interlocutors also related changes in African family and kinship systems and the rise in uncontrolled sexual behavior among youth to "moral decadence" and greed for individual (economic and social) benefits. Young women, in particular, were accused of being prostitutes (like Ajok in Simon's story discussed above).

Prostitution is a very strong image, which stands for society's loss of control over women's sexuality and fertility (Arnfred, 2004a: 16), and which is evoked in many contexts, past and present, in Uganda and other (African) countries - also, for instance, to legitimate repressive laws (see below). Promiscuous sexual relationships of women are seen to pose a threat to patrilineal descent systems and societies that are closely interconnected through affinal ties. In present day Uganda, prostitution and similar phenomena such as "transactional sex" entail risks which are even more concrete and whose impacts are experienced on a day to day basis: HIV/AIDS, abortion, and family break-up. From a women's perspective, the decision to have more than one sexual partner or to abort might be regarded as expression of agency and in some contexts even as intentional strategy in the sense that women are consciously taking control of their own sexuality, fertility and economic situation (cf. Honwana, 2012: 103f.; Sadgrove, 2007; Mills \& Ssewakiryanga, 2004). In the dominant societal discourse, however, such practices are seen as posing a serious challenge to established gender orders (see below).

"Transactional sex" was a frequent topic of debate among the young people I worked with in Gulu. Although cases of young men sleeping with older women were sometimes mentioned, it was usually young girls, who were accused of sleep- 
ing with older men for money and material wealth (personal conversations, cf. field notes e.g. 02.01.2011; 10.01.2011). In the weekly 'educational discussions' with young people at Gulu Youth Centre, "something for something love", "transactional or cross-generational sex" and their consequences such as HIV/AIDS and unwanted pregnancies were common topics of debates (e.g. field notes 11.05.2010; 26.08.2010; 14.09.2010). In one session, in which the question "Is poverty the main cause of unwanted pregnancy?" was debated, a university student argued that not poverty but the "materialism of girls" was the main reason for unwanted pregnancy. He continued by saying that pornography and the "influence of Western videos where girls wear miniskirts and do many immoral things which the girls here then want to imitate" encouraged Ugandan girls to behave like prostitutes (field notes 02.11.2010; my interpretation of exact wording).

In this sense, the perceived increase in women's sexual freedom was also postulated as a sign of and a reason for the "moral degeneration" of Acholi society discussed in the following.

\section{Narrative 2: Westernization as Threat to the Moral Integrity of African Society}

According to this narrative, moral correctness and integrity were particular 'cultural strengths' of "traditional African societies”. Respect (particularly of age and gender based hierarchies) was often mentioned by my interlocutors as the single most important principle regulating every aspect of social life. Other important rules they pointed out concerned proper conduct in public life, for example decent dressing, or no showing of (sexual) affections.

In contrast, "Western society" was seen as decadent and "morally degenerated", as could apparently be 'witnessed' in Western movies, popular culture and the behavior of "Westerners" (expatriates and tourists) in Uganda. Many respondents criticized the desire of Ugandan youth to imitate "Western culture", and interpreted the changes in gendered and sexual behavior as a sign of insetting "moral degeneration" of Ugandan society. The often used image of indecency and moral decay was the miniskirt (which I already referred to in the introduction) ${ }^{196}$, as reflected in this quotation by a male university student at a public debate (cf. field notes 24.11.2010):

"You see someone putting on a miniskirt in the village there and so disgrace our culture. Honestly, we have lost our conduct, our cultural behaviour has

${ }^{196}$ In the Ugandan daily newspaper Daily Monitor I often found articles which reinforced my interpretation that the miniskirt was one of the emblems of indecency and Western-induced moral decay. One article (“Kitgum - Mini-skirts banned”, 23.03 .2010 (N.N., 2010a)), for instance, discussed how miniskirts had been banned in a Kitgum village in order to counteract the increase in rape cases. In another ("Fort Portal NGO roots for dress code", 01.01.2011 (N.N., 2011b)), I read about a local NGO in Fort Portal, which had started to train girls between the ages of five and 18 how to dress appropriately. Recently, in the context of the debate on the proposed "Anti-Pornography Bill" (see below), Ugandans were even discussing whether women who wear miniskirts in public should be punished by law. 
really been lost.... When we leave this town and go to the village, we shall really be so much discriminated, because we differ so much from those people in the village. ... They will begin comparing us to people who come from outside... because of the way we conduct ourselves" (Audio record - Debate, 24.11.2010). ${ }^{197}$

This statement reveals that 'foreign' dressing styles were taken to be particularly obvious indications of a 'Western infestation' of urban Ugandan society. Girls and young women were commonly accused of wearing or wanting to wear miniskirts. In a similar vein, boys and young men were blamed for wearing their pants low ('baggy style') and trying to look like US-American 'gangsta rappers'. Other typical examples of "moral degeneration", some of which I have already mentioned, included: children and youths have lost respect for their elders - they are rude, do not listen to advice anymore, do not help their parents and grandparents at home, and are too money-minded. Women have lost respect for their husbands and male relatives - they refuse to fulfill their roles in the household, quarrel all the time, and are also too much money-minded. The descriptions of such 'misbehavior' reveal that especially older people and men who felt (relatively) disempowered feared that fundamental social values were jeopardized which, according to them, had formerly served to create stability in the society.

The fear of a moral degeneration of society as well as the previously discussed fears of a "Westernization" of African kinship and family systems can be related to a third threat: the breakdown of gendered orders in Acholi society.

\section{Narrative 3: Westernization as Threat to African Gender Orders}

In Ugandan media discourses as well as in conversations among my interlocutors, normative expectations of how men and women should ideally behave in Acholi society were distinguished from "Western" gender images, particularly regarding women. According to the narrative, in "traditional" African society, gender relations were marked by clearly differentiated, complementary roles and related gender and age-based hierarchies, which were perceived as very different from "Western" notions of gender equality. However, in contrast to common Western (feminist and development) discourses on African gender relations, most elders, male and female, I talked to did not think that these former social structures were discriminatory or 'gender-unequal'. Okello once explained to me: “This gender balance necessity is just being brought like that [but] the original respect was there, it was just natural,

197 The quotation is from a public debate at Gulu University which I already referred to in the previous chapter. In this debate, students from the debate club and the audience discussed the motion "This House resolves that Culture is being lost among the Youth". Although the positions taken by the teams in the debate and the statements given by the speakers do not necessarily correspond to their personal opinions on the matter discussed and are often exaggerated, they nevertheless reflect popular discourses and common opinions. 
there was no question about it, you know this is for a woman, this is for a man" (INT 26.09.2010).

The typical "traditional" African woman was depicted as a caring, loving 'mother' who respects her husband and in-laws and behaves according to culturally-defined gender rules. This image was sometimes contrasted with the typical white woman who is not married to her sexual partner, does not have children, dresses and behaves inappropriately in public, and does not show respect for gender-based hierarchies. The 'traditional African mother' was also contrasted to the young generation of Ugandan girls who no longer stick to established norms, dress codes and behaviors expected of women (e.g. field notes 07.03./13.08./10.09./30.10./02.11./28.11./20. \&21.12.2010; cf. also Kalumba, 2010c).

The typical African man was commonly portrayed as a well-respected protector and provider of his, ideally polygamous, family. This image was contrasted with the irresponsible young generation of Ugandan men, who have multiple sexual relationships and father many children without being able to properly marry the women and provide for their families ${ }^{198}$. This selfish and irresponsible behavior was seen as consequence of youth's desire for a "Western", urban, hedonistic lifestyle, and as a refusal to work hard on the fields as their parents had done. Most of my interlocutors, however, also referred to underlying social dynamics such as poverty, unemployment and the subsequent inability of young men to acquire the brideprice necessary to get married properly or to provide for a family.

Despite wide-ranging changes in Acholi society, images of gender roles and hierarchies have remained quite stable (Dolan, 2002). However, a growing number of men and women can no longer live up to these expected norms. In the literature on masculinities (e.g. Cleaver, 2002; Huisman, 2011; Silberschmidt, 2004), this has been attributed to complex processes that are linked, among many other things, to the introduction of capitalism during colonial times, subsequent neo-liberalization, related factors such as poverty and unemployment, and also the war. The breakdown of "hegemonic" models of masculinity (cf. Connell, 2005) is seen to pose a great challenge to established social orders and therefore to social stability, a concern which was also commonly expressed by my interlocutors:

"The behavior of women has changed these days and it is not easy to teach them anymore. They have started wearing trousers and always talk about women's rights. They don't respect and listen to their elders anymore, because of all these modern influences they are always rioting and referring to their rights and refuse to fulfill their traditional roles" (male elder, group interview Kapedopong 28.06.2010, translated from the Acholi original by Kenneth Oyet Odong).

198 The irresponsible and negligent young Ugandan man was a frequent point of discussion in Ugandan newspapers supplements such as Full Woman (Saturday Monitor), Intimate and Total Man (both Saturday Vision). Interestingly, white men were rarely mentioned directly as reference points in these discourses. 
"You know these women of nowadays - you find the one who is educated enough: she is now doing her own job. You find that she will not mind of you, because ... she only has her job, everything is in her hand: her salary, monthly... So what are you? What does she want?” (INT Daniel, 30.04.2010).

"To a rural person, a woman remains a woman and she has to do all the domestic chores, and a man remains the head of the family and the breadwinner. And yet they are not now breadwinners, it is women who now struggle there at night to get something to eat for their children" (INT Zipparoh, 23.03.2010).

The quotations express that the perceived breakdown of gender (and gerontocratic) orders, aggravated by the promotion of women's rights and education, causes uncertainty and instability as established hierarchies and power relations are being challenged. Men no longer feel valued, respected and needed. Women experience that men can no longer live up to the role as main provider, which in turn forces them to look for alternative sources of income and take over the man's role themselves.

As discussed above, the failure of men to live up to societal expectations seems to be perceived as more serious (by men themselves but also by society) than that of women, who seem more flexible to choose and adapt to new gendered identities. In many ways women, who for instance gain access to the labor market, succeed in getting an education, and single-handedly manage their household are, relatively seen, empowered, while men who fail to attain these achievements are relatively disempowered. Those who are affected by unemployment and poverty, for instance, are denied many opportunities which are (still) needed in Acholi society to achieve the status of an adult man, such as the ability to marry, to provide for a family, and to be the representative and head of the family in public life.

\subsubsection{Discourses on Westernization as Forms of Internal Social Critique}

As pointed out above, the debates about the values of tradition and modernity, and the disparities thus invoked between African and Western gender images and norms are hardly new. The famous Acholi poet and writer Okot P'Bitek took up very similar topics and images in his poem Song of Lawino (1989), first published in the 1960s shortly after Ugandan independence. In the poem, Lawino accuses her husband Ocol and her new co-wife Clementine of trying too hard to copy the lifestyle of "the whites", and defends Acholi customs by contrasting them sharply to 'Western culture'199. Indecent behavior and dressing, sexual immorality, abortions, and even loss of masculinity ("My husband has become a woman", ibid.: 119) are only some of the issues she criticizes as results of 'Westernization' in Acholiland.

${ }^{199}$ Rather than speaking of "Westerners" or the "Western culture" as is common in Uganda nowadays, Song of Lawino talks of the "white people" or the "white people's way". 
Lawino uses the characteristics and behavior of white people as negative reference points in order to condemn unwanted dynamics in Acholi society. As in my examples above, positive "traditional" values (e.g. authenticity, morality, communality) are asserted as a means to emphasize the dignity and sovereignty of 'African cultures' in a time where Africa is commonly depicted as a dark, backward, poor and dangerous continent - even by Africans themselves.

In the poem, Lawino takes pride in 'her' Acholi culture and appeals to others to do the same. Interestingly, she does not criticize the whites, but the Africans who are trying so hard to imitate them: "She [Lawino] thinks the customs of white people probably suit white people. She doesn't mind them following their own ways. ... But those Africans who insist on following the ways of white people are foolish, because they misunderstand their own ways and do not know themselves" (Heron, 1989: 19f.). This comment relates to my argument very well. It implies that complaints about 'Westernization' in Song of Lawino, like those in contemporary discourses, are not about or addressed to the West, but directed at Acholi society and aim to criticize those 'westernized Acholi' who are repudiating their own culture.

In the preceding pages, I have outlined the complex and contradictory ways in which Western influences (or what is labeled as such) and socio-cultural change were reflected among my Acholi interlocutors and in the Ugandan media. I have focused on discourses on Westernization and have argued that these are less about actions of Western actors, and more concerned with internal processes and dynamics within Acholi/Ugandan society. Although these discourses acknowledge societal changes as a consequence of adopting 'Western models' such as capitalism and often expose strong distinctions between "Acholi/Ugandan/African" and "Western" values and concepts, they do not present the West as forcing Ugandans to comply with 'Western ways of life'. Rather, references to the West are used as a means to negotiate contested norms in Ugandan society. Especially among the younger generation, the frequent references to the West also reflect a desire to be "Western" and "modern", to engage in a lifestyle they know from the media, and to overcome some of the constraints they relate to "traditional" African society, such as being controlled by male elders in the family and clan, or to labor in the fields instead of going to school. In this sense, the given examples illustrate an extensive and conflictive inter-generational debate which is taking place within Acholi/Ugandan society. This debate is inspired by the changes people are witnessing in their everyday lives, some of which, like HIV, teenage pregnancies, abortions, and decline in marriages, have or are seen to have very serious consequences for their communities. Furthermore, these debates reflect internal power struggles about maintaining or challenging the status quo.

All in all, Westernization seems to have very different implications from the discourse on neocolonialism which I introduce in the following section. Judging from my own data on Northern Uganda, references to neocolonialism were rare in discussions of socio-cultural change among my interlocutors. But there was one prominent exception: the recent debate on homosexuality. Here, claims of neocolo- 
nialism and Western interference were explicit and brought forward by all segments of the population. In the following, I briefly examine this debate, and suggest why homosexuality is so explicitly framed as a form of neocolonialism.

\subsection{Neocolonialism Discourses $\&$ the Debate about the "Anti-Homosexuality Bill"}

In October 2009, a Member of the Ugandan Parliament, David Baharti, proposed a legislative bill which would impose the death penalty on certain acts of homosexuality ${ }^{200}$. In Uganda, homosexuality is widely perceived as a foreign threat which needs to be controlled so that it does not 'infiltrate' society. ${ }^{201}$ In Ugandan public discourse (i.e. in the media, in political statements, in ordinary conversations) ${ }^{202}$, the attempts by human rights actors and Western states to pressure Uganda into taking a more liberal stance on homosexuality are often interpreted as forms of "neocolonialism"203.

Ever since Bahati's proposal of an "anti-homosexuality bill" became public, Uganda has been in the international headlines and on the agenda of human rights activists. The proposed law supposedly acknowledges the view of many Ugandans who state that homosexuality is something unnatural and fundamentally "un-African" which is being introduced in Uganda by "Westerners" and poses a threat which needs to be contained. What is interesting in this debate is the way homosexuality is framed as something which is enforced by outsiders. A common claim is that young people are being corrupted into becoming homosexuals and will then 'set upon'

200 The decision on the bill was postponed several times. In 2012 and early 2013, different media reports announced that the Ugandan government was in the process of debating a new law against homosexuality which, however, no longer included the possibility of passing a death sentence for severe cases of aggravated homosexuality (Bhandari, 2012; Böhm \& Kemper, 2013). The Ugandan Anti-Homosexuality Act was finally passed in December 2013 and signed by President Museveni in February 2014. Although it no longer includes the death-penalty, it still broadens the criminalization of same-sex relations.

${ }^{201}$ It is important to note that this radical opposition to homosexuality was strongly promoted and at least partly initiated by early Christian missionaries, and is still fuelled by fundamental American Evangelicals (cf. Böhm \& Kemper, 2013; Epprecht, 2008; Kapya Kaoma, 2010). Thus, and somewhat paradoxically, homophobia is also a 'Western import'. This aspect, however, is rarely touched upon in debates about the bill.

202 This discourse is well-depicted in the internationally acclaimed documentary "Call me Kuchu" (directed by Wright \& Zouhali-Worrall, 2012).

${ }^{203}$ In this sense, neocolonialism is an emic category used to describe undesirable foreign influences in Uganda. As an analytical concept, it was originally applied by African politicians and scholars in the immediate post-independence phase (e.g. Nkrumah, 1974) and in Marxist approaches (e.g. Amin, 1973). "Neocolonialism" is still regarded as a "key concept" in postcolonial studies and theory (cf. Ashcroft et al., 1998: 162f.). 
other Ugandans. The fact that people are agents who can make choices is strongly de-emphasized in this discourse. Homosexuality is seen as a 'structural force' which is highly contagious and 'automatically' turns people into homosexuals if it is not stopped at once. In contrast to other concepts (e.g. gender equality etc.) discussed above, which are perceived as Western and viewed with some skepticism, but nevertheless debated and appropriated at the local level, homosexuality seems to be rejected completely and references to neocolonialism are frequent in public discourses (cf. Wright \& Zouhali-Worrall, 2012). In an article entitled "Neo-colonialism fuels homosexuality in Africa" which was published in the New Vision, one of the two major daily newspapers in Uganda, Margaret Muhanga (2009), Member of Parliament for Kabarole District at the time of writing, claims:

"The dependency syndrome has increased to the extent that the elite who should direct the affairs of the country have betrayed the cause of our forefathers and become spokespersons of Western ways. October 23 was one of the worst days of my life when I woke up to read, with disbelief a one-anda-half page press release in The New Vision titled 'Anti-homosexuality or anti-human rights Bill' by a coalition of civil society organizations on human rights and constitutional law. What a tragedy for Africans who depend on others for a livelihood. The elite, including the women organizations, that sent this press release and paid handsomely for its publication, are slaves living under neo-colonialism. This is not their opinion or belief, it is their 'sponsors' who direct them what to do or say. What a disappointment we are to our society" (my emphasis).

The claim that Uganda is forced to accept homosexuality due to its aid and economic dependency on the West is apparent in this statement. A further claim is that Ugandan civil society and elites are being co-opted by the West and incited to "betray the cause of their forefathers". Here we find an explicit allegation that the West is forcing Ugandans to repudiate their established customs, norms, and ways of living. Generally, this press statement seems to reflect a relatively broad-based consensus that homosexuality is difficult to reconcile with a 'Ugandan' or 'African identity'.

The reference to neocolonialism in this discourse constitutes a strategic difference from the discourse on Westernization. Unlike the latter, which is primarily an internally-oriented critique of Ugandan society, the discourse on neocolonialism is explicitly about the role of the West. It is a form of external critique, directed at Western state and development actors who are trying to interfere with Uganda's national politics. Under the label of neocolonialism, issues like international power imbalances, inequalities in the world market and monetary system, and the ludicrousness of development aid are addressed. Judging from my own experience, the neocolonialism discourse and its underlying argumentation are primarily brought forward by Ugandan 'elites'. I encountered them in specific political and academic contexts, for example in university seminars or in political rallies (e.g. field notes 06.03.2010; 
18.11.2010), but rarely in 'normal' conversations by 'ordinary' Ugandans, as I have outlined above. The current debate on homosexuality, however, which was initiated in elite circles (i.e. by religious leaders and politicians), was quickly taken up and discussed in all segments of Ugandan society and in various contexts under the label of neocolonialism. Obviously, the reasons for this are very complex and would need to be analyzed more thoroughly than I can do in the scope of this chapter. Nevertheless, I want to briefly suggest some potential explanations.

One reason could be that discourses on homosexuality reflect (or are used to express) 'real' anxieties by the Ugandan population in the sense that homosexuality, in a very fundamental way, is seen to pose a threat to all the three areas outlined above: a threat to family and kinship models, to moral integrity, to gender orders, and thus, very generally, to the constructed notions of 'African identity'. This can be inferred from the article quoted above. The author provocatively asks: "If all of us were to become gay, where would the next generation come from? (...) These homosexuals cannot reproduce. They must recruit, and they want our children. (...) Ugandans must rise up and fight all sources of evil no matter how much money the West sends. Human dignity must be protected" (Muhanga, 2009). Here, homosexuality is perceived as a threat to the continuation of society as well as something immoral and against human dignity. The idea that homosexuality is something utterly 'unAfrican' is also reflected in the following quotations by male university students at a public debate at Gulu University (see above):

"Homosexuality, do you want to tell me that in African traditions, in African nations we had homosexuality? No, homosexuality is just being brought..."

"We should consider it within this context of morality: now, when you talk of adopting homosexuality, my dear, you know it is quite wrong for a man to climb on the back of another man. In our tradition - that is wrong!" (Audio Record - Debate, 24.11.2010)

The debaters dealt with a provocatively formulated question: whether "traditional culture" was being lost among contemporary Ugandan youth. The majority of the participating speakers (five out of eight) referred to the issue of homosexuality and claimed that it was a sign of the bad "Western" influence on Uganda and an indicator that young people (who engaged in or defended homosexual acts) were losing their "traditional culture". During the debate I got the impression that homosexuality had become an icon for all sorts of undesirable social developments and was used as a 'teaser' to discuss all sorts of issues (social values, cultural authenticity, national sovereignty, global power imbalance etc. to name but a few) which seemed to be of great concern to the debaters.

I noticed that the 'dangers' of homosexuality were evoked in all sorts of situations, and particularly in the context of youth educational and/or leisure activities, as the following example from my field notes $(09.05 .2010)$ reveals. I went to a threeday workshop organized by the Catholic Church on the outskirts of Gulu, where 
about 60-80 male and female students aged between 14 and 22 came together to discuss issues affecting their everyday lives. Towards the end of the third day, male and female youth were separated into groups for an 'advisory talk'. When afterwards I asked the Ugandan priest who had invited me to the workshop what sort of advice had been given to the boys, the first thing he mentioned, to my surprise, was that they had been advised to stay away from homosexuality. This example illustrates that the current discourse on homosexuality seems to resonate with 'real anxieties' in the Ugandan population or, respectively, that the discourse creates and reinforces these anxieties.

A different explanation is based on the assumption that the discourse on neocolonialism, like that on Westernization, is strategic and must be analyzed in the current political context in Uganda. In recent years the relations between the Museveni government and Western donors have become increasingly strained - among other things due to corruption scandals, an increasingly authoritarian style of governing and the problematic involvement of the Ugandan army in the Congo wars. Furthermore, support for the Museveni government by the Ugandan population seems to be fading. Both facts must be taken into account when looking at the current debate on homosexuality. The critical stance the Ugandan government has taken towards and the way it has framed this issue seems to be supported by large parts of the Ugandan population - though this does not necessarily imply a comprehensive approval of the "anti-homosexuality bill". At the same time it is an issue which provokes massive critique by the West. Thus, in 'allying' with the majority of the Ugandan population and taking up the prevailing negative sentiments towards homosexuality the Ugandan government is using the debate on homosexuality to demonstrate its strength and sovereignty against the West.

Despite Uganda's continuing dependence on Western support, President Museveni has increasingly resorted to anti-Western rhetoric in his speeches, and has asserted that Uganda is no longer willing to let Western nations dictate its domestic policy. He has used the neocolonialism allegation as a populist argument and portrayed his firm stance against Western intervention as a sign of his strength and autonomy as president, for instance with regard to election issues ${ }^{204}$, and to the proposed homosexuality law in relation to which the West exerted massive pressure in order to convince Museveni to withdraw it. In an interview on BBC "Hard Talk" in February 2012, he warned Western governments against making aid payments dependent on the respect of gay rights and said: "That would be their big mistake. They should be careful about black Africa", and continued: "Black Africans are very humble people; we never impose our views on anybody else. We are not like Europeans and Arabs who want to impose their views" (quoted in Butagira, 2012). Thus, it seems that the fierce debates about homosexuality are less about sexual practices and identities. Rather, the discourse is a strategic and political one which is used to

${ }^{204}$ Elections took place in February 2011. Some Western states had complained about irregularities and a biased electoral commission in the pre-election phase. 
stress the sovereignty and independence of the Ugandan government - also against critical voices within Ugandan civil society.

Nevertheless, the consequences of the discourses on homosexuality are very real. In October 2010, the Ugandan newspaper Rolling Stone published a list of 100 alleged homosexuals, including their photos and a banner that read "Hang them". In January 2011, the Ugandan gay rights activist David Kato was murdered (Wright $\&$ Zouhali-Worrall, 2012). These and other cases show that the homosexuality discourse not only has consequences for Uganda's external relations. The evocations of hatred and widespread anxieties also provoke extreme reactions and trigger adversary dynamics within Ugandan society. Thus, one could further suggest that the Ugandan government is also using the debate on homosexuality (and other forms of sexuality) as a means to exercise power and control over the Ugandan population. I will take up this point in the last section of this chapter.

\subsection{Discourses on Sexuality as Instruments of Power}

The debates I have outlined in this and the previous chapters reveal that discourses on socio-cultural change in Acholiland (and beyond) have a highly sexualized dimension. Based on Foucault's reflections in The History of Sexuality, I suggest that one possible explanation for the frequent references to sexuality in these discourses is that matters of sexuality are closely interwoven with power dynamics at the local, national and international level. I will briefly elaborate my argument by referring to recent measures adopted by the Ugandan government on matters concerning the sexuality of Ugandan citizens.

Following Foucault's argument that sexuality "appears (...) as an especially dense transfer point for relations of power" (1990: 103) I purport that discourses on sexuality in Uganda, especially those on 'abnormal' or 'dangerous' forms of sexuality, are part of a larger disciplining project, not only by international state and development actors, but also by local authorities and the state ${ }^{205}$. The "anti-homosexuality bill" is only one of a number of recent attempts to set up new or sharpen existing laws which aim to regulate potentially dangerous forms of sexuality and which define and target specific 'sexual subjects' (cf. Foucault, 1990: 105). Further examples include legal measures, which are related to AIDS (and the sexuality of 'ill' persons), defilement (and the sexuality of youth), prostitution (and the sexuality of women) and pornography (and the sexuality of 'perverts').

Regarding AIDS, Uganda is in the process of debating a new "HIV/AIDS Prevention and Control Bill" which, if enacted, would legislate for mandatory testing

205 The analysis of sexual discourses in Uganda with a Foucauldian approach presents an interesting topic for future study. Here, I only want to hint at the manifold ways power as well as disciplining and normalizing strategies by local authorities and the state are applied and become apparent through sexuality-related discourses and practices. 
of HIV, mandatory disclosure of a person's HIV status and the criminalization of intentional spread of the disease (cf. Basudde, 2012). The bill is a good example of a measure aimed at regulating the population by controlling the sexuality of individuals, specifically those of 'ill persons'. The proposed obligation to 'confess' one's HIV status, for instance, allows for a massive expansion of state control over matters related to the sexual life of individuals.

In order to protect (and control) youth sexuality and to 'discipline' intergenerational sexual relations, Uganda has set up a "defilement law" which provides that "[a]ny person, who performs a sexual act with another person who is below the age of 18 years, commits a felony known as defilement and is, on conviction, liable to life imprisonment" (Section 129 of the penal code, quoted in Byamukama, 2010). The law not only serves to protect youth but, in actual practice, is also being misused to sanction youth sexuality. In Gulu, I was often told about parents, who had accused young men (often below the age of 18) of defiling their daughters as a means of making money. The 'offenders', in many cases the daughter's secret boyfriends, were charged heavy fines and, if they were unable to pay, the case was reported and lead to the imprisonment of the 'offenders' (cf. Malinga, 2010). In this sense, the defilement law not only punishes adult's sexual abuse of minors, but in fact enables the regulation of all forms of youth sexuality.

Women's (promiscuous) sexuality is regulated, for instance, in Uganda's law on prostitution which defines a prostitute as "a person who, in public or elsewhere, regularly or habitually holds himself or herself out as available for sexual intercourse or other sexual gratification for monetary or other material gain" (Section 138 of the penal code quoted in Tamale, 2011c: 146). As Tamale (ibid.) rightly remarks,

"[c]learly this definition limits culpability of the offence to the sellers of sex (the majority of whom being women) and not to the clients (mostly men). What this means is that if a woman is found guilty of 'selling her sex' she is liable to a sentence of up to seven years while the client that paid for her service walks away Scot-free."

Following Tamale, one can argue that the law primarily seeks to control women's promiscuity, while men's promiscuous behavior is not sanctioned. The law must be seen in the context of gender and sexual discourses which, as previously outlined, generally associate promiscuous and/or extramarital sexual relations of women with prostitution, and which label girls and women who are known for such 'offenses' as prostitutes. A corresponding image of a male prostitute does not exist in these discourses.

Currently (in April 2013), Ugandan parliamentarians and citizens are heatedly debating an "Anti-Pornography Bill", first proposed in 2011, which seeks to punish

"[a]ny cultural practice, form of behavior or form of communication (...) that depicts a person engaged in explicit sexual activities or conduct, sexual 
parts of a person such as breasts, thighs, buttocks or genitalia, erotic behavior intended to cause sexual excitement or indecent act or behavior intended to corrupt morals" (cited in Walubiri, 2013, my emphasis).

Offenders face heavy fines or even up to ten years in prison. The bill has sparked big controversies, not only in Uganda but also internationally ${ }^{206}$. One frequently discussed point is whether the Bill also implies the prohibition of wearing miniskirts, and whether this would actually be desirable and "morally right" as one commentator (quoted in Tumusiime, 2013) put it ${ }^{207}$. This relates very well to my argument that the miniskirt is a crucial icon in Ugandan debates on social change. Furthermore, some observers have claimed that if the bill was to pass in its current form, it could also "prohibit the broadcasting of 'risqué' musical performances by Western singers such as Beyoncé and Madonna" (Guyson, 2013). In line with the general concerns about a "moral degeneration" of society, which I outlined above, proponents of the bill have argued that it could serve to prevent the young Ugandans from becoming a "generation brimming with immorality" (a Ugandan woman quoted in Tumusiime, 2013: 18). The bill thus enables the Ugandan state not only to censor media contents but also to define far-reaching standards of behavior which regulate what was formerly considered the personal choices of individual citizens.

The above-mentioned laws, which attempt to control and sanction 'dangerous' or 'abnormal' forms of sexual behavior, reveal the contested nature of sexual relations and the ways they are becoming increasingly charged with power - on the local, national and international level. Sexuality, as shown in the examples above, offers new entry points for the operations of power which according to Foucault (cf. introduction) relates to sexuality being an intersecting point between the individual body and the population as a whole. The proliferation of discourses on sexuality must be seen in relation to the general socio-cultural changes Acholi and Ugandan society is currently facing. Presumably, these discourses are not primarily concerned with sexuality, but reveal important insights into the state of societal relations and power struggles on a more general level.

${ }^{206}$ Again, we find that the issue is framed, by some, in terms of "African" vs. "Western" sexual norms and morals. Some commentators - applying the argumentation underlying the neocolonialism discourse - claim, for instance, that pornography is something "Western" and was introduced in Uganda through Western media (cf. e.g. Buturo, 2013).

${ }^{207}$ See for instance the articles "Uganda: Anti-Pornography Bill not about Mini-Skirts - Minister" by Walubiri (2013), “To Ban or not to Ban?” by Tumusiime (2013) or "Women Face Arrest for Wearing Miniskirts in Uganda in New Laws that also Ban Beyonce from Television” by Frymann (2013). 


\subsection{Concluding Remarks: Sexuality, "Africa" and "The West" as Strategic Fields $\&$ Figures in Discourses on Socio-Cultural Change}

From the beginning of my research in Northern Uganda, I was struck by the frequency of references to the West in conversations, media reports and other public discourses I encountered. I was particularly struck by the way the alleged differences between "Africa" and "the West" were discussed with reference to sexual matters. I decided to trace this phenomenon and to analyze the different ways these binary oppositions were used by individual speakers, not only in discourses on gender, kinship and sexuality, but also in other contexts.

I soon noticed the multivocality in the references to the West. On the one hand, the attribute "Western" seemed to be very positively denoted and to stand for economic development, power, wealth, prosperity, consumption, progress, beauty, education as well as freedom. On the other hand, it could also be used in a very negative sense, symbolizing immorality, egoism, individuality, disrespectfulness, decadence and materialism. In many debates and virtually irrespective of the topic, the West was compared to an (imagined) African/Uganda/Acholi 'other', which could either signify morality, integrity, respect, authenticity, societal solidarity and stability, or, negatively, "backwardness", poverty, gerontocracy, patriarchy and 'harmful cultural practices'. I have listed the various attributes in the following table.

Table 2: The Multivocality of Representations of Africa and the West

\begin{tabular}{|c|c|c|}
\hline & The West & Acholi/Uganda/Africa \\
\hline+ & $\begin{array}{l}\text { - Economic Development } \\
\text { - (Political) Power } \\
\text { - Wealth, Prosperity, Consumption } \\
\text { - Beauty } \\
\text { - Progress } \\
\text { - Education } \\
\text { - (Individual) Freedom }\end{array}$ & $\begin{array}{l}\text { - Morality, Integrity } \\
\text { - Respect } \\
\text { - Authenticity } \\
\text { - Societal Solidarity } \\
\text { - Stability } \\
\text { - Sexual Purity }\end{array}$ \\
\hline- & $\begin{array}{l}\text { - Sexual Promiscuity } \\
\text { - Immorality } \\
\text { - Egoism, Individuality } \\
\text { - Disrespectfulness } \\
\text { - Decadence, Materialism }\end{array}$ & $\begin{array}{l}\text { - "Backwardness" } \\
\text { - Poverty } \\
\text { - Gerontocracy } \\
\text { - Patriarchy } \\
\text { - 'Harmful Cultural Practices' }\end{array}$ \\
\hline
\end{tabular}


In this chapter, I have analyzed in great detail the ways these binary oppositions were used by my interlocutors and in the Ugandan media. I have argued that there are two different types of discourse which engage with 'Western-influenced' change: discourses on Westernization and discourses on neocolonialism. Both are strategic and represent different forms of social critique, one internally, the other externally oriented. They can be differentiated not only by looking at the terminology, but because they have different underlying motives and follow different lines of argumentation.

The discourse on neocolonialism, in Uganda and beyond, is highly politicized and criticizes global inequalities, the continuing Western dominance in international economic and fiscal politics and the hypocrisy of the development regime. It emphasizes that external, structural factors are responsible for the current problems of African states, and legitimizes practices by African governments, which defy Western understandings of democracy and human rights as signs of their autonomy and sovereignty. This discourse is also depicted in some parts of postcolonial literature, and reproduces the binary opposition between the "West and the Rest" (Hall, 1992). Judging from my empirical findings in Northern Uganda, however, it is largely an academic and elite discourse.

Discourses on Westernization, on the other hand, are much more ambiguous. Here, references to the West are sometimes arbitrary and can be connoted both negatively and positively, depending on the context and speaker. Based on my experiences, this discourse is much more common in everyday discussions of sociocultural change. In these discussions, the speakers engage with "Western" concepts, values and practices very pragmatically, and discuss whether these are desirable or not for their own society, irrespective of the 'mechanisms' which led to their introduction such as structural adjustment measures or humanitarian interventions. This also shows that Acholi/Ugandan people by no means just passively receive, but actively negotiate, refuse and appropriate "Western" concepts, norms and practices, and by using "the West" as a benchmark also negotiate different positionalities within their society.

On another level, this chapter took a closer look at the highly sexualized dimension of discourses on socio-cultural change. I argued that the way sexuality has been established as a focal point for disciplinary action and regulation provides important insights into power dynamics at the local, national and international level and reveals how these dynamics shape practices and discourses in the context of sociocultural change.

In summary, one could argue that Sexuality, "Africa" and "the West", in different ways, represent strategic fields or figures which can be framed in a certain manner and used as benchmarks to powerfully articulate and enforce certain positions in discourses on socio-cultural change. 


\section{Conclusion: Negotiating Socio-Cultural Change $\&$ the Future of Acholi Society}

During the time of my fieldwork in 2010 and early 2011, Northern Uganda had been recovering from the 20-year war between the LRA and the Ugandan government for four years. While war-related problems - access to basic needs, security, reconciliation and rehabilitation of former fighters - were still major concerns, especially for people who were in the process of resettling back to their original homes from the IDP camps, the focus of debates had shifted to a broader reflection of the socio-cultural changes that had occurred throughout the war years and their implications for the present and the future. At the center of these debates were various and often conflicting visions for and imaginations of post-war Acholi society, and implicated in these, conflicting notions of social order, norms and values.

These highly emotive and morally-charged debates constituted the starting point of my research. Based on observations and conversations during my fieldwork, I sought out to analyze how processes of socio-cultural change were perceived and how imaginations of post-war Acholi society were negotiated in different contexts 
and between different (groups of) social actors, for instance between youth and elders, men and women, local and international actors. As will become evident in the following conclusion, generational, gender and local-global relations proved to be of particular relevance to my analysis. Not only did the perceived changes in all three areas constitute a critical matter of debate. A speaker's positioning within these different sets of relations also crucially affected his/her perspective on socio-cultural change.

My study specifically focused on the perspective of urban youth, particularly those who were born and grew up during the years of the war and whom I therefore labelled the "war generation". My findings suggest that members of this war generation are currently faced with a particular situation of uncertainty and ambivalence. This is linked on the one hand to their experience of protracted war and their perception of the profound changes Acholi society has undergone as a result of the war and on the other hand to the expectations and hopes generally placed on Acholi youth as the 'pillars of the future' and the preservers of Acholi culture. I have argued that, in many ways, the war generation occupies a specific in-between position. Both in local and international discourses, it is seen as the link between the war-torn past and a prospective peaceful future and also between tradition and modernity, Uganda and the West. Members of the war generation are often blamed for "losing" Acholi culture, for disrespecting long-established norms and orders and for "westernizing" Acholiland". Implicit in these accusations, however, is also the hope that the young generation can re-establish social order and stability associated with the pre-war past and the realization that the fate of Acholi society is left in the hands of the young generation. Based on my observation that opinions on socio-cultural change are often voiced by using binary oppositions, I have claimed that members of the war generation are being discursively framed as standing at a crossroads: between past and future, tradition and modernity, Acholi culture and Western culture.

Placed in this pivotal position, most of my young interlocutors experienced feelings of uncertainty and confusion. They felt that they had to choose whether they wanted to be 'breakers with' or 're-makers of' the past, modernizers or traditionalists, conformers or spoilers, and often deliberated whether these seemingly conflicting notions could be reconciled. However, they not only perceived their in-between status as a cause of uncertainty, but also as a source of agency and a chance to shape the future of their society. This agency, as I have demonstrated, can be traced in the manifold ways that youth negotiate changes in generational, gender and local-global relations and thereby make use of different discourses and positionalities in order to establish, maintain and contest the social order.

My findings and the arguments I have put forth relate to broader debates on African youth among anthropologists and Africanist scholars. As in Northern Uganda, youth in many other African contexts are seen as crucial actors in the future development of their societies in the age of globalization. Paradoxically, enormous hopes are placed on the young generation as educated inventors, economic entrepreneurs, political reformers and cultural ambassadors, while at the same time young people 
are being marginalized in the formal political and economic sector, and are being blamed for westernizing African societies due to their adoption and adaptation of global popular culture. My study reveals, in a very concrete case, how young people deal with this paradox position ascribed to them in societal discourses, i.e. being seen, at the same time, as leaders and subordinates, agents and victims, makers and breakers. Although youth in Gulu face a very specific situation of uncertainty due to their experience of 20 years of war, to some extent their aspirations and actions, predicaments and problems are representative of the "waithood generation" (Honwana, 2012: 3ff.) of young people in Africa more generally.

In this concluding chapter, I aim to link my findings from Northern Uganda to broader debates on youth and youth agency in the context of intergenerational as well as gendered and global-local power dynamics, which represent central issues in many African societies today. I will introduce this chapter with a last extract from my field notes.

\subsection{Two Conversations - Extracts from my Field Notes}

January $2^{\text {nd }}, 2011$. The day has come to say goodbye to Akello's family. I have bought a chicken, which will be slaughtered for our farewell lunch, and while Akello and her mum are preparing the food in the kitchen hut, I sit outside with Akello's dad Okello. We talk about the coming elections and the many problems Uganda is currently facing such as corruption, low world market prices for raw materials and unemployment. Okello says that apart from all these political and economic problems it is also the behavior of the young generation that contributes to the crisis in Uganda and in Acholiland in particular. In his words"208: "The young generation now is refusing to dig, they are lazy. Soon, shortage of food crops will be a problem, even in the fertile lands of Northern Uganda. All these young people want to get wage employment - but where shall that come from, especially now that all the NGOs are pulling out?"

(...) We also talk about "cultural affairs" and I ask him what he thinks about the cultural institution Ker Kwaro Acholi. He replies that in principle he supports Ker Kwaro because it is a forum where the advice of elders is still respected and where young people can seek advice on matters concerning their lives. He sighs and then adds: "I wish young people would at least show some respect. When they come and ask for something or about something they should do it in a low voice. Then no elder would refuse to answer them. But young people today don't have that respect anymore, they want everything right at once, and if you don't give them, they start quarreling". He returns to my question about the cultural institution and emphasizes again that he supports its work,

${ }^{208}$ For readability purposes, I occasionally use direct speech in this section. However, the quotations should not be mistaken as recorded statements, but are all based on my field notes which I wrote some hours after the described events had taken place. The exact wording is thus my interpretation. 
but that Ker Kwaro should also incorporate knowledge from "the West" and not only "traditional knowledge": "Today it is necessary to combine different types of knowledge. It is important to have that local knowledge, but there is a lot the Acholi can learn from the West. Young people should grow up with both types of knowledge so that one day Uganda will prosper."

We remain silent for a while. Okello is cracking groundnuts and giving them to his grandchildren who are running around in the compound. Suddenly, he says that he wants Akello to go back to school. I am surprised that Okello brings up this topic because I know from Akello that she had to leave school because he was unable to pay for her fees $^{209}$. Nevertheless, I agree with Okello's remark and tell him that I think that Akello is a very bright girl and would surely profit from further education. He nods and recalls that she always did very well in school. Then he makes an interesting statement: he explains to me that he took her out of school because she was associating with the wrong group of people, that she was doing wrong things and therefore had to be taken out of the school environment. I am puzzled about Okello's interpretation of the reason for Akello's dropout, but just when I want to question him about the details, Akello walks up to us and asks me to join her in the kitchen hut.

I follow her and we chat about this and that while I help her to prepare the food. All of a sudden, Akello starts speaking about her father. She says that he promised to buy her new clothes for Christmas but that he never did, and when she asked him about it he started quarreling. She says that these days he is often quarreling, even with her mum. Then she adds that he always kept them well when they were growing up but now that he is old there are many problems. She talks about her father's co-wives: "For them and their children things were easier. Dad was still working when they were young and could send all of them to school. All of the children went to good schools and never had problems with school fees. But when my brothers and sisters and I were growing up, he stopped working and money problems started. We all had to struggle through school and most of us had to drop out eventually because dad couldn't pay. When I was in primary school there were many times, especially during the last two years, when he didn't pay regularly. I was often sent home but because I was so focused I always went back and asked to be taught. I was on the football and netball team so they sometimes allowed me to stay although the fees were not paid. I managed to finish my PLE (Primary Leaving Examination) very well. Actually, I was among the best from my school". She tells me about this proudly and then adds: "My father promised to send me to a boarding secondary school so I stayed home for a year and waited for the money". But the money never came so she then started secondary school at a cheaper public day school, but even there fees were always a problem. Eventually she had to drop out completely.

${ }^{209}$ Maybe Okello brought up the subject because he hoped that I would support him in paying for Akello's school fees. In fact, Akello and I had already talked several times about the idea of her going back to school and I had promised her to pay for her fees in the upcoming school year. It seemed, however, that Akello had not yet told Okello about our 'plan'. 
Akello talks at length about poverty as the major problem Acholi society and particularly young people are facing today. According to her, poverty is the reason for many familyconflicts and, even worse, also for the severe HIV/AIDS crisis in Northern Uganda: "It is really affecting everyone in Gulu so much. Young people are sleeping with older people just to get money. So many girls and boys these days want all these material things and the only way they see they can get them is by selling their bodies, also because there are no jobs. But they don't think of the consequences, they think they can tell from the outside appearance whether someone has HIV. Then they get their short-term money but later find out that they are infected. Once you are infected everything changes: the way you think, the way you feel, even the way you walk - because for the rest of your life you will be bitter and suffering. This bitterness is also the reason why people then intentionally spread the disease. At school we even learned that some girls put petroleum jelly in their vagina before sleeping with a man so that, even when he wants to use a condom, the condom will break and he will get infected. You know, it is largely women, who are spreading the disease here. Some women not only get AIDS from sleeping with sugar daddies, but also fall pregnant so that they are even more desperate for money."

I add that the high number of children might also be a problem for future Acholi society and Akello agrees: "My father's generation used to produce so many children because they had land and feeding them was easy. But these days, people are struggling, especially with school fees, and all the people who have so many children make them suffer. But young people today are changing their perspectives, they want to have less children." (...)

The food is ready and I move to Okello's hut, where I usually eat with the men. Akello's brother is also there. Today, Okello asks his wife to join us for the meal because it will be the last time we are eating together. As common for Acholi women of her generation she sits on the floor and not on chairs like the rest of us. Akello is not invited to eat with us and takes the meal in a separate hut with her young nieces and nephews. As I often do in situations like these I think about the complexity of gender, generational and intercultural relations and the power dynamics ingrained in them (field notes 02.01.2011).

The dialogues presented in this extract touch upon many issues which I have analyzed throughout this book, above all the conflictual relations between members of different generations, the gendered (and sexualized) dimensions of Acholi social life as well as the positioning and analysis of Acholi society in a globalized context. Both narratives, by Akello and her father, are concerned with current situations and perceptions of uncertainty and crisis: in the family, in Acholi and Ugandan society, and in international power relations. Both discuss these current crises in the context of generational and socio-cultural change.

Okello links problems on the local level such as unemployment and potential food insecurity to broader political and economic problems on the national and international level such as corruption, unfair trade conditions but also Uganda's dependency on NGOs. He blames the young generation for being lazy, having unrealistic economic expectations (seeking wage employment rather than working on the 
fields) and, indirectly, of endangering Acholi society by not respecting the wisdom and knowledge of Acholi elders and cultural leaders. At the same time, however, Okello also acknowledges that the young generation is growing up in a highly complex, globalized setting and should thus seek not only "traditional" knowledge but also "Western" education in order to cope with the challenges of today.

Akello, on the other hand, is primarily concerned with the immediate problems she faces on a day to day basis in her family and social life: family conflicts, poverty, AIDS and lack of future perspectives for members of her generation. In contrast to Okello, she blames the members of the older generation for many of these problems. Their "traditional" family models, based on polygyny and intended to produce numerous children, no longer work today, but, on the contrary, are the cause of many contemporary problems. Fathers are no longer able to fulfill their changed roles as providers which, in 'modern times', not only entail the provision of food and shelter, but also the ability to send children to school and to (occasionally) endow them with material goods such as clothes. As a consequence of the inability of fathers to provide these 'modern needs', young people are compelled to find their own ways to gain access to education and material goods. Therefore, and due to the lack of economic opportunities, many resort to risky 'income-generating activities' such as "transactional sex", which often cause a plethora of further problems such as HIV infections and unintended pregnancies. Akello's analysis of contemporary problems also has an interesting gender dimension which alludes to gender images I commonly encountered in Acholi society. These gender images depict men as irresponsible fathers and incapable providers, while women, especially younger ones, are portrayed as being jealous and vindictive, engaging in immoral and risky sexual practices and thus being the main transmitters of HIV/AIDS.

The interplay between gender, age and intercultural dynamics is evident in the final scene of the extract, which also reflects a common spatialization of gender relations in Acholi society. In many local contexts, for instance during social gatherings or meals, men and women, often further distinguished by age, are assigned to different, sometimes hierarchically-structured spaces. In the example above, Akello eats her meal in a separate room with the younger children. Her mother, who is allowed into a sphere normally reserved for men, sits on the floor while the men and the foreign female visitor sit on chairs. Most older and younger Acholi I met during my fieldwork seemed to assume that gender relations and practices in "Western culture" were in some ways different from Acholi gender norms and practices. However, in many cases it seemed to be no problem to integrate these "Western" gender norms into the local context without dissolving "local" gender norms (for instance by letting the Western, female visitor sit on a chair and eat with the men at the table, while the Acholi women adhered to "local" gender orders). In the context referred to above, the acknowledgement and application of these 'foreign' norms could be seen simply as a social courtesy, or it could be analyzed as a reflection of local-global hierarchies, in which Western women have a different status than Acholi women. In chapter 6, I have already discussed the complex attributions given to Acholi vs. 
Western gender ideologies in Ugandan discourses and the power dynamics thereby reflected. I will refer back to these findings in my discussion of gendered and sexualized power relations below.

All in all, the conversations and events described in the above extract hint at many important topics which constitute central concerns in post-war Acholi society and which are currently being negotiated among different groups of social actors in the context of changing generational, gender and local-global power relations. In the following, I recapitulate these debates and discourses in Northern Uganda, which I have presented throughout the chapters of this book, and situate my findings in broader scientific debates on youth and socio-cultural change in postcolonial Africa.

\subsection{Discourses on Socio-Cultural Change in the Context of Generational, Gendered \& Globalized Power Dynamics}

As I have repeatedly argued throughout my analysis, discourses on socio-cultural change in post-war Acholi society are characterized by frequent references to generational, gendered and globalized (power) relations. One of the reasons for this must be seen in the particular historical context in which these discourses have appeared.

Between 1986 and 2006, Northern Uganda was heavily affected by the armed conflict between the LRA and the Ugandan government, which caused a sustainable disruption of Acholi cultural, social, political and economic life. Furthermore, it brought about the displacement and encampment of large parts of the Acholi population as well as a large-scale intervention by Western development and political actors. I have shown how these events have shaped contemporary perspectives on Acholi culture and how they have affected the attempts to revive and 're-invent' Acholi culture (cf. chapter 4).

On the national level, the period between 1986 and today has been marked by the presidency of Museveni and his political party, the NRM. The Museveni government has not only been a major participant in the war, it has also managed to establish a specific pro-government narrative of Ugandan (recent) history through its national and international influence. This narrative has long dominated the outside perception of the war with very negative effects for the Acholi population. I have demonstrated that the establishment and consolidation of such selective narratives on the war and Ugandan history more generally have had a profound effect on historical developments and their interpretations, and continue to influence contemporary discourses (cf. Chap. 3).

During his reign, Museveni also introduced several political reforms (see Tripp, 2010), for instance with regard to women's rights, educational policies and economic liberalization, many of which were initiated in the context of structural adjustment 
programs dictated by Western states and development institutions. Throughout the period from 1986 until today, the presence of Western actors and concepts increasingly expanded from the political and economic sphere into all spheres of Ugandan public life and this became increasingly reflected in local and national discourses. In chapter 6, I have analyzed how this circulation of "Western" ideas and images of the West, furthered by the expansion of the mass media and the globalization of popular culture, has instigated different types of discourses which engage with 'Western-influenced' change in Uganda, namely discourses on Westernization and discourses on neocolonialism.

These and other events that occurred on the local, national and international level between 1986 and today are reflected in and shape contemporary discourses on socio-cultural change in Acholiland. Due to the war and related displacement, socio-cultural changes in Northern Uganda throughout the past three decades have been perceived as particularly radical and have involved fundamental changes in societal power structures and relations. Patriarchic and gerontocratic principles, which previously structured Acholi society, have been challenged by women and youth, who took over new roles during and after the war. Furthermore, and comparable to the situation in many other African countries, the increasing influence of 'Western' concepts and ideas, circulated through the globalized media and development regimes, have called into question established local belief and value systems. Not only the changes as such but, more importantly, the way they have come to be represented in local and national discourses, have created the notion that post-war Acholi society is currently at a crossroads - between past and future, tradition and modernity, Africanization or Westernization. The constant reinforcement of this notion of dichotomy and the complex attributions connected to concepts like tradition and modernity implicate that imaginations of a future Acholi society are particularly contested. And due to the specific power constellations thereby involved, these contestations often revolve around generational relations, gender relations and relations between Uganda and the West. All three areas are especially dense fields and transfer points of power relations and thus particularly interesting and suitable to study by drawing on the theories of Foucault as I have done throughout my analysis. It is in these fields that different types of discourses - local, national and global, political, economic and moral, colonial and postcolonial - become closely intertwined and, due to their sometimes contradictory nature, cause a situation of uncertainty, especially for youth.

\subsubsection{Generational Conflicts \& Power Relations}

In chapter 5, I have argued with reference to Mannheim (1928) that one can differentiate generation-based understandings and imaginations of Acholi culture and the role it is to play in the future, which are linked to the shared experiences members of different generations underwent during their lives, and particularly during their youth. The existence of a distinct "consciousness" among members of different 
"historical generations" in Gulu was reflected, among other things, in the conflictual nature many of my interlocutors attributed to intergenerational relations in Acholi society today and which I often encountered in everyday conversations (as shown in the extract above).

Intergenerational conflicts were often related to or occurred in the context of discourses on the perceived crisis of contemporary Acholi society. This crisis was related to the processes of disarray and change Acholi society had undergone since the beginning of the war. Despite the disruptive nature of former historical periods (i.e. colonial times, the Obote and Idi Amin regimes), these were rarely mentioned by my interlocutors in relation to the current situation. In contrast, the pre-war period seemed to be idealized as a time of relative stability and social order, and set apart from the war- and post-war mayhem. Although members of all generations identified similar aspects and manifestations of the crisis (most commonly poverty, unemployment, HIV/AIDS, family and marriage break-ups, land conflicts as well as economic and political marginalization) and acknowledged the overall context of the crisis (i.e. the post-war situation, Ugandan national politics and international political and economic dynamics), there seemed to be distinct generational perspectives regarding the reasons for the concrete, local manifestations of the current crisis, the societal groups who should be blamed for it and the solutions people espoused to overcome the crisis and to re-stabilize future Acholi society.

Members of the pre-war generation, i.e. those who had experienced the war as adults and elders, often blamed the crisis on Acholi youth. They claimed that today's youth were lazy, disrespectful, no longer valued Acholi cultural and moral principles, and that they had thus contributed to the breakdown and "moral degeneration" of Acholi society. In conversations and interviews I conducted, young people's lifestyle was often described as "westernized" and portrayed as revolving mainly around leisure activities (hanging out in video halls and clubs, drinking and being involved in inappropriate sexual relations) and material wealth (especially phones and clothes, often inappropriate ones like miniskirts and baggy pants). This individualistic lifestyle was seen to threaten established societal institutions like "traditional marriage", kinship systems, property laws and family-based labor arrangements (for instance related to the cultivation of family land). Furthermore, it led members of the older generations to blame the young generation for no longer being committed to communal relationships and being unwilling or unable to endure the hardships of marriage and working life like their parents and grandparents had done. A common assertion by adults and elders was that today's children and youth even refused to do their household chores and, when compelled to do so by their parents, cited discourses on children's rights and accused parents of violating these rights. In sum, elders accused youth of lacking dedication to the communal values which they regarded as necessary to overcome the perceived crisis of Acholi society.

Members of the war generation, in turn, accused elders and adults of neglecting and disregarding youth and not properly fulfilling their roles as advisors, caregivers and guardians. Young people often recounted how during the war, especially in 
the camps, parents had left their children to fend for themselves, while they drank or otherwise surrendered to the desperate situation. In the contemporary post-war situation, members of the older generations were often described by youth as being unwilling or unable to adapt to the changed circumstances and of still living in the past. Common expressions I encountered were that elders were "backward", lacked "modern" education and knowledge and did not understand the changed requirements and complex challenges of life in a capitalist, globalized world. Young people felt that their parents did not respect "modern" rights discourses, for instance on children's rights, which involved children's and youth's right to education and leisure time, freedom of expression and protection from 'child labor'. Furthermore, they claimed that "traditional" family models, based on polygyny and a large number of children, were no longer viable today and, on the contrary, were the cause of many intra-family conflicts, in which especially the children and their mothers had to suffer.

However, despite young people's skepticism with regard to some "traditional" practices and beliefs, which they saw as outdated and incompatible with "modern" life, most of them still valued Acholi culture and wanted to integrate some of its elements and principles into their everyday lives. In fact, many of my younger interlocutors complained that they did not really know enough about Acholi culture and accused their parents and grandparents of not passing on their cultural knowledge to the young generation.

For youth then, the essence of the crisis was the situation of uncertainty they currently found themselves in. They had grown up in a situation of great social upheavals in which collective norms, rules and conceptions of life were in flux. They were confronted with an equally unstable future in which they had to reconcile local and global demands in addition to the overall challenges of living in a society recovering from war. My interlocutors sometimes expressed that they felt unprepared for these challenges. Many of them had experienced profound disruptions of their early-childhood socialization due to family break-ups and the disintegration of communal structures, which had prevented them from learning some of the cultural practices and rules that for long had been and were still regarded as important social and cultural capital in Acholi society. Furthermore, due to the war-related disruption of their schooling and the lack of quality education generally associated with the introduction of UPE (Universal Primary Education) in Uganda from 1997 onwards, they had not had the chance to obtain a proper 'Western' education. Thus, they felt that they lacked the necessary skills and qualifications to find one of the scarce, well-paying jobs in the formal employment sector.

The disordered experiences many of my young interlocutors underwent during their childhood and youth are a key factor in understanding their current sense of uncertainty and their feeling of being 'stuck in between' past, present and future, tradition and modernity. On a broader, theoretical level, my findings can be linked to sociological studies of "biographical uncertainty", which I alluded to in the introduction. According to Reiter (2010: 8), 
"[e]xperience and its status in biographical projecting is the key category for an assessment of the quality of the linkage of past, present and future. Experiences are characterized by a dual temporal horizon: through experience we conserve and reinterpret the past in order to orient our (biographical) action towards the future (...). [A] sociological notion of biographical uncertainty is generally identified as the weakening of this linkage of experience, expectation and projecting due to an erosion of intersubjectively shared certainty in a special social situation" (emphasis in original).

The difficulty of establishing a coherent link between past experiences and future actions, which Reiter identifies as a major cause of uncertainty, seemed to be at the core of the 'cultural crisis' in Acholiland. This became evident from the commonly voiced assertion that the 20-year war had undermined the very foundations of Acholi society. Expectations and projections related to the future of Acholi society greatly differed among various social actors. The relevance of the past as a guide for the future was disparately assessed, especially between members of the older and members of the younger generation. Consequently, one can assume that this lack of a coherent past-future "horizon" led to an overall "erosion of intersubjectively shared certainty" among all members of Acholi society. This, in turn, caused feelings of uncertainty not only on the individual, "biographical" level, but also evoked feelings of 'cultural uncertainty' at the societal level, indicated by a perceived lack of a shared value system and the disagreement about which lifestyles were to be regarded as desirable, morally acceptable and sustainable. As argued above, members of different generations experienced the manifestations of this cultural uncertainty differently and subsequently drew different conclusions and options for action from it.

Elders essentially feared that "Acholi culture was getting lost", an expression I frequently encountered, and were at the forefront of the efforts to retraditionalize Acholi society. Connected to their fear of cultural loss was also a fear of losing the influential position given to elders in societies based on gerontocratic principles within the family, but also in the political sphere. In this sense, generational conflicts in Acholi society were not only about different values, beliefs and life conceptions, but essentially also about power.

Youth's reaction to the situation of cultural uncertainty involved very complex considerations. On the one hand, they resisted (in very diverse and sometimes subtle ways) elders' attempts to re-establish gerontocratic principles, and instead lobbied for the "modernization" of Acholi society based on the ideas of individual freedoms and 'democracy' (including notions of citizen rights, children's rights, women's rights etc.). They rebelled against the roles and expectations - in terms of lifestyle, occupation, marriage and family structures - which would have been required of them in "traditional" Acholi society and which were still envisioned by some of their parents and community elders. 
On the other hand, however, many youth were also drawn to the idea of reviving Acholi culture - for different reasons. Some felt obliged to preserve Acholi culture and to re-establish the reputation of the Acholi people in the Ugandan national context. Some felt nostalgic about Acholi culture and sad that they knew so little about their cultural heritage and had never really experienced "traditional life". And some believed that the revival of certain cultural practices and principles would help them to deal with current problems and crises. Youth's perspectives on Acholi culture seemed to be strongly influenced by the highly emotive societal discourse (promoted especially by elders and international actors), which 'burdened' the young generation with the task of 'saving' Acholi culture and suggested that only the revival and maintenance of Acholi traditions would lead to a restoration of social stability.

In chapter 5 , I identified a great range of perspectives on and reactions to sociocultural change within the war generation, which can be seen as a result of these complex considerations and confusing influences. My analysis revealed that members of the war generation adopted different discourses which encompassed different sentiments (e.g. ambivalence, creativity) and entailed different projections (e.g. retraditionalization or modernization) for the future of Acholi society. Their decision to position themselves in a certain way depended on individual characteristics (age, gender, social status, life experience) and the situational context. Most of the young people I met switched between different positions depending on the people they were interacting with and the power constellations thereby involved.

This also relativizes the extent to which one can speak of clearly separable generational perspectives on Acholi culture and socio-cultural change. Although, as I elaborated above, there are many aspects which are debated along generational lines, there are also crosscutting positions as well as intra-generational disparities. More important than the actual similarities or differences, however, is the general perception, (re-)produced in local discourses, that generational relations in Acholi society have become strained and conflictual. In some ways, this discursive creation of clearly distinguishable 'conflict groups', which are associated with dichotomous notions of tradition and modernity and which mutually blame each other for the crisis, might reflect an attempt to make sense of and explain the current state of affairs. Similar processes of dichotomization have been observed in other African contexts of severe crisis. Geissler and Prince (2010), for instance, analyze the ways a Luo community (JoUhero) in Western Kenya tries to cope with the disarray sparked by poverty, unemployment and the AIDS epidemic. They state:

"We, as much as JoUhero, need at times the convenient fictions that dichotomies (...) provide, in order to choose what to do in a given situation, to tell stories or to frame our analysis. An important reason for the prominence of such dualist patterns in contemporary Uhero, and consequently in this book, is the sense of crisis that we noted above: in a present that is experienced as a breakdown, tropes of rupture acquire acute significance. Whether one at- 
tributes this crisis to a breach with the past or to a failure to break through into the future, this radicalizes the modern dichotomies and brings concerns with alterity and identity to the fore" (Geissler \& Prince, 2010: 79).

In many ways, the debates within the Luo community described by Geissler and Prince make an interesting comparison to the situation I encountered among my Acholi interlocutors. As in Gulu, gender and generational relations within the Luo community in Kenya were perceived as being severely strained due to the pressure of illness and death, economic hardship and land scarcity and a widespread feeling that "the land was dying" and people's expectations of modernity had remained unfulfilled, especially for young Luo (Geissler \& Prince, 2010: 2ff.). Similar to my observations in Gulu, discourses about modernity, tradition and the West centered on normative behavior - Geissler and Prince (2010: 91) speak of a "moral battlefield" - and were based on a desire to understand and overcome the current crisis. One aspect, which was at the core of these debates, both in Uhero (cf. Geissler \& Prince, 2010: 89ff.) and in Acholiland, concerned gender orders and norms. Rules, which prescribed the 'right ways' of behaving often involved clearly defined gender roles, norms and practices, and men and women who violated these rules were accused of aggravating the crisis. I will summarize in the following how the perceived changes in gender relations in Acholi society constituted a central aspect in discourses on socio-cultural change and, in a very fundamental way, reflected power struggles about gender orders and hierarchies.

\subsubsection{Gendered \& Sexualized Power Relations}

As I have shown in chapters 4, 5 and 6, gender was an important and highly contested category in Acholi society, especially in discourses on socio-cultural change. Reflected in these discourses was a general conviction among all members of Acholi society that gender relations had radically changed throughout the past decades. This change was attributed to the displacement situation during the war and the introduction of "Western" practices and discourses (for instance on women's rights and gender equality) through development organizations and the media. The implications and practical manifestations of changing gender roles, orders, ideologies and norms were a matter of much debate and evoked wide-ranging conflicts and power struggles.

As in the case of generational conflicts discussed above, 'gender conflicts' seemed to be fought between outwardly homogenous 'groups', i.e. men and women, which mutually blamed each other for the current state of 'disorder'. In local discourses, I often found that women blamed men for being lazy, irresponsible, unable to provide for their families and of being unfaithful to their wife or wives. Men, on the other hand, accused women of being materialistic, promiscuous, disrespectful towards male authorities, and of refusing to fulfill their roles as wives and mothers. The actual situation, however, was much more complex than these mutual accusations 
between seemingly 'binary-opposed groups' would suggest. Conflict constellations were much more blurred and also involved generational power differences, for instance between young men and old men or young women and old women.

It appeared that both men and women struggled with the perceived breakdown of long-established hegemonic models of masculinity (and femininity), which challenged the established social orders and therefore social stability. Especially young men struggled with the fact that they could no longer live up to the roles as family heads and providers expected of them in Acholi society. Many of my male interlocutors insinuated that they no longer felt valued, respected and needed. My female interlocutors, on the other hand, reported that for various reasons men were no longer able to fulfill the increasingly challenging role as provider, which in turn forced them to look for alternative sources of income and take over the man's role themselves.

On the practical level, men's frustration about their perceived relative disempowerment and women's new assertiveness on account of their perceived relative empowerment led to sometimes violent conflicts. Incidences of Gender Based Violence (GBV) and aggressive sexual behavior of men towards women were seen, by my interlocutors, to have increased as a result of men trying to regain their former social position. This claim can also be found in the literature. Whyte et al. (2012: 12ff.), for instance, who analyze the way Acholi men are using "arguments of culture" in the resettlement process to deny unmarried women access to land and belonging, describe an increase in "patrilineal fundamamentalism". Similarly Branch (2008: 16), speculating on the nature of post-war relations and conflicts in Acholi society, has presumed that

"there is a significant possibility that post-war Acholi society may be characterized by an intensive disciplinary project carried out by men, especially men with family or clan authority, designed to eliminate what they see as the corruption that had infected Acholi society during the war and displacement. (...) Indeed, among men, the re-establishment of 'traditional authority' was often framed explicitly in terms of undoing the power gained by women and youth in the camps and imposing the power of men and elders over these putatively formerly subservient groups".

This quotation points to the combined effects of the perceived breakdown of gender and gerontocratic orders and the complex conflict lines between different gender and age groups of Acholi society connected to it. One particularly controversial aspect, which played a big role in everyday discourses and in inter-gender, intergenerational interactions, concerned sexual relations.

The commonly discussed practice of "transactional sex" is a case in point. Transactional sexual relations exemplify the complex intertwinement of age and economic status, agency and power as well as changes in values and desires. Young women usually 'choose' to get involved with a "sugar daddy" and profit from the exchange. In this sense, transactional sexual relations reflect new forms of women's agency and 
sexual liberty (cf. Groes-Green, 2013). Young men, on the other hand, often told me that because they could not provide the material assets today's women desired, women of their age group preferred to go out with older men. Economically powerful, older men thus reinforced their dominant position in society by preventing younger men from getting a girlfriend and, in the long run, from being able to get married $^{210}$.

I have explicated that, in addition to their gendered dimension, discourses on socio-cultural change and power dynamics in Acholiland also have a highly sexualized dimension, which I discussed in relationship to Foucault's theories (cf. Chap. 6). During my fieldwork, I observed numerous incidents, which may well be analyzed with reference to his argument that a) sexuality can be instrumentalized in various (for instance social, political, cultural and economic) power struggles, that b) discourses on sexuality infiltrate all spheres of social life, and that c) the sexual conduct of the population is often taken as a target for intervention by local authorities, state officials and international actors (see Foucault, 1990: 26). The interconnection between sexuality and power, individual and population, became especially evident in societal discourses on HIV/AIDS, youth sexuality, women's sexuality, homosexuality and pornography. All of these discourses linked various local and national crises to the changed and 'uncontrolled' sexual behavior of the Acholi or, respectively, the Ugandan population and thus implied that a tighter control of these 'threatening' forms of sexuality was necessary to re-establish social order and stability. Poignant examples were the discourses on youth sexuality and HIV/AIDS which I frequently encountered at Gulu Youth Centre.

In fact, the youth centre was essentially a drop-in centre for VCT (Voluntary Counseling and Testing for HIV/AIDS) and its main function, besides testing, was to inform and counsel young people about risky sexual behavior, HIV and other sexually transmitted diseases. Most of the weekly debates, in which the young women and men who had come for testing had to participate and which were chaired by a counselor, revolved around sexual issues: teenage pregnancies, "transactional sex", sexual networks (i.e. the ways sexually transmitted diseases could spread if one was involved with multiple sexual partners), abusive (sexual) relationships, but also love and sex, family planning, safer sex practices, or living with HIV. In these "girl and boy talks", the young participants were usually asked about their experiences (related to the topic of debate) and then discussed how risky sexual behavior among youth

${ }^{210}$ Even young men with girlfriends who had agreed to marry them could often not afford the exorbitant bride prices currently demanded in Gulu. Therefore, girls were sometimes pressured by their parents to choose a more prosperous partner. Whyte et al. (2012) describe that during the war, when people were living in the camps and few had the resources to pay brideprice, marriages were often celebrated without the brideprice payments otherwise seen as necessary to formalize a marriage and to integrate the wife and her children into the lineage of the husband. In the postwar phase, this lack of formalization has caused several problems, especially concerning women's right to patrilineal land and men's right to their children. Whyte et al. (2012: 10) tellingly state that even "[m]arriage had become a matter of uncertainty". 
had become a major cause of societal crisis. At the end of each session, the counselors advised the participants on how to lead a safe and responsible life and avoid the detrimental consequences of sex. In many ways, the counseling techniques exhibited in these sessions are reminiscent of Foucault's discussion of the modern discourses on sex - which according to him evolved in Europe from the $18^{\text {th }}$ century onwards in which confessions on sex are seen to generate certain general "truths".

In applying Foucault's argument about the "interplay between sex and truth" (1990: 57) - i.e. the idea that confessing about sex is needed to reveal certain truths - to the situation in the youth center (and potentially other situations), I propose that confessions and debates regarding the dangers of youth sexuality were not primarily concerned with sexuality as such. Rather, they were used to enter into a discussion about a whole range of problematic societal developments seen to be the cause of the current crisis. In chapter 6, I already discussed how in similar ways other 'threatening' forms of sexuality were debated in local and national discourses, and discursively established as 'threats' to social stability and survival. The pending "antihomosexuality bill" is only one, albeit very prominent, example of such debates.

The preceding section has shown the convoluted interconnections of generational, gender, economic, social and sexual relations in contexts of changing societal power structures, precarious livelihoods, declining marriage rates and kinship ties in Acholi society. The insights drawn from these discussions can be applied to other African contexts in which rapid changes (related to HIV/AIDS, war, globalization etc.) necessitate a re-organization of society that fundamentally challenges established gerontocratic and patriarchic principles and thus evokes bitter struggles for power, influence and social order. A further, much debated aspect of socio-cultural change in Acholi discourses and beyond relates to local-global power relations, and particularly the colonial and postcolonial role of the West in Africa. I will summarize my insights on this matter in the following section.

\subsubsection{Local-Global Power Relations}

Throughout this book, I have outlined the complex ways local-global power relations, more concretely relations between Acholiland (respectively Uganda and Africa) and the West, played a role in local discourses on socio-cultural change. Generally, it was inferred that Western influences were a fundamental driver of socio-cultural change in Uganda, and particularly in Acholiland, due to the largescale humanitarian and political intervention by Western state and development actors. I noted that my interlocutors frequently used binary oppositions to elaborate and evaluate 'Western-influenced' change in Uganda. On the one hand, they glorified the West as the embodiment of progress and 'role model' for Uganda. On the other hand they condemned the West as the epitome of evil and criticized its neocolonial tendencies to impose its political agendas and belief systems on African people. 
Discourses on Westernization and neocolonialism must be seen in the context of Uganda's high level of dependence on foreign, primarily Western aid interventions. These have targeted and influenced discourses, policies and practices in a broad range of fields, including the economic, political, judicial, military, cultural, social, and even religious sector. The impact of the 'humanitarian regime' in Northern Uganda has been repeatedly stressed throughout this book. Apart from the 'practical interventions' (i.e. support for the provision of food, shelter, health services, education facilities, infrastructure etc. in the war and post-war phase), Western development actors introduced new discourses and influenced existing ones on a broad range of subjects: the war, the camps, the LRA, post-war reconstruction, human rights, culture, 'child soldiers', lifestyles, morals and many others. I have pointed out (especially in chapters 3, 4 and 6) how these discourses came to pervade local perceptions and narratives. But I have also demonstrated that local actors by no means just passively received and adapted to these discourses, but also refused, appropriated and strategically used them to negotiate and take on different positions in different social contexts.

I have demonstrated that Western discourses, for example regarding gender equality or children's rights, which imply certain morals, norms and regulations, are often cited in local power struggles, for instance between youth and elders or men and women. Depending on the speaker and the situation, they can be used to emphasize the discriminatory and outdated nature of "traditional" Acholi social norms or, on the contrary, the corruption and decadence of "modern" Acholi society brought about by "Western" imports. I often witnessed how some of my interlocutors switched between seemingly contradictory discourses and positions depending on the context and its power constellations. In one situation, they would describe themselves and the Acholi people as helpless victims of war and in dire need of Western aid, and use this argument to convince me or other "Westerners" to provide financial support for them personally or for one of their projects (common examples included recording a song, making a film, setting up a $\mathrm{CBO}$ ). In other contexts, the same people would condemn the submissiveness and passivity of the Acholi people, who were always begging "Westerners" for money instead of relying on their own resources. Sometimes, they would add that this kind of behavior only led the arrogant "Westerners" to feel and act even more superior towards the local population.

However, while ambivalence and situational switching were common, positions regarding the desirability of Western interventions and the introduction of 'Western concepts' were not completely arbitrary, but also depended on individual characteristics (age, gender, social status, life experience, level of education etc.). Not surprisingly, young people generally supported a more pro-Western stance, while older people were often more skeptical about "Westernization". One reason could be that young people were more exposed to international media (via TV, films, internet etc.), which transmits glossy images of 'Western modernity' and advertizes Western popular culture. Another reason could be related to young people's more extensive access to 'Western' forms of education, which privilege certain (i.e. science-based) 
perspectives and ways of knowing as more 'truthful' than 'traditional' knowledge, and which imply that people who do not possess and believe in these 'modern' forms of knowledge will not be able to excel in a globalized, capitalist world.

This latter aspect is especially relevant when looking at generational conflicts and power struggles because, as Foucault has emphasized in Discipline and Punish (2002b [1975]), power is essentially dependent on the control of knowledge and, vice versa, the establishment of what is considered knowledge is based on power. In Acholi society, it has long been elders' control of knowledge that legitimated their privileged position in society. This power-knowledge base is now being challenged through the introduction of new forms of knowledge that are passed to the young generation through 'Western' models of mass education in schools. Not only is elders' knowledge no longer considered useful. In addition, they also lose their status as definers and providers of knowledge, who can control which morals, worldviews and epistemologies are passed on to the younger generation. The latter function has been largely taken over by modern institutions like schools and the media.

Intergenerational struggles about power and knowledge are by no means specific to the Acholi context, although the particular dynamics of change, especially the simultaneous breakdown of social ties during the war, the sudden influx of Western development actors and the expansion of 'Western' schooling and media, may have led to an intensification of these struggles in Acholi society. Worldwide, local power-knowledge struggles along generational lines have become closely interlinked with globalized, capitalist power relations and modern power-knowledge regimes, which purport specific views on what is needed and what can be gained in a globalized world. In Africa, as various recent studies have shown, youth are attracted by and believe in the idea of 'capitalist modernity' transmitted to them in schools and the media. At the same time, however, they realize that they can neither fulfill the criteria (for example a high level of quality education) necessary to succeed in this system, nor do they profit from its promised benefits. Paradoxically, through their better access to education and global media (when compared to former generations), youth's desire for 'capitalist modernity' has been enflamed, but at the same time they have been 'enlightened' about the global power imbalances inherent in this system. They can see - on television, in films, on the internet - on a day to day basis what is 'out there', but what remains inaccessible for most of them. Mbembe (2002: 271) has analyzed this phenomenon and pointed to the "problem of the object of desire in an economy of scarcity as one more transformative force in contemporary African practices of self formation." Analyzing the material dimension of this "desire", he suggests that

"the sites and the vectors of this imaginaire of consumption are to a large extent the same as those found elsewhere in the world. But one development in particular deserves special recognition here. This is the phenomenon, in all its manifold aspects, of an economy of desired goods that are known, that 
may sometimes be seen, that one wants to enjoy, but to which one will never have material access" (ibid.).

The findings from my study relate very well to this statement. For the majority of my young Acholi interlocutors, the realization that they were in many ways excluded from the imagined benefits of 'Western modernity' was not only a source of great frustration, but also contributed to their feeling of uncertainty and being 'stuck in between'. In their quest for a future vision of Acholi society, so it often seemed to me, they were torn between idealized narratives about the 'traditional past' promoted by their elders and idealized images of a spatially distant and seemingly unattainable 'Western present'. However, as I have pointed out in chapter 5, there were also those young people, who could make creative use of their state of being 'in between', and who could use their imaginations of past and present, tradition and modernity to build a vision for the future.

\subsection{Youth at the Crossroads - In Post-War Acholiland \& Beyond}

In recent years, African youths' perspectives on the state of their societies have become a subject of increased relevance in both basic and applied research. All current debates, popular and scientific, on the wide-ranging changes African societies have undergone in the past decades take into account the role young people have played in bringing about these changes and, more importantly, the role they are to play in the future of African societies. The 'Arab Spring' revolutions in Northern Africa and the Gulf Region, which were spearheaded by young people who were dissatisfied with their political leaders and the economic, political and social systems in their respective countries, have put the precarious and volatile situation of marginalized youth on the global news and political agendas. One of the pressing questions after the fall of the regimes in Tunisia and Egypt in 2011, brought about by youth-led popular protests, was whether these events would spark 'youth revolutions' in Sub-Saharan Africa, where life conditions for young people seem to be even more precarious and where large numbers of unemployed youth face bleak future perspectives due to the political mismanagement, corruption and nepotism of their aged political leaders. Uganda was one of the countries where a repeat of the revolts in Egypt and Tunisia seemed possible. After the disputed re-election of President Museveni in February 2011 and sparked by rising fuel and food prizes, the Ugandan opposition initiated a series of popular protests and demonstrations, which reminded of the revolutions during the Arab Spring. However, the Museveni regime did not topple and through its violent repressions of the protests managed to maintain the political status quo. Similarly, popular uprisings in other Sub-Saharan 
states, most notably Malawi and Equatorial Guinea, were quashed (Akidi, 2012; Kainja, 2011; Brune, 2011).

Nevertheless, these recent developments have made African leaders aware that youth are a force to reckon with and no longer tolerate the marginalization and repression they long had to face by the old generations of political and economic elites. Through the global media, new communication technologies and mass education young people in Africa have become increasingly (and more than ever) aware of the inequalities they face, not only in their local communities and nation states, but also within the international system. Conversely, local and national authorities are slowly coming to realize the dangers inherent in neglecting the concerns and ambitions of the young generation. In her recently published book on the Time of Youth, Honwana (2012: 3) declaims that

"[y] oung people (...) are beginning to assert their rights as citizens. They are rising up against unemployment, socioeconomic marginalization, unsound economic policies, corrupt governments, political exclusion, and lack of respect for their rights. These are cries for freedom by a generation yearning to make a place for itself in the world."

She goes on to emphasize the importance which has come to be attributed to youth as "critical indicator of the state of the nation, of its politics, economy, and social and cultural life" (ibid.) in contemporary societal developments and, consequently, also in academic research.

Like Honwana, numerous scholars have stressed that the rapid changes in generational relations across Africa, caused among other things by globalization and the AIDS epidemic, necessitate a 're-making' of African societies, which fundamentally challenges established societal principles and thus evokes bitter struggles for power, influence and social order. In my research, I have analyzed one particular case of societal 're-making' and the conflicts and discourses which accompany such processes of socio-cultural change.

The young people in my case study faced many of the challenges seen as characteristic for the contemporary generation of African youth: lack of quality education, unemployment, HIV/AIDS, political and economic marginalization. In addition to these 'general' problems, however, they had grown up in a context of protracted war and were now confronted with the very specific challenges of living in a slowly recovering post-war society and with particular vulnerabilities related among other things to traumas resulting from abduction, displacement and violence experienced during the war, loss of parents and relatives as well as broken kinship ties and uncertain (social and spatial) belonging ${ }^{211}$. One particular challenge, which I have focused on in my study, concerns the 'burden' placed on youth - at least discursively - of 'rebuilding' society and 'saving' Acholi culture. Youth are framed as "primary vehicles

${ }^{211}$ Some of these particular vulnerabilities are described in the recent studies by Spitzer \& Twikirize (2012), Verma (2012), Webster (2013) and Whyte et al. (2012). 
for social change" (Cheney, 2007: 3), who, through their actions and choices, decide over the fate of Acholi society.

As I have discussed throughout this concluding chapter, the combination of the above-noted challenges has placed Acholi youth in a specific situation of uncertainty. On their "uneasy path to normality" (Spitzer \& Twikirize, 2012), they seem to be at a crossroads - between war and peace, past and future, tradition and modernity, Africanization and Westernization. As Whyte et al. (2012: 15) have noted: "Now that they are returning to some kind of normality, it is evident that those exceptional circumstances [of the war] are not exactly past; it is not clear what the norms of normal are or should be."

Youth's in-between status, however, is not only a source of uncertainty, but also places them in a unique position to shape the future of their society. As I have shown, Acholi youth are not only victims but important agents who can strategically use their in-between position by drawing on different discourses and switching between societal roles and positions. Throughout this book, I have given numerous examples of the multiple and complex ways my young interlocutors made use of various societal discourses on "culture", "tradition" and "modernity" in their negotiations of generational, gender, family and peer-to-peer relations. Their shifting between roles and positions enabled them to introduce new practices and perspectives in some contexts, while adhering to established rules and social orders in others, for instance in the family or when elders were present. While many youths experienced their situation as ambivalent and saw their actions as a mere adaption to circumstances rather than an active expression of agency, the way they dealt with socio-cultural changes and conflicting societal demands was in many ways very creative and innovative. Especially in the fields of art, music and dance, young people gained inspiration from a variety of sources including 'traditional' and 'modern' popular culture, and sometimes combined them in quite thought-provoking ways.

My study takes up a recent trend in research on African youth, which has shifted from a predominant focus on youth "in crisis" or "as crisis" to more complex considerations of youth as social actors in situations of wide-ranging change, confusion and uncertainty. While various studies have discussed how young people cope with physical, economic and political uncertainty, my research has pointed to an often neglected aspect which may be termed cultural or even epistemological uncertainty. I have shown how young people not only strive for physical and economic wellbeing and political recognition but aspire for something much more comprehensive. In fact, their quest is one for certainty, for meaning and, in a larger sense maybe, for truth $^{212}$. While many studies have revealed African youth's impressive abilities for improvisation and short term strategies to deal with instable and often precarious

${ }^{212}$ I have borrowed this expression from David Pratten, who used it in his commentary on my (Vorhölter, 2013) and three other papers in the panel "Novel Spaces for African Youth: Creativity, Entrepreneurship and Political Action" during the European Conference on African Studies in Lisbon. 
social environments, less attention has been paid to their long-term aspirations, i.e. their desires to build stable societies which enable individual freedoms while being guided by collective moral principles, and their hopes of contributing to and becoming part of a global community. In these long-term quests for future certainties, young people and old people become mutually entangled rather than diametrically opposed. As my findings show, members of the young generation not only challenge, but also conform to and reproduce some of the discourses and power relations established by members of the older generation. And while they need the old generation as an 'imagined other' against which they can 'rebel', they also want and actively call on members of the old generation to fulfill their role as knowledge-sharers and patrons. On a theoretical level, the complexity and contradictions inherent in these dynamics can be well-captured by applying a Foucauldian approach to power. The strength of such an approach lies in its ability address - with a non-ideological gaze - how the various power relations at the mirco-level produce often unforeseen outcomes on the marco-level and how all forms of resistance inevitably take place within already existing systems of power.

A central challenge I faced in my study - and presumably one which poses a challenge for any anthropological study of youth - is the great diversity in the way young people imagine and try to create certainty and the question whether one can speak of youth as a distinct social category at all. In my analysis, I tried to overcome the latter difficulty by using Mannheim's concept of "historical generation" to speak about a clearly demarcated 'subgroup' of youth. However, this 'solution' only partly addresses the problem of diversity. Van Dijk et al. (2011) have recently pointed out that "youth" in Africa has in many ways become an ideology rather than a phenomenon or a concept, which people irrespective of their age make use of - for instance to position themselves in international development discourses or, as I have alluded to in my study, in local power structures. Youth, in this sense then, is a historically established discourse rather than a fixed category. Thus, one could argue, it becomes less important to define youth 'as such' and rather more important to ask who adopts the label youth and why and, respectively, who speaks about youth and in which context. As I have shown in my study with regard to other problematic terms such as "culture" or "the West", a Foucauldian discourse-analytical approach can help to identify emic or situational usages and relate them to analytical conceptualizations of such terms. I suggest that a similar approach may also be applied to deconstruct and reconfigure contemporary notions of youth.

On a theoretical level, questions related to generational power struggles, the relevance of age and experience, and the problem of diversity will remain central challenges for the anthropology of youth. With regard to my case study and the current situation in (Northern) Uganda, it remains to be seen how the war generation of Acholi ages and whether, after the uncertainties which shaped their childhood and youth, their futures will be more certain. How will this generation raise their own children and which values, norms and social orders will be the subject of future generational conflicts? Will peace, and not just the absence of war, return to Acho- 
liland and prevail? Or will existing grievances linger and new forms of violence and political conflict erupt? Is there a prospect for a 'youth revolution' in Uganda after all? Or will the old elites, stirred by the lures of economic power through recently discovered oil, maintain the status quo?

These and other questions might be taken up in future studies. And in some years to come we shall know which pathways the 'leaders of tomorrow' have chosen and which new crossroads they face in their quest for certainty. 



\section{References}

Abbink, Jon and van Kessel, Ineke (eds). 2005. Vanguard or Vandals - Youth, Politics and Conflict in Africa. Leiden: Brill.

Abbink, Jon. 2005. Being Young in Africa: The Politics of Despair and Renewal. In: Abbink, Jon and van Kessel, Ineke (eds). Vanguard or Vandals - Youth, Politics and Conflict in Africa. Leiden: Brill (1-34).

Abdullah, Ibrahim. 2005. "I am a Rebel" - Youth Culture and Violence in Sierra Leone. In: Honwana, Alcinda and De Boeck, Filip (eds). Makers and Breakers - Children and Youth in Postcolonial Africa. Oxford: James Currey $(172-187)$.

Abdullah, Ibrahim. 1998. Bush Path to Destruction: The Origin and Character of the Revolutionary United Front. In: The Journal of Modern African Studies, Vol. 36, No. 2 (203-235).

Abu-Lughod, Lila. 1991. Writing Against Culture. In: Fox, Richard G. (ed.). Recapturing Anthropology. Santa Fe: School of American Research Press (137-162). 
Acholi Heart Beat (official website): http://ugta.org/acholi_heart_beat.php, accessed 29.05.2012.

Acirokop, Prudence. 2010. The Potential and Limits of Mato Oput as a Tool for Reconciliation and Justice. In: Parmar, Sharanjeet; Roseman, Mindy Jane; Siegrist, Saudamini and Sowa, Theo (eds). Children and Transitional Justice - Truth-Telling, Accountability and Reconciliation. Published by the Human Rights Program at Harvard Law School. New York: UNICEF (267-292).

Adichie, Chimamanda. 2009. The Danger of a Single Story. TED, July 2009. Online at: http://www.ted.com/talks/chimamanda_adichie_the_danger_of_a_ single_story.html, accessed 10.10.2013.

Adogame, Afe, Echtler, Magnus and Vierke, Ulf (eds). 2008a. Unpacking the New - Critical Perspectives on Cultural Syncretization in Africa and Beyond. Wien: LIT.

Adogame, Afe, Echtler, Magnus and Vierke, Ulf. 2008b. Unpacking the New Critical Perspectives on Cultural Syncretization in Africa and Beyond. In: Adogame, Afe, Echtler, Magnus and Vierke, Ulf (eds). Unpacking the New - Critical Perspectives on Cultural Syncretization in Africa and Beyond. Wien: LIT (1-26).

Adong, J. and Lakareber, J. 2009. Luo-English Dictionary. Kampala: Fountain Publishers.

Afako, Barney. 2002. Reconciliation and Justice: "Mato Oput" and the Amnesty Act. In: Lucima, Okello (ed.). Protracted Conflict, Elusive Peace - Initiatives to End the Violence in Northern Uganda. London: Accord (64-67).

African Youth Charter. 2006. Online at: http://www.africa-union.org/root/ua/ conferences/mai/hrst/charter\%20english.pdf, accessed 18.10.2011.

Afshar, Haleh and Eade, Deborah (eds). 2004. Development, Women and War Feminist Perspectives. Oxford: Oxfam.

Akidi, Rachel. 2012. Can the Arab Spring Spread Across the Rest of Africa? In: The Huffington Post, $27^{\text {th }}$ January, 2012. Online at: http://www.huffingtonpost.co.uk/rachael-akidi/arab-spring-africa_b_1233961.html, accessed 04.04.2013.

Alber, Erdmute. 2004. Grandparents as Foster-parents: Transformations in Fosterrelations between Grandparents and Grandchildren in Northern Benin. In: Africa, Vol. 74, No. 1 (28-46).

Alber, Erdmute and Häberlein, Tabea. 2010. Ethnologische Generationenforschung in Afrika. In: Alber, Erdmute; Beer, Bettina; Pauli, Julia and Schnegg, Michael (eds). Verwandtschaft heute - Positionen, Ergebnisse und Perspektiven. Berlin: Reimer (281-304).

Alber, Erdmute; van der Geerst, Sjaak and Whyte, Susan R. (eds). 2008. Generations in Africa - Connections and Conflicts. Berlin: LIT. 
Allen, Tim. 2010. Bitter Roots: the "Invention" of Acholi Traditional Justice. In: Allen, Tim and Vlassenroot, Koen (eds). The Lord's Resistance Army. Myth and Reality. Oxford: James Currey (242-261).

Allen, Tim. 2006. Trial Justice - The International Criminal Court and the Lord's Resistance Army. London: Zed Books.

Allen, Tim. 1994. Ethnicity and Tribalism on the Sudan-Uganda Border. In: Fukui, Katsuyoshi and Markakis, John (eds). Ethnicity and Conflict in the Horn of Africa. London: James Currey (112-139).

Allen, Tim; Laker, Frederick; Porter, Holly and Schomerus, Mareike. 2010. Postscript: A Kind of Peace and Exported War. In: Allen, Tim and Vlassenroot, Koen (eds). The Lord's Resistance Army. Myth and Reality. Oxford: James Currey (279-288).

Allen, Tim and Vlassenroot, Koen (eds). 2010a. The Lord's Resistance Army. Myth and Reality. Oxford: James Currey.

Allen, Tim and Vlassenroot, Koen. 2010b. Introduction. In: Allen, Tim and Vlassenroot, Koen (eds). The Lord's Resistance Army. Myth and Reality. Oxford: James Currey (1-24).

Amin, Samir. 1973. Neo-colonialism in West Africa. New York: Monthly Review Press.

Amit-Talai, Vered and Wulff, Helena (eds). 1995. Youth Cultures - A Cross-cultural Perspective. London: Routledge.

Annan, Jeannie; Blattman, Christopher and Horton, Roger. 2006. The State of Youth and Youth Protection in Northern Uganda - Findings from the Survey for War Affected Youth. A Report for UNICEF Uganda. Kampala: UNICEF.

Annan, Jeannie; Blattman, Christopher; Carlson, Khristopher and Dyan Manzurana. 2008. The State of Female Youth in Northern Uganda - Findings from the Survey for War Affected Youth. Phase II. SWAY Project Northern Uganda.

Anyoli, Edward and Nanteza, Winnifred. 2010. Special Report: How the Bride Price Petition was Defeated. In: Saturday Vision, $3^{\text {rd }}$ April, 2010 (6-7).

Appadurai, Arjun. 2004. The Capacity to Aspire: Culture and the Terms of Recognition. In: Rao, Vijayendra and Walton, Michael (eds). Culture and Public Action. Stanford, CA: Stanford University Press (59-84).

Appadurai, Arjun. 1996. Modernity at Large - Cultural Dimensions of Globalization. Minneapolis: University of Minnesota Press.

Appadurai, Arjun. 1991. Global Ethnoscapes - Notes and Queries for a Transnational Anthropology. In: Fox, Richard (ed.). Recapturing Anthropology - Working in the Present. Santa Fe: School of American Research Press (191-210).

Appiah, Kwame Anthony. 2008. African Identities. In: Geschiere, Peter; Meyer, Birgit and Pels, Peter (eds). Readings in Modernity in Africa. Oxford: James Currey (88-92). 
Appiah, Kwame Anthony. 1991. Is the Post- in Postmodernism the Post- in Postcolonial? In: Critical Inquiry, Vol. 17, No. 2 (336-357).

Apter, David. 1967. The Political Kingdom in Uganda - A Study of Bureaucratic Nationalism. $2^{\text {nd }}$ Edition. Princeton: Princeton University Press.

ARLPI (Acholi Religious Leaders' Peace Initiative). 2001. Let my People Go: The Forgotten Plight of the People in the Displaced Camps in Acholi. Gulu: ARLPI.

Arnfred, Signe. 2004a. Introduction: Re-thinking Sexualities in Africa. In: Arnfred, Signe (ed.). Rethinking Sexualities in Africa. Uppsala: Nordiska Africainstitutet (7-34).

Arnfred, Signe. 2004b. "African Sexuality"/Sexuality in Africa: Tales and Silences. In: Arnfred, Signe (ed.). Rethinking Sexualities in Africa. Uppsala: Nordiska Africainstitutet (59-78).

Ashcroft, Bill, Griffiths, Gareth and Tiffin, Helen. 1998. Key Concepts in PostColonial Studies. London: New York (23-27).

Atkinson, Ronald R. 2010. "The Realists in Juba"? An Analysis of the Juba Peace Talks. In: Allen, Tim and Vlassenroot, Koen (eds). The Lord's Resistance Army. Myth and Reality. Oxford: James Currey (205-222).

Atkinson, Ronald R. 1999. The Roots of Ethnicity: the Origins of the Acholi of Uganda before 1800. Kampala: Fountain Publishers.

Atkinson, Ronald R. 1994. Acholi. In: Middleton, John and Rassam, Amal (eds). Encyclopedia of World Cultures - Volume IX - Africa and the Middle East. New York: G.K. Hall (3-7).

Atkinson, Ronald R. 1989. The Evolution of Ethnicity among the Acholi of Uganda: The Precolonial Phase. In: The American Society for Ethnohistory, Vol. 36, No. 1 (19-43).

Atkinson, Ronald R.; Lancaster Phil; Cakaj, Ledio and Lacaille, Guilaume. 2012. Do No Harm: Assessing a Military Approach to the Lord's Resistance Army. In: Journal of Eastern African Studies, Vol. 6, No. 2 (371-382).

Baerends, Els A. 1998. Changing Kinship, Family and Gender Relations in SubSaharan Africa. In: Risseeuw, Carla and Ganesh, Kamala (eds). Negotiation and Social Space - A Gendered Analysis of Changing Kin and Security Networks in South Asia and Sub-Saharan Africa. New Dehli: Thousand Oaks Publications (47-86).

Baines, Erin K. 2009. Complex Political Perpetrators - Reflections on Dominic Ongwen. In: The Journal of Modern African Studies, Vol. 47, No. 2 (163191).

Baines, Erin K. 2007. The Haunting of Alice: Local Approaches to Justice and Reconciliation in Northern Uganda. In: The International Journal of Transitional Justice, Vol 1, No. 1 (91-114).

Baller, Susann. 2010. Spielfelder der Stadt - Fußball und Jugendpolitik im Senegal seit 1950. Köln: Böhlau Verlag. 
Bangura, Yusuf. 1997. Understanding the Political and Cultural Dynamics of the Sierra Leone War: A Critique of Paul Richards' Fighting for the Rain Forest. In: Africa and Development, Vol. XXII, No. 3/4 (117-148).

Barker, Gary and Ricardo, Christine. 2005. Young Men and the Construction of Masculinity in Sub-Sahara Africa: Implication for HIV/Aids, Conflict and Violence. Washington: World Bank (Social Development Papers, Conflict Prevention and Reconstruction Unit, No. 26).

Basudde, Elvis. 2012. Uganda: HIV/Aids Bill Almost Ready. In: New Vision, $1^{\text {st }}$ December, 2012. Online at: http://allafrica.com/stories/201212030273. html?viewall=1, accessed 28.03.2013.

Baumann, Gerd. 2004. Grammars of Identity/Alterity - A Structural Approach. In: Baumann, Gerd and Gingrich, Andre (eds). Grammars of Identity/Alterity - A Structural Approach. New York: Berghahn (18-50).

Baumann, Gerd and Gingrich, Andre (eds). 2004. Grammars of Identity/Alterity - A Structural Approach. New York: Berghahn.

Behrend, Heike. 2007. Catholics and Cannibals: Terror and Healing in Tooro, Western Uganda. In: Rao, Aparno; Bollig, Michael and Böck, Monika (eds). The Practice of War - Production, Reproduction and Communication of Armed Violence. New York: Berghahn.

Behrend, Heike. 1999. Power to Heal, Power to Kill: Spirit Possession and War in Northern Uganda (1986-1994). In: Behrend, Heike and Luig, Ute (eds). Spirit possession, Modernity and Power in Africa. Oxford : James Currey (20-33).

Behrend, Heike. 1998. War in Northern Uganda - The Holy Spirit Movements of Alice Lakwena, Severino Lukoya and Joseph Kony (1986-1997). In: Clapham, Christopher (ed.). African Guerrillas. Oxford: James Currey (107-118).

Behrend, Heike. 1995. Power and Women as Spirit Mediums. In: Reh, Mechthild and Ludwar-Ene, Gudrun (eds). Gender and Identity in Africa. Münster: LIT (51-59).

Behrend, Heike. 1993. Alice und die Geister - Krieg im Norden Ugandas. München: Trickster.

Behrend, Heike. 1991. Is Alice Lakwena a Witch? The Holy Spirit Movement and its Fight Against Evil in the North. In: Hansen, Holger B. and Twaddle, Michael (eds). Changing Uganda. London: James Currey et al (162-177).

Benedict, Ruth. 2008 [1938]. Continuities and Discontinuities in Cultural Conditioning. In: LeVine, Robert A. and New, Rebecca, S. (eds). Anthropology and Child Development - A Cross-cultural Reader. Malden: Blackwell (42-48).

Bennett, Jane. 2011. Subversion and Resistance: Activist Initiatives. In: Tamale, Silvia (ed.). African Sexualities - A Reader. Cape Town: Pambazuka Press (77-100). 
Bennett, Jane. 2010. "Circles and Circles": Notes on African Feminist Debates around Gender and Violence in the C21. In: Feminist Africa, Vol. 14 (21-47).

Berger, Peter L. and Luckmann, Thomas. 2011 [1966]. The Social Construction of Reality: A Treatise in the Sociology of Knowledge. New York: Open Road Media.

Bernard, H. Russell. 2006. Research Methods in Anthropology - Qualitative and Quantitative Approaches. $4^{\text {th }}$ Edition. Oxford: Altamira.

Bhandari, Ron. 2012. Experts Weekly: Uganda's Anti-Homosexuality Bill. In: Think Africa Press, $17^{\text {th }}$ December, 2012. Online at: http://thinkafricapress. com/uganda/experts-weekly-ugandas-anti-homosexuality-bill, accessed 07.01.2013.

Birkhan, Barbara. 2012. Foucaults ethnologischer Blick - Kulturwissenschaft als Kritik der Moderne. Bielefeld: Transcript.

Blattman, Christopher and Annan, Jeannie. 2010. On the Nature and Cause of LRA Abductions: What the Abductees Say. In: Allen, Tim and Vlassenroot, Koen (eds). The Lord's Resistance Army. Myth and Reality. Oxford: James Currey (132-155).

Bochow, Astrid. 2008. Valentine's Day in Ghana: Youth, Sex and Secrets. In: Alber, Erdmute; van der Geerst, Sjaak and Whyte, Susan R. (eds). Generations in Africa - Connections and Conflicts. Berlin: LIT (333-356).

Boden, Gertrud. 2008. “The Young People Do What They Want”: Negotiating Intergenerational Relationships Among the Khwe of Namibia. In: Alber, Erdmute; van der Geerst, Sjaak and Whyte, Susan R. (eds). Generations in Africa - Connections and Conflicts. Berlin: LIT (113-136).

Bogner, Artur and Rosenthal, Gabriele. 2012. Die „unerzählten“ Geschichten von Außenseitern und deren Relevanz für die Analyse von (Post-)Konfliktkonfigurationen - Interviews mit Opfern kollektiver Gewalt in Norduganda (West Nile). In: Soziologus, Vol. 62, No. 2 (115-141).

Böhm, Andrea and Kemper, Anna. 2013. Missionare des Hasses. In: Die ZEIT, $21^{\text {st }}$ February, 2013 (10-11).

Boothby, Neil; Strang, Alison and Wessels, Michael (eds). 2006. A World Turned Upside Down - Social Ecological Approaches to Children in War Zones. Bloomfield: Kumarian Press.

Bourdieu, Pierre. 1976 [1972]. Entwurf einer Theorie der Praxis auf der ethnologischen Grundlage der kabylischen Gesellschaft. Frankfurt a. M.: Suhrkamp.

Bourgois, Philippe. 2003 [1996]. In Search of Respect - Selling Crack in El Barrio. $2^{\text {nd }}$ Edition. New York: Cambridge University Press.

Bourgois, Philippe and Schonberg, Jeff. 2009. Righteous Dopefiend. Berkeley: University of California Press. 
Boyden, Jo and de Berry, Joanne (eds). 2004. Children and Youth on the Front Line: Ethnography, Armed Conflict, and Displacement. New York: Berghahn.

Branch, Adam. 2012. Humanitarianism, Violence, and the Camp in Northern Uganda. In: Bakonyi, Jutta and Bliesemann de Guerva, Berit (eds). A Micro-Sociology of Violence: Deciphering Patterns and Dynamics of Collective Violence. London: Routledge (81-105).

Branch, Adam. 2011. Displacing Human Rights - War and Intervention in Northern Uganda. Oxford: Oxford University Press.

Branch, Adam. 2010. Exploring the Roots of LRA Violence: Political Crisis and Ethnic Politics in Acholiland. In: Allen, Tim and Vlassenroot, Koen (eds). The Lord's Resistance Army. Myth and Reality. Oxford: James Currey (25-44).

Branch, Adam. 2008. Gulu Town in War... and Peace? Displacement, Humanitarianism, and Post-War Crisis. London: LSE (Crisis States Working Papers Series No.2).

Brubacher, Matthew. 2010. The ICC Investigation of the Lord's Resistance Army: an Insider's View. In: Allen, Tim and Vlassenroot, Koen (eds). The Lord's Resistance Army. Myth and Reality. Oxford: James Currey (262-278).

Brune, Nancy E. 2011. Sub-Saharan Africa and the Arab Spring. In: World Politics Review, 20 ${ }^{\text {th }}$ December, 2011. Online at: http://www.worldpoliticsreview.com/articles/10995/sub-saharan-africa-and-the-arab-spring, accessed 05.04.2013.

Bucholtz, Mary. 2002. Youth and Cultural Practice. In: Annual Review of Anthropology, Vol. 31 (525-552).

Bundy, Colin. 1987. Street Sociology and Pavement Politics: Aspects of Youth and Student Resistance in Cape Town, 1985. In: Journal of Southern African Studies, Vol. 13, No. 3 (303-330).

Burgess, Thomas. 2005. Introduction to Youth and Citizenship in East Africa. In: Africa Today, Vol. 51, No. 3 (vii-xxiv).

Butagira, Tabu. 2012. Museveni Warns Obama on Gays. In: Daily Monitor Online, 25 ${ }^{\text {th }}$ February, 2012. Online at: http://www.monitor.co.ug/News/ National/-/688334/1334192/-/b07avqz/-/index.html, accessed 20.12.2012.

Buturo, Nsaba. 2013. In Defense of the Anti-Pornography Bill, 2011. In: New Vision, 30 ${ }^{\text {th }}$ April, 2013. Online at: http://www.newvision.co.ug/ news/642197-in-defence-of-the-anti-pornography-bill-2011.html, accessed 08.06.2013.

Byamukama, Dora. 2010. How Can the Law On Defilement Be Made More Effective? In: New Vision, 20 ${ }^{\text {th }}$ October, 2010. Online at: http://www.accessmylibrary.com/article-1G1-240090674/ can-law-defilement-made.html, accessed 28.03.2013.

Cagney, Erin Michelle. 2011. Post-Conflict Cultural Revival and Social Restructuring in Northern Uganda. Senior Thesis in Anthropology. University of 
Tennessee Honors Thesis Projects. Online at: http:/trace.tennessee.edu/cgi/ viewcontent.cgi?article $=2454 \&$ context $=$ utk_chanhonoproj $\&$ sei-redir=1\#search=\%22post $\% 20$ conflict $\% 20$ cultural $\% 20$ revival $\% 20$ northern\%20uganda\%22, accessed 07.07.2011.

Castro Varela, María do Mar and Dhawan, Nikita. 2005. Postkoloniale Theorie Eine kritische Einführung. Bielefeld: Transcript.

Chabal, Patrick. 2009. Africa - The Politics of Suffering and Smiling. London: Zed Books.

Charmaz, Kathy and Mitchell, Richard G. 2001. Grounded Theory in Ethnography. In: Atkinson, Paul; Coffey, Amanda; Delamont, Sara; Lofland, John and Lofland, Lyn (eds). Handbook of Ethnography. London: SAGE (160-174).

Chaudhary, M. Azam. 2006. Rhineland Ethnography and Pakistani Reflexivity. In: Zeitschrift für Ethnologie, Vol. 131, No. 1 (1-26).

Cheney, Kristen E. 2007. Pillars of the Nation - Child Citizens and Ugandan National Development. Chicago: University of Chicago Press.

Christiansen, Catrine; Utas, Mats and Vigh, Hendrik. E. (eds). 2006a. Navigating Youth, Generating Adulthood - Social Becoming in an African Context. Uppsala: Nordiska Afrikainstitutet.

Christiansen, Catrine; Utas, Mats and Vigh, Hendrik. E. 2006b. Introduction. In: Christiansen, Catrine; Utas, Mats and Vigh, Hendrik. E. (eds). Navigating Youth, Generating Adulthood - Social Becoming in an African Context. Uppsala: Nordiska Afrikainstitutet (9-28).

Ciaffa, Jay A. 2008. Tradition and Modernity in Postcolonial African Philosophy. In: Humanitas, Vol. XXI, No. 1+2 (121-145).

Cleaver, Francis. 2002. Men and Masculinities: New Directions in Gender and Development. In: Cleaver, Francis (ed.). Masculinities Matter: Men, Gender and Development. London: Zed Books (1-27).

Cohen, Albert. 1967 [1955]. Delinquent Boys - the Culture of the Gang. New York: Free Press.

Cohen, Stanley. 2002 [1972]. Folk Devils and Moral Panics: the Creation of the Mods and Rockers. $3^{\text {rd }}$ Edition. London: Routledge.

Cole, Jennifer. 2011. A Cultural Dialectics of Generational Change: The View From Contemporary Africa. In: Review of Research in Education, Vol. 35 (60-88).

Cole, Jennifer. 2010. Sex and Salvation: Imagining the Future in Madagascar. Chicago: University of Chicago Press.

Cole, Jennifer. 2008. Fashioning Distinction: Youth and Consumerism in Urban Madagascar. In: Cole, Jennifer and Durham, Deborah (eds). Figuring the Future: Youth and Temporality in a Global Era. Santa Fe: School of American Research Press (99-124). 
Cole, Jennifer. 2004. Fresh Contact in Tamatave, Madagascar: Sex, Money and Intergenerational Transformation. In: American Ethnologist, Vol. 31, No. 4 (573-588).

Cole, Jennifer and Durham, Deborah (eds). 2008a. Figuring the Future - Globalization and the Temporalities of Children and Youth. Santa Fe: School for Advanced Research Press.

Cole, Jennifer and Durham, Deborah. 2008b. Introduction: Globalization and the Temporality of Children and Youth. In: Cole, Jennifer and Durham, Deborah (eds). Figuring the Future - Globalization and the Temporalities of Children and Youth. Santa Fe: School for Advanced Research Press $(3-24)$.

Cole, Jennifer and Durham, Deborah (eds). 2007a. Generations and Globalization - Youth, Age, and Family in the New World Economy. Bloomington: Indiana University Press.

Cole, Jennifer and Durham, Deborah. 2007b. Introduction: Age, Regeneration, and the Intimate Politics of Globalization. In: Cole, Jennifer and Durham, Deborah (eds). Generations and Globalization - Youth, Age, and Family in the New World Economy. Bloomington: Indiana University Press (1-28).

Cole, Jennifer and Thomas, Lynn M. (eds). 2009. Love in Africa. Chicago: University of Chicago Press.

Coleman, Simon and Collins, Peter. (eds). 2006. Locating the Field - Space, Place and Context in Anthropology. Oxford: Berg.

Comaroff, Jean and Comaroff, John. 2005. Reflections on Youth - From the Past to the Postcolony. In: Honwana, Alcinda and De Boeck, Filip (eds). Makers and Breakers - Children and Youth in Postcolonial Africa. Oxford: James Currey (19-30).

Comaroff, Jean and Comaroff, John. 1999. Occult Economies and the Violence of Abstraction: Notes from the South African Postcolony. In: American Ethnologist, Vol. 26, No. 2 (279-303).

Comaroff, Jean and Comaroff, John. 1993. Introduction. In: Comaroff, Jean and Comaroff, John (eds). Modernity and Its Malcontents. Ritual and Power in Postcolonial Africa. Chicago: University of Chicago Press (xi-xxxvii).

Condon, Richard G. 1990. The Rise of Adolescence: Change and Life Stage Dilemmas in the Central Canadian Arctic. In: Human Organization, Vol. 49, No. 3 (266-279).

Connell, Robert W. 2005 [1995]. Masculinities. $2^{\text {nd }}$ Edition. Cambridge: Polity Press.

Constitution of Uganda. 1995. Online at: http:/www.ugandaembassy.com/ Constitution_of_Uganda.pdf, accessed 25.07.2012.

Convention on the Rights of the Child. 1989. Online at: http://www2.ohchr.org/ english/law/crc.htm, accessed 18.10.2011. 
Cornwall, Andrea. 2005. Introduction: Perspectives on Gender in Africa. In: Cornwall, Andrea (ed.). Readings in Gender in Africa. Bloomington: Indiana University Press (1-19).

Cornwall, Andrea; Harrison, Elizabeth and Whitehead, Ann. 2004. Introduction: Repositioning Feminisms in Gender and Development. In: IDS Bulletin, Vol. 35, No. 4 (1-10).

Cornwall, Andrea and White, Sarah C. 2000. Men, Masculinities and Development - Politics, Policies and Practice. In: IDS Bulletin, Vol. 31, No. 2 $(1-6)$.

Crazzolara, Josef Pascal. 1954. The Lwoo. Part III. Clans. Verona: Editrice Nigrizia.

Crazzolara, Josef Pascal. 1951. The Lwoo. Part II. Lwoo Traditions. Verona: Editrice Nigrizia.

Crazzolara, Josef Pascal. 1950. The Lwoo. Part I. Lwoo Migrations. Verona: Instituto Missioni Africane.

Crazzolara, Josef Pascal. 1938. A Study of the Acooli Language - Grammar and Vocabulary. London: Oxford University Press (Published for the International Institute of African Languages and Cultures).

Cruise O’Brian, Donal. 1996. A lost Generation? Youth Identity and State Decay in West Africa. In: Werbner, Richard and Ranger, Terrence (eds). Postcolonial Identities in Africa. London: New Jersey (55-74).

Das, Rheka and Nkutu, Anne. 2008. Evaluation of General Food Distribution in Northern Uganda: Gulu, Amuru and Kitgum Districts 2005-2008. Kampala: Norwegian Refugee Council/Nordic Consulting Group.

De Boeck, Filip and Honwana, Alcinda. 2005. Introduction: Children and Youth in Africa. Agency, Identity, Place. In: Honwana, Alcinda and De Boeck, Filip (eds). Makers and Breakers - Children and Youth in Postcolonial Africa. Oxford: James Currey (1-18).

De Temmerman, Els. 2001. Aboke Girls - Children Abducted in Northern Uganda. Kampala: Fountain Publishers.

Denscombe, Martyn. 2003. The Good Research Guide for Small-Scale Social Research Projects. $2^{\text {nd }}$ Edition. Maidenhead: Open University Press.

Dilger, Hansjörg. 2005. Leben mit Aids - Krankheit, Tod und soziale Beziehungen in Afrika: eine Ethnographie. Frankfurt a.M.: Campus.

Dilger, Hansjörg. 2003. Jugend und Aids in Tanzania. Reflexion und verbales Handeln in Diskursen junger Luo über Sexualität, Moral und Moderne. In: Luig, Ute and Seebode, Jochen (eds). Ethnologie der Jugend - Soziale Praxis, moralische Diskurse und inszenierte Körperlichkeit. Münster: LIT (241-271).

Diouf, Mamadou. 2003. Engaging Postcolonial Cultures: African Youth and Public Space. In: African Studies Review, Vol. 46, No. 2 (1-12).

Dolan, Chris. 2009. Social Torture - The Case of Northern Uganda, 1986-2006. New York: Berghahn. 
Dolan, Chris. 2002. Collapsing Masculinities and Weak States - A Case Study of Northern Uganda. In: Cleaver, Francis (ed.). Masculinities Matter: Men, Gender and Development. London: Zed Books (57-83).

Doom, Ruddy and Vlassenroot, Koen. 1999. Kony's Message: A new Koine? The Lord's Resistance Army in Northern Uganda. In: African Affairs, No. 98 (5-36).

Dracklé, Dorle. 1996a. Kulturelle Repräsentation von Jugend in der Ethnologie. In: Dracklé, Dorle (ed.). Jung und Wild - Zur kulturellen Konstruktion von Kindheit und Jugend. Hamburg: Dietrich Reimer (14-53).

Dracklé, Dorle. 1996b. Discourse Theory in Anthropology. In: van Bremen, Jan; Godina, Vesna and Platenkamp, Jos (eds). Horizons of Understanding An Anthology of Theoretical Anthropology in Europe. Leiden: CNWS Publications (24-42).

Dunn, Kevin C. 2004. Uganda: The Lord's Resistance Army. In: Review of African Political Economy, Vol. 31, No. 99 (139-142).

Durham, Deborah. 2008. Apathy and Agency: The Romance of Agency and Youth in Botswana. In: Cole, Jennifer and Durham, Deborah (eds). Figuring the Future - Globalization and the Temporalities of Children and Youth. Santa Fe: School for Advanced Research Press (151-178).

Durham, Deborah. 2004. Disappearing Youth: Youth as a Social Shifter in Botswana. In: American Ethnologist, Vol. 31, No. 4 (589-605).

Durham, Deborah. 2000. Youth and the Social Imagination in Africa: Introduction to Parts 1 and 2. In: Anthropological Quarterly, Vol. 73, No. 3 (113120).

Dwyer, John Orr. 1972. The Acholi of Uganda: Adjustment to Imperialism. PhD Dissertation. New York: Columbia University.

Eichstaedt, Peter. 2009. First Kill Your Family - Child Soldiers of Uganda and the Lord's Resistance Army. Chicago: Lawrence Hill Books.

Eisenstadt, Shmuel N. 2000. Multiple Modernities. In: Daedalus, Vol. 129, No. 1 (1-29).

El Jack, Amani. 2003. Gender and Armed Conflict - Overview Report. Brighton: BRIDGE.

El-Bushra, Judy and Sahl, Ibrahim M.G. 2005. Cycles of Violence - Gender Relations and Armed Conflict. Nairobi: ACORD.

Ellis, Amanda; Manuel, Claire and Blackden, Mark C. 2006. Gender and Economic Growth in Uganda - Unleashing the Power of Women. Washington: World Bank.

Epprecht, Marc. 2008. Heterosexual Africa? The History of an Idea From the Age of Exploration to the Age of AIDS. Athens: Ohio University Press.

Eriksson Baaz, Maria. 2001. Introduction - African Identity and the Postcolonial. In: Eriksson Baaz, Maria and Palmberg, Mai (eds). Same and Other - Negotiating African Identity in Cultural Production. Uppsala: Nordiska Afrikainstitutet (5-22). 
Esteva, Gustavo and Prakash, Madhu S. 1998. Grassroots Post-Modernism: Remaking the Soil of Cultures. London: Zed Books.

Fairclough, Norman. 2001. Language and Power $-2^{\text {nd }}$ Edition. Essex: Pearson Education Limited.

Fairclough, Norman. 1992. Discourse and Text: Linguistic and Intertextual Analysis within Discourse Analysis. In: Discourse and Society, Vol. 3, No. 2 (193-217).

Ferguson, James. 2008. Global Disconnect - Abjection and the Aftermath of Modernism. In: Geschiere, Peter; Meyer, Birgit and Pels, Peter (eds). Readings in Modernity in Africa. Oxford: James Currey (8-16).

Ferguson, James. 2006 Global Shadows: Africa in the Neoliberal World Order. Durham: Duke University Press.

Ferguson, James. 2005. Decomposing Modernity: History and Hierarchy after Development. In: Loomba, Ania (ed.). Postcolonial Studies and Beyond. Durham: Duke University Press (166-181).

Ferguson, James. 1999. Expectations of Modernity - Myths and Meanings of Urban Life on the Zambian Copperbelt. Berkeley: University of California Press.

Ferguson, James. 1990. The Anti-Politics Machine : "Development”, Depoliticization, and Bureaucratic Power in Lesotho. Cambridge: Cambridge University Press.

Fietze, Beate. 2009. Historische Generationen - Über einen sozialen Mechanismus kulturellen Wandels und kollektiver Kreativität. Bielefeld: Transcript.

Finnegan, Amy. 2013. The White Girl's Burden. In: Contexts, Vol. 12, No. 1 (30-35).

Finnström, Sverker. 2012. KONY 2012, Military Humanitarianism, and the Magic of Occult Economies. In: Africa Spectrum, Vol. 47, No. 2-3 (127135).

Finnström, Sverker. 2010. An African Hell of Colonial Imagination? The Lord's Resistance Army in Uganda, another Story... In: Allen, Tim and Vlassenroot, Koen (eds). The Lord's Resistance Army. Myth and Reality. Oxford: James Currey (74-92).

Finnström, Sverker. 2008. Living with Bad Surroundings - War, History and Everyday Moments in Northern Uganda. Durham: Duke University Press. Finnström, Sverker. 2006a. Wars of the Past and Wars in the Present: The Lord's Resistance Movement/Army in Uganda. In: Africa, Vol. 76. No. 2 (200220).

Finnström, Sverker. 2006b. Meaningful Rebels? Young Adults Perceptions on the Lord's Resistance Movement/Army in Uganda. In: Christiansen, Catrine; Utas, Mats and Vigh, Hendrik. E. (eds). Navigating Youth, Generating Adulthood - Social Becoming in an African Context. Uppsala: Nordiska Afrikainstitutet (203-227). 
Finnström, Sverker. 2005. 'For God and My Life' - War and Cosmology in Northern Uganda. In: Richards, Paul (ed.). No peace, no War - An Anthropology of Contemporary Armed Conflict. Athens: Ohio University Press (98-116).

Finnström, Sverker. 2003. Living with Bad Surroundings - War and Existential Uncertainty in Acholiland, Northern Uganda. Uppsala: Acta Universitatis Upsaliensis (Uppsala Studies in Cultural Anthropology 35).

Finnström, Sverker. 2001. In and Out of Culture - Fieldwork in War-torn Uganda. In: Critique of Anthropology, Vol. 2, No. 3 (247-258).

Foucault, Michel. 2005 [1968]. Antwort auf eine Frage. In: Defert, Daniel and Ewald, Francois (eds). Michel Foucault - Analytik der Macht. Frankfurt a. M.: Suhrkamp (25-51).

Foucault, Michel. 20024a [1969]. The Archaeology of Knowledge (Translated by A.M. Sheridan Smith). London: Routledge.

Foucault, Michel. 2002b [1975]. From Discipline and Punish. In: Haugaard, Mark (ed.). Power. A Reader. Manchester: Manchester United Press (188-204).

Foucault, Michel. 1995 [1966]. Die Ordnung der Dinge. Frankfurt a.M.: Suhrkamp.

Foucault, Michel. 1994 [1971]. Die Ordnung des Diskurses - Erweiterte Ausgabe. Frankfurt a.M.: Fischer.

Foucault, Michel. 1990 [1976]. The History of Sexuality. Vol. 1: An Introduction. New York: Vintage Books.

Foucault, Michel. 1981a [1969]. Archäologie des Wissens. Frankfurt a.M.: Suhrkamp.

Foucault, Michel. 1981b [1970]. The Order of Discourse. In: Young, Robert (ed.). Untying the Text - A Post-Structuralist Reader. Boston: Routledge and Kegan Paul (48-78).

Freeman, Derek. 1983. Margaret Mead and Samoa: The Making and Unmaking of an Anthropological Myth. Cambridge, MA: Harvard University Press.

Friedman, Jonathan. 1994. The Political Economy of Elegance - An African Cult of Beauty Consumption and Identity. In: Friedman, Jonathan (ed.). Consumption and Identity. Chur: Harwood Academic Publishers (167-187).

Frymann, Abigail. 2013. Women Face Arrest for Wearing Miniskirts in Uganda in New Laws that also Ban Beyonce from Television. In: Daily Mail, $6^{\text {th }}$ April, 2013. Online at: http://www.dailymail.co.uk/news/article-2304913/ Ugandan-women-wearing-miniskirts-face-arrest-new-anti-pornographylaws.html, accessed 16.04.2013.

Furlong, Andy and Cartmel, Fred. 1997. Young People and Social Change: Individualization and Risk in late Modernity. Buckingham: Open University Press. 
Gable, Eric. 2000. The Culture Development Club: Youth, Neo-Tradition, and the Construction of Society in Guinea Bissau. In: Anthropological Quarterly, Vol. 73, No. 4 (195-203).

Geissler, Paul and Prince, Ruth. 2010. The Land is Dying: Contingency, Creativity and Conflict in Western Kenya. New York: Berghahn.

Gersony, Robert. 1997. The Anguish of Northern Uganda - Results of a Fieldbased Assessment of the Civil Conflicts in Northern Uganda. Kampala: USAID.

Geschiere, Peter; Meyer, Birgit and Pels, Peter (eds). 2008a. Readings in Modernity in Africa. Oxford: James Currey.

Geschiere, Peter; Meyer, Birgit and Pels, Peter. 2008b. Introduction. In: Peter Geschiere (ed.). Readings in Modernity in Africa. London: Indiana University Press (1-6).

Giddens, Anthony. 1991. Modernity and Self-Identity - Self and Society in the Late Modern Age. Stanford: Stanford University Press.

Girling, Frank Knowles. 1960. The Acholi of Uganda. London: Her Majesty's Stationery Office.

Glaser, Barney G. and Strauss, Anselm L. 2005 [1967]. Grounded Theory - Stategien qualitativer Forschung. $2^{\text {nd }}$, revised Edition (Translated by Axel T. Paul and Stefan Kaufmann). Bern: Verlag Hans Huber.

Green, Matthew. 2009. The Wizard of the Nile - The Hunt for Africa's Most Wanted: A Bloody Conflict, a Messianic Madman, and Army of Child Soldiers. London: Portobello Books.

Groes-Green, Christian. 2013. "To Put Men in a Bottle”: Eroticism, Kinship, Female Power, and Transactional Sex in Maputo, Mozambique. In: American Ethnologist, Vol, 40, No. 1 (102-117).

Gupta, Akhil and Ferguson, James. 1997a. Discipline and Practice: "The Field" as Site, Method and Location in Anthropology. In: Gupta, Akhil and Ferguson, James (eds). Anthropological Locations - Boundaries and Grounds of a Field Science. Berkeley: University of California Press (1-46).

Gupta, Akhil and Ferguson, James. 1997b. Culture, Power, Place - Ethnography at the End of an Era. In: Gupta, Akhil and Ferguson, James (eds). Culture, Power, Place - Explorations in Critical Anthropology. Durham: Duke University Press (1-29).

Gupta, Akhil and Ferguson, James. 1997c. Beyond "Culture": Space, Identity, and the Politics of Difference. In: Gupta, Akhil and Ferguson, James (eds). Culture, Power, Place - Explorations in Critical Anthropology. Durham: Duke University Press (33-51).

Guyson, Nangayi. 2013. Uganda's Anti-Pornography Bill - "If a Woman Wears a Miniskirt, We Will Arrest Her”. In: ThinkAfricaPress, 22 ${ }^{\text {nd }}$ April, 2013. Online at: http://allafrica.com/stories/201304221138.html?viewall=1, accessed 07.06.2013. 
Hall, Stanley G. 1911 [1904]. Adolescence: Its Psychology and its Relation to Physiology, Anthropology, Sociology Sex, Crime, Religion and Education. 2 Volumes. New York: Appleton.

Hall, Stuart. 2001. Foucault: Power, Knowledge and Discourse. In: Wetherell, Margaret; Taylor, Stephanie and Yates, Simeon J. (eds). Discourse Theory and Practice - A Reader. London: Sage (72-81).

Hall, Stuart. 1997a. The Work of Representation. In: Hall, Stuart (ed.). Representation - Cultural Representations and Signifying Practices. London: Sage (13-74).

Hall, Stuart. 1997b. The Spectacle of the 'Other'. In: Hall, Stuart (ed.). Representation - Cultural Representations and Signifying Practices. London: Sage (223-290).

Hall, Stuart. 1996a. Introduction. Who needs 'Identity'? In: Hall, Stuart and Du Gay, Paul (eds). Questions of Cultural Identity. London: Sage (1-17).

Hall, Stuart. 1996b. The Question of Cultural Identity. In: Hall, Stuart; Held, David; Hubert, Don and Thompson, Kenneth (eds). Modernity: An Introduction to Modern Societies. Malden: Blackwell (595-634).

Hall, Stuart. 1992. The West and the Rest: Discourse and Power. In: Hall, Stuart and Gieben, Bram (eds). Formations of Modernity. Cambridge: Polity Press (276-320).

Hall, Stuart and Jefferson, Tony (eds). 1991 [1975]. Resistance through Rituals Youth Subcultures in Post-war Britain. London: Harper Collins Academic.

Haller, Dieter. 2012. Die Suche nach dem Fremden - Geschichte der Ethnologie in der Bundesrepublik 1945-1990. Frankfurt a.M.: Campus.

Handler, Richard and Linnekin, Jocelyn. 1984. Tradition, Genuine or Spurious. In: Journal of American Folklore, Vol. 97, No. 385 (273-290).

Hannerz, Ulf. 1996. Transnational Connections - Culture, People, Places. London: Routledge.

Hansen, Holger B. and Twaddle, Michael. 1991. Introduction. In: Hansen, Holger B. and Twaddle, Michael (eds). Changing Uganda. London: James Currey (1-19).

Hansen, Karen Tranberg. 2005. Getting Stuck in the Compound: Some Odds Against Social Adulthood in Lusaka, Zambia. In: Africa Today, Vol. 51 (3-16).

Hansen, Karen Tranberg. 2002. Commodity Chains and the International Second Hand Clothing Trade: Salaula and the Work of Consumption in Zambia. In: Jean Ensminger (ed.). Theory in Economic Anthropology. Walnut Creek: AltaMira (221-236).

Hansen, Karen Tranberg. 1999. Secondhand Clothing Encounters in Zambia: Global Discourses, Western Commodities and Local Histories. In: Fardon, Richard; Binsbergen, Wim van; Dijk, Rijk van (eds). Modernity on a Shoestring: Dimensions of Globalization, Consumption and Development in Africa and Beyond. Leiden: EIDOS (207-225). 
Harlacher, Thomas. 2009. Traditional Ways of Coping with Consequences of Traumatic Stress in Acholiland - Northern Ugandan Ethnography from a Western Psychological Perspective. Dissertation zur Erlangung der Doktorwürde an der Philosophischen Fakultät der Universität Freiburg (Schweiz). Online at: http://ethesis.unifr.ch/theses/downloads.php?file=HarlacherT. pdf, accessed 14.02.2013.

Hastrup, Kirsten. 1992. Writing Ethnography - State of the Art. In: Okely, Judith and Callaway, Helen (eds). Anthropology and Autobiography. London: Routledge (116-133).

Haugaard, Mark. 2002. Foucault. In: Haugaard, Mark (ed.). Power. A Reader. Manchester: Manchester United Press (181-204).

H.E.A.L.S. on Facebook: http://www.facebook.com/healsuganda?v=info, accessed 24.07.2012.

Hebdige, Dick. 1988 [1979]. Subculture - The Meaning of Style. London: Routledge.

Hendrickson, Hildi (ed.). 1996. Clothing and Difference - Embodied Identities in Colonial and Post-Colonial Africa. Durham: Duke University Press.

Hermann, Elfriede. 2011. Introduction - Engaging with Interactions: Traditions as Context-Bound Articulations. In: Hermann, Elfriede (ed.). Changing Contexts, Shifting Meanings: Transformations of Cultural Traditions in Oceania. Honolulu: University of Hawaii Press in Association with the Honolulu Academy of Arts (1-19).

Hermann, Elfriede. 1995. Emotionen und Historizität. Der emotionale Diskurs über die Yali-Bewegung in einer Dorfgemeinschaft der Ngaing, Papua New Guinea. Berlin: Dietrich Reimer.

Heron, G.A. 1989. Introduction: Song of Lawino and Song of Ocol. Nairobi: East African Educational Publishers (1-33).

Hobsbawm, Eric. 1983. Introduction: Inventing Traditions. Hobsbawm, Eric and Ranger, Terence (eds). The Invention of Tradition. Cambridge: Cambridge University Press (1-14).

Hodkinson, Paul. 2007. Youth Cultures: A Critical Outline of Key Debates. In: Hodkinson, Paul and Deike, Wolfgang (eds). Youth Cultures - Scenes, Subcultures and Tribes. New York: Routledge (1-22).

Hodkinson, Paul and Deike, Wolfgang (eds). 2007. Youth Cultures - Scenes, Subcultures and Tribes. New York: Routledge.

Honwana, Alcinda. 2013. Youth and Revolution in Tunesia. London: Zed Books. Honwana, Alcinda. 2012. The Time of Youth - Work, Social Change, and Politics in Africa. Sterling, VA: Kumarian Press.

Honwana, Alcinda. 2005. Innocent and Guilty - Child-Soldiers as Interstitial and Tactical Agents. In: Honwana, Alcinda and De Boeck, Filip (eds). Makers and Breakers - Children and Youth in Postcolonial Africa. Oxford: James Currey (31-52). 
Honwana, Alcinda and De Boeck, Filip (eds). 2005. Makers and Breakers Children and Youth in Postcolonial Africa. Oxford: James Currey.

Huisman, Carie Stenfansky. 2011. Once Patriarchs and Warriors: Masculinity and Modernity in Karamoja, Uganda. In: Praxis - The Fletcher Journal of Human Security, Vol. XXVI (60-80).

Hunter, Mark. 2002. The Materiality of Everyday Sex: Thinking beyond "Prostitution”. In: African Studies, Vol. 61, No. 1 (99-120).

HuRiFo (Human Rights Focus). 2007. Fostering the Transition in Acholiland: From War to Peace, from Camps to Home. Gulu: Human Rights Focus.

HuRiFo (Human Rights Focus). 2002. Between Two Fires - The Human Rights Situation in the "Protected Camps" in Gulu District, Northern Uganda. Gulu: HuRiFo. Online at: http://www.humiliationstudies.org/documents/ OnenBetweenTwoFires.pdf, accessed 29.11.2011.

HuRiWa (Human Rights Watch). 1997. The Scars of Death - Children Abducted by the Lord's Resistance Army in Uganda. New York: Human Rights Watch.

ICG (International Crisis Group). 2012. Uganda - No Resolution to Growing Tensions. Nairobi: ICG (Africa Report No. 187, April 2012).

ICG (International Crisis Group). 2011. The Lord's Resistance Army - End Game? Nairobi: ICG (Africa Report No. 182).

ICG (International Crisis Group). 2010. LRA - A Regional Strategy beyond Killing Kony. Nairobi: ICG (Africa Report No. 157).

ICC (International Crisis Group). 2004. Northern Uganda - Understanding and Solving the Conflict. Nairobi: ICG (Africa Report No. 77).

IDMC (Internal Displacement Monitoring Centre). 2010. Uganda: Difficulties Continue for Returnees and Remaining IDPs as Development Phase Begins - A Profile of the Internal Displacement Situation 28 December, 2010. Geneva: IDMC/Norwegian Refugee Council. Online at: http://www. internal-displacement.org/8025708F004BE3B1/(httpInfoFiles)/AA7A8C B8B06E752DC12578070057B4C6/\$file/Uganda+-+December+2010.pdf, accessed 29.11.2011.

INAMO. 2011. "Game Over”, Special Edition No. 4, published 12th March, 2011.

Invisible Children. 2012a. Invisible Children: Kony 2012. Film directed by Jason Russel (30 min.).

Invisible Children. 2012b. Kony 2012 - Part II. Beyond Famous. Film directed by Jason Russel (20 min.).

Invisible Children. 2006. Invisible Children: Rough Cut. Film directed by Jason Russel, Bobby Bailey and Laren Poole (55 min.).

Invisible Children. Official Website: http://www.invisiblechildren.com/history. html, accessed 28.03.2012. 
IRIN. 2007. In Depth: Youth in Crisis: Coming of Age in the $21^{\text {st }}$ Century.

Online at: http://www.irinnews.org/pdf/in-depth/Youth-in-crisis-IRIN-InDepth.pdf, accessed 17.10.2011.

Johnson, Shaun. 1988. "The Soldiers of Luthuli": Youth in the Politics of Resistance in South Africa. In: Johnson, Shaun (ed.). South Africa: No Turning Back. London: Macmillan Press (94-152).

Jok, Madut Jok. 2005. War, Changing Ethics and the Position of Youth in South Sudan. In: Abbink, Jon and van Kessel, Ineke (eds). Vanguard or Vandals Youth, Politics and Conflict in Africa. Leiden: Brill (143-160).

Kagwanja, Peter Mwangi. 2005. Clash of Generations? Youth Identity, Violence and the Politics of Transition in Kenya, 1997-2002. In: Abbink, Jon and van Kessel, Ineke (eds). Vanguard or Vandals - Youth, Politics and Conflict in Africa. Leiden: Brill (81-109).

Kainja, Jimmy. 2011. What the Arab Spring can learn from Sub-Saharan Africa.

$31^{\text {st }}$ October, 2011. Online at: http://www.opendemocracy.net/jimmykainja/what-arab-spring-can-learn-from-sub-saharan-africa, accessed 05.04.2013.

Kalinaki, Daniel K. 2012. Kony Video is a Sad Trailer for Uganda's Invisible Generation. In: Daily Monitor, $15^{\text {th }}$ March, 2012 (11).

Kalumba, Robert. 2010a. Why Marriages Break-up? In: Daily Monitor, $2^{\text {nd }}$ November, 2010.

Kalumba, Robert. 2010b. G-spot is a Myth? In: Saturday Monitor (Full Women Supplement), $6^{\text {th }}$ March, 2010 (12).

Kalumba, Robert. 2010c. What Have our Women Turned into? In: Daily Monitor Online, $5^{\text {th }}$ July, 2011. Online at: http://www.monitor.co.ug/LifeStyle/ Reviews/-/691232/1194318/-/c7hole/-/index.html, accessed 05.07.2011.

Kalyegira, Timothy. 2012. Africans are not Brainwashed but how Do we Explain Uganda's Failure? In: Daily Monitor, $18^{\text {th }}$ March, 2012 (21).

Kaplan, Robert D. 1994. The Coming Anarchy - How Scarcity, Crime, Overpopulation, Tribalism, and Disease are Rapidly Destroying the Social Fabric of our Planet. In: The Atlantic Monthly, February 1994.

Kapya Kaoma, 2010. The U.S. Christian Right and the Attack on Gays in Africa. In: Public Eye. Online at: http://www.publiceye.org/magazine/v24n4/uschristian-right-attack-on-gays-in-africa.html, accessed 24.03.2011.

Karlström, Mikael. 2004. Modernity and Its Aspirants: Moral Community and Developmental Eutopianism in Buganda. In: Current Anthropology, Vol. 45, No. 5 (595-619).

Karlström, Mikael. 1996. What Makes a Citizen? Imagining Democracy: Political Culture and Democratisation in Buganda. In: Africa, Vol. 66, No. 4 (485-505).

Kasfir, Nelson. 1976. The Shrinking Political Arena: Participation and Ethnicity in African Politics, with a Case Study of Uganda. Berkeley: University of California Press. 
Kelle, Udo und Kluge, Susanne. 2010. Vom Einzelfall zum Typus. Fallvergleich und Fallkontrastierung in der qualitativen Sozialforschung. $2^{\text {nd }}$ Revised Edition. Wiesbaden: VS Verlag für Sozialwissenschaften.

Keller, Reiner 2008. Wissenssoziologische Diskursanalyse. Grundlegung eines Forschungsprogramms. $2^{\text {nd }}$ Edition. Wiesbaden: VS Verlag für Sozialwissenschaften.

Keller, Reiner 2007. Diskurse und Dispositive analysieren. Die Wissenssoziologische Diskursanalyse als Beitrag zu einer wissensanalytischen Profilierung der Diskursforschung. In: Forum: Qualitative Sozialforschung, Vol. 8, No. 2 (1-32).

Keller, Reiner 2006. Wissenssoziologische Diskursanalyse. In: Keller, Reiner; Hirseland, Andreas; Schneider, Werner and Viehöver, Willy (eds). Handbuch Sozialwissenschaftliche Diskursanalyse. Band 1: Theorien und Methoden. $2^{\text {nd }}$ Revised and Updated Edition. Wiesbaden: VS Verlag für Sozialwissenschaften (115-146).

Keller, Reiner. 2005. Analysing Discourse. An Approach From the Sociology of Knowledge. In: Forum: Qualitative Social Research, Vol. 6, No. 3 (1-13).

Keller, Reiner 1997. Diskursanalyse. In: Hitzler, Ronald; Honer, Anne (eds). Sozialwissenschaftliche Hermeneutik. Eine Einführung. Opladen: Leske + Budrich (309-333).

Ker Kwaro Acholi. 2010a. Final Report (Unpublished Report).

Ker Kwaro Acholi. 2010b. Acholi Principles on Gender Relations (Unpublished Report).

Khisa, Isaac and Nalugo, Mercy. 2010. Otunnu Demands Investigation of Luwero Triangle massacres. In: Daily Monitor, $16^{\text {th }}$ March, 2010. Online at: http://africannewsanalysis.blogspot.com/2010/03/otunnu-demands-investigation-of-luwero.html, accessed 22.11.2011.

Kiplagat, Bethuel. 2002. Reaching the 1985 Nairobi Agreement. In: Lucima, Okello (ed.). Protracted Conflict, Elusive Peace - Initiatives to End the Violence in Northern Uganda. London: Accord (24-27).

Knauft, Bruce M. (ed.). 2002. Critically Modern - Alternatives, Alterities, Anthropologies. Bloomington: Indiana University Press.

Knighton, Ben. 2003. The State as Raider Among the Karamojong: 'Where there are no Guns, they Use the Threat of Guns'. In: Africa, Vol. 73. No. 3 (427-455).

Kratz, Corinne A. 1993. "We've Always Done It like This... except for a Few Details": "Tradition" and "Innovation" in Okiek Ceremonies. In: Comparative Studies in Society and History, Vol. 35, No. 1 (30-65).

Kuster, Reto and Santschi, Martina. 2006. Krieg in Acholiland - Ethnizität, Gewalt und Politk im Norden Ugandas. Bern: Institut für Sozialanthropologie (Arbeitsblatt No. 36.).

Kwach Academy: http://www.kwachacademy.net/, accessed 29.05.2012. 
Lamwaka, Caroline. 2002. The Peace Process in Northern Uganda 1986-1990. In: Lucima, Okello (ed.). Protracted Conflict, Elusive Peace - Initiatives to End the Violence in Northern Uganda. London: Accord (28-33).

Lange, Siri. 2001. "The Shame of Money" - Criticism of Modernity in Swahili Popular Drama. In: Eriksson Baaz, Maria and Palmberg, Mai (eds). Same and Other - Negotiating African Identity in Cultural Production. Uppsala: Nordiska Afrikainstitutet (143-158).

Larkin, Brian. 1997. Indian Films and Nigerian Lovers: Media and the Creation of Parallel Modernities. In: Africa, Vol 67, No. 3 (406-440).

Lauser, Andrea and Bräunlein, Peter. 1996. Fließende Übergänge... Kindheit, Jugend, Erwachsensein in einer ritualarmen Gesellschaft (Mangyan/Mindoro/Philippinen). In: Dracklé, Dorle (ed.). Jung und Wild - Zur kulturellen Konstruktion von Kindheit und Jugend. Hamburg: Dietrich Reimer (152-182).

Le Meur, Pierre-Yves. 2008. Between Emancipation and Patronage: Changing Intergenerational Relationships in Central Benin. In: Alber, Erdmute; van der Geerst, Sjaak and Whyte, Susan R. (eds). Generations in Africa - Connections and Conflicts. Berlin: LIT (209-236)

Lentz, Carola. 2009. Der Kampf um die Kultur - Zur Ent- und Re-Soziologisierung eines ethnologischen Konzepts. In: Soziale Welt, Vol. 60, Nr. 3 (305-324).

Lentz, Carola. 2006. Ethnicity and the Making of History in Northern Ghana. Edinburgh: Edinburgh University Press.

Leopold, Marc. 2005. Inside West Nile - Violence, History and Representation on an African Frontier. Oxford: James Currey.

Leopold, Mark. 1999. "The War in the North”: Ethnicity in Ugandan Press Explanations of Conflict, 1996-97. In: Allen, Tim and Seaton, John (eds). The Media of Conflict: War Reporting and Representations of Ethnic Violence. London: Zed Books (219-243).

Lewis, Desiree. 2005. African Gender Research and Postcoloniality: Legacies and Challenges. In: Oyewumi, Oyeronke (ed.). African Gender Studies -

A Reader. New York: Palgrave Macmillan (381-396).

Leys, Colin. 1967. Politicians and Policies: An Essay on Politics in Acholi, Uganda, 1962-65. Nairobi: East African Publishing House.

Lirri, Evelyn. 2010. New Aids Infections Worrying - Museveni. In: Daily Monitor, $3^{\text {rd }}$ June, 2010 (7).

Liu Institute for Global Issues. 2005. Roco Wat I Acoli: Restoring Relationships in Acholiland: Traditional Approaches to Justice and Reintegration. Vancouver: Liu Institute for Global Issues.

Loimeier, Roman; Neubert, Dieter and Weißköppel, Cordula (eds). 2005a. Globalisierung im lokalen Kontext - Perspektiven und Konzepte von Handeln in Afrika. Münster: LIT. 
Loimeier, Roman; Neubert, Dieter and Weißköppel, Cordula. 2005b. Einleitung. In: Loimeier, Roman; Neubert, Dieter and Weißköppel, Cordula (eds). Globalisierung im lokalen Kontext - Perspektiven und Konzepte von Handeln in Afrika. Münster: LIT (1-30).

Loomba, Ania; Kaul, Suvir; Bunzl, Matti; Burton, Antoinette and Esty, Jed. 2005. Beyond what? An Introduction. In: Loomba, Ania; Kaul, Suvir; Bunzl, Matti; Burton, Antoinette and Esty, Jed (eds). Postcolonial Studies and Beyond. Durham: Duke University Press (1-40).

Low, Anthony and Pratt, Cranford. 1960. Buganda and British Overrule 19001955: Two Studies. London: Oxford University Press.

Low, Setha M. and Lawrence-Zúñiga, Denise (eds). 2003. The Anthropology of Space and Place - Locating Culture. Malden: Blackwell.

Lucima, Okello (ed.). 2002. Protracted Conflict, Elusive Peace - Initiatives to End the Violence in Northern Uganda. London: Accord.

Luig, Ute and Seebode, Jochen (eds). 2003a. Ethnologie der Jugend - Soziale Praxis, moralische Diskurse und inszenierte Körperlichkeit. Münster: LIT.

Luig, Ute and Seebode, Jochen. 2003b. Einleitung. In: Luig, Ute and Seebode, Jochen (eds). Ethnologie der Jugend - Soziale Praxis, moralische Diskurse und inszenierte Körperlichkeit. Münster: LIT (9-40).

Lunde, Henriette. 2006. Night Commuting in Gulu, Northern Uganda: From Spontaneous Strategy to New Social Institution. MA Thesis. Oslo: Fafo (Fafo Report 549).

Magubane, Zine. 2003. Introduction. In: Magubane, Zine (ed.). Postmodernism, Postcoloniality and African Studies. Trenton: Africa World Press (vii-xvi).

Malinga, Joseph. 2010. Defilement Crime on the Rise in Uganda. In: The Guardian, $7^{\text {th }}$ October, 2010. Online at: http://www.guardian.co.uk/katine/2010/ oct/06/uganda-katine-defilement, accessed 28.03.2013.

Malinowski, Bronislaw. 2001 [1927]. Sex and Repression in Savage Society. London: Routledge.

Mamdani, Mahmood. 2012. What Jason didn't Tell Gavin and his Army of Invisible Children. In: Daily Monitor, 13 ${ }^{\text {th }}$ March, 2012 (20).

Mamdani, Mahmood. 2004 [1996]. Citizen and Subject. Contemporary Africa and the Legacy of Colonialism. Kampala: Fountain Publishers.

Mamdani, Mahmood. 1983. Imperialism and Fascism in Uganda. Nairobi: Heinemann Educational Books.

Mamdani, Mahmood. 1976. Politics and Class Formation in Uganda. New York: Monthly Review Press.

Mannheim, Karl. 1972 [1952]. The Problem of Generations. In: Mannheim, Karl (Edited and Translated by Paul Kecskemeti). Essays on the Sociology of Knowledge. London: Routledge and Keagan Paul (276-320).

Mannheim, Karl. 1928. Das Problem der Generationen. In: Kölner Vierteljahreshefte für Soziologie, Vol.6 (157-185 \& 309-330). 
Manzurana, Dyan; Raven-Roberts, Angela and Parpart, Jane (eds). 2005. Gender, Conflict and Peacekeeping. Lanham: Rowman and Littlefield.

Marcus, Rachel. 1993. Gender and HIV/AIDS in Sub-Saharan Africa: the Cases of Uganda and Malawi. Brighton: BRIDGE.

Masquelier, Adeline. 2009. Lessons from Rubi: Love, Poetry, and the Educational Value of Televised Dramas in Niger. In: Cole, Jennifer and Lynn, Thomas M. (eds). Love in Africa. Chicago: University of Chicago Press (204-228). Matanda, Dennis. 2010. On Life and Romance - When Men Tend to be Rather Scarce. In: Saturday Monitor (Full Women Supplement), 24 ${ }^{\text {th }}$ April, 2010 (13).

Mato Oput Project. 2009. Community Perspectives on the Mato Oput Process. CTA; The Institute for Global Leadership, Tufts University; IPSS, Gulu University. Online at: http://www.internal-displacement.org/8025708F0 04CE90B/\%28httpDocuments\%29/F1A4C4A98929FB7CC125765F0 078943B/\$file/Community+Perspectives+on+Mato+Oput.pdf, accessed 12.02.2013.

Mbembe, Achille. 2008. The New Africans - Between Nativism and Cosmopolitanism. In: Geschiere, Peter; Meyer, Birgit and Pels, Peter (eds). Readings in Modernity in Africa. Oxford: James Currey (107-111).

Mbembe, Achille. 2002. African Modes of Self-Writing. In: Public Culture, Vol. 14, No.1 (239-273).

Mbembe, Achille. n.d. Notes on the Postcolony. Berkeley: University of California Press.

McDonnell, Faith J.H. and Akallo, Grace. 2007. Girl Soldier - A Story of Hope for Northern Uganda's Children. Grand Rapids: Chosen Books.

McEvoy-Levy, Soibhán (ed.). 2006. Troublemakers or Peacemakers? Youth and Post-Accord Peace Building. Notre Dame, Indiana: University of Notre Dame Press.

McKay, Susan and Mazurana, Dyan. 2004. Where are the Girls? Girls in Fighting Forces in Northern Uganda, Sierra Leone and Mozambique: Their Lives during and after War. Montreal: Rights and Democracy. International Centre for Human Rights and Development.

McRobbie, Angela and Garber, Jenny. 1991 [1975]. Girls and Subcultures: An Exploration. In: Hall, Stuart and Jefferson, Tony (eds). Resistance through Rituals - Youth Subcultures in Post-war Britain. London: Harper Collins Academic (209-222).

Mead, Magaret. 1949 [1928]. Coming of Age in Samoa: a Psychological Study of Primitive Youth for Western Civilizations. New York: Mentor Library.

Meyer, Birgit and Geschiere, Peter. 1999. Introduction. In: Meyer, Birgit and Geschiere, Peter (eds). 1999. Globalization and Identity: Dialectics of Flow and Closure. Oxford: Blackwell (1-16).

Mills, David and Ssewakiryanga, Richard. 2005. "No Romance without Finance": Commodities, Masculinities and Relationships amongst Kam- 
palan Students. In: Cornwall, Andrea (ed.). Readings in Gender in Africa. Bloomington: Indiana University Press (90-95).

Mills, Sara. 2007. Der Diskurs. Tübingen: Narr Franke Attempo.

Miss Acholi (official website): http://www.missacholi.com/, accessed 14.05.2012.

Mohanty, Chandra Talpade. 1988. Under Western Eyes: Feminist Scholarship and Colonial Discourses. In: Feminist Review, Vol. 30 (61-88).

Muhanga, Magaret. 2009. Neo-colonialism Fuels Homosexuality in Africa. In: New Vision, 26 ${ }^{\text {th }}$ October, 2009. Online at: http://www.newvisionuganda. info/PA/8/459/699133, accessed 23.03.2011.

Müller, Klaus E. 1992. Initiationen. In: Müller, Klaus E. and Treml, Alfred K. (eds). Ethnopädagogik. Berlin: Dietrich Reimer (61-82).

Mwangola, Mshai S. 2007. Leaders of Tomorrow? The Youth and Democratization in Kenya. In: Murunga, Godwin R. and Nasong'o, Shadrack, Wanjala (eds). Kenya - The Struggle for Democracy. London: Zed Books (129-163).

Ndikumana, Léonce and Nannyonjo, Justine. 2007. From Failed State to Good Performer? - The Case of Uganda. In: Boyce, James K. and O'Donnell, Madalene (eds). Peace and the Public Purse - Economic Policies for Postwar Statebuilding. London: Lynne Rienner (12-54).

Ngabirano, John. 2010. Too Late for Otunnu to Rewrite Luwero History. In: The Observer, 26 ${ }^{\text {th }}$ March, 2010. Online at: www.observer.ug/index. php?option=com_content $\&$ view=article $\&$ id=7794:too-late-for-otunnuto-rewrite-luwero-history\&catid=37:guest-writers\&Itemid=66, accessed 22.11.2011.

Ngoga, Pascal. 1998. Uganda: The National Resistance Army. In: Clapham, Christopher (ed.). African Guerrillas. Oxford: James Currey (107-118).

Ngugi Wa Thiongo'o. 1965. The River Between. Nairobi: East African Educational Publishers.

Nielsen, Erik Solevad. 2008. Ethnic Boundaries and Conflict in Darfur - an Event Structure Hypothesis. In: Ethnicities, Vol. 8, No. 4 (427-462).

Nix, Andrea and Fine, Sean (directors). 2007. War Dance. Documentary Film (105 min.).

Njambi, Wairimu N. 2004. Dualisms and Female Bodies in Representations of African Female Circumcision: A Feminist Critique. In: Feminist Theory, Vol. 5, No. 3 (281-303).

Nkrumah, Kwame. 1974. Neo-colonialism: the Last Stage of Imperialism. London: Panaf.

N.N. 2011a. Uganda: Teachers Threaten to Strike Over Salaries. In: New Vision, $13^{\text {th }}$ July 2011. Online at: http://allafrica.com/stories/201107140580.html, accessed 22.04.2013.

N.N. 2011b. Fort Portal NGO Roots for Dress Code. In: Daily Monitor, $1^{\text {st }}$ January, 2011.

N.N. 2010a. Kitgum - Mini-skirts Banned. In: Daily Monitor, $23^{\text {rd }}$ March, 2010. 
N.N. 2010b. Otunnu is right on Luwero probe, Ogole Insists. In: Uganda Correspondent, July 2010. Online at: www.ugandacorrespondent.com/articles/2010/07/otunnu-is-right-on-luwero-probe-ogole-insists/\#more-560, accessed 22.11.2011.

Ntarangwi, Mwenda. 2009. East African Hip Hop: Youth Culture and Globalization. Urbana: University of Illinois Press.

Nyambedha, Erick Otieno. 2008. Sharing Food: Grandmothers and "the Children of Today" in Western Kenya. In: Alber, Erdmute; van der Geerst, Sjaakand Erdmute, Susan R. (eds). Generations in Africa - Connections and Conflicts. Berlin: LIT (71-90).

Nyambedha, Erick Oieno, Wandibba Simiyu and Aagaard-Hansen, Jens. 2003. "Retirement lost" - The New Role of the Elderly as Caretakers for Orphans in Western Kenya. In: Journal of Cross-Cultural Gerontology, Vol. 18, No. 2 (33-52).

Nzita, Richard. 1997. Peoples and Cultures of Uganda. $3^{\text {rd }}$ Edition. Kampala: Fountain Publishers.

O'Kadameri, Billie. 2002. LRA and Government Negotiations 1993-1994. In: Lucima, Okello (ed.). Protracted Conflict, Elusive Peace - Initiatives to End the Violence in Northern Uganda. London: Accord (34-41).

O'Laughlin, Bridget. 1997. Missing Men? The Debate over Rural Poverty and Women-Headed Households in Southern Africa. The Hague: Institute of Social Studies (Working Paper No. 252).

Obita, James Alfred. 2002. First International Peace Efforts 1996-1998. In: Lucima, Okello (ed.). Protracted Conflict, Elusive Peace - Initiatives to End the Violence in Northern Uganda. London: Accord (42-45).

OCHA. 2006. 'Northern Uganda-IDP Population as of February, 2006' (Map). Online at: http://www.reliefweb.int/rw/RWB.NSF/db900SID/ AHAA-6N3JNQ? OpenDocument, accessed 29.11.2011.

Ocholla-Ayayo, A.B.C. 1980. The Luo Culture - A Reconstruction of the Material Culture Patterns of a Traditional African Society. Wiesbaden: Franz Steiner.

Ocowun, Chris. 2010. HIV/AIDS on the Rise in Gulu District. In: New Vision, $26^{\text {th }}$ May, $2010(7)$.

Ogenga Otunnu. 2002. Causes and Consequences of the War in Acholiland. In: Lucima, Okello (ed.). Protracted Conflict, Elusive Peace - Initiatives to End the Violence in Northern Uganda. London: Accord (10-13).

Okot P'Bitek. 1989 [1966]. Song of Lawino and Song of Ocol (English Translation). Nairobi: East African Educational Publishers.

Okot P'Bitek. 1980. Religion of the Central Luo. Kampala: Ugandan Literature Bureau.

Okurut, Mary Karooro (Minister for Information and National Guidance). 2012. The Government of Uganda Position on the Kony 2012 Documentary. In: Daily Monitor, $18^{\text {th }}$ March, 2012 (28f.). 
Omara-Otunnu, Amii. 1992. The Struggle for Democracy in Uganda. In: The Journal of Modern African Studies, Vol. 30, No. 3 (443-463).

Omurungi, Sharon M. 2010. Simply Lose that Belly after Giving Birth. In: Saturday Monitor (Full Women Supplement), 4 ${ }^{\text {th }}$ September, 2010 (5).

Onyango-Odongo, Jamal and Webster, J.B. (eds). 1976. The Central Luo during the Aconya. Nairobi: East African Literature Bureau.

Ortner, Sherry. B. 2006. Anthropology and Social Theory - Culture, Power and the Acting Subject. Durham: Duke University Press.

Ortner, Sherry B. 2001. Specifying Agency: The Comaroffs and Their Critics. In: Interventions, Vol. 3, No. 1 (76-84).

Ortner, Sherry B. 1997. Thick Resistance: Death and the Cultural Construction of Agency in Himalayan Mountaineering. In: Sherry B. Ortner (ed.). The Fate of "Culture". Geertz and Beyond. Berkeley: University of California Press (136-163).

Otto, Patrick Oguru. 2002. Implementing the 1999 Nairobi Agreement. In: Lucima, Okello (ed.). Protracted Conflict, Elusive Peace - Initiatives to End the Violence in Northern Uganda. London: Accord (52-57).

Otto, Ton and Pedersen, Poul. 2005. Disentangling Traditions: Culture, Agency and Power. In: Ton Otto and Pedersen, Poul (eds). Tradition and Agency: Tracing Cultural Continuity and Invention. Aarhus: Aarhus University Press (11-49).

Oyewumi, Oyeronke (ed.). 2005. African Gender Studies - A Reader. New York: Palgrave Macmillan.

Oyewumi, Oyeronke. 2002. Conceptualizing Gender: The Eurocentric Foundations of Feminist Concepts and the Challenge of African Epistemologies. In: Jenda: A Journal of Culture and African Women Studies, Vol. 2, No. 1 $(13-27)$.

Oyewumi, Oyeronke. 1997. The Invention of Women. Making an African Sense of Western Gender Discourses. Minneapolis: University of Minnesota Press.

Pain, Dennis. 1997. “The Bending of Spears" - Producing Consensus for Peace \& Development in Northern Uganda. London: International Alert.

Paine, Clare. 2011. Imagining "Traditional” Authorities in Africa: A Case of Ker Kwaro Acholi in Northern Uganda. Paper presented at the $4^{\text {th }}$ European Conference on African Studies (ECAS) in Uppsala, Sweden. 17 $7^{\text {th }}$ June, 2011.

Pala, Achola O. 2005. Definitions of Women and Development: An African Perspective. In: Oyewumi, Oyeronke (ed.). African Gender Studies A Reader. New York: Palgrave Macmillan (299-312).

Parikh, Shanti A. 2005. From Auntie to Disco: the Bifurcation of Risk and Pleasure in Sex Education in Uganda. In: Adams, Vincanne and Pigg, Stacey L. (eds). Sex in Development. Durham: Duke University Press (125-158). 
Parsons, Talcott. 1964. Essays in Sociological Theory. Revised Edition. New York: Free Press of Glencoe.

Peachey, Dean E. 2012. The Elusive Quest for Reconciliation in Northern Uganda. In: Palmer, Nicola; Clark, Phil and Granville, Danielle (eds). Critical Perspectives in Transitional Justice. Cambridge: Intersentia (289-310).

Perrot, Sandrine. 2010. Northern Uganda; a 'Forgotton Conflict', Again? The Impact of the Internationalization of the Resolution Process. In: Allen, Tim and Vlassenroot, Koen (eds). The Lord's Resistance Army. Myth and Reality. Oxford: James Currey (187-204).

Pham, Phoung and Vinck, Patrick. 2010. Transition to Peace. A Population-Based Survey on Attitudes about Social Reconstruction and Justice in Northern Uganda. Berkeley: Human Rights Center, University of California.

Poblicks, Nyeko Caesar. 2002. Kacoke Madit: A Diaspora Role in Promoting Peace. In: Lucima, Okello (ed.). Protracted Conflict, Elusive Peace - Initiatives to End the Violence in Northern Uganda. London: Accord (62-63).

Population Reference Bureau. 2011. World Population Data Sheet 2011. Online at: http://www.prb.org/Publications/Datasheets/2011/world-populationdata-sheet.aspx, accessed 18.10.2011.

Preisendörfer, Bruno. 2008. „Links, bis es weh tut - Die Wiederkehr des Sozialen und die Furcht der Bürger“. In: Le Monde Diplomatique, No. 8628, $11^{\text {th }}$ July, 2008.

Prince, Ruth. 2009. Christian Salvation and Luo Tradition: Arguments of Faith in a Time of Death in Western Kenya. In: Becker, Felicitas and Geissler, Wenzel P. (eds). Aids and Religious Practice in Africa. Leiden: Brill (4984).

Prince, Ruth. 2008. Struggling for Growth in Western Kenya: Modernity, Tradition, Generation and Gender. In: Alber, Erdmute; van der Geerst, Sjaak and Whyte, Susan R. (eds). Generations in Africa - Connections and Conflicts. Berlin: LIT (137-162).

Probst, Peter; Deutsch, Jan-Georg and Schmidt, Heike. 2002. Introduction: Cherished Visions and Entangled Meanings. In: Jan-Georg Deutsch, Heike Schmidt and Peter Probst (eds). African Modernities. Entangled Meanings in Current Debate. Portsmouth: Heinemann (1-17).

Prunier, Gérard. 2004. Rebel Movements and Proxy Warfare: Uganda, Sudan and the Congo (1986-1999). In: African Affairs, Vol. 103, No. 412 (359-383).

Quayson, Ato \& Goldberg, David T. 2002. Introduction: Scale and Sensibility. In: Goldberg, David T. and Quayson, Ato (eds). Relocating Postcolonialism. Oxford: Blackwell (xi-xxii).

Rahnema, Majid and Bawtree, Victoria (eds). 1997. The Post-Development Reader. London: Zed Books.

Reis, Ria. 2008. Inventing a Generation: the Revitalization of Umcwasho in Swaziland in Response to the HIV/AIDS crisis. In: Alber, Erdmute; van der 
Geerst, Sjaak and Whyte, Susan R. (eds). Generations in Africa - Connections and Conflicts. Berlin: LIT (163-182).

Reiter, Herwig. 2010. Context, Experience, Expectation, and Action - Towards an Empirically Grounded, General Model for Analyzing Biographical Uncertainty. In: Forum: Qualitative Social Research, Vol. 11, No. 1 (1-17).

Republic of Uganda. 2001. The National Youth Policy - A Vision for Youth in the $21^{\text {st }}$ Century. Kampala: Ministry of Gender, Labour and Social Development.

Richards, Audrey I. 1956. Chisungu: A Girls' Initiation Ceremony among the Bemba of Northern Rhodesia. London: Faber and Faber.

Richards, Paul and Peters, Krijn. 1998. "Why we fight"? Voices of Youth Combatants in Sierra Leone. In: Africa, Vol. 62, No. 2 (183-210).

Richards, Paul. 1996. Fighting for the Rain Forest: War, Youth and Resources in Sierra Leone. London: James Currey.

Ringsted, Mette Line. 2008. Collisons in Life-Courses: Teenage Motherhood and Generational Relations in North-East Tanzania. In: Alber, Erdmute; van der Geerst, Sjaak and Whyte, Susan R. (eds). Generations in Africa - Connections and Conflicts. Berlin: LIT (357-380).

RLP (Refugee Law Project). 2004. Behind the Violence: Causes, Consequences and the Search for Solutions to the War in Northern Uganda. Kampala: RLP (Working Paper No. 11, February 2004).

RLP (Refugee Law Project). 2005. Peace First, Justice Later: Traditional Justice in Northern Uganda. Kampala: RLP (Working Paper No. 17, July 2005).

Roberts, Brian. 2005. Biographical Formation and Communal Identities - Studying Individual and Communal Experiences of Social Change. In: Völter, B.; Dausien, B.; Lutz, H. and Rosenthal, G. (eds). Biographieforschung im Diskurs. Wiesbaden: VS Verlag für Sozialwissenschaften (84-102).

Rodriguez Soto, Carlos. 2009. Tall Grass - Stories of Suffering and Peace in Northern Uganda. Kampala, Uganda: Fountain Publishers.

Rodriguez, Carlos. 2002. The Role of the Religious Leaders. In: Lucima, Okello (ed.). Protracted Conflict, Elusive Peace - Initiatives to End the Violence in Northern Uganda. London: Accord (58-59).

Roth, Claudia. 2008. "Shameful!" The Inverted Intergenerational Contract in Bobo-Dioulasso, Burkina Faso. In: Alber, Erdmute; van der Geerst, Sjaak and Whyte, Susan R. (eds). Generations in Africa - Connections and Conflicts. Berlin: LIT (47-70).

Rottenburg, Richard. 2002. Weit hergeholte Fakten: eine Parabel der Entwicklungshilfe. Stuttgart: Lucius \& Lucius.

Rubongoya, Joshua B. 2007. Regime Hegemony in Museveni's Uganda - Pax Musevenica. New York: Palgrave Macmillan.

Ruffing, Reiner. 2008. Michel Foucault. Paderborn: Wilhelm Fink. 
Sadgrove, Jo. 2007. "Keeping Up Appearances": Sex and Religion amongst University Students in Uganda. In: Journal of Religion in Africa, Vol. 37 (116-144).

Sahlins, Marshall. 1999. Two or Three Things that I Know about Culture. In: The Journal of the Royal Anthropological Institute, Vol. 5, No. 3 (399-421).

Sathyamurthy, T.V. 1986. The Political Development of Uganda, 1900-1986. Aldershot: Gower.

Schäfer, Rita. 2008. Frauen und Kriege in Afrika - Ein Beitrag zur Gender-Forschung. Frankfurt a.M.: Brandes \& Apsel.

Schlee, Günther. 2006. Wie Feindbilder entstehen. Eine Theorie religiöser und ethnischer Konflikte. München: Beck.

Schlegel, Alice and Barry, Herbert III. 1979. Adolescent Initiation Ceremonies: A Cross-Cultural Code. In: Ethnology, Vol. 18, No. 2 (199-210).

Schlegel, Alice and Barry, Herbert III. 1980.The Evolutionary Significance of Adolescent Initiation Ceremonies. In: American Ethnologist, Vol. 7, No. 4 (696-715).

Schomerus, Mareike. 2010. Chasing the Kony Story. In: Allen, Tim and Vlassenroot, Koen (eds). The Lord's Resistance Army. Myth and Reality. Oxford: James Currey (293-112).

Scott, James C. 1998. Seeing like a State - How Certain Schemes to Improve the Human Condition have Failed. New Haven: Yale University Press.

Sharp, Lesley A. 2002. The Sacrificed Generation - Youth, History, and the Colonized Mind in Madagascar. Berkeley: University of California Press.

Shaw, Timothy M. and Mbabazi, Pamela K. 2008. Two Africas? Two Ugandas? An African 'Democratic Development State'? Or another 'Failed State'? In: Nhema, Alfred and Zeleza, Paul Tiyambe (eds). The Roots of African Conflicts - The Causes and Costs. Oxford: James Currey (214-238).

Silberschmidt, Margrethe. 2004. Masculinities, Sexuality and Socio-Economic Change in Rural and East Africa. In: Arnfred, Signe (ed.). Rethinking Sexualities in Africa. Uppsala: Nordiska Africainstitutet (233-250).

Silberschmidt, Margrethe. 2001. Disempowerment of Men in Rural and Urban East Africa: Implications for Male Identity and Sexual Behavior. In: World Development, Vol. 29, No. 4 (657-671).

Silberschmidt, Margrethe and Rasch, Vibeke. 2001. Adolescents Girls, Illegal Abortions and "Sugar-Daddies" in Dar es Salaam: Vulnerable Victims and Active Social Agents. In: Social Science and Medicine, Vol. 52 (1815-1826).

Simonse, Simon. 2005. Warriors, Hooligans and Mercenaries: Failed Statehood and the Violence of Young Male Pastoralists in the Horn of Africa. In: Abbink, Jon and van Kessel, Ineke (eds). Vanguard or Vandals - Youth, Politics and Conflict in Africa. Leiden: Brill (243-266).

Skelton, Tracey and Valentine, Gill (eds). 1998. Cool Places - Geographies of Youth Cultures. London: Routledge. 
Slemon, Stephen. 1995. The Scramble for Post-Colonialism. In: Ashcroft, Bill; Griffiths, Gareth and Tiffin, Helen (eds). 1995. The Post-colonial Studies Reader. London: Routledge (45-52).

Spitzer, Helmut and Twikirize, Janestic M. 2012. War-affected Children in Northern Uganda: No Easy Path to Normality. In: International Social Work, Vol. 56, No. 1 (67-79).

Ssekamwa, J.C. 2000 [1997]. History and Development of Education in Uganda. Kampala: Fountain Publishers.

Straight Talk Foundation. Online at: http://www.straighttalkfoundation.org/, accessed 14.01.2013.

Stroeken, Koen. 2008. Tanzania's "New Generation”: The Power and Tragedy of a Concept. In: Alber, Erdmute; van der Geerst, Sjaak and Whyte, Susan R. (eds). Generations in Africa - Connections and Conflicts. Berlin: LIT (289-310).

Stroeken, Koen. 2005. Immunizing Strategies: Hip-Hop and Critique in Tanzania. In: Africa, Vol. 75, No. 4 (488-509).

Tabaire, Bernard. 2012. Invisible Children and the Rise of Young Africans, at least Online. In: Daily Monitor, March $18^{\text {th }} 2012$.

Tabaire, Bernard and Okao, Jackie. 2010. Uganda's National Budget 2010/2011: How Strategic are the Budget Priorities? Synthesis Report of the Proceedings of the $10^{\text {th }}$ Session of the State of the Nation Platform. Kampala: ACODE (ACODE Policy Dialogue Series No.14, 2010).

Tagesschau. 2012. 5000 Soldaten sollen Kony und die LRA bekämpfen. $23^{\text {rd }}$ March, 2012. Online at: http://www.tagesschau.de/ausland/kony104.html, accessed 23.04.2012.

Tamale, Silvia (ed.). 2011a. African Sexualities - A Reader. Cape Town: Pambazuka Press.

Tamale, Silvia. 2011b. Researching and Theorizing Sexualities in Africa. In: Tamale, Silvia (ed.). African Sexualities - A Reader. Cape Town: Pambazuka Press (11-36).

Tamale, Silvia. 2011c. Paradoxes of Sex Work and Sexuality in Modern-Day Uganda. In: Tamale, Silvia (ed.). African Sexualities - A Reader. Cape Town: Pambazuka Press (145-173).

Tamale, Silvia. 2009. Law, Sexuality and Politics in Uganda: Challenges for Women's Human Rights NGOs. In: Mutua, Makau (ed.). Human Rights NGOs in Africa - Political and Normative Tensions. Kampala: Fountain Publishers (51-74).

Tibatemwa-Ekirikubinza, Lillian. 1999. Women's Violent Crime in Uganda More Sinned against than Sinning. Kampala: Fountain Publishers.

Tripp, Aili Mari. 2010. Museveni’s Uganda - Paradoxes of Power in a Hybrid Regime. Boulder: Lienne Rienner.

Tripp, Aili Mari. 2000. Women and Politics in Uganda. Madison: The University of Wisconsin Press. 
Trouillot, Michel-Rolph. 2003. Global Transformations - Anthropology in a Modern World. New York: Palgrave MacMillan.

Tumusiime, Abdulaziizi K. 2013. To Ban or not to Ban? In: Daily Monitor, $11^{\text {th }}$ April, 2013 (18-19).

Turner, Victor. 1967. The Forest of Symbols: Aspects of Ndembu Ritual. Ithaca: Cornell University Press.

Turton, David. 2002. War and Ethnicity. Global Connections and Local Violence. Woodbridge: Boydell and Brewer.

Uganda Bureau of Statistics (2012). Population in Principal Cities and Towns. Online at: http://www.citypopulation.de/Uganda-Cities.html, accessed 29.01.2013.

UNDP. 2006. Youth and Violent Conflict - Society and Development in Crisis. New York: UNDP. Online at: http://www.undp.org/cpr/whats_new/ UNDP_Youth_PN.pdf, accessed 14.10.2011.

USAID/UNICEF. 2006. A Hard Homecoming - Lessons Learned from the Reception Centers Process in Northern Uganda: An Independent Study produced by Tim Allen and Mareike Schomerus. Washington: MSI.

Utas, Mats. 2005. Agency of Victims - Young Women in the Liberian Civil War. In: Honwana, Alcinda and De Boeck, Filip (eds). Makers and Breakers Children and Youth in Postcolonial Africa. Oxford: James Currey (53-80).

Valentine, Gill; Skelton, Tracey and Chambers, Deborah. 1998. Cool Places - an Introduction to Youth and Youth Cultures. In: Skelton, Tracey and Valentine, Gill (eds). Cool Places - Geographies of Youth Cultures. London: Routledge (1-32).

Van Acker, Frank. 2004. Uganda and the Lord's Resistance Army. The New Order no one Ordered. In: African Affairs, Vol. 103, No. 412 (335-357).

Van Dijk, Rijk; de Bruijn, Miriam; Carlos, Cardoso and Butter, Inge. 2011. Introduction: Ideologies of Youth. In: Africa Development, Vol. XXXVI, No. 3 $\& 4(1-17)$.

Van Leeuwen, Theo. 2008. Discourse and Practice. New Tools for Critical Discourse Analysis. New York: Oxford University Press.

Verma, Cecilie Lanken. 2012. Truths out of Place: Homecoming Intervention, and Story-Making in War-Torn Northern Uganda. In: Children's Geographies, Vol. 10, No. 4 (441-455).

Vincent, Joan. 1999. War in Uganda: North and South. In: Reyna, S.P. and Downs, R.E. (eds). Deadly Developments: Capitalism, States and War. Amsterdam: Gordon and Breach (107-132).

Vorhölter, Julia. 2013. Rebuilding Society after the War - Creative Contributions by Acholi Youth. Paper presented at the 5th European Conference on African Studies (ECAS) in Lisbon, Portugal. 28 ${ }^{\text {th }}$ June, 2013.

Vorhölter, Julia. 2012. Negotiating Social Change: Ugandan Discourses on Westernisation and Neo-colonialism as Forms of Social Critique. In: The Journal of Modern African Studies, Vol. 50, No. 2 (283-307). 
Vorhölter, Julia. 2010a. Perceptions, (Re)-Productions and Transformations of Gender Roles and Norms among Youth in Northern Uganda. Paper presented at the XVII ISA-Sociology World Congress in Göteborg, Sweden. $14^{\text {th }}$ July, 2010.

Vorhölter, Julia. 2010b. Counseling of a Nation - Adoptions and Adaptations of Hegemonic Gender Discourses in Uganda. Paper presented at the Workshop on "Counseling and Cultural Change in Africa" at the Amsterdam School of Social Science. $6^{\text {th }}$ February, 2010.

Walubiri, Moses. 2013. Uganda: Anti-Pornography Bill not about Mini-Skirts Minister. In: New Vision, $10^{\text {th }}$ April, 2013. Online at: http://allafrica.com/ stories/201304101289.html, accessed 16.04.2013.

Wasonga, Joseph. 2009. Rediscovering Mato Oput: The Acholi Justice System and the Conflict in Northern Uganda. In: Africa Peace and Conflict Journal, Vol. 2, No. 1 (27-38).

Webster, Jayanni. 2013. Peace Education and Its Discontents: An Evaluation of Youth, Violence, and School-Based Peace Programs in Northern Uganda. In: Pursuit, Vol. 4, No. 2 (59-80).

Weiss, Brad. 2005. The Barber in Pain - Consciousness, Affliction and Alterity in Urban East Africa. In: Honwana, Alcinda and De Boeck, Filip (eds). Makers and Breakers - Children and Youth in Postcolonial Africa. Oxford: James Currey (102-120).

Weißköppel, Cordula. 2005. „Hybridität“ - die ethnographische Annäherung an ein theoretischen Konzept. In: Loimeier, Roman; Neubert, Dieter and Weißköppel, Cordula (eds). Globalisierung im lokalen Kontext - Perspektiven und Konzepte von Handeln in Afrika. Münster: LIT (311-347).

Welsch, Wolfgang. 1999. Transculturality - the Puzzling Form of Cultures Today. In: Featherstone, Mike and Lash, Scott (eds). Spaces of Culture: City, Nation, World. London: Sage (194-213).

Werbner, Richard and Ranger, Terence (eds). 1996. Postcolonial Identities in Africa. London: New Jersey.

Wesch, Ulrike. 2011. Peace-building from Abroad: The Influence of the AcholiDiaspora on the Peacebuilding Process in Northern Uganda. Paper presented at the $4^{\text {th }}$ European Conference on African Studies (ECAS) in Uppsala, Sweden. $17^{\text {th }}$ June, 2011.

Westbrook, David. 2000. The Torment of Northern Uganda: A Legacy of Missed Opportunities. In: The Online Journal of Peace and Conflict Resolution, No. 3.2. Online at: http://www.ciaonet.org/olj/ojpcr/ojpcr_3_2/ojpcr_3_2a. html, accessed 29.11.2011.

Whyte, Susan R.; Alber, Erdmute, and Geissler, P. Wenzel. 2004. Lifetimes Intertwined: African Grandparents and Grandchildren. In: Africa, Vol. 74, No. $1(1-5)$.

Whyte, Susan R.; Alber, Erdmute and van der Geerst, Sjaak. 2008. Generational Connections and Conflicts in Africa: An Introduction. In: Alber, Erdmute; 
van der Geerst, Sjaak and Whyte, Susan R. (eds). Generations in Africa Connections and Conflicts. Berlin: LIT (1-26).

Whyte, Susan R.; Babiiha, Suleyman M.; Mukyala, Rebecca and Meinert, Lotte. 2012. Remaining Internally Displaced: Missing Links to Security in Northern Uganda. In: Journal of Refugee Studies, online publication (1-19). Whyte, Susan R. and Whyte, Michael. 2004. Children's Children: Time and Relatedness in Eastern Uganda. In: Africa, Vol. 74, No. 1 (76-94).

Whyte, William F. 1955 [1943]. Street Corner Society. Chicago: Chicago University Press.

Wiegratz, Jörg. 2010. Fake Capitalism? The Dynamics of Neo-Liberal Moral Restructuring and Pseudo-Development: The Case of Uganda. In: Review of African Political Economy, Vol. 37, No. 124 (123-137).

Willis, Paul. 1977. Learning to Labor: How Working Class Kids Get Working Class Jobs. Farnborough: Saxon House.

Wittrock, Björn. 2000. Modernity: One, None, or Many? European Origins and Modernity as a Global Condition. In: Daedalus, Vol. 129, No. 1 (31-60).

World Bank. 2008. Youth Employment - Key to Conflict Prevention, Poverty Reduction. Washington: World Bank. Online at: http://web.worldbank. org/WBSITE/EXTERNAL/COUNTRIES/AFRICAEXT/0,,contentM DK:21997667-pagePK:146736 -piPK:146830-theSitePK:258644,00.html, accessed 14.10.2011.

World Vision, 2005. Pawns of Politics: Children, Conflict and Peace in Northern Uganda. World Vision International.

Wright, Katherine Fairfax and Zouhali-Worrall, Malika (dirs.). 2012. Call me Kuchu. USA/Uganda (90 min.).

Wulff, Helena. 1995. Introducing Youth Culture in Its Own Right: The State of the Art and New Possibilities. In: Amit-Talai, Vered and Wulff, Helena (eds). Youth Cultures - A Cross-Cultural Perspective. London: Routledge $(1-18)$.

Wyrod, Robert. 2008. Between Women's Rights and Men's Authority: Masculinity and Shifting Discourses of Gender Difference in Urban Uganda. In: Gender and Society, Vol. 22, No.6 (799-823).

Zeleza, Paul T. 2003. Historicizing the Posts: The View from African Studies. In: Magubane, Zine (ed.). Postmodernism, Postcoloniality and African Studies. Trenton: Africa World Press (1-38). 
9. Appendix 


\subsection{Acronyms}

AIDS

A-Level

ARLPI

$\mathrm{CBO}$

CCCS

$\mathrm{DEO}$

DJ

DP

DRC

FDC

FEDEMU

GBV

GUTA

GYC

H.E.A.L.S

HIV

HSMF

HURIFO

HURIWA

ICC

ICG

IDMC

IDP

IMF

INAMO

INT

IPSS

IRIN
Acquired Immune Deficiency Syndrome

Advanced Level

Acholi Religious Leaders' Peace Initiative

Community-based Organization

Centre of Contemporary Cultural Studies (Birmingham)

District Education Officer

Disk Jockey

Democratic Party

Democratic Republic Congo

Forum for Democratic Change

Federal Democratic Movement of Uganda

Gender-based Violence

Gulu Theatre Artists

Gulu Youth Centre

Health, Education, Arts, Literacy and Sports

Human Immunodeficiency Virus

Holy Spirit Mobile Forces

Human Rights Focus

Human Rights Watch

International Criminal Court

International Crisis Group

Internal Displacement Monitoring Centre

Internally Displaced Person

International Monetary Fund

Informationsprojekt Naher und Mittlerer Osten

Interview

Institute of Peace and Strategic Studies

Integrated Regional Information Network 
KKA

KM

LCs

LDU

LGBTI

LRA/M

LTC

$\mathrm{MC}$

$\mathrm{NGO}$

NRM/A

OCHA

O-Level

RDC

RLP

UGX

UN

UNDP

UNLA

UNICEF

UPC

UPDA/M

UPDF

UPE

USAID

VCT

WFP

ZFD
Ker Kwaro Acholi

Kacoke Madit

Local Councils

Local Defense Unit

LesbianGayBisexualTransIntersex

Lord's Resistance Army/Movement

Luo Talent Centre

Master of Ceremony

Non-governmental Organization

National Resistance Movement/Army

(NRA renamed to UPDF in 1995)

Office for the Coordination of Humanitarian Affairs

Ordinary Level

Resident District Commissioner

Refugee Law Project

Ugandan Shilling

United Nations

United Nations Development Program

Uganda National Liberation Army

United Nations Children's Fund

Uganda People's Congress

Uganda People's Democratic Army/Movement

Ugandan People's Defense Forces

Universal Primary Education

United States Agency for International Development

Voluntary Testing and Counseling

World Food Program

Ziviler Friedensdienst 


\subsection{Acholi Terms}

$\begin{array}{ll}\text { abila } & \text { Ancestral shrine } \\ \text { ajwaka } & \text { Spirit medium } \\ \text { awak } & \text { Working party for communal field work } \\ \text { boda boda } & \text { Motorbike taxi } \\ \text { bulu } & \text { Youth } \\ \text { cen } & \text { Spirit of people who died violently } \\ \text { jok (pl. jogi) } & \text { Spirit(s) } \\ \text { kaka } & \text { Clan; extended family unit whose members } \\ & \text { can trace their genealogical links to a known } \\ \text { common male ancestor } \\ \text { kacoke madit } \\ \text { lawi rwodi } \\ \text { mato oput }\end{array}$




\subsection{Figures}

9.3.1. Figure 1: Map of Uganda, including Acholi Sub-Region

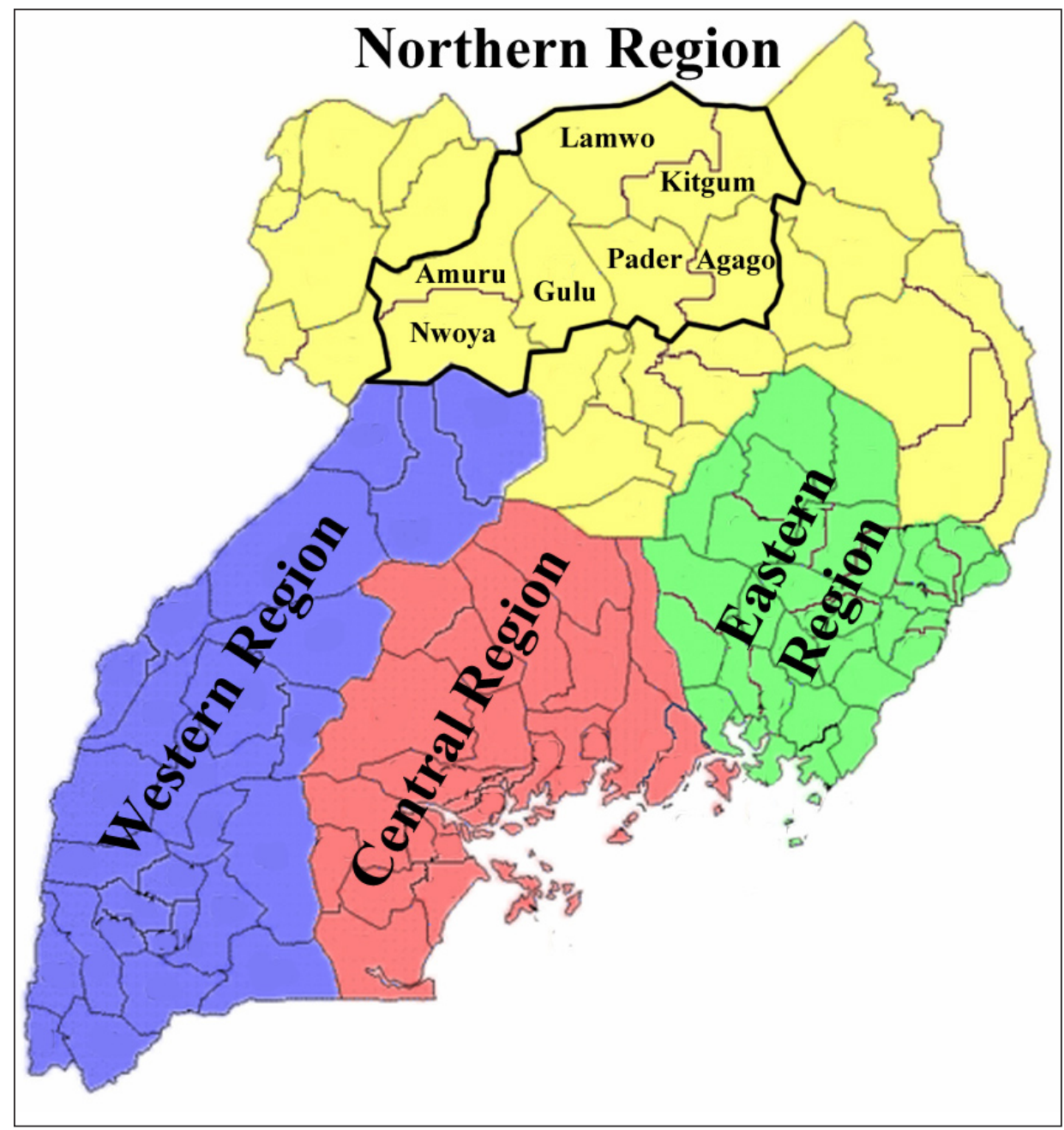

Map of Uganda (http://en.wikipedia.org/wiki/File:Uganda_districts_2010.png, cited 18.02.2013; modified by Martin Morlock); black-rimmed: Acholi sub-region with its seven districts Gulu, Kitgum, Pader, Amuru, Nwoya, Lamwo and Agago (status as of 2011). 
Julia Vorhölter: Youth at the Crossroads

9.3.2. Figure 2: Map of Uganda, including major towns \& neighboring countries

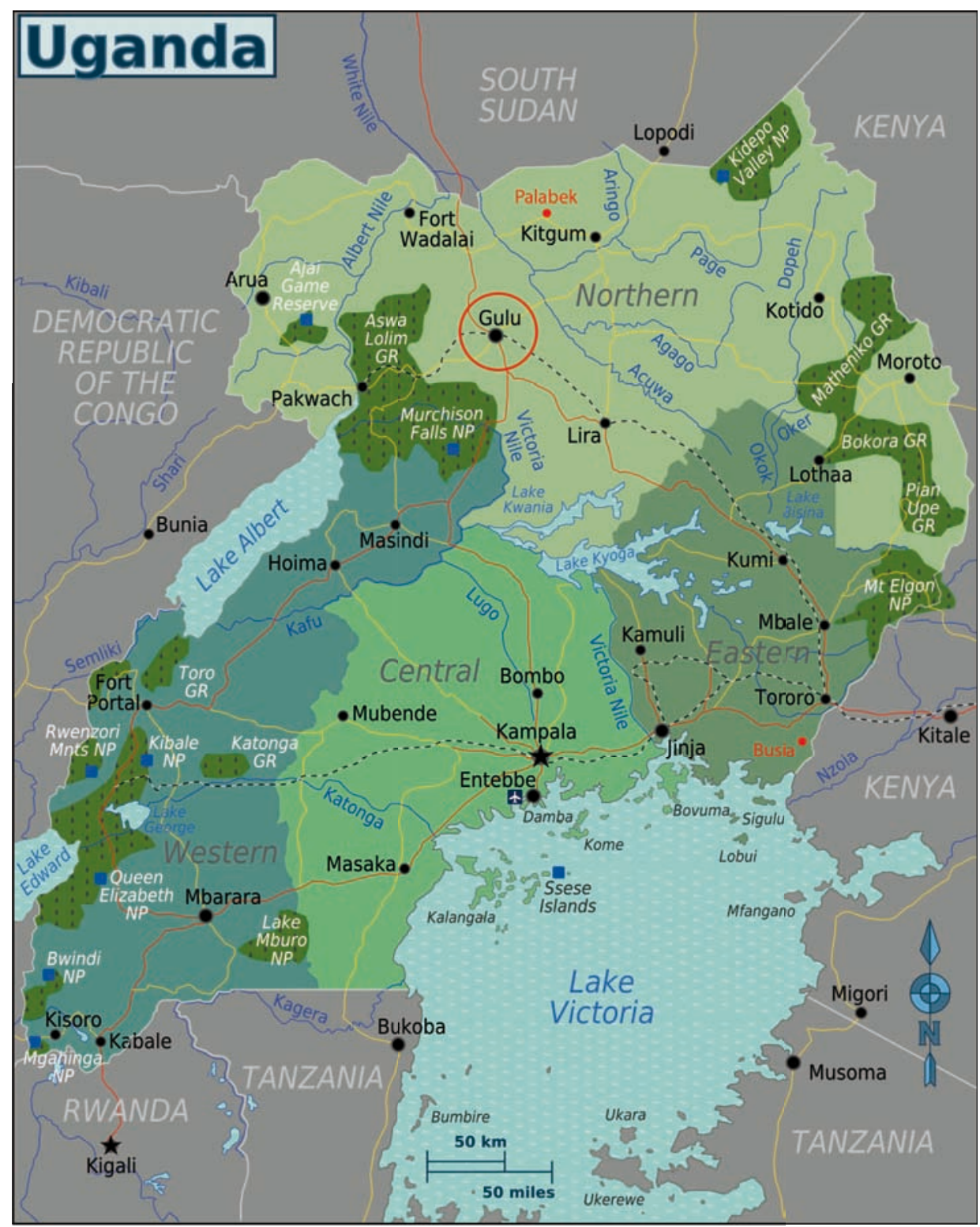

Map of Uganda including major towns and neighboring countries [Busia and Palabek added by J.V.] (http://en.wikipedia.org/wiki/File:Uganda_Regions_map.png, cited 16.05.2014); circled: Gulu Municipality. 
9.3.3. Figure 3: Socio-Demographic Characteristics, Acholi Districts, 2010 Survey

\begin{tabular}{lrrrrr}
\hline & Gulu & Amuru & Kitgum & Pader & Total \\
\hline Sex (\% women) & 50.3 & 51.7 & 49.6 & 49.7 & 50.3 \\
\hline Age (average) & 39.1 & 37.9 & 39.0 & 38.6 & 38.6 \\
\hline Education Level (\%) & & & & & \\
\hline None & 23.8 & 34.9 & 39.1 & 37.0 & 35 \\
\hline Primary incomplete & 44 & 39.6 & 33.9 & 42.4 & 40 \\
\hline Primary complete & 12.3 & 11.1 & 11.7 & 6.4 & 10 \\
\hline Vocational Training & 3.1 & 0.9 & 3.2 & 4.6 & 3.1 \\
\hline Secondary incomplete & 11.3 & 7.2 & 9.5 & 7.4 & 8.6 \\
\hline Secondary complete or above & 5.5 & 6.2 & 2.5 & 2.2 & 3.9 \\
\hline Literacy & \multicolumn{7}{c}{$\begin{array}{r} \\
\text { Read/write (\% yes) }\end{array}$} & 59.4 & 48.7 & 51.8 & 52.8 & 52.8 \\
\hline Poverty & 13,105 & 9,642 & 6,503 & 4,043 & 7,716 \\
\hline Average income last 7 days (UGX*) & 23,157 & 16,935 & 10,976 & 6,442 & 13,259 \\
\hline Average income per week (UGX) & 14 & 27 & 22 & 17 & 20 \\
\hline Poorest asset quintile (\%) & 3.9 & 2.8 & 2.9 & 3.0 & 3.1 \\
\hline Average number of assests & & & & &
\end{tabular}

* At the time of the survey, 1 US dollar was traded for approximately 2,000 UGX.

Source: Pham \& Vinck, 2010: 16, adapted from original by J.V.

The above-cited socio-demographic characteristics are based on a statistical survey conducted by Phoung Pham \& Patrick Vinck in the four Acholi districts Gulu, Amuru, Kitgum and Pader (the recent divisions of these districts, cf. figure 1, were not taken into account) in April and May 2010. A total of 2,498 individuals in 154 villages were interviewed. Presumably, the average income, level of education and literacy rate in Gulu Municipality were slightly higher than the above averages suggest as the survey has a rural bias. Unfortunately, I did not find any reliable income statistics for Gulu Municipality. 
9.3.4. Figure 4: Urban Population Development in Uganda - Selected Towns

\begin{tabular}{llrrrrr}
\hline Name & Region & 1969 & 1980 & 1991 & 2002 & $\mathbf{2 0 1 1}$ \\
\hline Arua & North & 10,837 & $\ldots$ & 22,217 & 43,929 & 59,400 \\
\hline Entebbe & Central & 21,096 & 21,289 & 42,763 & 55,086 & 79,700 \\
\hline Fort Portal & West & 7,947 & 26,806 & 32,789 & 40,993 & 47,100 \\
\hline Gulu & North & 18,170 & 14,958 & 38,297 & 119,430 & 154,300 \\
\hline Jinja & East & 47,872 & 45,060 & 65,169 & 71,213 & 89,700 \\
\hline Kabale & West & 8,234 & 21,469 & 29,246 & 41,344 & 44,600 \\
\hline Kampala & Central & 330,700 & 458,503 & 774,241 & $1,189,142$ & $1,659,600$ \\
\hline Kasese & West & 7,213 & 9,917 & 18,750 & 53,907 & 74,300 \\
\hline Kira ${ }^{213}$ & Central & $\ldots$ & $\ldots$ & & 124,067 & 179,800 \\
\hline Kitgum & North & 3,242 & 4,961 & 12,978 & 41,821 & 59,700 \\
\hline Lira & North & 7,340 & 9,122 & 27,568 & 80,879 & 108,600 \\
\hline Masaka & Central & 12,987 & 29,123 & 49,585 & 67,768 & 74,100 \\
\hline Masindi & West & 5,226 & 4,958 & 10,839 & 28,300 & 45,400 \\
\hline Mbale & East & 23,544 & 28,039 & 53,987 & 71,130 & 91,800 \\
\hline Mbarara & West & 16,078 & 23,255 & 41,031 & 69,363 & 83,700 \\
\hline Nansana & Central & $\ldots$ & $\ldots$ & $\ldots$ & 62,044 & 89,900 \\
\hline Soroti & East & 12,398 & 15,048 & 40,970 & 41,711 & 66,000 \\
\hline Tororo & East & 15,977 & 16,707 & 26,783 & 34,810 & 43,700 \\
\hline Nin & & & & &
\end{tabular}

Principal Cities

\begin{tabular}{llr}
\hline Name & Region & $\mathbf{2 0 1 1}$ \\
\hline Kampala & Central & $1,659,600$ \\
\hline Kira $^{213}$ & Central & 179,800 \\
\hline Gulu & North & 154,300 \\
\hline Lira & North & 108,600 \\
\hline Mbale & East & 91,800 \\
\hline Nansana & Central & 89,900 \\
\hline Jinja & East & 89,700 \\
\hline Mbarara & West & 83,700 \\
\hline Entebbe & Central & 79,700 \\
\hline
\end{tabular}

Source: Uganda Bureau of Statistics (2012)

${ }^{213}$ The comparatively high population of Kira is explained by the fact that the town lies very close (approximately 17 kilometers) to the central business district of Kampala. 


\subsection{List of Interviews}

9.4.1. Interview with Acholi Elder

\begin{tabular}{llll}
\hline Name & Date & Location $^{214}$ & $\begin{array}{l}\text { Details (Year and place of birth, Level } \\
\text { of Education, Profession... })^{215}\end{array}$ \\
\hline $\begin{array}{l}\text { Okello (and } \\
\text { his son }\end{array}$ & 26.09 .2010 & Family home & $\begin{array}{l}\text { Okello: born 1937, retired school teacher, } \\
\text { married with } 5 \text { co-wives [Samuel: born } \\
\text { Samuel) }\end{array}$ \\
& & $\begin{array}{l}\text { 1984, O-Level (Junior Secondary School), } \\
\text { boda boda driver, married with 2 children] }\end{array}$ \\
\hline
\end{tabular}

\subsubsection{Interviews with Acholi Youth}

\begin{tabular}{|c|c|c|c|}
\hline Name & Date & Location $^{214}$ & $\begin{array}{l}\text { Details (Year and place of birth, Level } \\
\text { of Education, Profession....) }\end{array}$ \\
\hline Simon & 31.03 .2010 & Gulu Youth Centre & $\begin{array}{l}\text { Born } 1992 \text { in Pader (village), enrolled in } \\
\text { A-Level (Senior Secondary School) }\end{array}$ \\
\hline Ojok & 31.03 .2010 & Gulu Youth Centre & $\begin{array}{l}\text { born in Pader (village), enrolled at Gulu } \\
\text { University, }\end{array}$ \\
\hline Cyclo & 09.04 .2010 & Gulu Youth Centre & $\begin{array}{l}\text { born } 1988 \text { in Gulu (town), finished A- } \\
\text { Level }\end{array}$ \\
\hline Elima & 09.04 .2010 & Gulu Youth Centre & $\begin{array}{l}\text { born } 1990 \text { in Pader (village), enrolled in } \\
\text { A-Level }\end{array}$ \\
\hline Denis & 16.04 .2010 & Gulu Youth Centre & $\begin{array}{l}\text { born } 1986 \text { in Amuru (village), started but } \\
\text { did not finish A-Level }\end{array}$ \\
\hline A.B. & 16.04 .2010 & Gulu Youth Centre & $\begin{array}{l}\text { born 1975, lived in Canada from 1991- } \\
2009\end{array}$ \\
\hline Nura & 21.04 .2010 & Gulu Youth Centre & $\begin{array}{l}\text { born } 1990 \text { in the village, enrolled in } \\
\text { O-level }\end{array}$ \\
\hline Martin & 21.04 .2010 & Gulu Youth Centre & $\begin{array}{l}\text { Born } 1984 \text { in Gulu (town), completed } \\
\text { O-Level (Junior Secondary School) }\end{array}$ \\
\hline Laurence & 28.04 .2010 & Gulu Youth Centre & $\begin{array}{l}\text { born in } 1991 \text { in Gulu (town), has finished } \\
\text { his O-level and is waiting to go for his } \\
\text { A-level }\end{array}$ \\
\hline
\end{tabular}

${ }^{214}$ All interviews were conducted in Gulu Municipality unless otherwise stated.

215 The information concerning the level of education and profession was obtained during the time of my research, i.e. in 2010/early 2011, and may no longer be accurate. 
Julia Vorhölter: Youth at the Crossroads

\begin{tabular}{|c|c|c|c|}
\hline Daniel & 30.04 .2010 & Gulu Youth Centre & $\begin{array}{l}\text { born in } 1990 \text { in Gulu (village); enrolled } \\
\text { in O-Level }\end{array}$ \\
\hline Odong & 04.05 .2010 & Luo Talent Centre & $\begin{array}{l}\text { Born in } 1991 \text { in Kitgum (village), has } \\
\text { finished A-level; enrolled in teacher's } \\
\text { college }\end{array}$ \\
\hline Innocent LTC & 04.05 .2010 & Luo Talent Centre & $\begin{array}{l}\text { Born in } 1989 \text { in Gulu (village); has } \\
\text { finished A-Level; working at local gas } \\
\text { station }\end{array}$ \\
\hline Omony & 08.05 .2010 & Luo Talent Centre & $\begin{array}{l}\text { Born in } 1994 \text { in Gulu (town), enrolled in } \\
\text { O-Level }\end{array}$ \\
\hline Atim & 08.05 .2010 & Luo Talent Centre & $\begin{array}{l}\text { Born in } 1995 \text { in Gulu (town), enrolled in } \\
\text { Primary School }\end{array}$ \\
\hline Ajoka & 08.05 .2010 & Luo Talent Centre & $\begin{array}{l}\text { Born in } 1991 \text { in Gulu (town), enrolled in } \\
\text { O-Level }\end{array}$ \\
\hline Helen & 08.05 .2010 & Luo Talent Centre & $\begin{array}{l}\text { Born in } 1995 \text { in Pader (village), enrolled } \\
\text { in Primary School }\end{array}$ \\
\hline Lagen & 08.05 .2010 & Luo Talent Centre & $\begin{array}{l}\text { born in } 1993 \text { in Kitgum (village), enrolled } \\
\text { in O-Level }\end{array}$ \\
\hline Alice & 06.10 .2010 & Bobbi, Gulu District & $\begin{array}{l}\text { Born in } 1984 \text { in Pader (village), police } \\
\text { officer }\end{array}$ \\
\hline Akello & 26.11.2010 & My place, Pece & $\begin{array}{l}\text { Born in } 1991 \text { in Gulu (town), finished Pri- } \\
\text { mary School, had to drop out of O-Level }\end{array}$ \\
\hline Joseph & 14.12 .2010 & Gulu Youth Centre & $\begin{array}{l}\text { Born } 1990 \text { in Masindi, finished A-Level, } \\
\text { working as a volunteer at Gulu Youth } \\
\text { Centre }\end{array}$ \\
\hline
\end{tabular}


9.4.3. Interviews with NGO-Representatives

\begin{tabular}{|c|c|c|c|}
\hline Name & Date & Location ${ }^{216}$ & $\begin{array}{l}\text { Details (Year and place of birth, Level } \\
\text { of Education, Profession....) }\end{array}$ \\
\hline EM & 16.03 .2010 & $\begin{array}{l}\text { American Refugee } \\
\text { Council, Office }\end{array}$ & $\begin{array}{l}\text { American, female, in her 30s, GBV Coor- } \\
\text { dinator for American Refugee Council }\end{array}$ \\
\hline Rocki & 16.03.2010 & $\begin{array}{l}\text { American Refugee } \\
\text { Council, Office }\end{array}$ & $\begin{array}{l}\text { Acholi, male, in his early 30s, GBV-Ca- } \\
\text { pacity-Building-Manager for American } \\
\text { Refugee Council }\end{array}$ \\
\hline Ojara & 17.03.2010 & $\begin{array}{l}\text { Gulu Youth Develop- } \\
\text { ment Association, } \\
\text { Office }\end{array}$ & $\begin{array}{l}\text { Acholi, male, born in 1984, General } \\
\text { Secretary for Gulu Youth Development } \\
\text { Association }\end{array}$ \\
\hline Faith & 18.03.2010 & $\begin{array}{l}\text { Gulu Youth centre, } \\
\text { office }\end{array}$ & $\begin{array}{l}\text { Alur, female, born in 1970, Manager of } \\
\text { Gulu Youth Centre }\end{array}$ \\
\hline Zipporah & 23.03 .2010 & NGO Forum, Office & $\begin{array}{l}\text { Acholi, born in 1987, Gulu Youth Leader- } \\
\text { ship Programme Officer }\end{array}$ \\
\hline SK & 23.03 .2010 & $\begin{array}{l}\text { Ker Kwaro Acholi } \\
\text { Headquarters }\end{array}$ & $\begin{array}{l}\text { Acholi, female, in her late twenties, Ker } \\
\text { Kwaro Acholi Project Officer GBV }\end{array}$ \\
\hline $\begin{array}{l}\text { Vincent } \\
\text { Ochieng }\end{array}$ & 26.03 .2010 & $\begin{array}{l}\text { District Administra- } \\
\text { tion Headquarters, } \\
\text { office }\end{array}$ & $\begin{array}{l}\text { Acholi, male, in his } 40 \text { s, District Educa- } \\
\text { tion Officer }\end{array}$ \\
\hline Mike & 29.03 .2010 & $\begin{array}{l}\text { Ker Kwaro Acholi } \\
\text { Headquarters }\end{array}$ & $\begin{array}{l}\text { Acholi, male, in his } 40 \text { s, Ker Kwaro Acholi } \\
\text { Coordinator of the SPRING Project }\end{array}$ \\
\hline $\begin{array}{l}\text { Odong and } \\
\text { Bangi }\end{array}$ & 27.04 .2010 & $\begin{array}{l}\text { Gulu Youth Coalition } \\
\text { for Peace, office }\end{array}$ & $\begin{array}{l}\text { Acholi, male, both in their } 20 \text { s, leaders of } \\
\text { the Gulu Youth Coalition for Peace }\end{array}$ \\
\hline
\end{tabular}

${ }^{216}$ All interviews were conducted in Gulu Municipality unless otherwise stated.

217 The information concerning the level of education and profession was obtained during the time of my research, i.e. in 2010/early 2011, and may no longer be accurate. 
9.4.4. Group Interviews in Rural Areas

\begin{tabular}{lcccc}
\hline Location $^{218}$ & Date & $\begin{array}{c}\text { Number of } \\
\text { Participants } \\
\text { (Total) }^{219}\end{array}$ & $\begin{array}{c}\text { Male-Female Ratio } \\
\text { of Participants }\end{array}$ & $\begin{array}{c}\text { Youth-Elder Ratio } \\
\text { of Participants }\end{array}$ \\
\hline Bobbi & 06.10 .2010 & 19 & 11 male, 8 female & 3 elders, 16 youth \\
\hline Bungutera & 03.10 .2010 & 27 & 17 male, 10 female & 3 elders, 24 youth \\
\hline Kapedopong & 28.06 .2010 & 17 & 8 male, 9 female & 7 elders, 10 youth \\
\hline Pabbo, & 23.10 .2010 & 15 & 9 male, 6 female & 2 elders, 13 youth \\
Amuru District & & & & \\
\hline Paicho & 17.10 .2010 & 23 & 17 male, 6 female & 4 elders, 19 youth \\
\hline Wii Aweng & 26.09 .2010 & 39 & 12 male, 27 female & 20 elders, 19 youth \\
\hline
\end{tabular}

${ }^{218}$ All in Gulu District unless otherwise stated.

${ }^{219}$ It proved to be impossible to limit the number of interview participants in the group interviews my research assistants and I carried out in the rural areas. Usually, as soon as my research assistants had announced our arrival and arranged the interview setting, the majority of the villagers came over to observe and/or participate in the interview. In the end, this often turned out to be an advantage, because big discussions emerged between the participants which reflected quite a number of different voices and perspectives.

${ }^{220}$ The ages of the people considered youth and elders respectively greatly varied in the different interview contexts. The youth-elder ratios given here are rough estimates based on the self-definitions given by the interview participants. 


\subsection{Short Biography of Most Important Interlocutors}

\begin{tabular}{|c|c|c|}
\hline Name & $\begin{array}{c}\text { No. of Meetings/ } \\
\text { Conversations }\end{array}$ & Details \\
\hline Akello & 50 & $\begin{array}{l}\text { Akello, } 19 \text { at the time of my research, was one of my most } \\
\text { important interlocutors during my stay in Gulu. I first met } \\
\text { her in the weekly sessions of the "Gulu Taling Straight" } \\
\text { hip hop project, where I also met Simon. Akello had to } \\
\text { drop out of school in Senior } 3 \text { because her parents could } \\
\text { no longer afford to pay her school fees. During the time } \\
\text { of research, she was working in different unskilled jobs in } \\
\text { order to earn money to sustain herself and her one-year } \\
\text { old daughter, but in her free time she sometimes partici- } \\
\text { pated in hip hop contests and was well-known in the lo- } \\
\text { cal scene. Over the course of my stay in Gulu, we became } \\
\text { close friends and usually met at least once a week. She } \\
\text { often took me to see and talk with her family, introduced } \\
\text { me to the hip hop scene and the life of young people in } \\
\text { Gulu, and accompanied me to different events. }\end{array}$ \\
\hline GYC staff & 41 & $\begin{array}{l}\text { Gulu Youth Centre was one of my central research ven- } \\
\text { ues and the people who worked and volunteered there } \\
\text { were very important interlocutors throughout my stay. } \\
\text { They accepted me as a volunteer and I often joined the } \\
\text { youth talk sessions, helped out at the reception desk or } \\
\text { accompanied the outreach to VCT-sessions in the rural } \\
\text { areas and at public events in Gulu. I learned many as- } \\
\text { pects about youth and youth life from the different staff } \\
\text { members and by speaking to the young people who } \\
\text { came to GYC for youth services. }\end{array}$ \\
\hline $\begin{array}{l}\text { Hip Hop } \\
\text { Group }\end{array}$ & 26 & $\begin{array}{l}\text { The "Gulu Talking Straight" hip hop project consisted of } \\
\text { approximately } 20 \text { young people (in their late teens and } \\
\text { early twenties) and two "trainers". The aim of the project } \\
\text { was to train the participants in creative writing and } \\
\text { other basic music skills and then give each participant } \\
\text { the chance to record a song in a record studio after their } \\
\text { training. I found out about the project by coincidence } \\
\text { from one of the staff members at Gulu Youth Centre. } \\
\text { From the beginning, I joined nearly all of the bi-weekly } \\
\text { training sessions and thus established close contact to }\end{array}$ \\
\hline
\end{tabular}


Julia Vorhölter: Youth at the Crossroads

the group. I conducted interviews with some of the participants and spent a lot of time at the project, especially in the first phase of my research. Even after the project had officially ended I maintained sporadic contact with some of the young hip hoppers.

\begin{tabular}{|c|c|c|}
\hline Fred & 24 & $\begin{array}{l}\text { Fred, } 25 \text { at the time of my research, was another very } \\
\text { important interlocutor and close friend. He was the } \\
\text { chairperson of the GUTA traditional dance group and } \\
\text { I met during one of my first visits to the group. After } \\
\text { a while, we also started to meet outside of the dance } \\
\text { practice sessions and he introduced me to many places } \\
\text { and events in Gulu. We often had very long conversa- } \\
\text { tions and debates about culture and cultural changes, } \\
\text { life of young people in Gulu, gender relations, Western } \\
\text { influences on Uganda, politics and other topics pertain- } \\
\text { ing to my research. Fred had finished university and after } \\
\text { some months of unemployment started to work for a } \\
\text { government agency. }\end{array}$ \\
\hline GUTA & 21 & $\begin{array}{l}\text { The "Gulu Theatre Artists" (GUTA) were a "cultural } \\
\text { group", consisting of male and female children and } \\
\text { youth between the ages of roughly ten to thirty who } \\
\text { met regularly to practice and perform traditional Acholi } \\
\text { dances. Throughout my stay in Gulu, I visited their dance } \\
\text { practices and their performances in public venues and at } \\
\text { dance competitions on a regular basis. I also conducted } \\
\text { interviews with a number of the GUTA members and } \\
\text { some became regular and important interlocutors. }\end{array}$ \\
\hline Williams & 20 & $\begin{array}{l}\text { I already met Williams, in his mid-20s, during my first stay } \\
\text { in Gulu. He was working in one of the local internet cafes } \\
\text { and I often had lengthy conversations with him when } \\
\text { I went there to check my emails. He had just finished } \\
\text { university and many of his friends, who had also finished } \\
\text { university and were not yet working and/or were not } \\
\text { yet married, came to hang out at the internet place. All } \\
\text { of them were big fans of English Premier League soccer } \\
\text { and I sometimes joined them to watch a game. I also } \\
\text { often accompanied Williams and his friend to the weekly } \\
\text { pub quiz at one of the bars in Gulu. Thus, I gained some } \\
\text { insights into the lives of 'elite youth' in Gulu. }\end{array}$ \\
\hline
\end{tabular}




\begin{tabular}{|c|c|c|}
\hline Julie & 19 & $\begin{array}{l}\text { Julie, in her late } 20 \text { s, was my flat mate and colleague at } \\
\text { IPSS. She came from a middle-class, highly educated } \\
\text { family and had grown up in Kampala. We often had } \\
\text { lengthy conversations about life in Gulu and 'ordinary } \\
\text { Acholi society', which Julie, although she was half-Acholi } \\
\text { herself, regarded from a similar 'outsider perspective' as } \\
\text { I did. }\end{array}$ \\
\hline $\begin{array}{l}\text { Florence } \\
\text { and family }\end{array}$ & 15 & $\begin{array}{l}\text { I was introduced to Florence, in her 30s, and her four chil- } \\
\text { dren, by Lioba, a fellow German anthropologist, whom I } \\
\text { met and became close friends with in Gulu (see below). } \\
\text { Florence lived alone with her children in a little village } \\
\text { setting at the outskirts of Gulu. She had a basic level of } \\
\text { education and throughout her life had been working } \\
\text { in a number of different unskilled jobs with in-between } \\
\text { periods of being unemployed. Florence had experienced } \\
\text { life in Gulu before and during the war and often told us } \\
\text { about these times. She was also a great proverb- and } \\
\text { story-teller and had a big repertoire of cultural knowl- } \\
\text { edge. I usually met with Florence, her children and Lioba } \\
\text { to have dinner; sometimes I also visited her at her place } \\
\text { or we all went out for a particular event. }\end{array}$ \\
\hline $\begin{array}{l}\text { Okello/ } \\
\text { Akello's } \\
\text { family }\end{array}$ & 14 & $\begin{array}{l}\text { Akello often took me to visit her family home and I } \\
\text { developed a close relationship especially with her father } \\
\text { Okello and her brother Samuel. Since her mother could } \\
\text { only speak Acholi our conversations remained fairly } \\
\text { limited. I also met some of Akello's other brothers and } \\
\text { sisters as well their children. The regular visits to Akello's } \\
\text { family enabled me to get a good insight into Acholi fam- } \\
\text { ily relations. }\end{array}$ \\
\hline Joel & 13 & $\begin{array}{l}\text { Joel, in his late } 20 \text { s, was one of the "trainers" of the } \\
\text { hip hop project. He called himself a music artist and } \\
\text { producer and had recently landed a relatively success- } \\
\text { ful song, which was played on the local radio stations. } \\
\text { Joel introduced me to the Gulu hip hop scene and I even } \\
\text { recorded a song with him and one of his friends in one of } \\
\text { the local record studios. }\end{array}$ \\
\hline
\end{tabular}


Julia Vorhölter: Youth at the Crossroads

\begin{tabular}{|c|c|c|}
\hline Ruth & 12 & $\begin{array}{l}\text { Ruth, in her late 20s, worked at Gulu Youth Centre and } \\
\text { over time became an important interlocutor and friend. } \\
\text { I sometimes visited her at her place in the outskirts of } \\
\text { Gulu, where she lived with her } 9 \text {-year-old son. Ruth often } \\
\text { talked to me about gender and family relations and } \\
\text { the difficult situation of women in Acholi society. She } \\
\text { once took me to visit her father and his family in Lamwo } \\
\text { district, which was a very inspiring and insightful trip for } \\
\text { me. }\end{array}$ \\
\hline Simon & 10 & $\begin{array}{l}\text { Simon, } 18 \text { at the time of my research, was a participant } \\
\text { in the hip hop project, where I first met him and often } \\
\text { chatted with him during and after the training sessions. } \\
\text { We remained in touch even after the project was finished } \\
\text { and I met him on a fairly regular basis in town, at hip hop } \\
\text { events or when I visited his youth cultural group. Simon } \\
\text { was a very open converser and I was often amazed and } \\
\text { amused by the stories he told me about the Gulu youth } \\
\text { scene. Simon dropped out of A-Level and tried to pursue } \\
\text { a hip hop career but in a recent telephone conversation } \\
\text { (December 2012) I learned that he had taken up his stud- } \\
\text { ies again. }\end{array}$ \\
\hline Opio & 10 & $\begin{array}{l}\text { Opio, also in his mid-20s, was a friend of Williams and } \\
\text { I usually met him on Thursday night for the pub quiz. } \\
\text { He had also finished university and was looking for a } \\
\text { job. Opio was one of the most politically-interested and } \\
\text { critical people I met and we often had interesting discus- } \\
\text { sions about Ugandan politics, elite corruption, but also } \\
\text { cultural affairs and social relations in Acholi society. }\end{array}$ \\
\hline Christopher & 4 & $\begin{array}{l}\text { Christopher, in his 40s, was another person who was } \\
\text { introduced to me by Lioba. Christopher was a real } \\
\text { 'self-made man' and entrepreneur, involved in all sorts } \\
\text { of businesses. He was also a stern supporter of 'Acholi } \\
\text { traditions' and often 'lectured' Lioba and me on Acholi } \\
\text { customs and conventions. Christopher had two wives } \\
\text { and a number of children and had recently started to } \\
\text { partly settle back to the rural areas. Like Florence, he was } \\
\text { also a great story-teller and 'cultural expert'. }\end{array}$ \\
\hline
\end{tabular}




\begin{tabular}{|c|c|c|}
\hline Joseph & 4 & $\begin{array}{l}\text { I met Joseph, } 20 \text { at the time, at Gulu Youth Centre, where } \\
\text { he later came to work as a volunteer. He wrote a lot of } \\
\text { poetry in which he talked about his life experiences as a } \\
\text { young man in Uganda. He often showed me his poetry } \\
\text { and sometimes we had lengthy debates about some of } \\
\text { the topics he talked about, especially Ugandan politics. } \\
\text { Towards the end of my stay, I had some very long and } \\
\text { thought-provoking conversations with Joseph and even } \\
\text { after I left he continued to send me some of his poetry. }\end{array}$ \\
\hline Lioba & $\begin{array}{l}\text { I did not count } \\
\text { the times I met } \\
\text { Lioba, but as we } \\
\text { became close } \\
\text { friends, were col- } \\
\text { leagues at IPSS, } \\
\text { and lived in close } \\
\text { proximity, we saw } \\
\text { each other nearly } \\
\text { every day of my } \\
\text { fieldwork. }\end{array}$ & $\begin{array}{l}\text { Lioba is a fellow German anthropologist, whom I met } \\
\text { and became close friends with in Gulu. Lioba has been } \\
\text { living in Gulu for several years and is working as a re- } \\
\text { searcher and senior lecturer at the Institute of Peace and } \\
\text { Strategic Studies. Lioba was a very important interlocu- } \\
\text { tor during my fieldwork, not only as a friend, but also in } \\
\text { her function as an anthropologist and resource person. } \\
\text { She often gave me valuable advice on my research and } \\
\text { she introduced me to several people and places in Gulu. }\end{array}$ \\
\hline
\end{tabular}



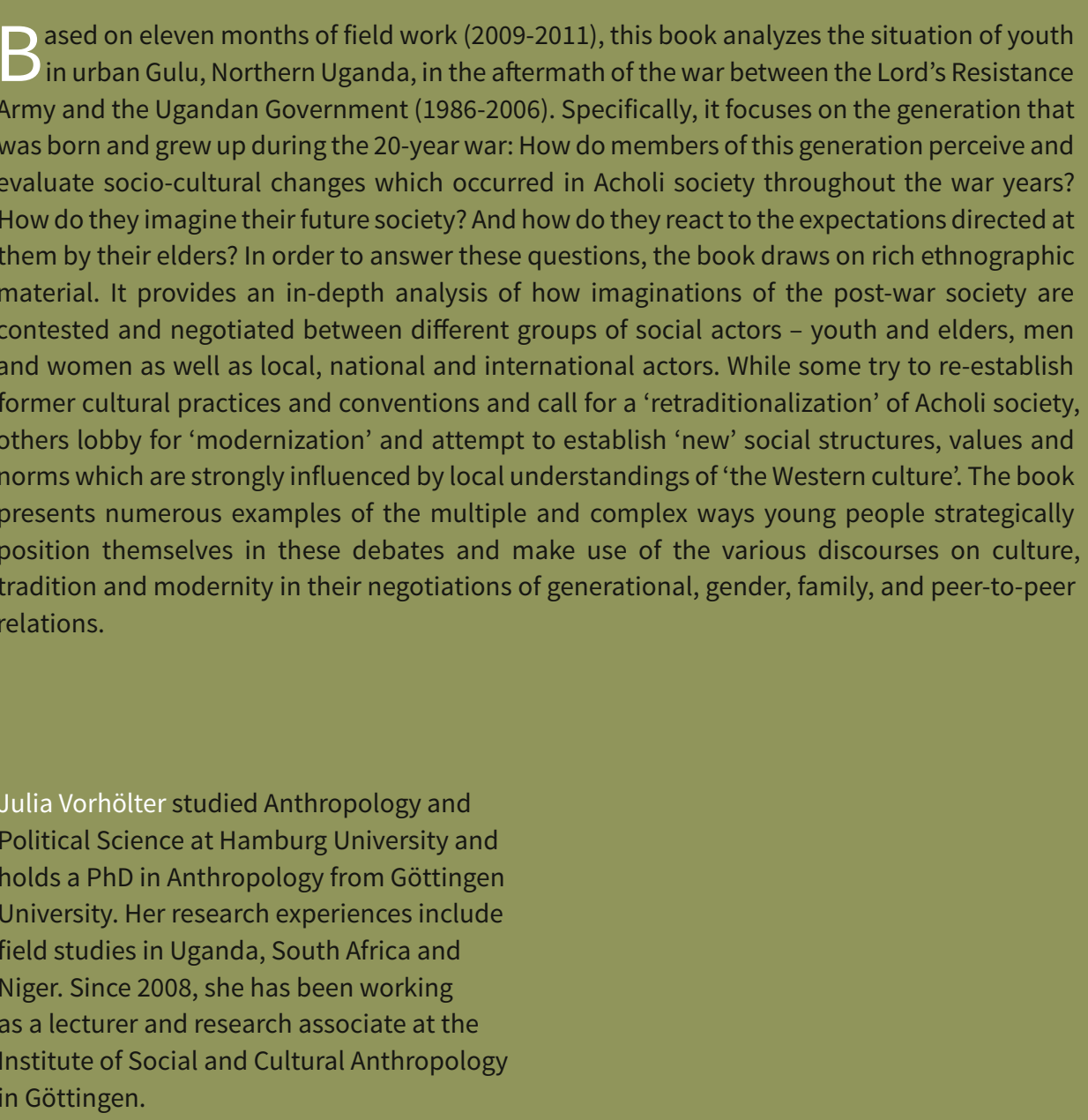

ISSN: $2199-5346-86395-169-6$ 